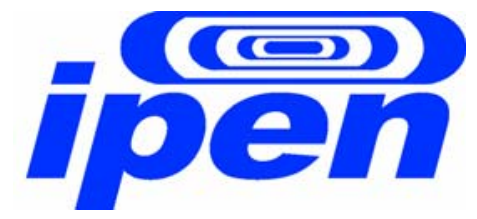

AUTARQUIA ASSOCIADA À UNIVERSIDADE DE SÃO PAULO

\title{
OTIMIZAÇÃO DO PROCESSO DE USINAGEM DE TITÂNIO COM LASER PULSADO DE NEODÍMIO
}

\section{IVAN ALVES DE ALMEIDA}

Tese apresentada como parte dos requisitos para obtenção do Grau de Doutor em Ciências na área de Tecnologia Nuclear - Materiais.

Orientador: Dr. Wagner de Rossi

São Paulo 
IVAN ALVES DE ALMEIDA

\section{Otimização do Processo de Usinagem de Titânio com Laser Pulsado de Neodímio}

Tese apresentada ao Instituto de Pesquisas Energéticas e Nucleares como parte dos requisitos para obtenção do Grau de Doutor em Ciências

Área de Concentração: Tecnologia Nuclear Materiais

Orientador: Dr. Wagner de Rossi

Novembro - 2007 


\section{FOLHA DE APROVAÇÃO}

Ivan Alves de Almeida

Otimização do Processo de Usinagem de Titânio com Laser Pulsado de Neodímio

Tese apresentada ao Instituto de Pesquisas Energéticas e Nucleares como parte dos requisitos para obtenção do Grau de Doutor em Ciências

Área de Concentração: Tecnologia Nuclear Materiais

Aprovado em:

Banca Examinadora

Prof. Dr.

Instituição:

Assinatura:

Prof. Dr.

Instituição:

Assinatura:

Prof. Dr.

Instituição:

Assinatura:

Prof. Dr.

Instituição:

Assinatura:

Prof. Dr.

Instituição:

Assinatura: 


\section{DEDICATÓRIA}

A minha família com amor, admiração e gratidão por sua compreensão,

carinho, presença e apoio incondicional ao longo do período de elaboração deste trabalho. 


\section{AGRADECIMENTOS}

Ao meu orientador, Dr. Wagner de Rossi, por toda sua dedicação, empenho e honestidade no decorrer da orientação.

Ao Dr. Nilson D.Viera Jr., por possibilitar a elaboração deste trabalho no Centro de Laser e Aplicações - CLA.

Ao meu primo, amigo Dr. José Roberto Berretta, pelo apoio e amizade.

Ao Laboratório de Fenômenos de superfície da Escola Politécnica da USP, Dr Amilton Sinatora e técnico Leandro Justino de Paula, pela cooperação e realização dos ensaios de microdureza.

Ao Dr. Maurício David M. das Neves pelo conhecimento oferecido generosamente.

Ao Dr. Spero P. Morato e a Lasertools pela colaboração.

À Dra. Sônia Licia Baldochi e Dra. Izilda Ramieri por disponibilizar equipamentos do laboratório.

À Dra. Vera Lucia pela análise de fluorescência de raios-X.

Ao Laboratório de análise metrológicas $(\mathrm{CCN})$, técnico Felipe B.J. Ferrufino pela realização dos ensaios de inspeção superficial.

Ao técnico Rubens (CTMSP) pelo fornecimento das análises de rugosidade.

Ao IPEN/CNEN por ceder as instalações para a realização deste trabalho.

Aos meus colegas do Centro de Lasers e aplicações e do Centro de Ciências e Tecnologia de Materiais, especialmente para Marco Andrade, Paulo da Silva, Elsa Papp, Tort Vidal, Nildemar e Glauson.

Aos órgãos de fomento a pesquisa FINEP, CAPES, FAPESP e IFM que indireta ou diretamente auxiliaram com financiamentos aos projetos e a bolsa de pesquisa. 


\section{RESUMO}

\section{A. ALMEIDA. Otimização do Processo de Usinagem de Titânio com Laser}

Pulsado de Neodímio. 2007. Tese (Doutorado) - Tecnologia Nuclear Materiais IPEN, Universidade de São Paulo, São Paulo, 2007.

Um requisito do processo de manufatura é a necessidade de se obter peças processadas, caracterizadas pela boa qualidade de acabamento superficial, baixa rugosidade e a conservação de suas propriedades metalúrgicas. Essas condições motivaram o desenvolvimento deste estudo, no qual selecionou-se o processamento de materiais a laser para o corte do titânio, unindo uma tecnologia a um metal de recente aplicação. Além disso, a versatilidade e as vantagens, como também a tendência global do setor industrial, tornaram-se fatores preponderantes na utilização do laser como ferramenta de usinagem. Neste presente trabalho foram investigados os efeitos da usinagem por laser pulsado de Nd:YAG sobre a qualidade, como também a formação de fases na superfície de corte e analisados pela aplicação do planejamento experimental. Para isso, chapas de titânio comercialmente puro (grau 2) e da liga Ti-6Al-4V (grau 5), com espessuras de 0,5 e 1,0 milímetros, foram empregadas na realização dos ensaios sob ação do laser. As amostras obtidas foram analisadas por microscopia ótica (MO), microscopia eletrônica por varredura (MEV), ensaios de microdureza e inspeção superficial da rugosidade. Capturaram-se digitalmente as imagens do material ressolidificado, aderido na superfície de corte para determinação da formação de rebarbas. Com base nestes dados construíram-se arranjos fatoriais, por meio da metodologia de planejamento experimental (DOE), a fim de avaliar o grau de influência dos parâmetros e suas possíveis interações e assim averiguar sua significância estatística. Verificou-se um endurecimento superficial na região do corte a laser com nitrogênio, em virtude da formação de nitretos (TiN) sob uma fina camada da zona de ressolidificação. Apesar da complexidade das interações entre os diversos parâmetros envolvidos no processamento a laser, os resultados corroboram que a otimização do processo de corte a laser do titânio pode ser factível.

Palavras-chave: Processamento de materiais a laser; Laser pulsado Nd:YAG; titânio; Projeto e Análise de experimentos (DOE). 


\section{ABSTRACT}

I. A. ALMEIDA. Optimization of Titanium Machining by Pulsed Nd:Yag Laser. 2007. Thesis (Doctoral) - Tecnologia Nuclear Materiais - IPEN, Universidade de São Paulo, São Paulo, 2007.

The main goal of this work was to establish the requirements for laser processed parts to satisfy uniform surface finish, low roughness and preservation of the mechanical and functional properties of the parts. Lasers became a versatile machining tool that satisfies the modern trends in material processing. In this study, the cutting quality factors of sheets of pure titanium and its alloys, by pulsed Nd:Yag laser, were investigated according to the Design and Analysis of Experiments. Laser pulse energy, laser pulse length, pressure of the protective/reactive gas, cutting speed, were considered the key laser parameter processing factors. In this Design, a factorial arrangement, regarding several combinations of these different processing factors, was performed and the influence of each one was also taken into consideration. The cutting process was performed on commercially pure titanium (grade 2) and the alloy Ti-6Al-4V (grade 5) sheets. The obtained samples were analyzed through optical microscopy in order to determine the edge roughness formations. The samples were also analyzed by scanning electron microscopy and submitted to micro hardness tests and surface roughness inspections. An increase on the surface hardness on the cut region and the formation of nitrogen precipitates under a thin layer of a melted zone were verified. In spite of the complexity of the interactions between this diversity of parameters, it is possible to optimize the titanium laser cutting.

Keywords: laser machining; Nd:YAG laser; titanium; Design and Analysis of experiments (DOE). 


\section{LISTA DE ILUSTRAÇÕES}

Figura 1 - Fluxograma das interações entre projeto, seleção de materiais e processamento em função do desenvolvimento de um projeto............................. 17

Figura 2 - Titânio: fonte e características.................................................................... 22

Figura 3 - Diferença dos raios atômicos dos elementos intersticiais para a rede

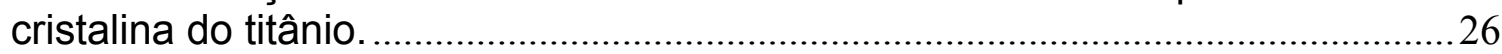

Figura 4 - Esquema representativo da transformação do titânio. ...................................28

Figura 5 - (a) Classificação e composição das ligas de titânio distribuídas em relação pseudobinário diagrama de fase isomorfo. (b) Diagrama de fase isomorfo pseudobinário relacionando a curva martensitica (Mi/MF) com os campos de fase $\alpha+\beta$.

Figura 6 - Fotomicrografias das superfíces do Ti puro (a) e da liga Ti6Al4V (b)........30

Figura 7 - Síntese da classificação das ligas de titânio e suas características...........33

Figura 8 -Tipos dos diagramas binários de fase das ligas de titânio. ............................34

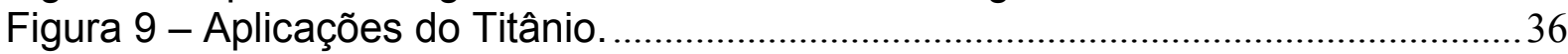

Figura 10 - Evolução dos modelos atômicos até a invenção do laser.......................... 44

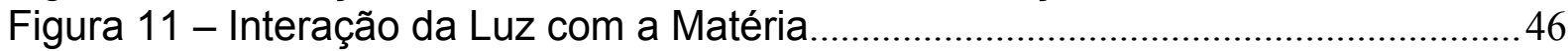

Figura 12 - Esquema ilustrativo da produção do feixe laser........................................ 49

Figura 13 - Estrutura do mercado mundial de vendas dos sistemas a laser.............51

Figura 14 - Produção e distribuição mundial de lasers industriais. ...............................51

Figura 15 - Comércio mundial de vendas da indústria óptico-eletrônica (a) laser por

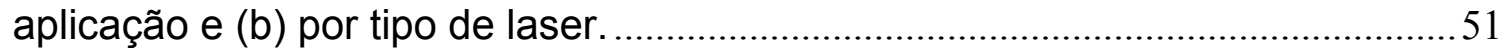

Figura 16 - Quadro Geral das aplicações industriais a laser.......................................53

Figura 17 - Diagrama das variáveis envolvidas no processamento de materiais a

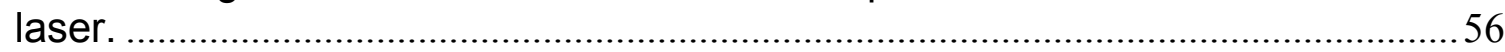

Figura 18 - Faixa do espectro eletromagnético com diferentes tipos de lasers..........57

Figura 19 - Distribuição do campo elétrico na seção transversal do feixe laser. .......61

Figura 20 - Propagação do feixe laser e propriedades. ................................................ 61

Figura 21 - Processo de corte - interação do feixe laser com o material. ....................65

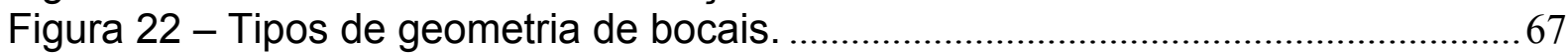

Figura 23 -Interações aerodinâmicas do fluxo de gás no processo de corte a laser.67

Figura 24 - Representação das combinações do Projeto Fatorial Fracionado $2^{(3-1)} .80$

Figura 25 - Especificações e características dos gases. ............................................. 83

Figura 26 - Representação: A) do arranjo de amostras no software Mastercam, B)

Dimensões do corte de cada amostra, C) amostras embutidas............................8 85

Figura 27 - Vista panorâmica da Central de Processamento de Materiais a Laser, no

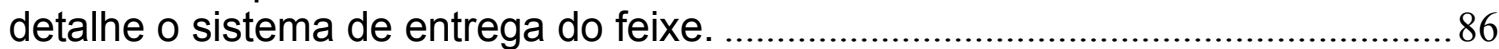

Figura 28 - Ilustração da técnica para determinar o ponto focal................................. 88

Figura 29 - Metodologia de captura da imagem digital. ..............................................91

Figura 30 - Dados comparativos entre: (a) imagens de uma única amostra. (b) três amostras distintas $A$ unidade das dimensões em $\mathrm{mm}$. ....................................... 92

Figura 31 - Foto da configuração do equipamento para capturar a imagem das

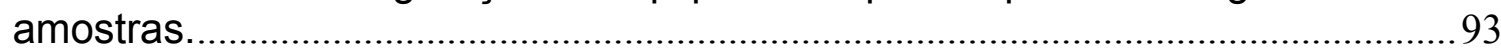

Figura 32 - Ilustração da análise de inspeção superficial. ..........................................99

Figura 33 - Centro de usinagem industrial................................................................ 99

Figura 34 - Ilustração dos pontos de indentação do ensaio de microdureza dinâmica.

Vista transversal da região de corte (esquerda); vista de topo da superfície de corte (direita) com lixamento parcial. 
Figura 35 - Esquema ilustrativo do gráfico da carga pela profundidade de penetração em um ensaio de microdureza dinâmica.

Figura 36 - Difratômetro de raios-X, marca Philips, modelo MPD1880 utilizado neste trabalho.....

Figura 37 - Micrografia ótica da superfície de corte doTi c.p (ataque com reagente weck).Nota-se a presença de precipitados de nitrogênio (pontos escuros) na região de fusão (área clara).

Figura 38 - (1) MEV da superfície de corte com pulsos aparentes. Região marcada com (A) é material base, com (B) zona termicamente afetada. (2) Detalhe da superfície de corte, observa-se precipitados de nitrogênio (pontos escuros) na região de fusão (área clara).

Figura 39 - Micrografia ótica da superfície de corte da liga Ti c.p. (grau 2) usinada a laser com gás nitrogênio. Zona de fusão e dendritas. (amostra Ticp_laser)..... 109

Figura 40 - Detalhe da superfície de corte da liga Ti c.p. (grau 2) usinada a laser com gás nitrogênio. Três micrografias da zona de fusão.

Figura 41 - Ensaio de microdureza convencional - comparação entre os valores de dureza do material base laminado e superfície usinada a laser do Titânio puro (grau 2).

Figura 42 - llustração da seqüência de pontos realizados na superfície de corte do Ti-cp (grau 2) usinada a laser com gás nitrogênio (amostra Ticp_laser)........... 110

Figura 43 - Ensaio de microdureza convencional - comparação entre os valores de dureza do material base laminado e superfície usinada a laser da Liga Ti-6Al-4V (grau 5).

Figura 44 - llustração da seqüência de pontos realizados na superfície de corte da liga Ti-6Al-4V usinada a laser com gás nitrogênio (amostra Ti64laser). ............. 111

Figura 45 - Sobreposição dos difratogramas de raios- $X$, alguns picos de $\mathrm{TiN}$ e $\mathrm{Ti}$

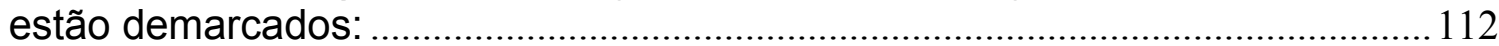

Figura 46 - Difratograma de raios-X do titânio puro grau 2 laminado.

Figura 47 - Difratograma de raios-X da superfície usinada a laser do titânio puro grau 2

Figura 48 - Difratograma de raios-X material laminado da liga Ti-6Al-4V grau 5... 114

Figura 49 - Difratograma de raios-X superfície usinada a laser da liga Ti-6Al-4V grau 5.

Figura 50 - Ensaio de microdureza convencional - comparação entre os valores de dureza da superfície de corte usinada a laser sob diferentes gases (série 6804 amostras).

Figura 51 - Diagrama cristalográfico: comparação entre cortes com gás nitrogênio, argônio e hélio.

Figura 52 - Micrografia da zona de ressolidificação e ZTA - formação de martensita.

Figura 53 - MEV da zona de ressolidificação e ZTA - formação de martensita. ..... 118

Figura 54 - Ensaio de microdureza convencional da superfície usinada a laser da Liga Ti-6Al-4V (amostra 6804-B).

Figura 55 - llustração da seqüência de pontos realizados na superfície de corte da liga Ti-6Al-4V usinada a laser com gás nitrogênio (amostra 6804-B).....

Figura 56 - Micrografia com a seqüência do teste e os valores médios de dureza da liga Ti-6Al-4V usinada a laser com gás argônio [amostra (6804-C)].

Figura 57 - Gráficos da carga pela profundidade de penetração, Dureza pela carga e Módulo de Elasticidade pela carga para o ensaio de microdureza instrumentada (amostra $6804-$ C). 
Figura 58 - Variação Rugosidade x Energia (a). Variação Rebarba x Energia (b)... 125

Figura 59 - Variação Rugosidade x Taxa de sobreposição de pulsos (a)................. 125

Figura 60 - Gráfico de influência para cada parâmetro em resposta a rebarba - (6 fatores).

Figura 61 - Diagrama de influência individual e das interações para DOE com 6 fatores.

Figura 62 - Aderência de rebarba na borda de corte (a) na pior condição (b) melhor resultado para DOE com 6 fatores

Figura 63 - Gráfico de influência para cada parâmetro em resposta a rebarba - (4 fatores).

Figura 64 - Diagrama de influência individual e das interações para DOE com 4 fatores

Figura 65 - Comparação entre planejamento experimental de 6 e 4 fatores.

Figura 66 - Fotografia da superfície de corte (a) na pior condição (b) melhor resultado para DOE com 4 fatores.

Figura 67 - Gráfico comparativo da quantidade de rebarbas entre DOE com 6 e 4 fatores.

Figura 68 - Diagramas de influência para DOE 4 fatores na LASAG:

Figura 69 - Micrografia com a seqüência do teste e os valores médios de dureza da liga Ti-6Al-4V usinada a laser com gás argônio [amostra CPML Y(30)]

Figura 70- Gráficos da carga pela profundidade de penetração, Dureza pela carga e Módulo de Elasticidade pela carga do $1^{\circ}$ ao $3^{\circ}$ ensaio de microdureza instrumentada [amostra CPML Y(30)].

Figura 71- Gráficos da carga pela profundidade de penetração, Dureza pela carga e Módulo de Elasticidade pela carga para o $4^{\circ}$ e $5^{\circ}$ ensaio de microdureza instrumentada [amostra CPML Y(30)]

Figura 72 - Comparação entre pior e melhor condição de material ressolidificado aderido (Borda a).

Figura 73 - Material ressolidificado aderido (Borda b) entre pior e melhor condição de

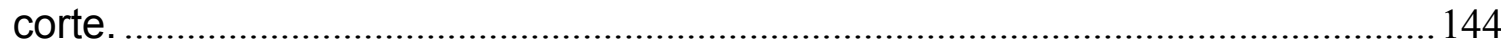

Figura 74 - Detalhe da rebarba aderida entre pior e melhor condição de corte....... 144

Figura 75 - (MEV) Detalhe da microestrutura na amostra de menor rebarba. ......... 145

Figura 76 - (MEV) Detalhe da microestrutura na amostra de maior rebarba............ 145

Figura 77 - Diagramas de influência para DOE: (A) 6 fatores; (B) 4 fatores (CPML).

Figura 78 - Diagramas de influência para DOE 4 fatores na LASAG:

Figura 79 - Superfície de corte - diferença de rugosidade 


\section{LISTA DE TABELAS}

Tabela 1 - Elementos estabilizadores do Titânio...............................................................27

Tabela 2 - Teores da composição do Ti c.p pela norma ASTM F67 ............................29

Tabela 3 - Comparação do preço entre materiais.......................................................... 35

Tabela 4 - Distribuição do consumo de titânio pelo mercado de aplicação...................35

Tabela 5 - Causas mais comuns de falhas em implantes metálicos ${ }^{62}$..........................39

Tabela 6 - Comparação entre diferentes sistemas de corte ${ }^{85,}$.....................................5 53

Tabela 7 - Guia para a construção do planejamento experimental............................. 73

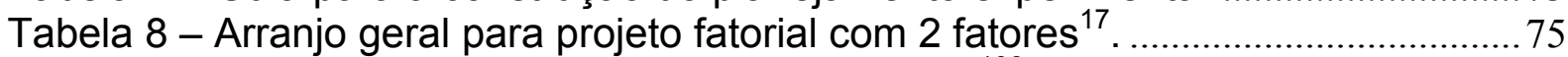

Tabela 9 - Tabela de erros para o teste de hipóteses ${ }^{108}$............................................ 76

Tabela 10 - Análise de variância baseado na soma dos quadrados. ........................... 78

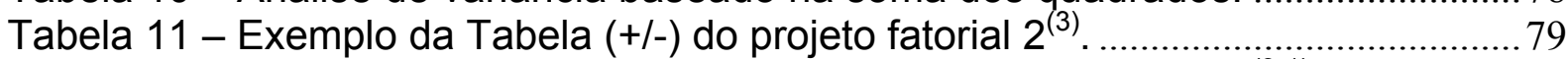

Tabela 12 - Combinações lineares para projeto fatorial fracionado $2^{(3-1)}$................... 80

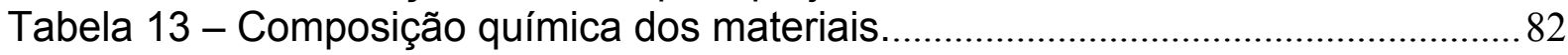

Tabela 14 - Propriedades físico-químicas, térmicas e mecânicas do Ti c.p. (grau 2) e

da liga Ti-6Al-4V (grau 5)'.......................................................................................... 82

Tabela 15 - Composição química dos materiais analisados no IPEN e as normas

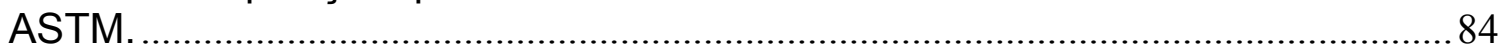

Tabela 16 - Características da CPML. ..................................................................... 85

Tabela 17 - Seleção inicial dos parâmetros fixos e variáveis........................................87

Tabela 18 - Variação dos parâmetros do laser, dimensão dos furos obtidos e $v_{\max }$ corte.

Tabela 19 - Grupo de amostras, suas velocidades e taxa de sobreposição para três condições diferentes de corte.

Tabela 20 - Tipo de análise, equipamento e instituição. ............................................. 94

Tabela 21 - Processamento da liga Ti-6Al-4V com diferentes gases inertes.............95

Tabela 22 - Configuração do Projeto fatorial fracionado de 6 fatores.......................... 96

Tabela 23 - Configuração do Projeto fatorial de 4 fatores. ............................................ 97

Tabela 24 - Condições dos Ensaios de microdureza. .................................................. 101

Tabela 25 - Relação das amostras submetidas ao ensaio de microdureza dinâmico.

Tabela 27 - Valores do ensaio de microdureza instrumentada na amostra 6804 - C.

Tabela 28 - Quantidade de rebarba $\left(\mathrm{mm}^{2}\right)$ medida para três energias e quatro taxas de sobreposição diferentes. ................................................................................. 123

Tabela 29 - Rugosidade $(\mu \mathrm{m})$ medida para três energias e quatro taxas de sobreposição diferentes.

Tabela 30 - Análise de variância para acabamento superficial das peças usinadas de titânio.

Tabela 31 - Modelo experimental ensaio DOE para 6 fatores a 2 níveis(Rebarba).127

Tabela 32 - Modelo experimental ensaio DOE para 4 fatores a 2 níveis (Rebarba).

Tabela 33 - Modelo experimental ensaio DOE para 4 fatores a 2 níveis (LASAG-

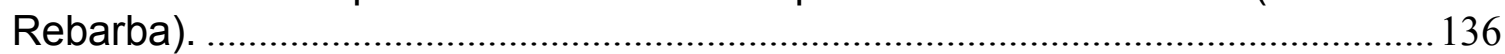

Tabela 34 - Margem de erro no processo de captura da rebarba. ........................... 139

Tabela 35 - Valores de microdureza instrumentada da amostra CPML- Y(30)....... 141 
Tabela 36 - Dados coletados de rugosidade para ensaio DOE para 6 fatores a 2

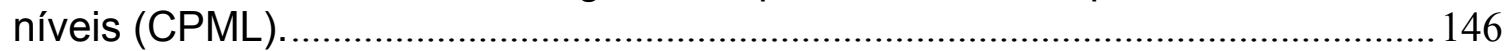

Tabela 37 - Dados coletados de rugosidade para ensaio DOE para 4 fatores a 2 níveis (CPML) .............................................................................................. 147

Tabela 38 - Dados coletados de rugosidade para ensaio DOE para 4 fatores a 2 níveis (LASAG)

Tabela 39 - Modelo experimental ensaio DOE para 6 fatores a 2 níveis (Rugosidade).

Tabela 40 - Modelo experimental ensaio DOE para 4 fatores a 2 níveis (Rugosidade).

Tabela 41 - Modelo experimental ensaio DOE para 4 fatores a 2 níveis (LASAGrugosidade) 


\section{LISTA DE SIGLAS}

ABNT

ANOVA

ANVISA

ASTM

BPFPM's

CAD

CAM

CAPES

CCC

$\mathrm{CCN}$

CCTM

CLA

$\mathrm{CNC}$

CNEN

CPML

CTA

CTMSP

DF

DOE

EFO

EPUSP

FAPESP

FFC

FINEP

Fo

$\mathrm{HCP}$

IEAv

IPEN

IPT

LADICON

LCT

LFS

$M^{2}$

MEV ou SEM

$\mathrm{MO}$

MS

$\mathrm{Nd}: Y A G$
Associação Brasileira de Normas Técnica.

"Analysis of variance" - Análise de variância

Agência Nacional de Vigilância Sanitária.

"American Society of Testing and Materials"

Boas Práticas de Fabricação de Produtos Médicos.

"Computer Aided Desing" - Projeto Assistido por Computador

"Computer Aided Manufacturing" - Fabricação Assistida por Computador

Coordenação de Aperfeiçoamento de Pessoal de Nível Superior

Estrutura cristalina cúbica de corpo centrado.

Centro do Combustível Nuclear

Centro de Ciências e Tecnologia de Materiais

Centro de Aplicações a Laser

"Computer Numeric Control" - Controle Numérico Computadorizado

Comissão Nacional de Energia Nuclear

Central de Processamento de Materiais a Laser

Centro-Geral de Tecnologia Aeroespacial

Centro Tecnológico da Marinha em São Paulo

"Degree of freedom" - Grau de liberdade

"Design Of Experiments" - Projeto de Experimentos

Divisão fotônica

Escola Politécnica da Universidade de São Paulo

Fundação de Amparo à Pesquisa do Estado de São Paulo

"Fray-Farthing-Chen Cambridge Process", método de processo do Ti

Financiadora de Estudos e Projetos

Razão entre médias

Estrutura cristalina hexagonal compacta.

Instituto de Estudos Avançados

Instituto de Pesquisas Energéticas e Nucleares

Instituto de Pesquisas Tecnológicas do Estado de São Paulo.

Laboratório de Desenvolvimento de Instrumentação e Combustível Nuclear

Laboratório de Caracterização Tecnológica

Laboratório de Fenômenos de Superfície

Fator de qualidade do feixe

Microscopia eletrônica por varredura/ "Scanning electron microscopy" Microscopia ótica

"Mean Square" - Razão entre médias

"Neodymium-doped Yttrium Aluminium Garnet" - um bastão cristal granada de Ítrio e Alumínio dopado com neodímio. 
SS

$\mathrm{Ti}-$ c.p.

Ti-6Al-4V

ZTA ou HAZ
"Sum of Square" - Soma dos quadrados

Titânio comercialmente puro

Liga de Titânio Alumínio Vanádio

Zona termicamente afetada - Heat affected zone

\section{LISTA DE SÍMBOLOS}

$\left({ }^{\circ} \mathrm{C}\right)$

$\left(\mathrm{g} . \mathrm{cm}^{-3}\right)$

$(\mathrm{Pa})$

(GPa)

(MPa)

$\left(\mathrm{mm}^{2}\right)$

$(\mathrm{Pm})$

(E)

W

(f)

$(\mathrm{Hz})$

$\left(\mathrm{N}_{2}\right)$

(s)

$\left(\mathrm{mm} \cdot \mathrm{min}^{-1}\right)$

(J)

(Ar)

$(\mathrm{He})$

$(\mu \mathrm{m})$

(TiN)

(bar)

psi

(HV)
Unidade: graus Celsius, grandeza: temperatura.

Unidade: gramas por centímetros cúbicos, grandeza: densidade de massa.

Unidade: Pascal $\left(\mathrm{N} / \mathrm{m}^{2}\right)$, grandeza: pressão.

Prefixo do SI (gigapascal) $10^{9}$

Prefixo do SI (megapascal) $10^{6}$

Prefixo do SI (milímetros) $10^{-3}$ metro, grandeza: comprimento.

Prefixo do SI milímetros elevado ao quadrado, grandeza: área.

Potência média real de saída do laser.

Energia contida em cada pulso laser.

Unidade: watt, grandeza: potência.

Taxa de repetição dos pulsos ou o número de pulsos laser por segundo.

Unidade: hertz, grandeza: freqüência.

nitrogênio

diâmetro

Prefixo do SI milisegundo $10^{-3}$, grandeza: tempo.

Unidade: segundo, grandeza: tempo

Unidade: milímetros por minuto, grandeza: velocidade.

Unidade: joule, grandeza: energia.

Argônio

Hélio

Prefixo do SI micro $10^{-6}$, grandeza: comprimento

nitreto de titânio

Unidade: $\mathrm{Bar}=\left(10^{5} \mathrm{~Pa}\right)$, grandeza: pressão.

Unidade: psi $\approx\left(6,9 \times 10^{3} \mathrm{~Pa}\right)$, grandeza: pressão.

Dureza Vickers 


\section{SUMÁRIO}

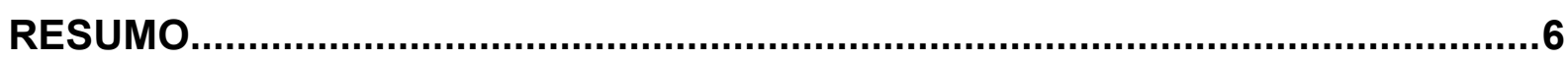

ABSTRACT

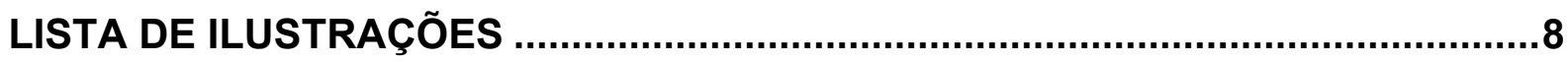

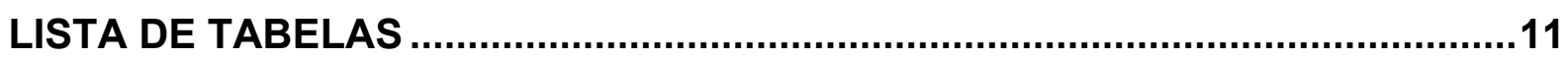

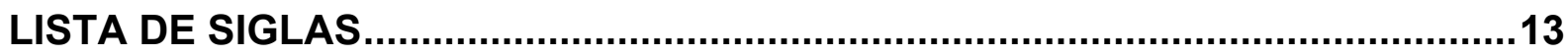

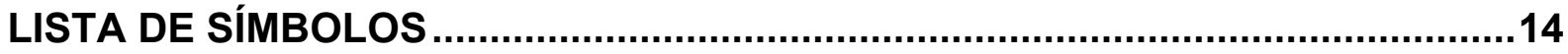

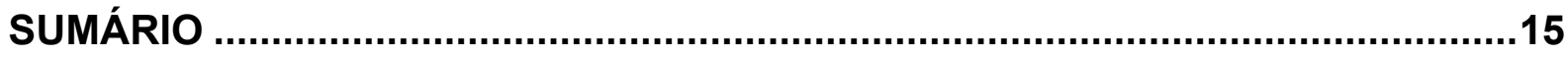

1. INTRODUÇÃO

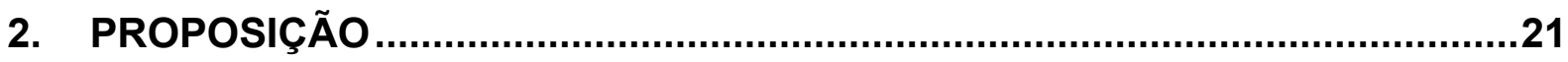

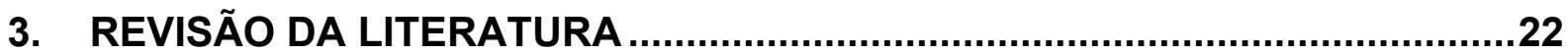

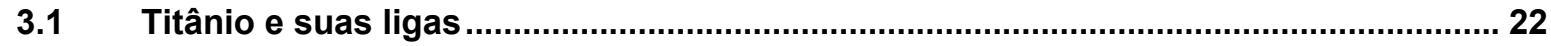

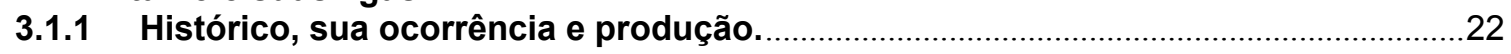

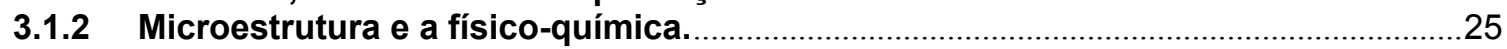

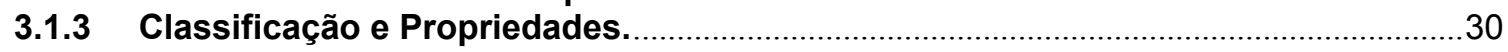

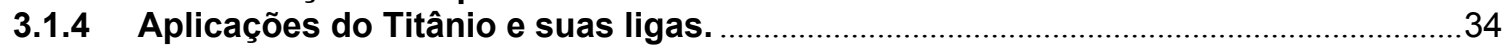

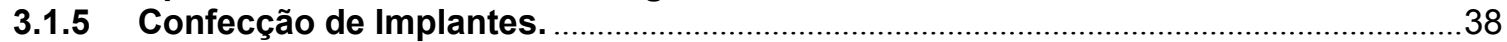

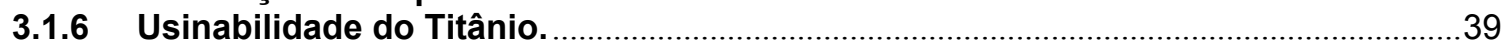

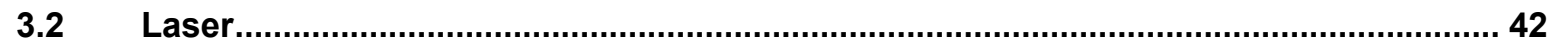

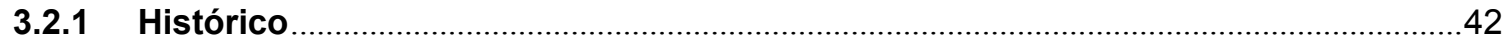

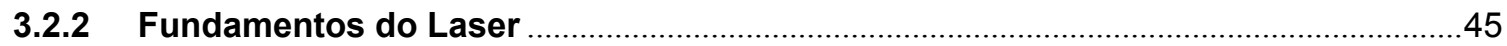

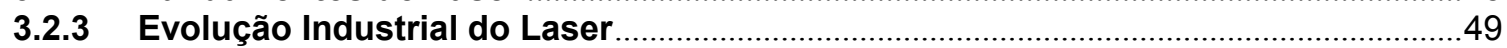

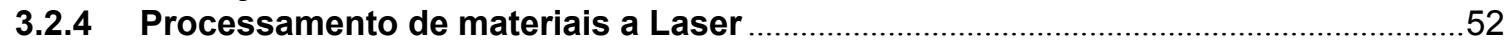

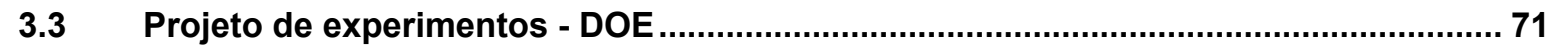

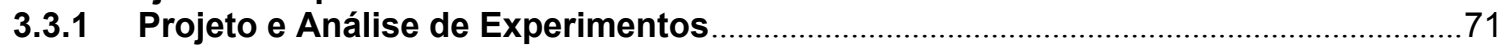

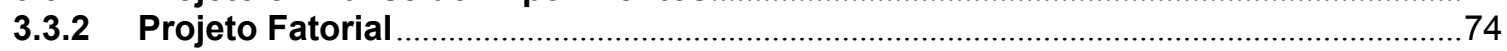

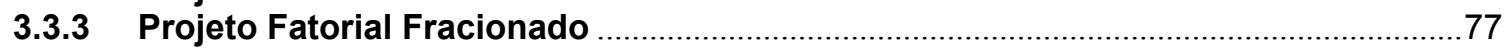

4. MATERIAIS E MÉTODOS ....................................................................

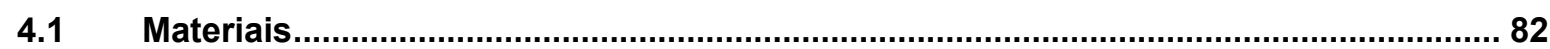

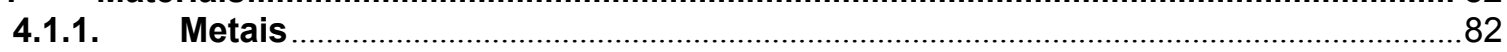

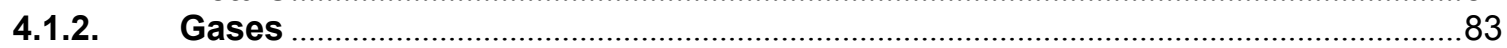

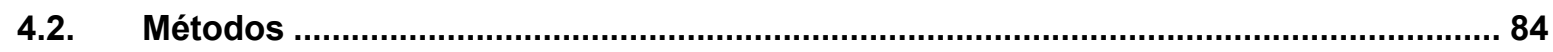

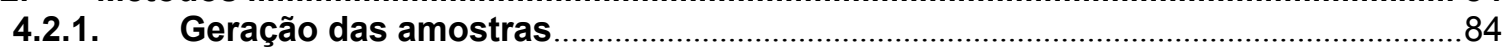

5. RESULTADOS E DISCUSSÃO.............................................................106

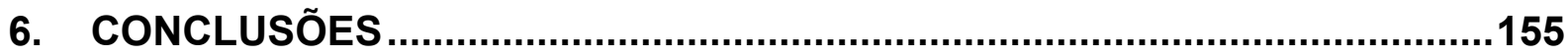

7. REFERÊNCIAS ..................................................................................159 


\section{INTRODUÇÃO}

O cenário mundial sofreu significativas transformações nas últimas duas décadas, atingindo os mais diversos setores da sociedade. Estas mudanças proporcionaram uma aceleração nos processos econômicos e na evolução tecnológica.

Esta realidade impõe um novo conceito nos níveis de exigência e exerce pressão no aumento dos padrões de qualidade. Desta forma, a competitividade torna-se maior e mais acirrada.

Como conseqüência, os setores científico e industrial inseridos neste mercado competitivo, o qual é influenciado pelos efeitos da globalização e da preocupação com o desenvolvimento sustentável, devem se adequar através da inclusão de novas tendências e tecnologias. Em resposta a esta tendência, o pensamento empreendedor é essencial para ambos os setores. Isso implica em estimular o desenvolvimento ampliando as bases tecnológicas, coordenar o gerenciamento de recursos escassos, fixar alvos e objetivos factíveis, assim como procurar inovar.

Dentro desse contexto mercadológico está imerso o universo em que os profissionais, pluralistas em conhecimentos e habilidades, procuram selecionar o tipo de material, o processamento mais apropriado, suas vantagens/desvantagens e as diferentes implicações no resultado final do produto para satisfazer os requisitos do mercado atual.

A Figura 1 mostra esquematicamente as relações interativas entre projeto, processamento e materiais, que somados delimitam o caminho, composto por uma série de etapas e informações de diversas naturezas, determinante do produto final. 


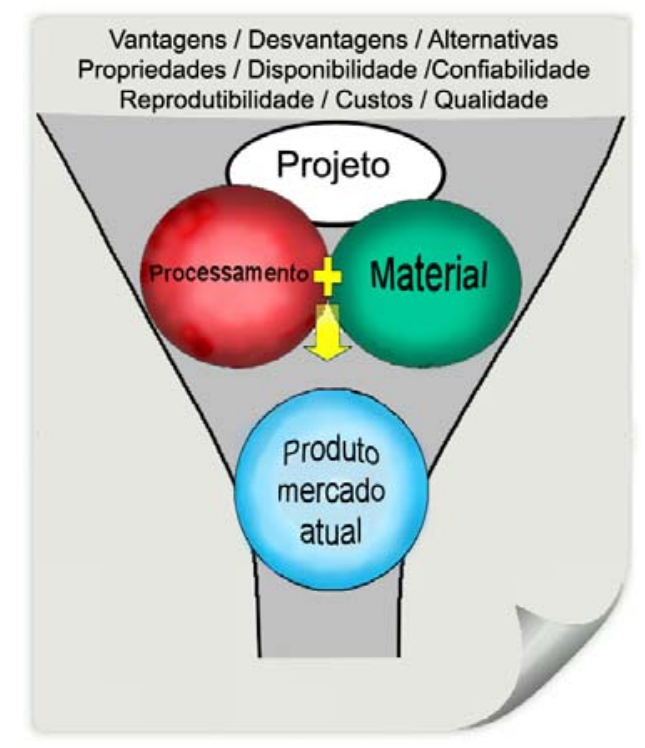

Figura 1 - Fluxograma das interações entre projeto, seleção de materiais e processamento em função do desenvolvimento de um projeto.

Em diversos segmentos do setor industrial, o processamento de materiais a laser ${ }^{1}$ tornou-se uma alternativa interessante e competitiva em relação aos métodos convencionais de manufatura. Atualmente, sua aplicação é diversificada ${ }^{2}$, principalmente devido aos seus benefícios e a sua versatilidade, abarcando mercados como o da indústria automotiva, aeroespacial e médica. Esta tecnologia exerce grande interesse, pois consegue agregar inúmeras vantagens. As mais importantes são: processo sem contato e sem desgaste de ferramenta, possibilidade de uso de atmosfera controlada, alta densidade e controle de energia, flexibilidade no caminho do feixe, simplicidade de fixação, facilidade no processo de automação, pequena zona termicamente afetada, alta velocidade de processo, excelente qualidade da borda, baixa emissão de poluição, entre outras ${ }^{3}$.

Entretanto, existe uma lacuna de desconhecimento entre as investigações teóricas e experimentais que determine a real influência dos parâmetros no processamento a laser. Este fato, devido à complexidade do processo, é mais evidente no sistema de laser pulsado ${ }^{4,5}$. 
Inicialmente, a aplicação de um feixe de luz para o processamento de materiais envolve um mecanismo em que se faz necessário à adequação do tipo de laser ao material selecionado, bem como da geometria do objeto a ser usinado. O tipo de laser é determinado pelo comprimento de onda de sua emissão e pelo regime de operação, contínuo, pulsado, chaveado, etc.

A partir desta seleção, também é imprescindível escolher e ajustar os vários parâmetros relativos ao processamento a laser que exercem influência na qualidade do resultado final, no custo e na velocidade de processo, entre outros ${ }^{6,7}$.

Concomitantemente, outro fator importante correlacionado ao desenvolvimento de um produto é a utilização de novos materiais para sua confecção, visando à redução dos custos e a melhoria no padrão de qualidade dos mesmos. Nota-se, nesta corrida tecnológica, o uso cada vez mais freqüente de materiais plásticos e das fibras, os quais se encontram amplamente disseminados em diversos setores. Essa concorrência, como conseqüência, promoveu uma reação no ramo siderúrgico em busca de avanços na pesquisa de novos materiais metálicos. Neste panorama, uma readaptação da produção do titânio e suas ligas, entre outros metais, se torna cada vez mais importante.

Atualmente, este metal tem se tornado objeto de intensa pesquisa e de extrema utilidade em inúmeras aplicações da indústria e da medicina. Contudo, em virtude do alto custo ${ }^{8}$ de produção, sua utilização ainda é limitada.

Após a década de 50, o titânio despertou grande interesse em diversas aplicações da engenharia, principalmente devido às suas características metalúrgicas e mecânicas, tais como: densidade razoavelmente baixa $\left(4,5 \mathrm{~g} \cdot \mathrm{cm}^{-3}\right)$, médio módulo de elasticidade (105 GPa) e valores do limite de resistência à tração de $1350 \mathrm{MPa}^{9,10}$. 
O titânio também apresenta elevada resistência à corrosão em temperatura ambiente e excelente biocompatibilidade ${ }^{11}$. Além disso, sua dureza e a relação resistência mecânica pelo peso são outras propriedades muito úteis e atraentes para diversas aplicações.

Estas características favoráveis deste metal, contudo, também podem gerar entraves aos métodos convencionais de produção, como alto desgaste de ferramentas, tempo de usinagem e custos operacionais mais elevados.

Neste contexto, o desenvolvimento da usinagem a laser do titânio e suas ligas $^{12}$ surge como processo alternativo para a confecção de inúmeros componentes, especialmente para as áreas aeroespacial e biomédica. Neste caso, as dificuldades relacionadas aos processos convencionais, como alta dureza e resistência ao desgaste desaparecem completamente devido à natureza da interação da luz com a matéria.

Como a usinagem visa a excelência de qualidade, o processamento a laser para um determinado material deve obedecer a uma combinação precisa dos inúmeros parâmetros envolvidos ${ }^{13}$. Estes parâmetros são: densidade de potência; modo transversal do feixe laser; polarização da luz; velocidade do processo; características físicas e metalúrgicas do material; geometria e diâmetro do bocal; distância bocal/peça; comprimento focal da lente utilizada; tipo, pressão, fluxo e pureza do gás de assistência; energia e duração temporal do pulso laser; comprimento de onda; distribuição energética no ponto focal, entre outros ${ }^{14}$.

Os parâmetros descritos acima são inúmeros, desse modo, procurou-se neste trabalho desenvolver um estudo que permita evidenciar quais são os mais influentes no processo de corte e suas possíveis interações. A metodologia de análise 
emprega o Projeto de Experimentos ("Design of Experiments") - DOE em busca da otimização ${ }^{15}$ destes parâmetros.

Uma tendência dos projetos tecnológicos é a inclusão de conhecimentos multidisciplinares, aplicados em conjunto com a modelagem matemática, simulações numéricas e realização de experimentos. A aplicação de um modelo estatístico permite estimar uma escala com os valores dos parâmetros mais influentes do sistema. Por meio da aplicação das teorias de Planejamento Experimental (DOE) é possível determinar uma região com melhores resultados e desta maneira, reduzir a amplitude do campo inicial, assim como obter uma otimização do processo e consequentemente uma redução de custos.

Esta abordagem consiste em um método de experimentação, em que são feitas alterações propositais nas variáveis de entrada de um processo (fatores), de tal modo a observar os efeitos correspondentes nas variáveis de saídas (respostas) $^{16}$.

De acordo com Montgomery ${ }^{17}$, o método de variar somente um fator, enquanto os outros são mantidos fixos, não é adequado, principalmente se existir a possibilidade de interações destas influências. Neste caso, o uso de modelos experimentais fatoriais é o mais indicado, pois este promove uma investigação de todas as combinações dos diferentes fatores.

Baseado nestes fatos, o escopo do presente trabalho foi determinar os efeitos da usinagem aplicados no processamento de placas metálicas de titânio e suas ligas, sob ação de um laser pulsado de Nd:YAG. O trabalho também procurou proporcionar uma otimização dos parâmetros relativos ao processo pela análise estatística de um arranjo fatorial direcionado para melhoria da qualidade de acabamento superficial do corte. 


\section{PROPOSIÇÃO}

Determinar os efeitos da usinagem de corte a laser pulsado sobre a qualidade de acabamento e a formação de fases na superfície são tarefas evidentemente complexas, em virtude dos inúmeros fenômenos envolvidos no processo.

A qualidade do processamento a laser de um determinado material está relacionada a uma série de parâmetros que atuam individualmente e também interagem entre si.

O objetivo é buscar parâmetros para uma usinagem otimizada de chapas de titânio. Os critérios para estabelecer essas condições de corte estarão relacionados com a qualidade superficial de acabamento, tais como, menor quantidade de rebarbas e menor rugosidade. As características metalúrgicas da camada ressolidificada, também serão fatores a se considerar na otimização do processo. Isso será realizado pela verificação da influência dos seguintes parâmetros: energia de pulso, largura temporal, pressão do gás, velocidade de corte, comprimento focal da lente, posição do foco.

Será utilizado também o método estatístico, projeto de experimentos, na análise da interação entre as diversas variáveis do processo para classificar o nível de importância de cada uma, configurar uma faixa de operação e demonstrar suas inter-relações. Além de estender a metodologia estudada neste trabalho, em laboratório, para um equipamento com características de produção industrial.

Todos os objetivos mencionados têm caráter inédito e a sua junção propicia uma ferramenta científica-tecnológica, útil e importante, para o setor produtivo. 


\section{REVISÃO DA LITERATURA}

\subsection{Titânio e suas ligas}

\subsubsection{Histórico, sua ocorrência e produção.}

O elemento metálico atualmente conhecido como titânio foi descoberto na Inglaterra em 1791, pelo Reverendo William Gregor. Este estudioso em minerais identificou a presença de um novo elemento no mineral "menachanite" (areia magnética). Vários anos depois, o mesmo elemento foi redescoberto no rutilo, pelo químico alemão M. H. Klaproth ${ }^{18,19}$ e por este nomeado de titans, do latim: o primeiro filho da Terra. A ocorrência natural do titânio é verificada, particularmente, em minerais sob a forma de: Anatásio/Rutilo $\left(\mathrm{TiO}_{2}\right)$, Ilmenita $\left(\mathrm{FeTiO}_{3}\right)$, Perovskita $\left(\mathrm{CaTiO}_{3}\right)$ e Titanita $\mathrm{CaTi}\left(\mathrm{OSiO}_{4}\right)$, conforme ilustrado na Figura 2.

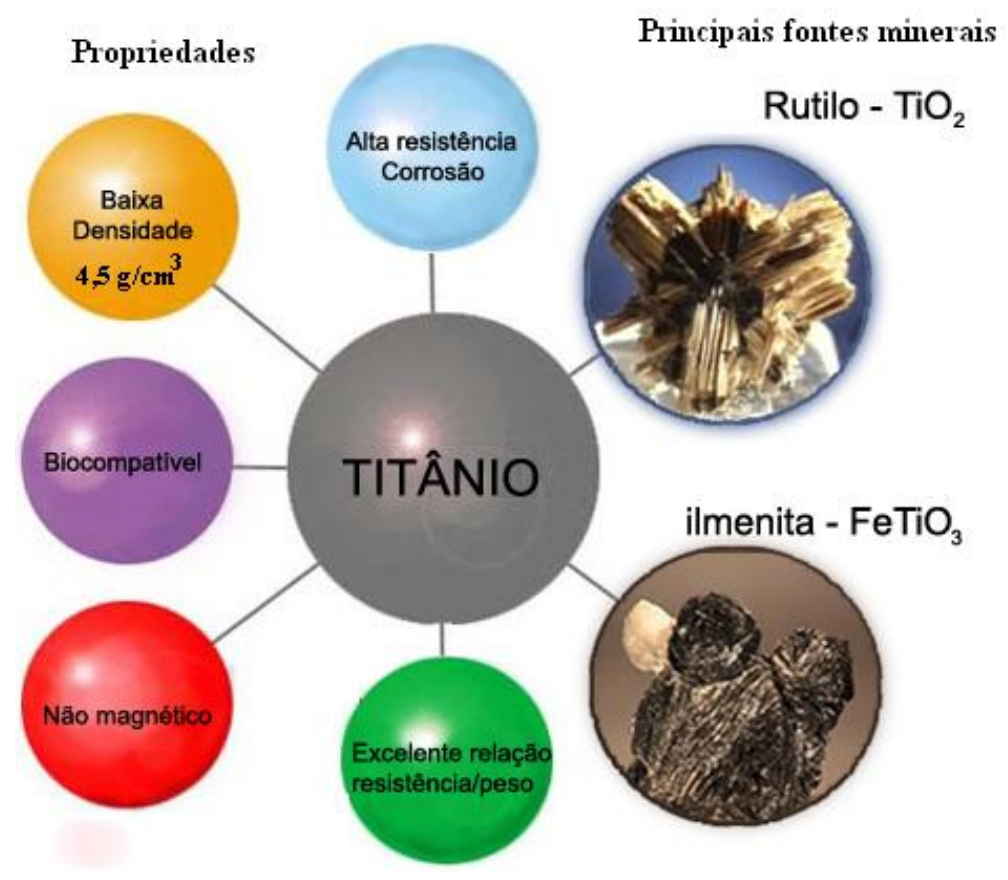

Figura 2 - Titânio: fonte e características. 
O metal na forma pura só foi produzido em 1910 por Matthew A. Hunter, o qual aqueceu $\mathrm{TiCl}_{4}$ com sódio a temperatura de $700-800^{\circ} \mathrm{C}$ em ambiente com gás argônio.

Um composto muito importante inserido na história deste metal é o dióxido de titânio $\left(\mathrm{TiO}_{2}\right)$ encontrado no mineral rutilo. Durante a primeira Guerra Mundial foi utilizado como técnica de camuflagem e ficou conhecido como cortina de fumaça. $\mathrm{O}$ $\mathrm{TiO}_{2}$ é obtido pela reação do tetracloreto de titânio $\left(\mathrm{TiCl}_{4}\right)$ com água e desta reação forma-se uma enorme quantidade de fumaça branca ${ }^{20}$.

Segundo Everhart ${ }^{21} 1954$, o titânio é o quarto elemento mais abundante da crosta terrestre. Contudo, esta abundância não significa que sua exploração seja economicamente viável. Os minerais devem estar concentrados em grandes depósitos para assim proporcionar uma extração rentável. Além disso, a complexidade do processo de produção deste metal ainda é relativamente elevada.

Atualmente, os processos de produção mais utilizados são:

a) no processo Kroll (pirometalúrgico), o $\left(\mathrm{TiCl}_{4}\right)$ é obtido pela ação do cloro e carbono sobre a ilmenita e depois reduzido pelo uso de magnésio metálico. Este método foi desenvolvido a partir de 1946 pelo metalurgista William J. Kroll e ainda hoje é um dos processos mais utilizados.

$$
\begin{gathered}
2 \mathrm{TiFeO}_{3}+7 \mathrm{Cl}_{2}+6 \mathrm{C} \rightarrow 2 \mathrm{TiCl}_{4}+2 \mathrm{FeCl}_{3}+6 \mathrm{Co} \\
\mathrm{TiCl}_{4}+2 \mathrm{Mg} \rightarrow 2 \mathrm{MgCl}_{2}+\mathrm{Ti}
\end{gathered}
$$

b) no processo Hunter emprega-se o sódio metálico como redutor. Porém, mais oneroso que o processo Kroll. 
c) no processo Dow-Howmet ocorre uma redução eletrolítica, a qual gera um produto conhecido por titânio esponja ou metal esponja que sofre várias operações de fusão para ser convertido em titânio metálico.

Mundialmente, existem várias pesquisas sendo desenvolvidas para gerar um novo modo de explorar e produzir o titânio na tentativa de baratear substancialmente um dos mais nobres metais da indústria. As mais importantes e recentes são:

- Na Rússia, engenheiros do Instituto de Metalurgia de Baikov desenvolveram uma forma de extrair o titânio do rutilo separando-o do quartzo presente na areia ${ }^{22}$

- Na Austrália, empresa CSIRO e Light Metals Flagship - desenvolvem esforços para a redução de custos de produção do metal extraído da $\operatorname{areia}^{23}$

- Nos Estados Unidos, as empresas Altair Nanotechnologies e Titanium Metals Corporation, uma das maiores fornecedoras mundiais de titânio, uniram-se para utilizar um novo processo criado pelos professores George Zheng Chen, Derek Fray e Tom W. Farthing da Universidade de Cambridge. O processo, chamado "Fray-Farthing-Chen (FFC) Cambridge Process" é utilizado para extrair metais e ligas de seus óxidos sólidos por meio da eletrólise em sais fundidos. Ao contrário do método pirometalúrgico, o FFC que é um método eletrolítico permite uma extração muito mais econômica. Esta nova técnica ${ }^{24}$ pode ser resumida pela reação: 
Segundo Gerdemann ${ }^{25} 2001$, a indústria acreditava que após a segunda guerra mundial o titânio se tornaria popular como o alumínio. Entretanto, este fato nunca ocorreu, pois a sua extração continua muito onerosa. A energia necessária para a produção de uma tonelada deste metal chega a ser em torno de 16 vezes maior do que é preciso para se obter a mesma quantidade de aço. Nenhum, dos novos processos pesquisados resultou na redução dos custos, o que impediu o crescimento do titânio no mercado.

\section{Produção do titânio no mercado mundial.}

O alto valor pela produção deste metal, cerca de US\$12.000,00 por tonelada, ainda é um fator limitante do seu potencial de utilização, restringindo-se a 50.000 toneladas por ano.

\subsubsection{Microestrutura e a físico-química.}

O grande valor deste material entre os metais não ferrosos está associado às suas propriedades. Suas características físico-químicas permitem-lhe formar uma grande variedade de ligas com diferentes tipos de metais.

Pouco reativo em temperatura ambiente, o titânio aquecido sofre a ação dos não-metais, dando compostos estáveis, duros e refratários, como o nitreto (TiN), o carbeto $(\mathrm{TiC})$ e os boretos $\left(\mathrm{TiB}\right.$ e $\left.\mathrm{TiB}_{2}\right)$. O titânio dissolve-se no ácido fluorídrico, com o qual forma complexos de flúor.

O estado de oxidação mais estável do titânio é +4, embora existam compostos no qual sua valência é +2 ou +3 . É um elemento de transição com o último nível eletrônico incompleto $\left(1 s^{2} 2 s^{2} 2 p^{6} 3 s^{2} 3 p^{6} 4 s^{2} 3 d^{2}\right)$ o que lhe proporciona uma grande afinidade pelos elementos hidrogênio, carbono, nitrogênio e oxigênio, todos formadores de soluções sólidas intersticiais ${ }^{26,27,28}$. 
Os compostos formados com cada um desses elementos proporcionam alterações nas suas propriedades e dessa forma modificam a dureza e a resistência mecânica do metal puro e suas ligas.

Devido ao fato do seu diâmetro atômico ser muito pequeno, conforme visto na Figura 3, o hidrogênio apresenta elevada difusibilidade e deste modo é facilmente absorvido pelas estruturas cristalinas, inclusive em temperaturas baixas. $\mathrm{O}$ resfriamento lento de $400^{\circ} \mathrm{C}$ até a temperatura ambiente favorece a precipitação sob a forma de hidretos de titânio que reduzem relevantemente a tenacidade e a ductibilidade. A sua interação com o titânio ${ }^{29}$ gera uma simples transformação eutetóide de fase alfa + hidreto, formado diretamente da fase beta. Um forte efeito estabilizador sobre campo da fase beta resulta no decréscimo da temperatura de transformação da fase alfa para beta de $882^{\circ} \mathrm{C}$ para temperatura eutetóide de $300^{\circ} \mathrm{C}$.

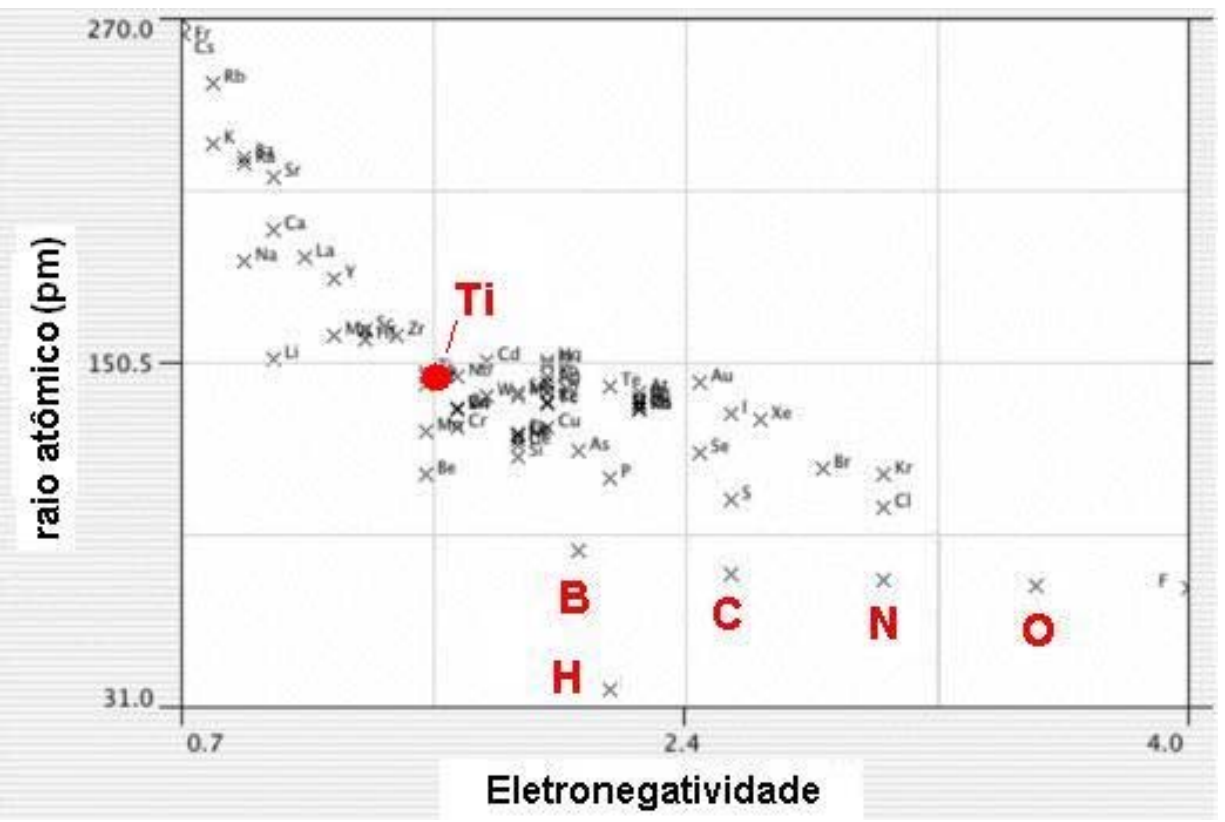

Figura 3 - Diferença dos raios atômicos dos elementos intersticiais para a rede cristalina do titânio ${ }^{30}$. 
A presença de nitrogênio e oxigênio também provoca redução na tenacidade alterando as propriedades mecânicas do material. Neste caso, observa-se a formação de estruturas aciculares, conhecidas como estruturas de Widmanstätten. Essa estrutura é caracterizada por um padrão geométrico resultante de uma nova fase formada em certo plano cristalográfico, relativa à estrutura do sólido. A adição desses elementos promovem a estabilização da fase Ti- $\alpha$ e a formação de um peritético $L+\alpha->\beta$.

Outro elemento que igualmente reduz a ductibilidade e tenacidade é o carbono. Entretanto, em teores até $0,3 \%$ pode formar carbetos que resultam no aumento da resistência mecânica.

Assim como pequenas adições desses elementos supra citados influenciam nas propriedades do titânio, a adição de determinados elementos de liga, acima de certos teores, geram mudanças significativas nos campos de estabilidade das fases e nas temperaturas de transformação. Portanto, é muito importante a adequação dos teores máximos destes elementos às exigências das normas técnicas. Verifica-se na Tabela 1 alguns destes exemplos ${ }^{31}$.

Tabela 1 - Elementos estabilizadores do Titânio.

\begin{tabular}{|c|c|c|}
\hline & \multicolumn{2}{|c|}{ Estabilizadores } \\
\hline & fase Ti- $\alpha$ & fase Ti- $\beta$ \\
\hline $\begin{array}{l}\text { Intersticiais } \\
\text { (ocupam os interstícios, } \\
\text { vãos da matriz). }\end{array}$ & Carbono, Nitrogênio, Oxigênio & Hidrogênio \\
\hline Substitucionais & $\begin{array}{c}\text { Adições de Al, Nd, B } \\
\text { (estabilizam a fase Ti- } \alpha \text { através }\end{array}$ & $\begin{array}{l}\text { Adições de } \mathrm{V}, \mathrm{Nb}, \mathrm{Zr} \text {, Ta e Hf } \\
\text { (promovem a decomposição desta } \\
\text { fase por uma reação isomorfa). }\end{array}$ \\
\hline $\begin{array}{l}\text { (substituem os átomos } \\
\text { do Ti na rede cristalina). }\end{array}$ & $\begin{array}{l}\text { de uma reação do tipo peritetóide } \\
\qquad \beta+\gamma->\alpha) .\end{array}$ & $\begin{array}{l}\text { Adições de } \mathrm{Fe}, \mathrm{Mn}, \mathrm{Pd}, \text { e Si } \\
\text { (promovem a sua decomposição } \\
\text { por reação do tipo eutetóide). }\end{array}$ \\
\hline
\end{tabular}


A estrutura cristalina pode ser definida como a distribuição espacial ordenada de um padrão constituído por um ou mais átomos. A característica físico-química do material é determinada pela estrutura do arranjo atômico ou molecular ${ }^{32}$.

O titânio puro é um material alotrópico (ou polimórfico), pois sua estrutura cristalina sofre alterações conforme a variação térmica. Na condição da temperatura ambiente apresenta estrutura cristalina hexagonal compacta $(\mathrm{HCP})$ e é denominada de fase alfa $(\alpha)$. Entretanto, acima de $883^{\circ} \mathrm{C}$ (temperatura transus) sua estrutura modifica-se para cúbica de corpo centrado (CCC). Nesta situação, visualizada na Figura 4, a estrutura é conhecida por fase beta $(\beta)$ e se mantém estável até atingir a temperatura de fusão $\left(1672{ }^{\circ} \mathrm{C}\right)$. A fase $\gamma$ é do tipo intermetálica, cuja estrutura cristalina e estequiometria dependem do elemento de liga adicionado ${ }^{33}$.
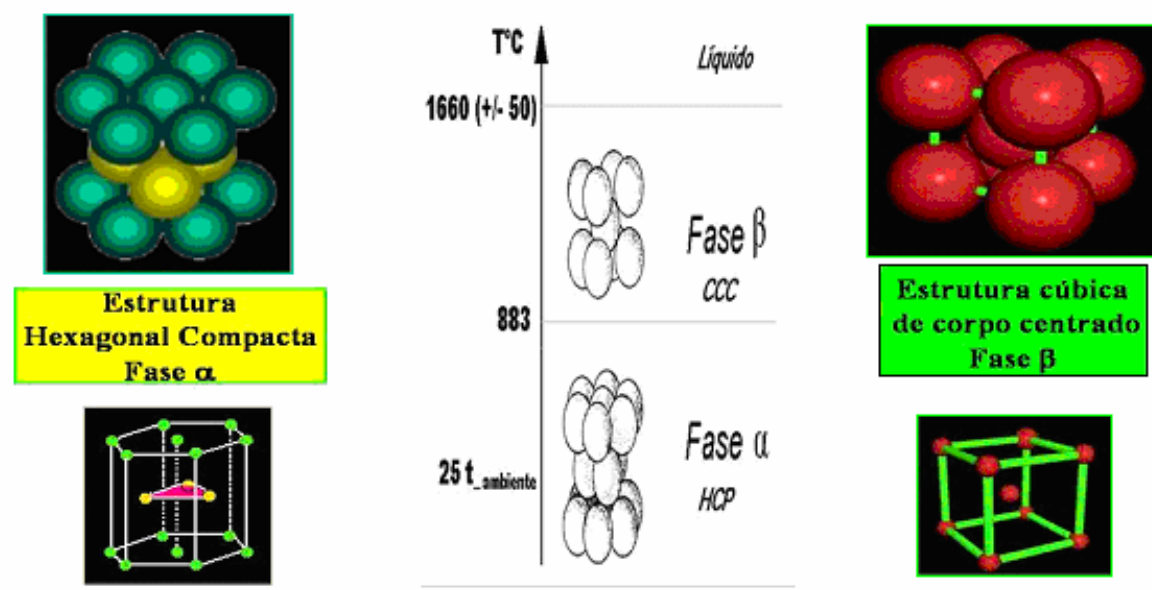

Figura 4 - Esquema representativo da transformação do titânio ${ }^{34}$.

A classificação metalúrgica do titânio ${ }^{35}$, segundo o sistema da ASTM (American Society of Testing and Materials) é determinada sob a seguinte forma: titânio comercialmente puro (Ti c.p.) ${ }^{36}$ de diferentes graus (também denominado como "não-ligados") e as ligas: alfa $(\alpha)$, alfa-beta $(\alpha+\beta)$ e beta $(\beta)$, as quais definem a predominância das fases presentes na microestrutura. 
O Ti c.p. apresenta teores entre 98 a $99,5 \%$ de pureza e conforme a norma ASTM F67 é classificado em quatro categorias, variando de acordo com os teores de nitrogênio, hidrogênio, oxigênio, carbono e ferro. Seus valores podem ser observados pelos dados da Tabela 2.

Tabela 2 - Teores da composição do Ti c.p pela norma ASTM F67.

\begin{tabular}{|c|c|c|c|c|}
\hline \multirow{2}{*}{ ASTM67 - composiçăo máxima (\%) pip } \\
\hline & Grau 1 & Grau 2 & Grau 3 & Grau 4 \\
\cline { 2 - 5 } Elementos & max. & max. & max. & max. \\
\hline Hidrogênio & \multicolumn{5}{|c|}{0,015} \\
\hline Nitrogênio & 0,03 & 0,03 & 0,05 & 0,05 \\
\hline Carbono & \multicolumn{5}{|c|}{0,08} \\
\hline Oxigênio & 0,18 & 0,25 & 0,35 & 0,4 \\
\hline Ferro & 0,2 & 0,3 & 0,3 & 0,5 \\
\hline Titânio & \multicolumn{5}{|c|}{ Balanço } \\
\hline
\end{tabular}

Existe ainda uma outra classificação mais abrangente, na qual a divisão está associada às curvas de transformação martensítica inicial e final (Mi/Mf). Deste modo, conforme demonstrado na Figura 5, as cinco classes estão divididas em: ligas $(\alpha)$, ligas pseudo- $\alpha$, ligas $(\alpha+\beta)$, ligas pseudo- $\beta$ e ligas $\beta^{37,38}$.

As cinéticas de transformação destas fases, durante o resfriamento, estão diretamente relacionadas às propriedades metalúrgicas e mecânicas do material. Fases metaestáveis podem ocorrer conforme essas condições de transformação.

O aumento da resistência mecânica como a alteração da microestrututra, no caso do Ti c.p., são obtidos somente por uma série de encruamento e recozimento. Nesta variação estrutural, observa-se a formação de fase alfa com contornos irregulares a partir de um rápido resfriamento da fase beta ${ }^{39}$. 


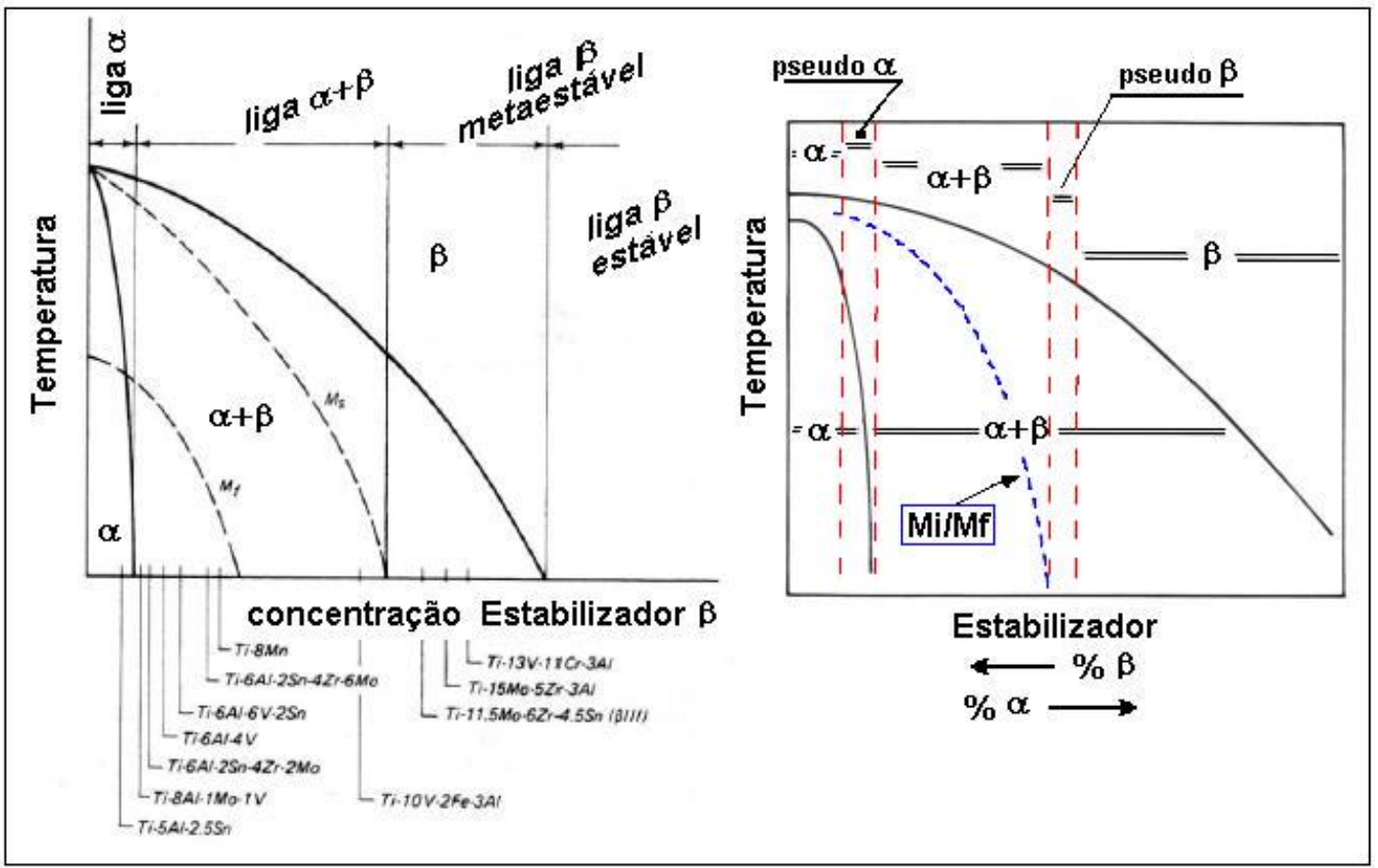

Figura 5 - (a) Classificação e composição das ligas de titânio distribuídas em relação pseudobinário diagrama de fase isomorfo. (b) Diagrama de fase isomorfo pseudobinário relacionando a curva martensitica (Mi/MF) com os campos de fase $\alpha+\beta$.

Como ilustração dos materiais abordados, a Figura 6 mostra fotomicrografias das superfíces do Ti puro (a) e também da liga Ti-6Al-4V(b).
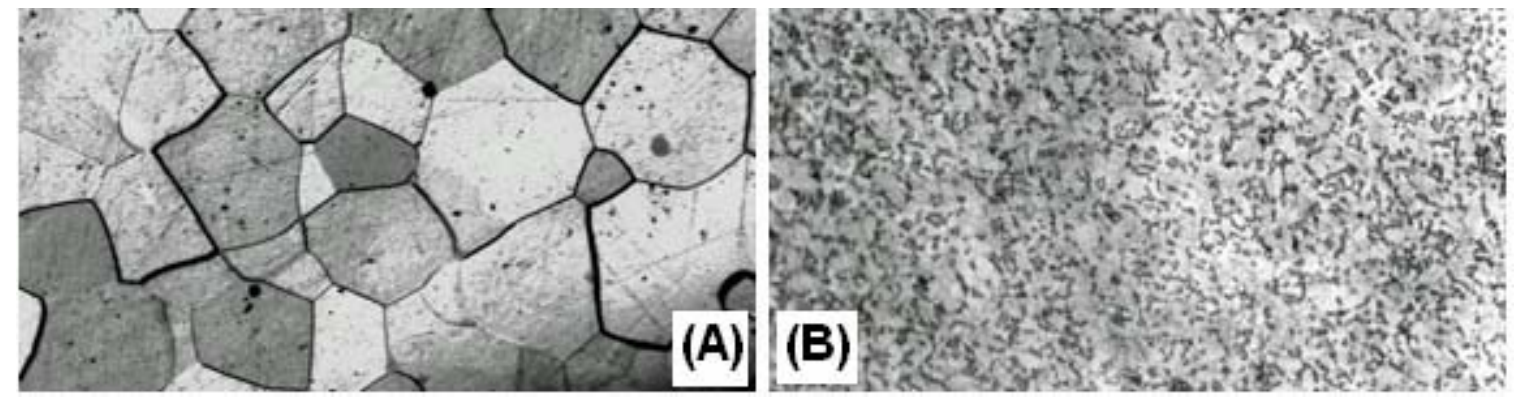

Figura 6 - Fotomicrografias das superfíces do Ti puro (a) e da liga Ti6Al4V (b). Aumento de $200 x^{40}$.

\subsubsection{Classificação e Propriedades.}

Conforme citado anteriormente, existem duas abordagens diferentes para classificação deste material. A primeira é relativa às fases presentes na microestrutura e a segunda considera a curva de transformação martensítica 
(Mi/Ms). Ambas considerações foram sintetizadas e estão descritas a seguir em função da fase predominante na microestrutura e suas propriedades.

\section{Liga alfa ( $\alpha)$}

A microestrutura e as propriedades das ligas monofásicas alfa $(\alpha)$ e do Ti c.p. não podem ser alteradas pelo tratamento térmico. Essas modificações, como aumento de dureza e resistência mecânica, somente são atingidas pelo processo de deformação plástica e ou mecânica (mecanismo de encruamento e recozimento). Outro mecanismo que pode ser aplicado nestas ligas é o endurecimento por solução sólida. Neste caso, elementos de liga (soluto) são adicionados no solvente (titânio), visando à formação de soluções sólidas substitucionais ou intersticiais. O efeito dessa interação gera uma restrição no movimento das discordâncias e consequentemente a liga é endurecida ${ }^{41,42}$.

O alumínio é o elemento estabilizador mais importante e a sua inclusão favorece o aumento da temperatura de transformação alfa-beta. Contudo, seu teor deve ser mantido abaixo de $7 \%$ para evitar a fragilização em baixa temperatura, devido à formação da fase Ti3Al (aluminetos de titânio). Devido ao resfriamento rápido, a transformação martensítica é uma característica dessas ligas.

As propriedades da liga alfa são: resistência à deformação (superior das ligas beta), razoável ductibilidade, boa tenacidade, média resistência mecânica, alta resistência à corrosão e excelente propriedades mecânicas em temperaturas criogênicas. 


\section{Liga beta $(\beta)$}

A liga $(\beta)$ pode ser obtida com a adição de elementos estabilizadores desta fase. As propriedades desta liga são inerentes à fase beta retida após resfriamento ao ar, o que as caracterizam por apresentar boa combinação de resistência mecânica, alta forjabilidade, média conformabilidade e baixo módulo de elasticidade $^{38}$. Entretanto, em virtude dos altos teores de elemento de liga utilizados para sua produção, fator este que eleva muito o custo, sua aplicação é bastante limitada ${ }^{43,44}$.

Apesar do alto custo, estudos mais recentes sobre biocompatibilidade indicam o uso das ligas Ti-13Nb-13Zr (TNZ) e Ti-35Nb-7Zr-5Ta(TNZT) em substituição das ligas Ti-6Al-4V (alfa+beta), especialmente para aplicações biológicas ${ }^{45,46}$.

A porcentagem dos estabilizadores da fase beta (betagênicos) configuram a classificação de metaestável ou estável para as ligas de titânio deste tipo, conforme pode ser observado na Figura 5. Enquanto metaestável são inadequadas ao trabalho em temperaturas baixas, pois podem precipitar, transformando-se parcialmente em fases binárias (alfa+beta) e tornarem-se propensas à fratura ${ }^{28} .0$ tratamento de solubilização e envelhecimento (estabilização), nestas ligas, permite atingir melhores valores de resistência mecânica com adequada ductilidade.

\section{Liga alfa+beta $(\alpha+\beta)$}

Uma parcela de aproximadamente $70 \%$ da produção mundial das ligas de titânio está dirigida a confecção das ligas $(\alpha+\beta)$, graças as suas propriedades. Entre estas ligas, a mais importante é a liga Ti-6Al-4V que abarca um vasto campo de aplicações, especialmente nos setores aeroespaciais e médicos. 
Estes tipos de liga são caracterizados pela presença de ambos estabilizadores ( $\alpha$ e $\beta$ ) que propiciam uma grande variação de microestruturas bifásicas. O resfriamento rápido pode induzir a formação de estruturas martensíticas ( $\alpha^{\prime}$ e $\left.\alpha^{\prime \prime}\right)$, ou a retenção da fase $\beta$ na forma metaestável, o que altera as propriedades da liga.

A aplicação do correto tratamento (solubilização, envelhecimento e outros) e diferentes faixas de temperatura permitem obter diversos níveis de resistência mecânica. Suas principais propriedades são: excelente relação resistência/peso, razoável soldabilidade, boa conformabilidade e resistência à corrosão ${ }^{28,33}$.

O quadro representado na Figura 7 resume as principais características delineadas no texto referente à classificação das ligas de titânio e na Figura 8 verifica-se um diagrama geral com a classificação dos diagramas binários de fase, os tipos e as diferentes porcentagens de estabilizadores das ligas de titânio.

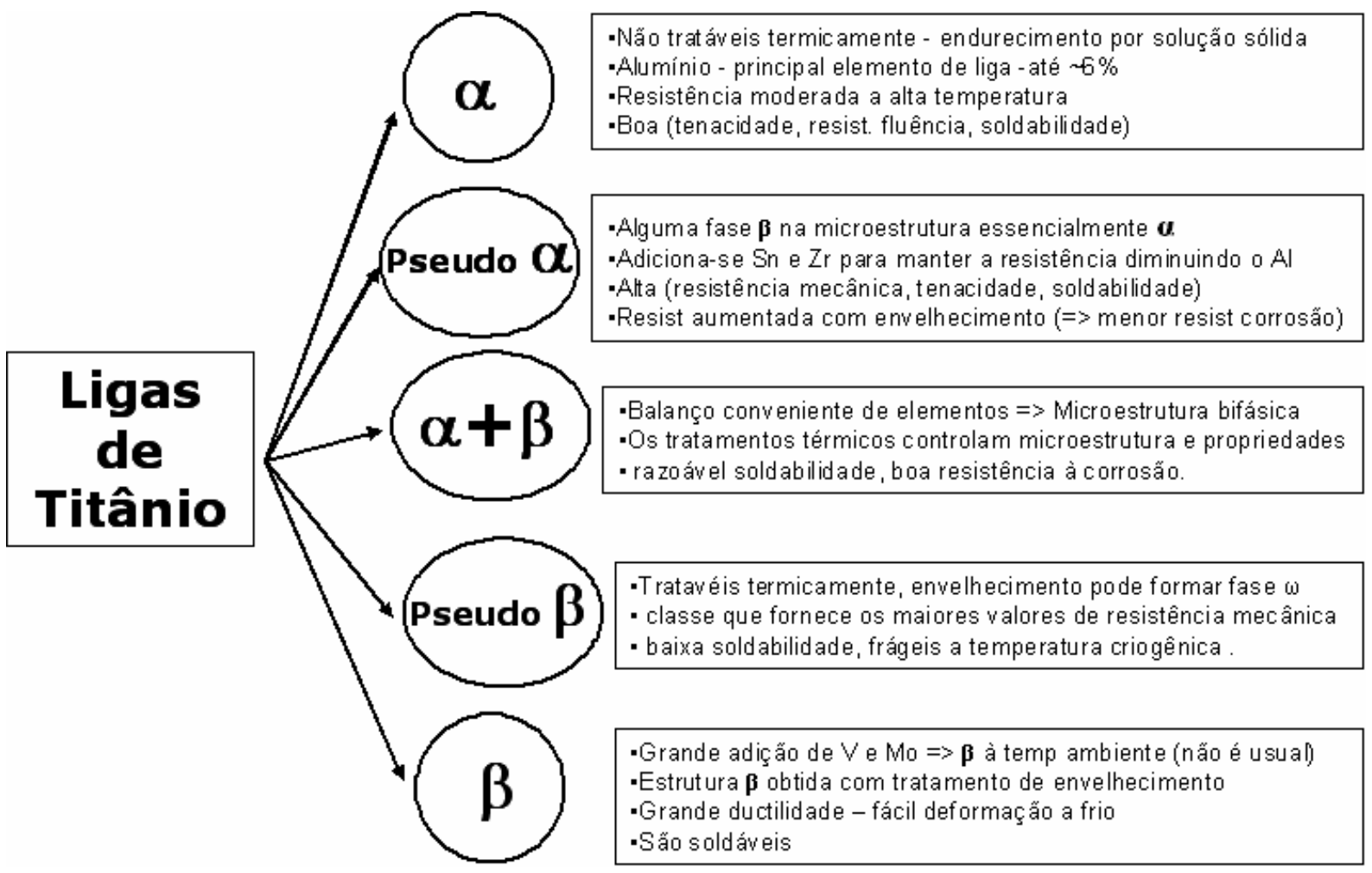

Figura 7 - Síntese da classificação das ligas de titânio e suas características. 


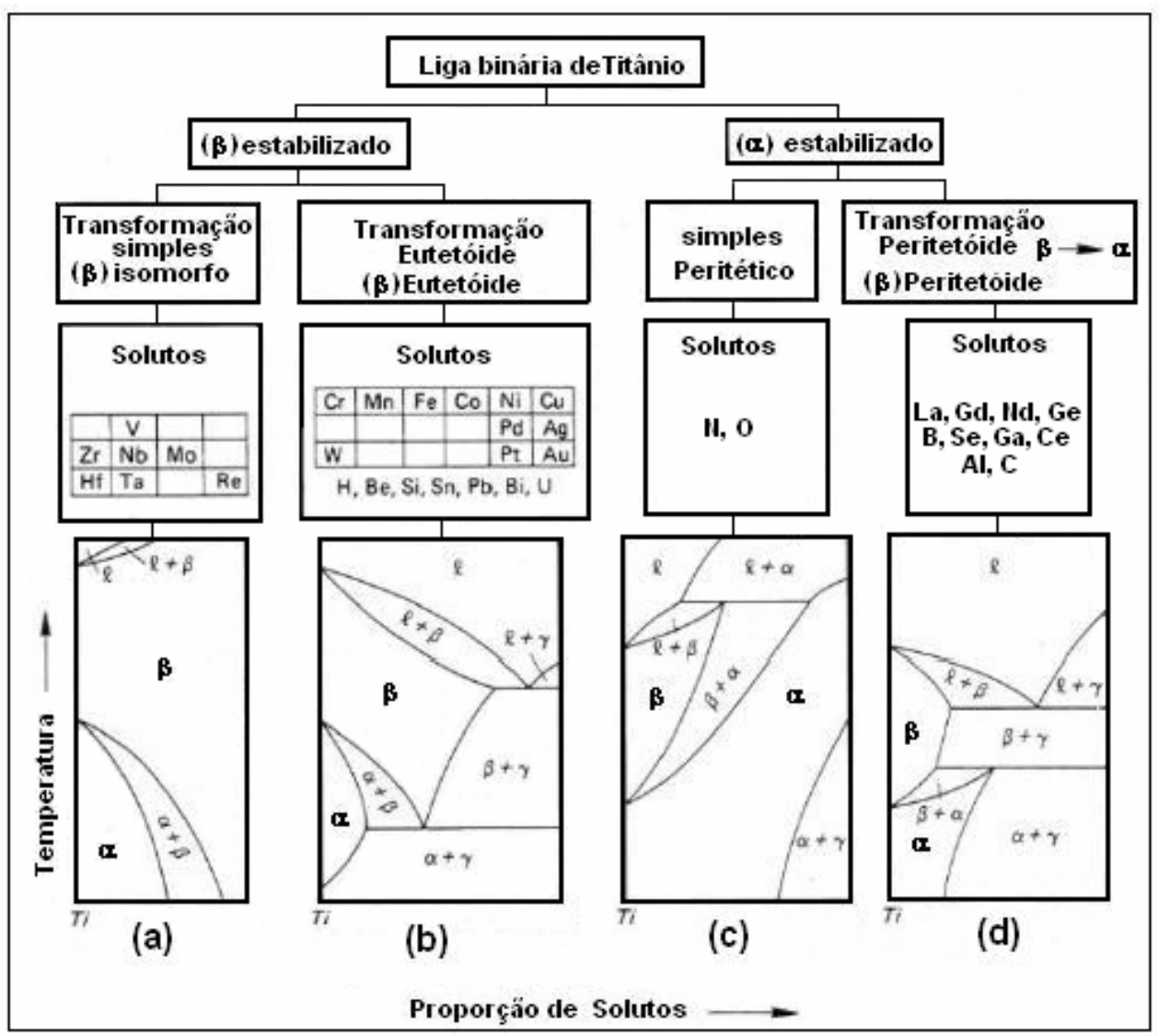

Figura 8 -Tipos dos diagramas binários de fase das ligas de titânio.

a) Elemento $X$ é estabilizador da fase Ti- $\beta$ (transformação isomorfa:Ti- $\beta$->Ti- $\alpha$ );

b) Elemento $X$ é estabilizador da fase Ti- $\beta$ (transformação eutetóide: Ti- $\beta$ - $>$ Ti- $\alpha+\mathrm{Ti}-\gamma$ );

c) Elemento $X$ é estabilizador da fase Ti- $\alpha$ (transformação isomórfa: Ti- $\beta$ - $>$ Ti- $\alpha$ );

d) Elemento $X$ é estabilizador da fase Ti- $\alpha$ (transformação peritetóide: Ti- $\beta+\mathrm{Ti}-\gamma->\mathrm{Ti}-\alpha)^{47}$.

\subsubsection{Aplicações do Titânio e suas ligas.}

A seleção do material apropriado para uma determinada aplicação envolve uma avaliação complexa que correlacione os aspectos econômicos, tecnológicos, as propriedades e o desempenho desejado. Portanto, o custo inicial do material pode ser compensado pelas vantagens pertinentes ao mesmo, dependendo da sua 
finalidade. Uma lista com os preços do mercado de metais está descrita na Tabela 3 para situar a diferença entre os valores do titânio com o aço e o alumínio

Tabela 3 - Comparação do preço entre materiais ${ }^{48}$.

\begin{tabular}{cccc} 
& Aço & $\begin{array}{c}\text { Material }(\mathbf{U} \mathbf{\text { /kg }} \\
\text { Alumínio }\end{array}$ & Titânio \\
\hline minério & 0,04 & 0,22 & 0,48 (rutilo) \\
metal & 0,22 & 0,22 & 12,00 \\
lingote & 0,33 & 2,53 & 20,00 \\
chapa & $0,66-1,3$ & $2,2-11,00$ & $33,00-110,00$ \\
\hline
\end{tabular}

As propriedades mecânicas e físico-químicas do titânio e suas ligas são considerações importantes que permitem justificar a substituição de outros materiais menos onerosos por este metal. Em razão de suas propriedades, o uso deste metal pode ser dividido em três categorias ${ }^{49}$ : a) excelente relação resistência mecânica/peso; b)alta resistência à corrosão; c) biocompatibilidade.

O emprego do titânio e suas ligas estão disseminados entre as mais diferentes aplicações de vários setores do mercado mundial. Na Tabela 4 observam-se os valores consumidos de titânio, nas diversas formas disponíveis, em relação à área de utilização.

Tabela 4 - Distribuição do consumo anual de titânio pelo mercado de aplicação ${ }^{50}$.

\begin{tabular}{cc}
\hline Mercado de Aplicação & Consumo (t) \\
\hline Indústria Química & $20000-25000$ \\
e ligada à geração de Energia & $14000-19000$ \\
Aeroespacial Civil & $3000-4000$ \\
Esporte e Lazer & 3000 \\
Construção civil e Arquitetura & 500 \\
Médica e Odontológica & 800 \\
Outras & 1000 \\
\hline TOTAL & $42300-53300$ \\
\hline
\end{tabular}


$\mathrm{Na}$ relação resistência mecânica/peso as ligas de titânio podem ser empregadas em componentes das turbinas, partes estruturais das aeronaves e dos veículos blindados de combate (tanques de guerra), em que a faixa de temperatura permanece acima de $150^{\circ} \mathrm{C}$ e abaixo de $500^{\circ} \mathrm{C}$.

A característica de resistência à corrosão favorece o uso das ligas para fabricação de componentes navais, dutos e trocadores de calor para indústria química, risers ${ }^{51}$ (equipamento que permite a circulação dos fluidos nos serviços de sondagem) nas plataformas de exploração petrolífera, entre outros.

Além da resistência à corrosão, a biocompatipilidade é outra propriedade do titânio e suas ligas que possibilita a aplicação deste material na manufatura de implantes cirúrgicos, especialmente ortopédicos e ortodônticos.

Com finalidade didática procurou-se representar na Figura 9 um panorama das aplicações do titânio nas diferentes áreas do mercado global.

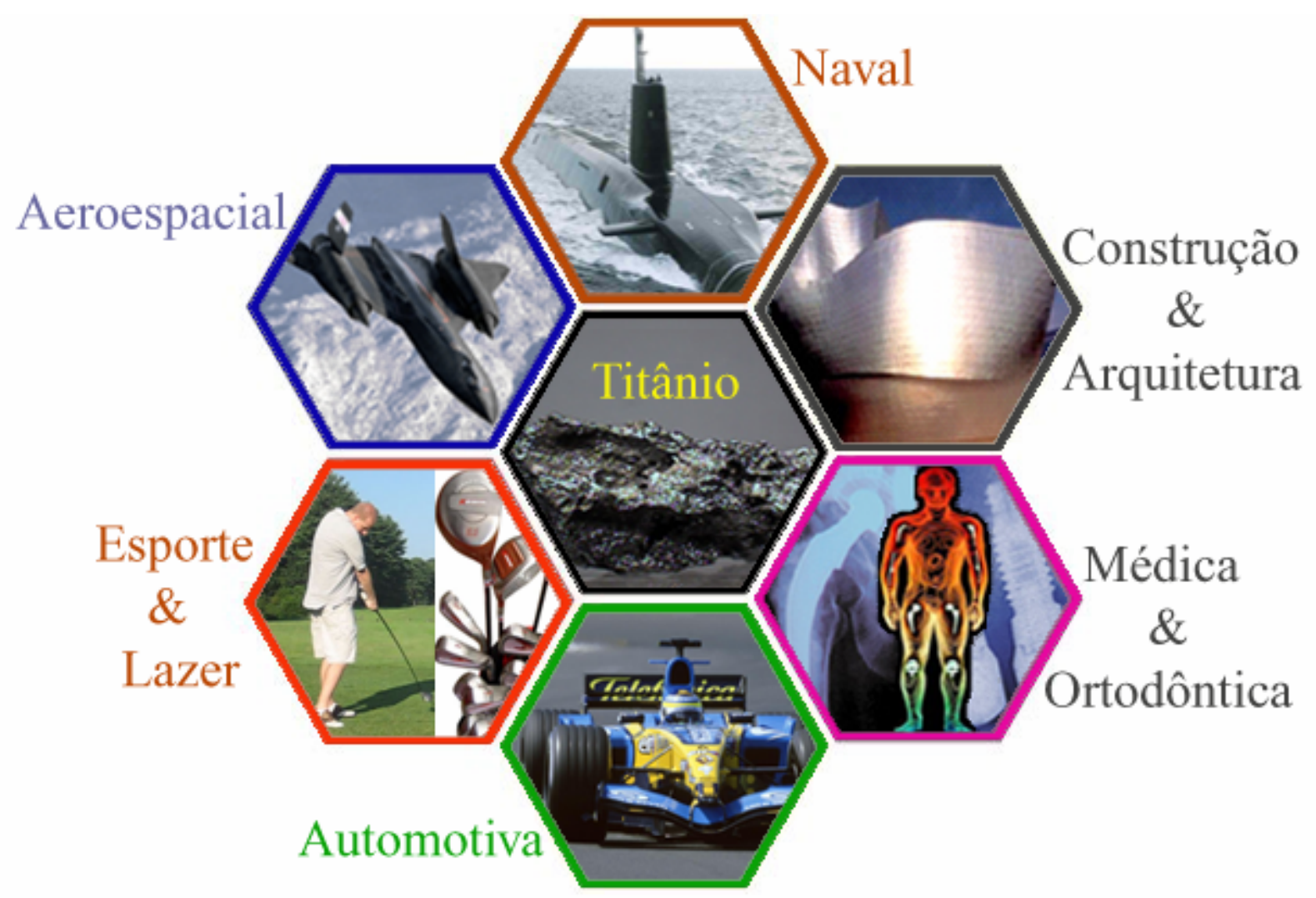

Figura 9 - Aplicações do Titânio. 
O interesse e a evolução da utilização de implantes para recuperação de indivíduos lesionados intensificou-se durante o período das grandes guerras mundiais. Tal fato impulsionou as pesquisas de materiais biocompatíveis ${ }^{52}$ que implicaram na realização de testes em animais a partir de 1940 pelos pesquisadores Williams ${ }^{53}$ e Leventhall ${ }^{54}$. Somente no ano de 1965 culminou o primeiro implante dentário em um ser humano, desenvolvido por Bränemark ${ }^{55}$.

Atualmente, a liga Ti-6Al-4V e o Ti. c.p. são os materiais mais usados na produção de próteses e dispositivos médicos e odontológicos, por apresentam uma boa combinação de propriedades (baixo módulo elástico, resistência à corrosão e biocompatibilidade $)^{56}$.

Como mencionado anteriormente, recentes pesquisas sugerem a substituição do vanádio e do alumínio, presentes na liga Ti-6Al-4V, por outros elementos como nióbio ( $\mathrm{Nb}$ ), zircônio ( $\mathrm{Zr}$ ) e tântalo (Ta), estabilizadores da fase $\beta$. Estas ligas, quando submetidas a esforços cíclicos de impacto e atrito, como também à ação do meio fisiológico do corpo, podem sofrer uma modificação do potencial elétrico dos elementos que as compõe. Essa alteração, do alumínio e do vanádio, propicia a formação de óxidos nocivos que podem causar reações adversas ao homem, o que seria evitado com a presença do $\mathrm{Nb}, \mathrm{Ta}_{\mathrm{e}} \mathrm{Zr}^{26,57}$.

Outro fator que justifica a utilização do nióbio é a redução do módulo de elasticidade. A liga Ti-6Al-4V apresenta um módulo de elasticidade aproximadamente de $120 \mathrm{GPa}$, nas ligas $\beta$ Ti-15Mo-5Al-3Zr e Ti-29Nb-13Ta-4.6Zr esses valores caem para 60 e $80 \mathrm{GPa}$, respectivamente, que são mais próximos ao dos ossos, os quais variam entre 17 a $30 \mathrm{GPa}^{31}$. Essas propriedades proporcionariam melhor compatibilidade química e mecânica e dessa forma 
estenderiam o período de permanência do implante, sem que houvesse necessidade da revisão cirúrgica do mesmo.

Entretanto, o custo da produção destas ligas é ainda superior aos implantes de Ti-6Al-4V e exerce grande peso na seleção do material, especialmente quando comparados ao valor comercial dos implantes mais empregados que custam cerca de U\$ 2,5 mil para as ligas Ti-6Al-4V e U\$ 700 para as próteses confeccionadas em aço inoxidável austenítico AISI-SAE $316 \mathrm{~L}^{58,59}$.

\subsubsection{Confecção de Implantes.}

Um aspecto muito importante referente aos biomateriais é o gerenciamento e a certificação destes produtos utilizados como implantes e próteses. A Agência Nacional de Vigilância Sanitária (ANVISA) tem aperfeiçoado a legislação com intuito de gerar formas de controle rigoroso da qualidade destes materiais e com isso certificar as empresas que atendem os requisitos de Boas Práticas de Fabricação de Produtos Médicos (BPFPM's) ${ }^{60}$, reduzindo o risco de defeitos.

Desde a década de 40, mais de cem milhões de materiais metálicos foram implantados em seres humanos. Esse amplo quadro deveria estimular os órgãos de vigilância a intensificar a fiscalização e desse modo reduzir o índice de falhas dos implantes.

As falhas podem ocorrer por uma série de fatores, como erro de projeto, seleção inadequada do material, defeitos de fabricação e fora da especificação vigente, entre outros. Azevedo e Hippert ${ }^{61}$ sintetizaram as causas mais comuns das falhas em implantes como demonstrado na Tabela 5. 
Tabela 5 - Causas mais comuns de falhas em implantes metálicos ${ }^{61}$.

\begin{tabular}{ll}
\hline \multicolumn{1}{c}{ Etapa } & \multicolumn{1}{c}{ Causa das falhas } \\
\hline Projeto do implante & $\begin{array}{l}\text { Seção transversal insuficiente, esforços cíclicos associados à } \\
\text { presença de alta concentração de tensões. }\end{array}$ \\
Fabricação do implante & $\begin{array}{l}\text { Presença de defeitos no material e no produto (tolerâncias } \\
\text { inadequadas no dimensionamento). }\end{array}$ \\
Seleção do material & Material e propriedades incompatíveis. \\
Procedimento cirúrgico & Incorreta seleção do implante e erro no procedimento médico. \\
Reparação óssea & $\begin{array}{l}\text { Afrouxamento em virtude da reabsorção óssea } \\
\text { Uso impróprio }\end{array}$ \\
\hline
\end{tabular}

Uma investigação da conformidade de alguns implantes confeccionados na liga Ti-6AL-4V, realizada pelo Laboratório de Metalografia e Análise de Falhas, no Instituto de Pesquisas Tecnológicas do Estado de São Paulo (IPT), ficou constatado que a falta de concordância com os requisitos mínimos das normas da Associação Brasileira de Normas Técnica (ABNT/ISO) acarretaram fraturas prematuras pela presença de defeitos de fabricação, montagem e manuseio.

Portanto, a fabricação de um implante deve ser muito criteriosa, obedecer a normas e procurar por processos que geram a menor interferência no material.

\subsubsection{Usinabilidade do Titânio.}

Novos métodos como casting (fundição), forjamento isotérmico e sinterização estão sendo utilizados e estudados para reduzir o custo da usinagem do titânio. Contudo, ainda hoje, a maior parte da manufatura deste metal está direcionada para a usinagem convencional. 
O primeiro estudo determinado a obter maior controle operacional da usinagem do titânio e por meio deste diminuir o tempo de processamento, como também, o desgaste excessivo das ferramentas, só foi realizado em 1951, pelo Laboratório de Materiais da força aérea americana $(U S A F)^{62}$. O titânio e suas ligas são popularmente conhecidos como metal "difícil de se usinar". Na realidade, essa denominação está intimamente ligada às propriedades mecânicas e às características metalúrgicas deste material que influenciam no grau de dificuldade da usinagem. Os parâmetros de usinagem, o tipo e as características das ferramentas, as condições de refrigeração, além das condições intrínsecas do material contribuem para a determinação da usinabilidade ${ }^{63}$.

O fato de apresentar baixa condutividade térmica e de reagir quimicamente com vários elementos resulta em problemas como: o aquecimento excessivo causado pela má dissipação, a aderência e a soldagem do metal com as arestas de corte. Este conjunto de ocorrências favorece o desgaste e a rápida degeneração das ferramentas. Além disso, o acabamento superficial e a precisão da peça podem ser comprometidos pela relação entre o grau de deformação do material e as condições de usinagem. O titânio e suas ligas apresentam baixo módulo de elasticidade, com valores até $50 \%$ menor do que dos aços. Esta característica, combinada a uma certa configuração operacional de corte, pode gerar vibrações no sistema e a perda de contato entre material e ferramenta, acarretando deformações indesejadas no objeto usinado ${ }^{64,65}$.

Alguns parâmetros básicos descritos a seguir foram configurados para otimizar a usinagem convencional do titânio e assegurar uma boa qualidade no acabamento superficial. O controle rígido destes parâmetros e a seleção correta do tipo de ferramenta e fluido refrigerante, também interferem no processo. Para uma melhor 
eficiência no processamento deste metal é necessário: utilizar baixas velocidades, manter alta taxa de avanço, usar grande volume e fluxo de fluido refrigerante, empregar ferramenta afiada e trocá-la no primeiro sinal de desgaste ${ }^{66,67,68}$.

Apesar de vários avanços tecnológicos, especialmente no desenvolvimento de novos materiais (carboneto de tungstênio, nitreto de boro cúbico, cerâmicas), como também dos processos para confecção das ferramentas de corte, a situação da taxa de remoção de material no titânio e suas ligas permanecem muito próximas dos estudos realizados na década de 60. O uso de ferramentas especiais (alto custo) muitas vezes proporciona um acréscimo de 20 a 30\% na velocidade de corte, e isto, deve ser considerado para balancear economicamente a produção.

Essa incapacidade de realizar uma melhora contundente no desempenho da usinagem convencional possibilita à aplicação de métodos não tradicionais como o processamento a laser. 


\subsection{Laser}

Fundamentada em idéias e estudos originados nos diversos campos da física e engenharia, especialmente no modelo quântico desenvolvido por Max Planck e Einstein, a palavra Laser emerge em 1960. A terminologia de origem inglesa é escrita na forma de um acrograma que tem por significado (Light Amplification by Stimulated Emisssion of Radiation), ou seja, amplificação da luz por emissão estimulada de radiação.

Em contraste com a conhecida fonte de luz incandescente, a qual emite fótons em todas as direções e sob um amplo espectro de comprimento de onda, o laser apresenta propriedades particulares que o tornam uma excelente ferramenta para uso científico e tecnológico. As principais características dessa fonte de luz são: a monocromaticidade, a coerência, um feixe estreito de baixa divergência e a possibilidade de alta intensidade ${ }^{69}$.

\subsubsection{Histórico}

Hoje em dia, a ampla difusão do laser deve-se, bastante, a esse espírito investigador ao longo do processo histórico de experiências, descobertas, erros e acertos, inseridos no contexto da estrutura atômica e na propagação da luz.

O questionamento sobre a constituição da matéria iniciou-se na antiguidade. Tal fato conduziu vários filósofos a formularem teorias para explicar o mundo. Entretanto, como eram pensadores geravam conceitos sem valorizar a experimentação. Somente, no período renascentista surge o princípio de que o cientista para concretizar suas formulações teóricas e observar os fenômenos em estudo, necessitaria realizar diversas experiências. 
Deste momento em diante, ocorre à transformação dos aspectos filosóficos do átomo em conceito científico e assim nasce um novo período caracterizado pelo rigor e critérios dos procedimentos de pesquisa, particularmente nas áreas química e física.

No início do século XIX, nota-se uma explosão de idéias, conforme representado na Figura 10, com estudos já desvinculados da religião que revolucionaram a forma de compreensão do universo. Uma nova realidade é estruturada, impulsionada inicialmente pela consideração do átomo como uma esfera rígida de Dalton, logo depois a constatação do elétron por Thomson e seguido do modelo planetário de Rutherford. O produto desses desenvolvimentos resultou nos postulados de Planck e Niels Bohr com o desenvolvimento do modelo quântico.

Neste momento, o modelo atômico quântico proposto descreveria o átomo com elétrons girando ao redor do núcleo sem emitir energia, fato que ocorreria somente por meio do salto dos elétrons entre as órbitas interna e externa (esse salto é conhecido como transição eletrônica) ${ }^{70,71}$.

Em virtude disso, foi possível explicar a neutralidade da matéria pela relação entre o núcleo de carga positiva em equilíbrio dinâmico com os elétrons de carga negativa. Além disso, justificar como uma carga elétrica negativa em movimento acelerado, descrita por uma trajetória circular, não emitia luz constantemente e nem colidia com o núcleo, até o colapso da matéria. 


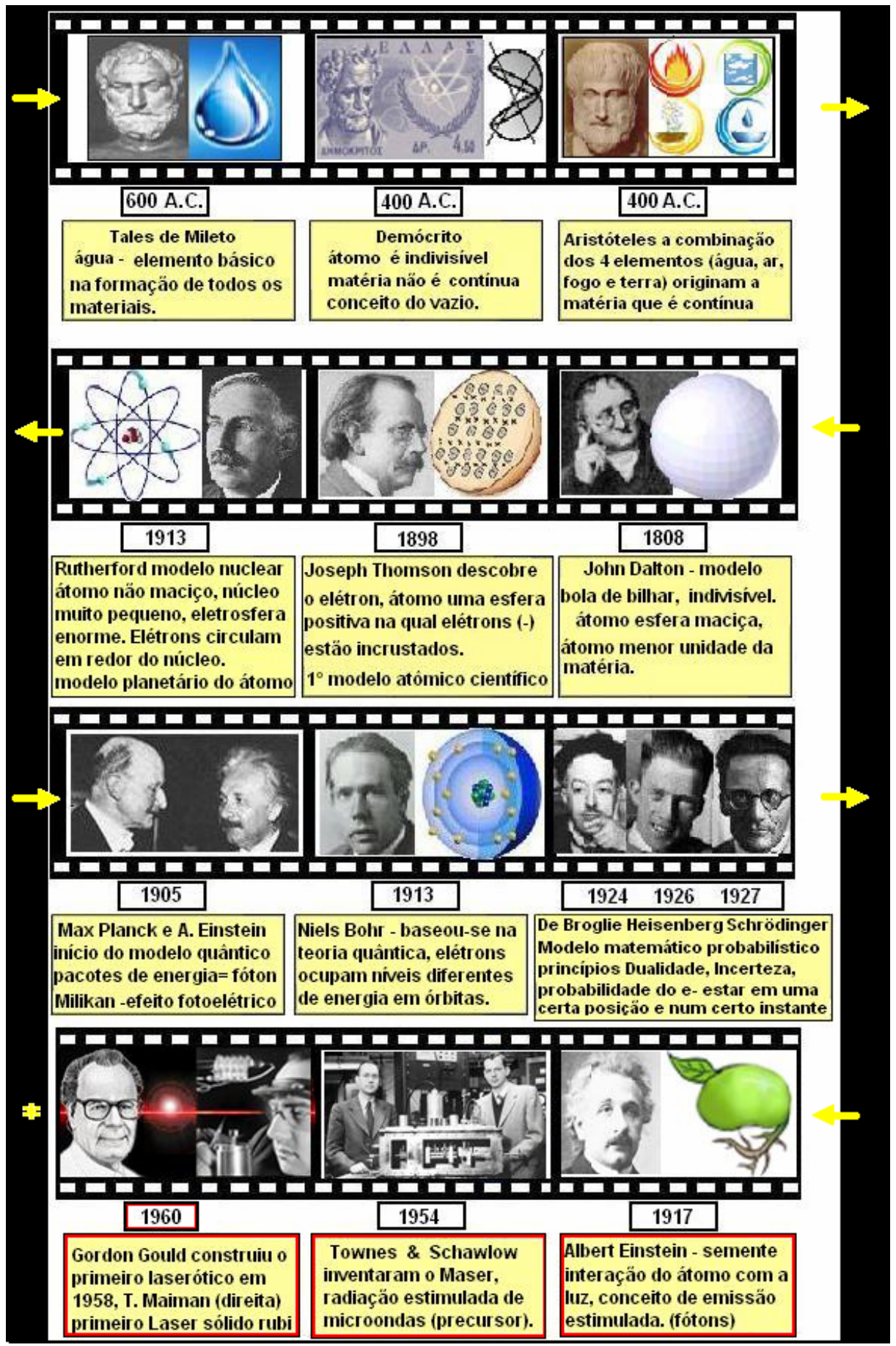

Figura 10 - Evolução dos modelos atômicos até a invenção do laser.

Esse conceito motivou Albert Einstein que em 1917, na realização dos seus estudos, introduziu a idéia de quantização da radiação, juntamente ao efeito fotoelétrico e assim previu a emissão estimulada. Contudo, toda essa base teórica
só floresceu após a Segunda Guerra Mundial por meio dos estudos
espectroscópicos de moléculas para gerar radiação estimulada na região de 
microondas. Esse trabalho foi realizado por Charles Townes e Arthur Schawlow em 1954, que o nomearam de MASER (microwave amplification by stimulated emission of radiation), i.e., amplificação de microondas por emissão estimulada de radiação ${ }^{72,73}$.

A partir de 1960 e nos anos seguintes, o estudo direcionado a amplificação da luz culminou com a descoberta do Laser, resultando na invenção do primeiro laser de estado sólido com rubi por Theodore Maiman ${ }^{74}$ e no laser de hélio-neônio gasoso pelo Dr. Ali Javan ${ }^{75,76}$.

Inicialmente, o advento do laser estava atribuído à pesquisa básica, fato satirizado por alguns céticos da época, pois sua aplicação ainda era indeterminada e obscura.

Atualmente com a pesquisa e o desenvolvimento tecnológico é possível encontrar diversos tipos de lasers aplicados no setor de processamento de materiais, tais como: laser de gás carbônico $\mathrm{CO}_{2}(\lambda=10,6 \mu \mathrm{m})$, laser de neodímio (Nd:YAG) $(\lambda=1,06 \mu \mathrm{m})$ e Laser de fibra (fibra ótica dopada com elementos de terras raras, érbio por exemplo) bombeados por diodo com alta potência, entre vários outros disseminados nas mais diversificadas áreas e aplicações.

\subsubsection{Fundamentos do Laser}

A emissão estimulada é o princípio físico que permitiu a invenção dos lasers. Albert Einstein, por meio do estudo iniciado por Planck sobre a distribuição espectral da radiação do corpo negro e da concepção do efeito fotoelétrico (Millikan,1916), afirmou que a quantização da energia dos osciladores harmônicos poderia também ser estabelecida como se a luz consistisse de quanta de energia. Desta maneira, a 
luz abordada como fenômeno ondulatório passou a ser descrita como constituída de pequenas partículas de energia eletromagnética - fótons.

Novamente, Einstein estudou a interação dos átomos com a luz e introduziu o conceito de emissão estimulada, além do já existentes, absorção (estimulada) e decaimento espontâneo. A Figura 11 ilustra os conceitos abordados sobre emissão.

Para simplificar o entendimento da produção de luz no laser, suponha que um átomo possua somente dois estados simples de energia $E_{1}$ e $E_{2}$, em que $E_{2}>E_{1}$. Se um conjunto $Z_{1}$ desses átomos com elétrons de valência que se encontram no estado fundamental de energia $E_{1}$, (menor energia) interage com o campo de radiação de densidade $\rho(v)$, ocorrendo o fenômeno que segundo Einstein um número igual a $Z_{1} \rho(v) P, P$ é a constante de probabilidade de interação, passará ao estado de energia $E_{2}$ (maior energia). Os $Z_{2}$ átomos, cujos elétrons estão no estado de energia $E_{2}$, podem emitir radiação pelo processo de emissão espontânea ou estimulada.

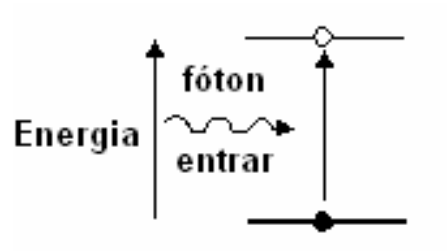

Absorção

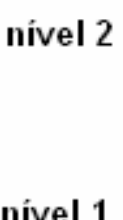

nível 1

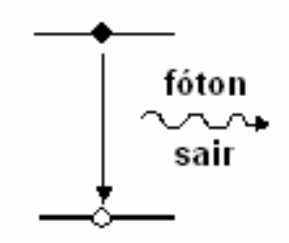

Emissão espontânea

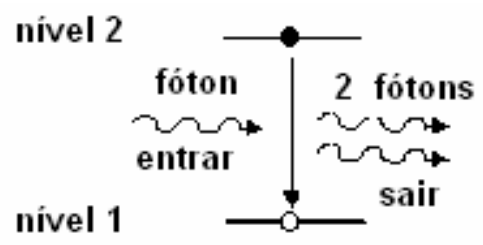

Emissão estimulada

Figura 11 - Interação da Luz com a Matéria

Para obter a ação laser é necessário manter uma taxa de emissão estimulada maior que as taxas de absorção e emissão espontânea, ou seja, o número de fótons deve ser grande, como também, garantir um maior número de átomos no estado excitado $\left(Z_{2}>Z_{1}\right)$. O elétron no nível 2 (excitado) apresenta uma forte tendência a retornar para o nível 1 (fundamental) e quando exposto a um agente (fóton) externo produzirá outro fóton (luz) idêntico com mesma energia e em fase. 
Portanto, a luz que é propiciada pela emissão, em virtude dos elétrons excitados decaírem dos seus maiores níveis energéticos de forma estimulada, será um feixe laser ao amplificar este fenômeno, por meio do uso de espelhos para realimentar os fótons neste meio e provocar a interação com os átomos.

Basicamente, a geração do laser necessita de um meio ativo, um sistema de bombeamento e um ressonador óptico.

- meio ativo ou meio de ganho - é a parte principal do laser, onde ocorre a amplificação da luz através da emissão estimulada. Pode se apresentar nos estados: sólido, líquido ou gasoso, contendo um conjunto de átomos, moléculas ou íons, onde se dará a emissão espontânea e a estimulada. Um exemplo é o cristal de Nd:YAG (Ytrium Aluminum Garnet $-\mathrm{Y}_{3} \mathrm{Al}_{5} \mathrm{O}_{12}$ dopado com neodímio). $\mathrm{O}$ dopante neodímio, na forma de íon $3+$, é o elemento em que ocorre a transição eletrônica responsável pela emissão de luz.

- bombeamento - Esse conjunto de átomos (ou ainda íons, ou moléculas) do meio ativo, em equilíbrio termodinâmico, necessita de fornecimento de energia de uma fonte externa para passar para o estado excitado; ou seja, o bombeamento proporciona uma maior população no nível superior de energia fato conhecido como: inversão de população. A fonte de bombeamento pode ser uma descarga elétrica, uma lâmpada ou um outro laser. Um exemplo é a cavidade de bombeamento óptico, na qual, uma lâmpada de arco de xenônio ou de kriptônio fornece energia para a excitação dos íons 3+ do neodímio.

- Ressonador - é constituído por dois espelhos posicionados paralelamente entre si, no qual um dos espelhos tem refletividade de $100 \%$ e outro parcial, permitindo que parte da radiação circulante no ressonador seja transmitida. 
Sua principal função é agir como um elemento de realimentação altamente seletivo, armazenando luz que circula entre os espelhos e permitindo que parte do sinal óptico emitido pelo meio ativo retorne para ser amplificado. Esta amplificação ocorre de modo coerente e colimado, resultando em um estreito feixe de luz direcionado perpendicularmente às superfícies dos espelhos. Além disso, o ressonador também é responsável pela distribuição espacial de intensidade do feixe laser, e também exerce influência nas propriedades espectrais e de potência da radiação emitida.

Para que a energia armazenada pelo meio ativo seja transformada em oscilação "LASER", a densidade de inversão de população do meio ativo deve assegurar um ganho, não saturado, que iguale as perdas no ressonador. Ao limitar o nível e a natureza destas perdas é possível controlar os vários parâmetros da emissão laser, como a potência de saída, a distribuição do espectro de freqüências, a estabilidade da radiação emitida e a qualidade espacial e temporal do feixe.

Os principais conceitos abordados aqui sobre a geração da luz laser podem ser verificados na Figura 12. Obviamente que aqui são apresentados apenas os conceitos mais básicos e de uma forma muito resumida; maiores detalhes podem ser encontrados em "Springer Handbook of Lasers and Optics - capítulo 11"77. 


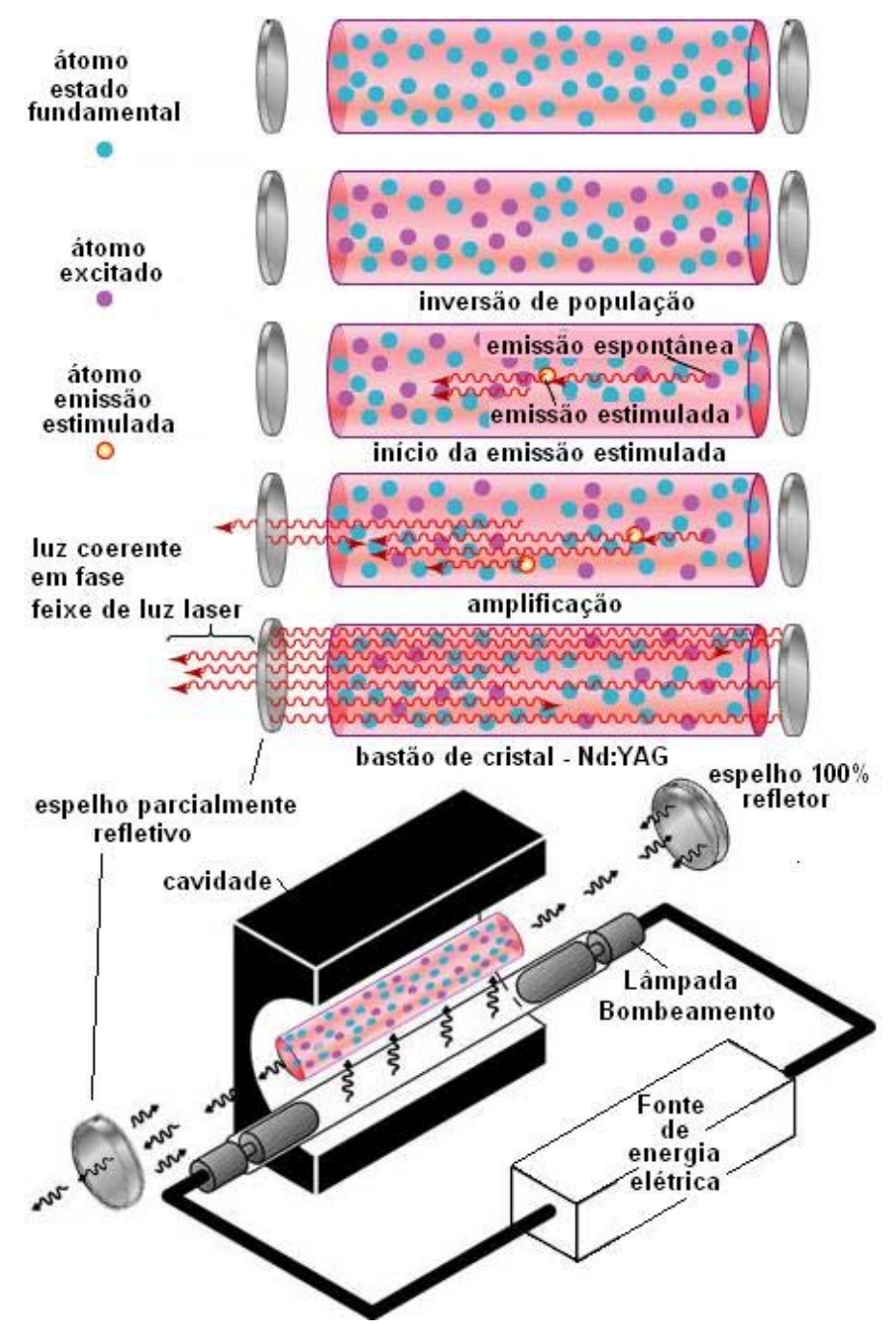

Figura 12 - Esquema ilustrativo da produção do feixe laser ${ }^{78}$.

\subsubsection{Evolução Industrial do Laser}

Ao longo de três décadas, após seu descobrimento, a tecnologia laser era restrita a aplicações em laboratórios de pesquisa e pouco apropriada à rotina industrial pela baixa confiabilidade e durabilidade dos equipamentos da época.

A partir dos anos 90, com a evolução da eletrônica e o desenvolvimento da engenharia, direcionada especificamente a construção de lasers, estes equipamentos tornaram-se mais confiáveis e conquistaram espaço em diversos setores de aplicação.

A estabilidade alcançada em virtude do avanço tecnológico proporcionou um amadurecimento da indústria ótico-eletrônica e laser, mas ainda é prematuro afirmar 
que suas bases mercadológicas estão consolidadas, particularmente quando comparada à história comercial automobilística e aeronáutica. Segundo especialistas do mercado financeiro, o setor está em fase inicial e conforme adquire um maior papel no mercado global, torna-se sujeito aos fatores macroeconômicos, podendo ser afetado pelas taxas e juros, taxas de câmbio, balanços comerciais da bolsa, preços do petróleo, entre outros.

Entretanto, nota-se a disseminação de diferentes equipamentos em diversas áreas com um crescente número de vendas pelo mundo ${ }^{79,80,81}$, como demonstrado na Figura 13.

Atualmente, o laser é causa de uma profunda revolução no setor de manufatura. Sua versatilidade o torna uma alternativa atraente para diversos problemas de difícil solução, apresentando ainda qualidade, custos e produtividade bastante compensadores.

O cenário global da produção e aquisição dos sistemas a laser está concentrado na maior parte entre Norte América e Europa, já mais recente, a China começa a conquistar boa projeção mundial. Um panorama dessa distribuição é abordado no gráfico da Figura 14, juntamente com a divisão de aplicações do laser.

Os tipos de lasers, na área industrial de processamento de materiais, com maior projeção no momento são: o laser de $\mathrm{Nd}$ : YAG, o laser de $\mathrm{CO}_{2}$. A partir de 2006, nota-se uma expansão do mercado mundial na comercialização do laser de fibra, aparentemente em razão das suas características, da queda do valor de compra e da economia nos custos operacionais. Essa tendência no progresso comercial da indústria óptico-eletrônica pela distribuição dos tipos de laser e pela sua aplicação pode ser observada na Figura 15. 


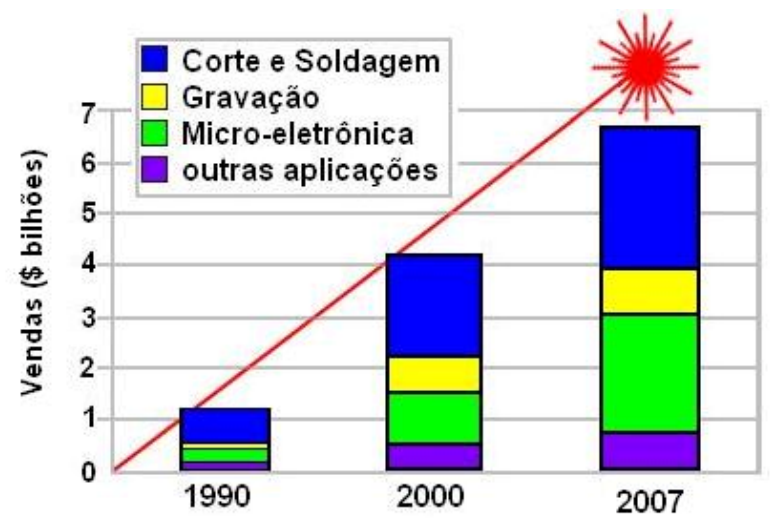

Figura 13 - Estrutura do mercado mundial de vendas dos sistemas a laser.

Produção \& Distribuição Mundial de lasers industriais em 2005 referente às:

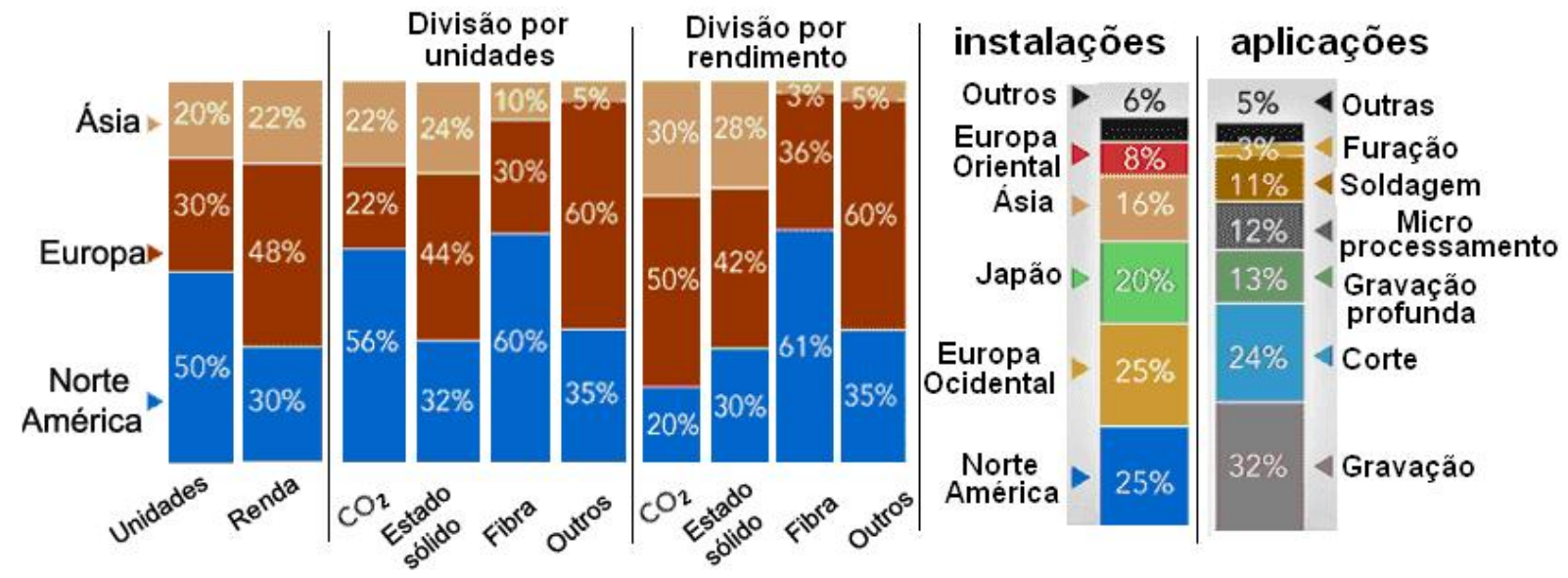

Figura 14 - Produção e distribuição mundial de lasers industriais.

Comércio mundial - vendas de laser por aplicação

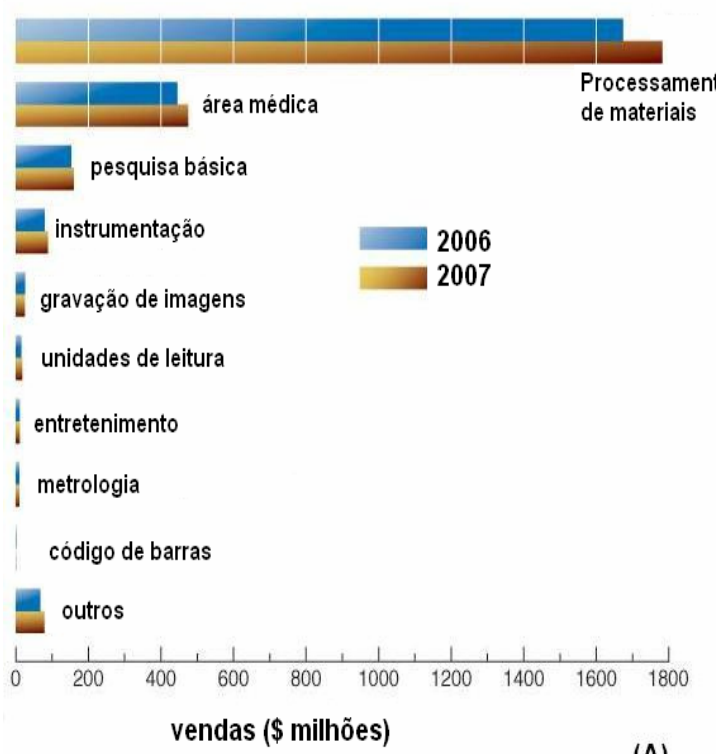

(A)

Comércio mundial - vendas distribuição por tipo de laser

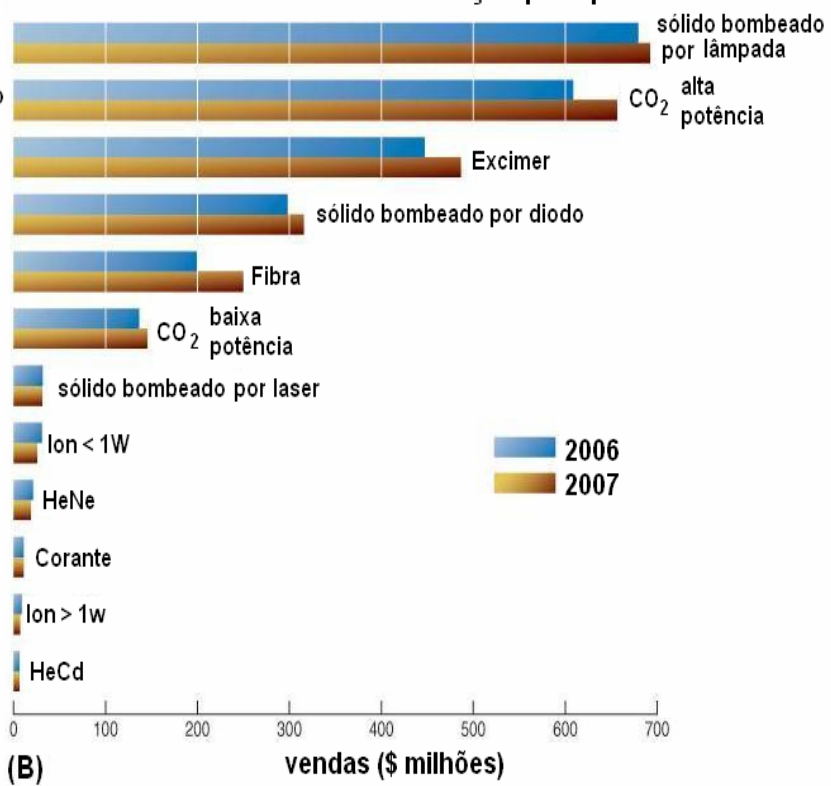

(B)

Figura 15 - Comércio mundial de vendas da indústria óptico-eletrônica (a) laser por aplicação e (b) por tipo de laser. 


\subsubsection{Processamento de materiais a Laser}

\section{Tipos de processamento}

O crescimento mais expressivo do laser ocorreu em processamento de materiais, especialmente nas empresas de pequeno e médio porte ${ }^{3}$, por apresentarem maior facilidade de personalização de um novo produto, flexibilidade na adequação da demanda e agilidade no fornecimento. Esse tipo de empresa ficou conhecida pela expressão inglesa: job shop e sua definição é de firma especializada com ambiente de produção sob encomenda, na garantia de abastecimento das grandes indústrias.

A gama de vantagens atribuída ao processamento de materiais com o emprego do laser permitiu sua difusão entre as diversas aplicações industriais. As principais aplicações executadas pelo laser ${ }^{2,82}$ são: corte, furação, solda, tratamento térmico, marcação e "alloying" (processo de obtenção de liga por fundição).

Outro fator que contribuiu para o aumento da sua demanda é a coerência espacial, que caracteriza o feixe laser como uma ferramenta de alta densidade de radiação focalizada em uma área muito pequena. Por meio do controle da intensidade do feixe altera-se a carga térmica fornecida ao material e assim determina-se sua aplicação, conforme a transformação obtida na superfície. Verificase na Figura 16 as várias aplicações em razão da intensidade aplicada.

Como mencionado anteriormente, as vantagens do uso de um feixe de luz para o processamento ${ }^{83,84}$ de materiais são inúmeras, somente o custo do investimento inicial poderia ser a principal desvantagem, contudo tal fato pode ser compensado pela qualidade do produto, pela automação e pela baixa intervenção do operador. 


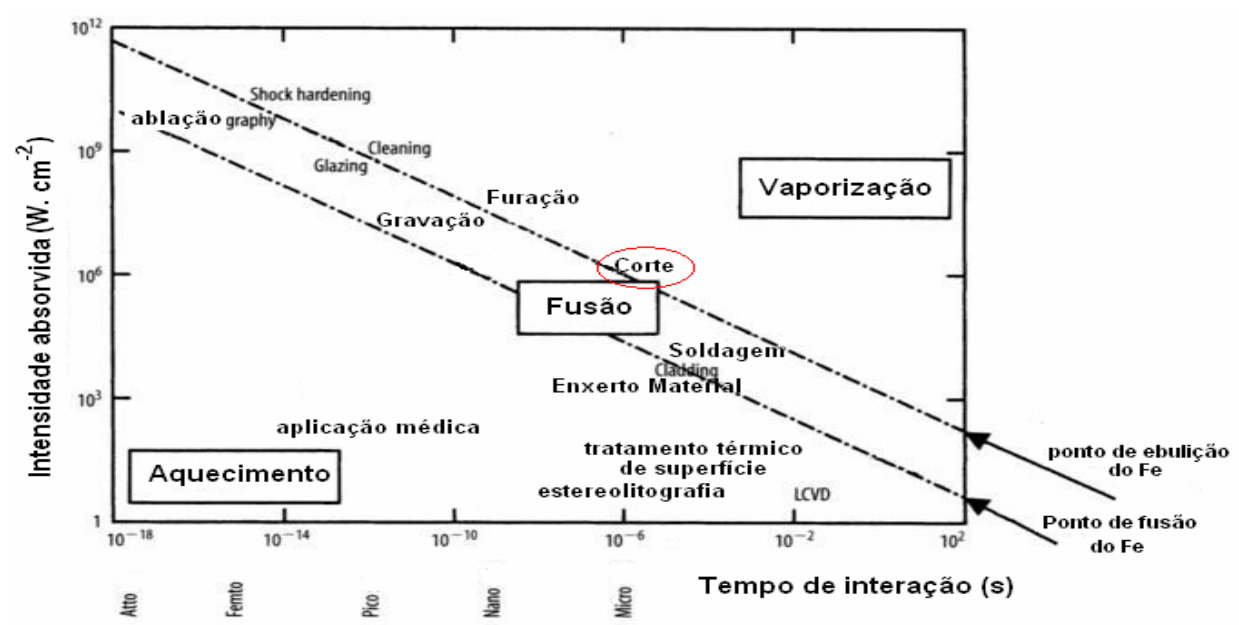

Figura 16 - Quadro Geral das aplicações industriais a laser ${ }^{85}$.

\section{Comparação com outros métodos de usinagem.}

Comparativamente à usinagem convencional, a utilização do processo de corte com laser é uma alternativa disponível que pode atingir o índice desejado de produtividade, qualidade e flexibilidade. A conquista desse patamar de exigências depende da correta escolha do sistema. Na Tabela 6 é possível verificar algumas características do laser em comparação com outros métodos.

Tabela 6 - Comparação entre diferentes sistemas de corte ${ }^{85,86}$.

\begin{tabular}{|c|c|c|c|c|c|c|c|}
\hline & Laser & $\begin{array}{l}\text { EDM } \\
\text { a fio }\end{array}$ & Plasma & Oxicorte & $\begin{array}{c}\text { Jato } \\
\text { d'água } \\
\text { abrasivo }\end{array}$ & $\begin{array}{l}\text { Fresadora } \\
\text { NC }\end{array}$ & Puncionadora \\
\hline $\begin{array}{l}\text { Custo do } \\
\text { sistema }\end{array}$ & Alto & Médio & Médio & Baixo & Alto & Médio & Alto \\
\hline $\begin{array}{l}\text { Custo } \\
\text { operacional }\end{array}$ & Médio & Alto & Alto & Baixo & Alto & Médio & Médio \\
\hline $\begin{array}{l}\text { Qualidade } \\
\text { do corte }\end{array}$ & Boa & Boa & Ruim & Ruim & Boa & Boa & Média \\
\hline $\begin{array}{l}\text { Volume de } \\
\text { produção }\end{array}$ & Alto & Médio & Médio & Médio & Médio & Médio & Alto \\
\hline $\begin{array}{l}\text { Velocidade } \\
\text { produtiva }\end{array}$ & Alta & Lenta & Alta & Lenta & Lenta & Lenta & Alta \\
\hline $\begin{array}{l}\text { Desgaste } \\
\text { ferramental }\end{array}$ & Não & Sim & Não & Não & Sim & Sim & Sim \\
\hline $\begin{array}{l}\text { Flexibilidade } \\
\text { de materiais }\end{array}$ & Alta & Baixa & Baixa & Baixa & Alta & Alta & Baixa \\
\hline $\begin{array}{l}\text { Dificuldade } \\
\text { de formas }\end{array}$ & Alta & Média & Boa & Razoável & Boa & Média & Média \\
\hline $\begin{array}{l}\text { Espessura } \\
\text { Máx. (mm) }\end{array}$ & 25 & 100 & 50 & 1300 & $25-150$ & - & 12 \\
\hline $\begin{array}{l}\text { Integração do } \\
\text { sistema }\end{array}$ & Boa & Difícil & Boa & Boa & Boa & Boa & Boa \\
\hline Nível de ruído & Baixo & Médio & Alto & Alto & Alto & Médio & Alto \\
\hline
\end{tabular}




\section{Conceito básico de processamento de materiais a laser}

Grassi $^{3}$ comparou o fenômeno de focalização da luz solar por meio de uma lente de aumento sobre um papel com a ação do laser, para conceituar didaticamente o processamento de materiais a laser. Em ambos os casos, a luz é concentrada em um pequeno ponto focal, em seqüência o material absorve a energia e a temperatura aumenta rapidamente. O resultado observado no papel é a queima do mesmo devido à absorção da energia luminosa. No caso do laser, o processo é o mesmo, o material exposto à radiação eletromagnética interage com os fótons do intenso feixe de luz, transformando a energia absorvida em uma carga térmica. Essa transformação pode provocar diferentes estados termodinâmicos no material, conforme as suas propriedades de absorção, reflexão e condução. Em virtude do balanço energético, entre a intensidade do feixe e as propriedades do material, é possível variar o processo de um leve aquecimento, passar pela fusão e chegar até a vaporização do mesmo.

Entretanto, apesar da similaridade dos processos citados, no processamento de materiais a laser, além da intensidade incomparavelmente maior, existe ainda a possibilidade de controlar os fenômenos envolvidos a fim de se obter uma ação precisa e de excelente qualidade. Para isso ocorrer de modo satisfatório é necessário definir a aplicação desejada e considerar cada opção disponível no mercado.

\section{Seleção do sistema laser para o corte.}

Existem diversos tipos de lasers disponíveis para a usinagem de diferentes materiais. A configuração do processo mais apropriado também depende do regime de operação (possibilidade operacional: contínuo ou pulsado), em conjunto com vários sistemas de posicionamento e comando numérico computadorizado (CNC). 
Desta forma, a seleção do tipo de laser, o qual é caracterizado pelo comprimento de onda, variando do infravermelho ao ultravioleta, é fator crucial na determinação do sistema.

Entretanto, a escolha inicial é sucedida pela adequação de diversos parâmetros para cada processo específico, e isto envolve o nível de potência (ou energia), a largura temporal do pulso, a taxa de repetição, a forma espacial do feixe, o tipo e a pressão do gás de assistência, e muitos outros. Além disso, esta seleção também é dependente do material, da qualidade final almejada, do custo, da velocidade de processo, entre outros ${ }^{6,7}$.

A qualidade do processamento a laser de um determinado material está diretamente relacionada a um grande número de fatores. Os parâmetros listados a seguir assumem um papel fundamental no nível de acabamento e devem ser ajustados com precisão para otimizar o corte a laser.

- densidade de potência.

- modo transversal do feixe.

- polarização da luz.

- velocidade do processo.

- características do material.

- geometria e diâmetro do bico.

- distância bico/peça.

- distância focal.

- $\quad$ tipo, pressão, fluxo e pureza do gás.

- energia e duração temporal do pulso laser.

- comprimento de onda.

- distribuição energética no ponto focal.

Por meio do diagrama da Figura 17 é possível inferir a complexidade da malha de parâmetros envolvida no processo de corte. A definição das variáveis de entrada, algumas intrínsecas ao sistema, e o controle das operacionais, antes mesmo de 

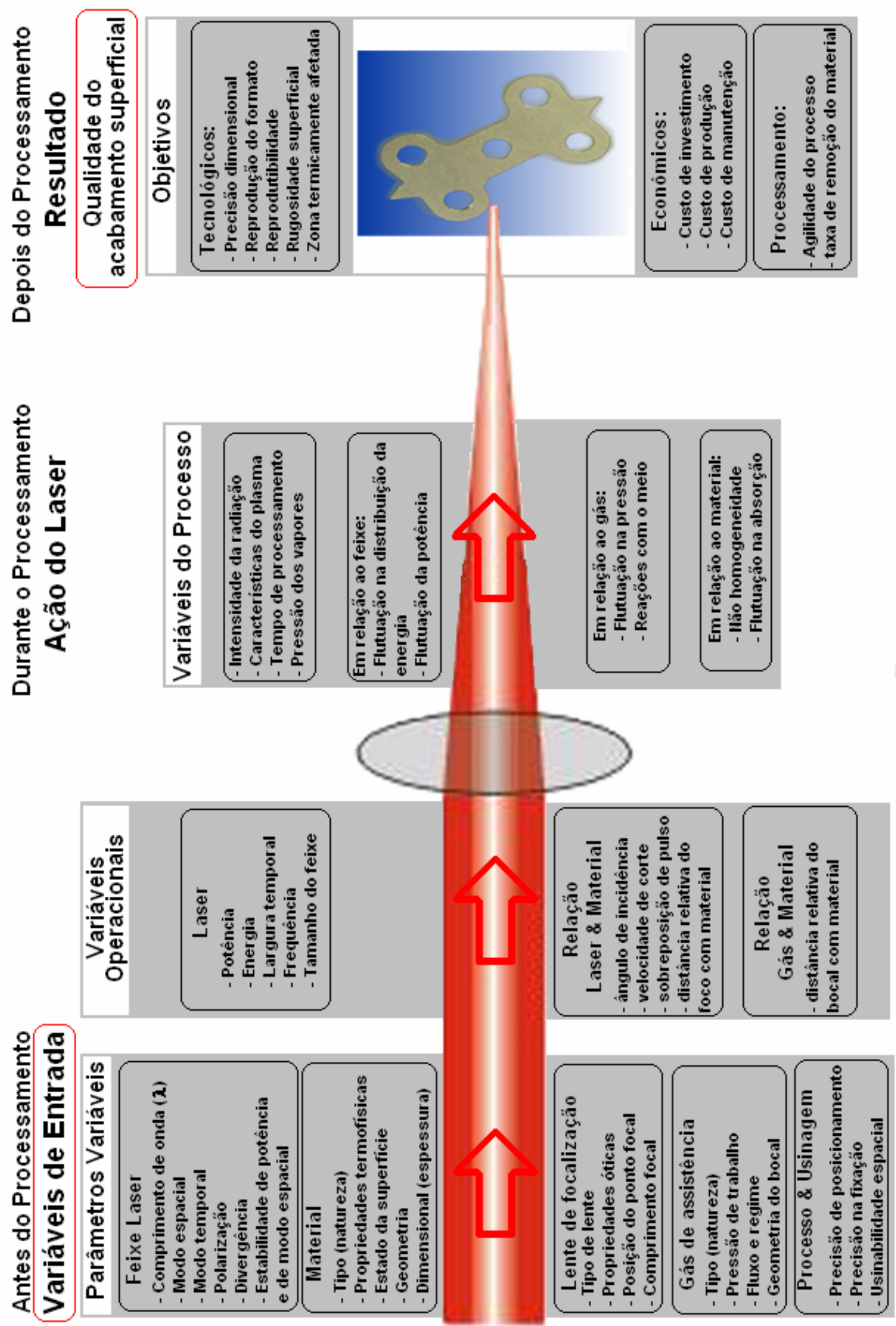

Figura 17 - Diagrama das variáveis envolvidas no processamento de materiais a laser. 
iniciar o processamento do material, determinam o modo de interação do feixe durante a ação laser, o que por fim resultará no acabamento superficial do material usinado.

Uma abordagem considerando cada parâmetro é descrita a seguir para uma melhor compreensão do nível de influência destes fatores no sucesso do processamento de materiais a laser.

\section{Comprimento de onda do laser $(\lambda)$}

A faixa de opção do comprimento de onda para a aplicação industrial é ampla dentro do espectro eletromagnético. Uma representação da disponibilidade pode ser verificada na Figura 18.

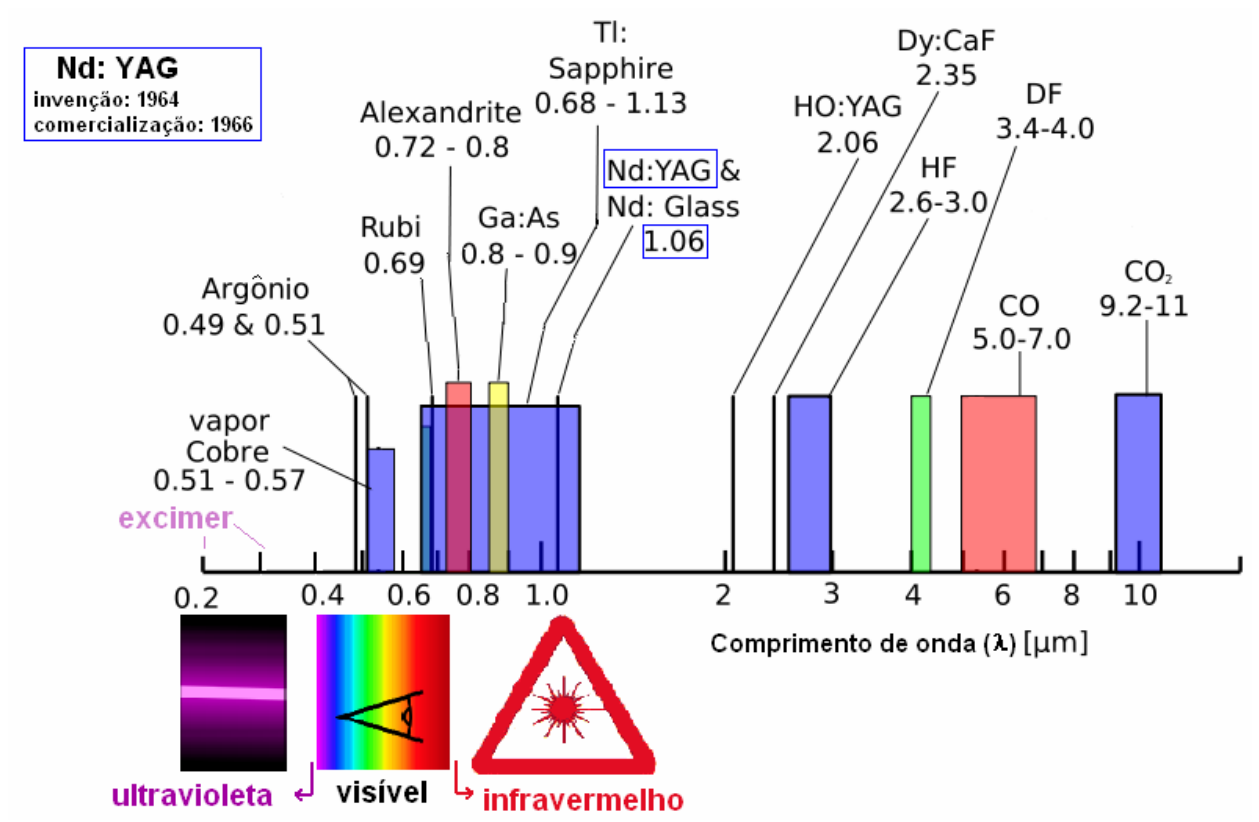

Figura 18 - Faixa do espectro eletromagnético com diferentes tipos de lasers ${ }^{87}$.

O comprimento de onda $(\lambda)$ é um fator limitante para o sucesso de determinada aplicação $^{88,89}$, pois como cada material apresenta diferentes propriedades, a absorção da radiação eletromagnética varia entre os diversos comprimentos de onda, tornando a ação laser ineficaz para alguns casos. 
O tamanho do ponto focal do feixe laser é afetado diretamente pelo comprimento de onda $(\lambda)$. Verifica-se pela equação (1) a sua relação e por meio desta, calcula-se o mínimo diâmetro teórico $\left(d_{\min }\right)$ pelas propriedades do laser.

$$
d \min =\frac{4 M^{2} f \lambda}{\pi D_{L}}
$$

Defini-se: $M^{2}$ = fator de qualidade do feixe em relação à perfeita distribuição Gaussiana, $f=$ comprimento focal da lente, $D_{L}$ o diâmetro do feixe incidente antes da lente de focalização.

No balanço energético da interação do laser com a matéria, além da energia absorvida, deve-se contabilizar a energia perdida pela refletividade. Cada material possui uma estrutura atômica particular e consequentemente sua refletividade é diferente para cada comprimento de onda. Além disso, a refletividade está relacionada à rugosidade e oxidação superficial, temperatura, ângulo de incidência e alteração da topografia do material ${ }^{90}$.

O processamento de metais, em geral, é mais eficiente com ondas eletromagnéticas com comprimentos de onda mais curtos, pois a refletividade aumenta e a energia de radiação (de cada fóton) diminui com o aumento do comprimento de onda. Isto é verdade, contudo, apenas no início do processo, pois com a fusão do material a sua refletividade já não depende tanto do comprimento de onda da radiação incidente, apresentando uma absorção quase que total para uma grande gama do espectro eletromagnético.

\section{Focalização}

A seleção do tipo de lente a ser utilizado deve considerar as características do feixe laser, pois o diâmetro do ponto focal e a distância de variação focal (profundidade do foco) sofrem suas influências. 
Como demonstrado pela equação (1) o diâmetro focal do feixe laser é diretamente proporcional ao comprimento focal da lente e inversamente ao diâmetro do feixe incidente na lente de focalização. O interessante para o processamento de materiais seria manter o menor diâmetro com o maior comprimento focal possível, entretanto na situação real isto é bem difícil.

\section{Profundidade do foco (zf)}

O feixe laser após incidir na lente de focalização converge em um plano com um certo diâmetro (df) e a uma determinada distância focal da lente (f), depois então diverge com um diâmetro maior. No estrangulamento do feixe existe um comprimento em que o diâmetro do feixe varia até $5 \%$ e a intensidade permanece quase inalterada. Esta variação representada na equação (2) é chamada de profundidade do foco (DOF - depth of focus). Para o processamento de materiais, quanto maior está profundidade melhor, pois a densidade de energia é mantida constante em um maior comprimento.

$$
z_{f}=0,32 \times \frac{4 M^{2} \lambda}{\pi} \times\left(\frac{f}{D_{L}}\right)^{2}
$$

O cálculo da profundidade de foco também pode ser obtida por meio da relação com o número focal (f-number), descrito pelas equações (3)e (4).

$$
\begin{aligned}
& f-\text { number }=\frac{f}{D_{L}} \\
& z_{f}=2(f-\text { number }) d_{f}
\end{aligned}
$$

Outra maneira de se caracterizar a profundidade de foco é através do chamado parâmetro de Rayleigh $Z_{R}$. 
Neste caso, a uma distância $Z_{R}$ da sua cintura, a área do feixe laser dobra de tamanho (equação 5). Assim, este parâmetro é definido como:

$$
Z_{R}=\frac{\pi\left(\omega_{0}\right)^{2}}{M^{2} \lambda}
$$

\section{Parâmetros do feixe laser (modulação)}

Cada feixe laser possui propriedades físicas derivadas dos detalhes construtivos do equipamento laser, como do meio ativo, bombeamento e ressonador. Isto implica em diferenças de distribuição espacial da intensidade e de polarização, fatores que influenciam no resultado e na eficiência do processo a laser.

Normalmente, um sistema gera ondas eletromagnéticas com vários modos longitudinais e transversais. Ao se realizar um corte transversal (plano perpendicular) da distribuição da intensidade em relação ao eixo de propagação obtém-se um padrão espacial da radiação para caracterizar o feixe, conhecido como TEM (modo eletromagnético transversal). Geralmente, o feixe é composto pela superposição de diversos modos transversais e sua representação é feita por meio de índices que indicam o número de campos projetados em relação ao corte transversal. O modo TEM $_{00}$ é o de mais baixa ordem e apresenta uma distribuição gaussiana de intensidade. Este modo é o que possui o menor diâmetro e a menor divergência, o que o torna mais adequado para qualquer aplicação, pois a irradiação é mais uniforme e mais intensa no centro. Quanto maior é o número de modos, maior será a dificuldade de focalização do feixe. Infelizmente, nem sempre é possível a utilização de feixes com puro modo $\mathrm{TEM}_{00}$, pois quando existe a necessidade de altas potências, a presença de modos de ordem maior é quase que inevitável .Alguns exemplos de padrões podem ser verificados na Figura 19.

Para quantificar a qualidade do feixe compara-se o produto do ângulo de divergência e o diâmetro no ponto focal (beam waist diameter) entre um feixe real e 
o feixe gaussiano ideal. A razão destes produtos é um fator conhecido como $\mathrm{M}^{2}$, o qual está representado, juntamente com os vários fatores descritos nesta seção na Figura 20, para uma melhor visualização e compreensão do tema abordado.

No processamento de materiais manter um $\mathrm{M}^{2}$ baixo significa obter melhor eficiência no processo com menor aporte térmico (zona termicamente afetada) e maior precisão do feixe por meio do menor canal de corte (Kerf).

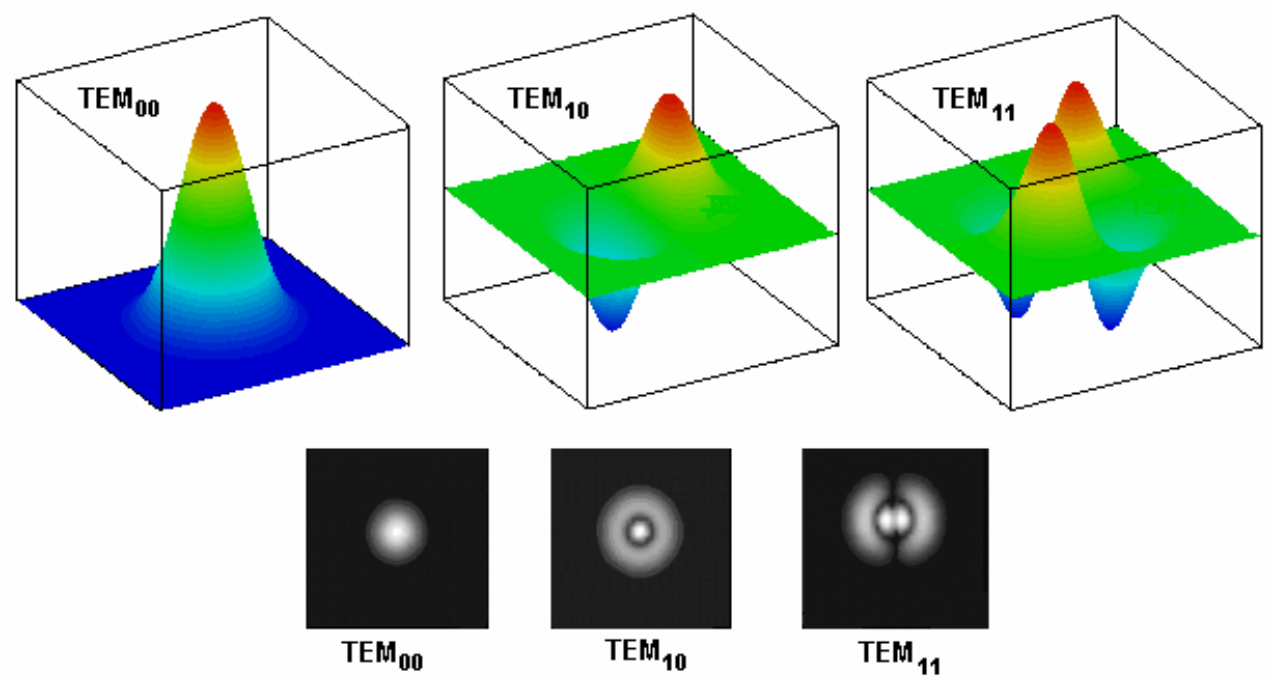

Figura 19 - Distribuição do campo elétrico na seção transversal do feixe laser ${ }^{91}$.

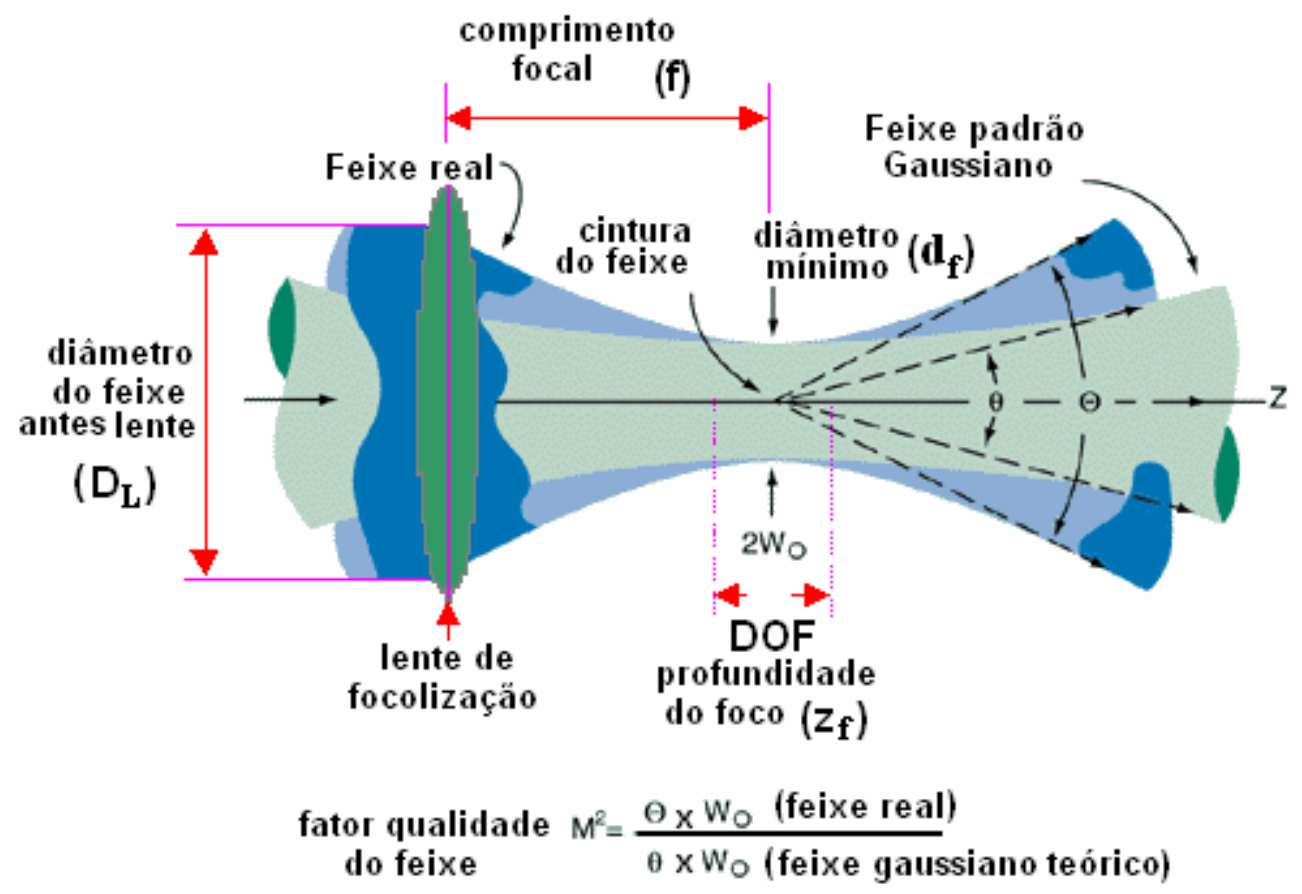

Figura 20 - Propagação do feixe laser e propriedades ${ }^{92}$. 


\section{Divergência do feixe}

Diferente da fonte de luz incandescente o feixe laser se propaga paralelo (colimado). Existe na verdade, uma pequena divergência $\theta$ que leva a uma expansão de seu diâmetro. Esta divergência é influenciada pelo comprimento de onda $(\lambda)$ e o diâmetro da cintura do feixe (posição ao longo da direção de propagação em que o feixe laser apresenta o menor raio), conforme visto na equação (6).

$$
\frac{\theta}{2}=\frac{\lambda}{\pi \omega_{0}}
$$

\section{Polarização}

As ondas eletromagnéticas, denominadas como não-polarizadas, apresentam diversos planos de vibração do campo elétrico, i.e., ao examinar uma projeção do feixe de luz natural com um corte perpendicular à direção de propagação, constatase que existe um vetor elétrico vibrando igualmente em todas as direções perpendiculares ao eixo do feixe. No caso do laser, a luz pode ser polarizada, o que significa manifestar direções predominantes de oscilação, como paralela e perpendicular ao plano de incidência do feixe.

Essa propriedade da onda afeta a absorção do feixe pelo material acarretando efeitos no processo, como assimetria do canal de sangria do corte (kerf) e aderência de material ressolidificado diferente para cada direção de corte. Por esse motivo, nas aplicações de corte é interessante ter um uma luz circularmente polarizada ou não polarizada. 


\section{Duração temporal (Contínuo ou Pulsado)}

A transferência de energia no processamento de materiais pode ser realizada por feixe contínuo $(\mathrm{CW})$ ou pulsado ${ }^{93}$.

Por meio da equação (7) pode-se estimar a intensidade típica na região do corte para o caso de um laser pulsado.

$$
\text { Laser pulsado: } \quad \mathrm{I}=\mathrm{E} .\left(\mathrm{t}_{\mathrm{p}} \cdot \mathrm{A}\right)^{-1}
$$

Onde: (I) é a intensidade; $(E)$ é a energia por pulso; $\left(t_{p}\right)$ é a largura temporal do pulso laser e (A) é a área do feixe no ponto focal.

A operação no regime pulsado, do laser de $\mathrm{Nd}$ :YAG, permite o controle exato da potência pico que é igual a relação entre energia/largura temporal de cada pulso sobre o alvo de trabalho. O posicionamento por controle CNC com utilização de uma mesa de deslocamento de alta precisão possibilita a escolha do exato ponto a ser processado. A manipulação do feixe laser, pelo controle dos parâmetros do ressonador óptico, propicia ainda um refinamento da ferramenta de usinagem (diâmetro do feixe focalizado) e o conseqüente controle da intensidade e da largura de kerf (sangria do corte). Esta possibilidade de controle de diversos parâmetros simultâneos torna o laser de Nd:YAG pulsado um equipamento extremamente versátil e muito útil em uma variedade de aplicações.

A maioria dos atuais sistemas de corte a laser empregados por job shops no país são de lasers de $\mathrm{CO}_{2}$, com alta potência, mesas muito grandes, e com pouca possibilidade de controle dos parâmetros de corte. Muitas vezes inadequados ao corte de precisão em materiais muito finos, incapazes de realizar furações precisas com alta razão de aspecto de precisão e são bastante limitados a aplicações de soldagem. 
No caso de um laser pulsado, o controle da potência pico e da intensidade fornece condições para estabelecer o balanço entre o fluxo de energia entregue ao material e a perda desta energia por reflexão e condução. Este balanço da dinâmica do fluxo de energia por elemento volumétrico delimita a velocidade de aquecimento do elemento e por fim determina seu estado físico durante o pulso laser ${ }^{94}$.

Assim, com uma intensidade moderada $\left(10^{6}-10^{7} \mathrm{~W} . \mathrm{cm}^{-2}\right)$ é possível liquefazer o material no preciso ponto focal. O deslocamento desta "poça líquida", segundo um desenho predeterminado e armazenado no $\mathrm{CNC}$, em sincronismo com um forte jato de gás também direcionado sobre o mesmo ponto focal do laser, resultará em um canal de corte limpo, com pequeno kerf. Desta forma, configura-se um processo de corte que pode ser visualizado na Figura 21 pela representação do mecanismo de interação entre o feixe laser e o titânio.

Se ao invés disso, reduzir ainda mais a intensidade $\left(10^{4}-10^{5}\right.$ W.cm $\left.{ }^{-2}\right)$, o material é liquefeito com baixíssima perda por evaporação e/ou ejeção e nesta situação, uma solda de precisão pode ser obtida. Contudo, neste caso é necessário substituir o forte jato de gás por uma atmosfera protetora de gás inerte, diferentes fluxos e pressões de trabalho.

A utilização de altas intensidades (acima de $10^{7}$ W.cm ${ }^{-2}$ ), por sua vez, conduz a uma grande perda de material por evaporação e, especialmente, por ejeção de líquido. Portanto, este regime é empregado para a furação por percussão, em que uma alta razão de aspecto caracteriza a expulsão do material fundido no interior da cavidade (antes de se completar o furo) com alta energia cinética.

Os parâmetros de operação de um laser pulsado, e em particular, do equipamento utilizado neste trabalho são, portanto, a energia por pulso, a largura temporal de cada pulso laser e a sua taxa de repetição. A relação entre a energia e 
a largura temporal fornece a desejada potência pico, enquanto que a taxa de repetição determina qual a velocidade permitida para o processo.

A manipulação do feixe laser fornece ainda a possibilidade de se controlar o preciso diâmetro deste feixe em seu ponto focal; isto, além de determinar a intensidade utilizada também propicia o controle do kerf e do diâmetro do furo para o caso de furação. A região de extensão destes parâmetros determina ainda a espessura do material processado e a velocidade do processo.

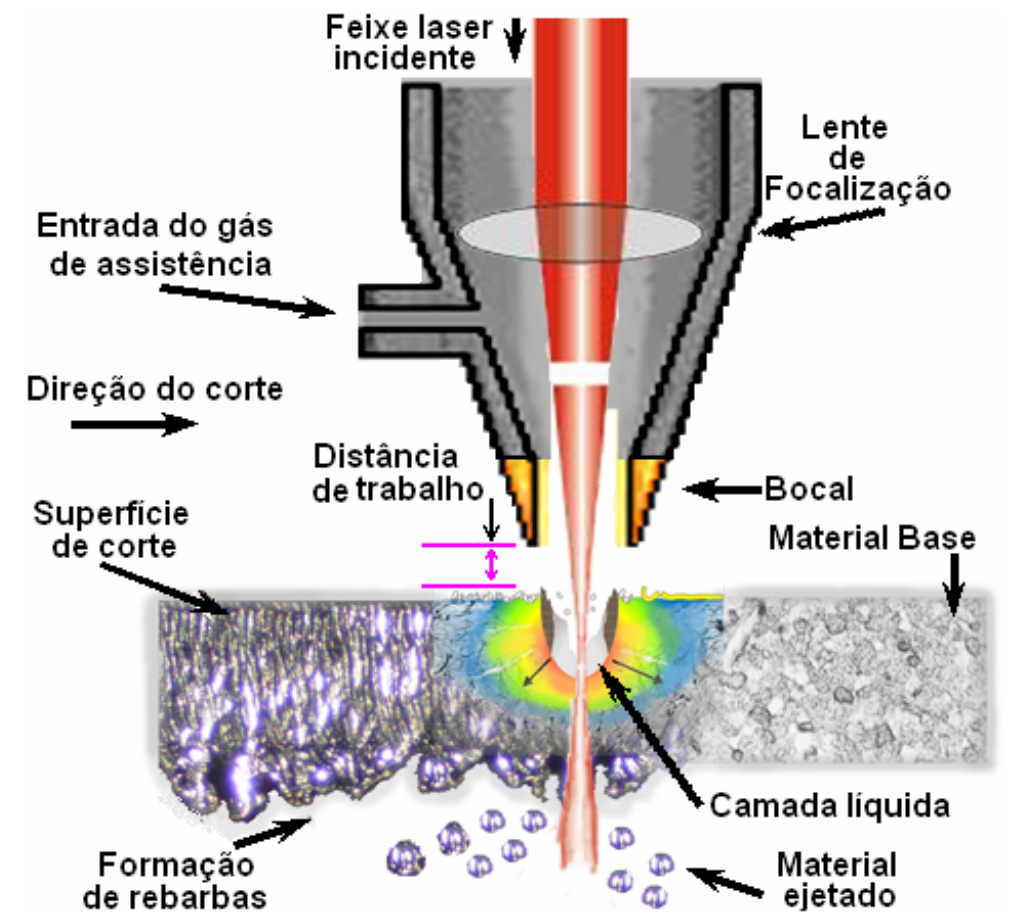

Figura 21 - Processo de corte - interação do feixe laser com o material.

\section{Gás de assistência}

No corte a laser, representado na Figura 21, o gás exerce um papel fundamental, ou seja, é essencial para concretizar a usinagem. A ação mecânica para remover o material fundido do canal de corte e o resfriamento por convecção forçada da zona aquecida pelo laser são funções executadas pelo gás de assistência. Portanto, a qualidade do acabamento superficial e a velocidade de corte estão intimamente ligadas a este fator. 
Inserido neste contexto, a eficiência do processo depende de uma série de fatores, que consiste desde a simples escolha do tipo de gás até o seu regime operacional. Os parâmetros como pureza e pressão do gás ${ }^{95}$, regime subsônico ou supersônico, geometria do bocal (dimensional do diâmetro, ângulo e perfil de construção), distância de trabalho entre material e bocal, cada um apresenta um nível de importância que interfere substancialmente no processamento de materiais.

O efeito da seleção do tipo de gás divide basicamente o processo de corte em dois modos ${ }^{96}$ : (a) reativo: emprega o oxigênio para realizar o corte. Este gás reage exotermicamente com os metais ferrosos, gerando um acréscimo na carga térmica que amplifica a ação do laser e dessa forma possibilita um aumento na velocidade de operação; (b) não reativo: utiliza-se de gases inertes que pode propiciar uma superfície de corte com pequena zona termicamente afetada, livre de óxidos e rebarbas.

Entretanto, em ambos procedimentos existem problemas em detrimento da qualidade de acabamento. Uma das dificuldades é eliminar as rebarbas na borda de saída do corte. Normalmente, aplicam-se maiores pressões e fluxos para sobrepor a alta viscosidade do volume de material fundido e impedir a aderência deste na superfície, evitando a formação de rebarbas. Contudo, essa prática conduz a um consume excessivo de gases e a amplificação dos gastos.

Existem várias investigações, modelos matemáticos e simulações computacionais que abordam a relação entre a geometria do bocal e as características dinâmicas do fluxo de gás ${ }^{97}$. 


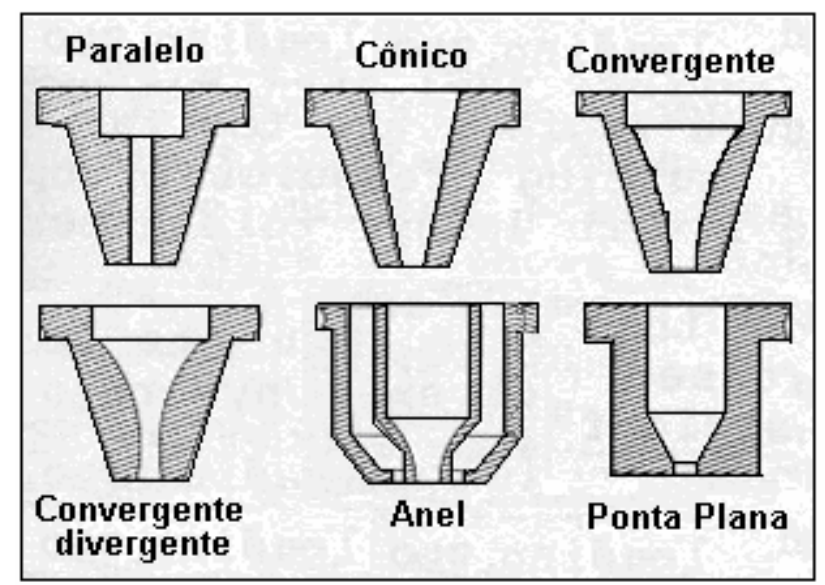

Figura 22 - Tipos de geometria de bocais.

A maioria dos bocais industriais ${ }^{98}$ são cônicos e/ou paralelos convergentes com fluxo subsônico a transônico, algumas formas mais comuns estão apresentadas na Figura 22. Nesta condição de regime e geometria do bocal associada à alta pressão é comum a formação de ondas de choque normais (MSD) e oblíquas ${ }^{99,100}$, que podem provocar uma perda de energia. O aparecimento de jatos turbulentos favorece a uniformidade do escoamento, ocasionando a redução na capacidade de remover o material, alterações no índice de refração, mudanças na focalização do feixe e consequentemente a qualidade do corte piora, como representado na Figura 23.

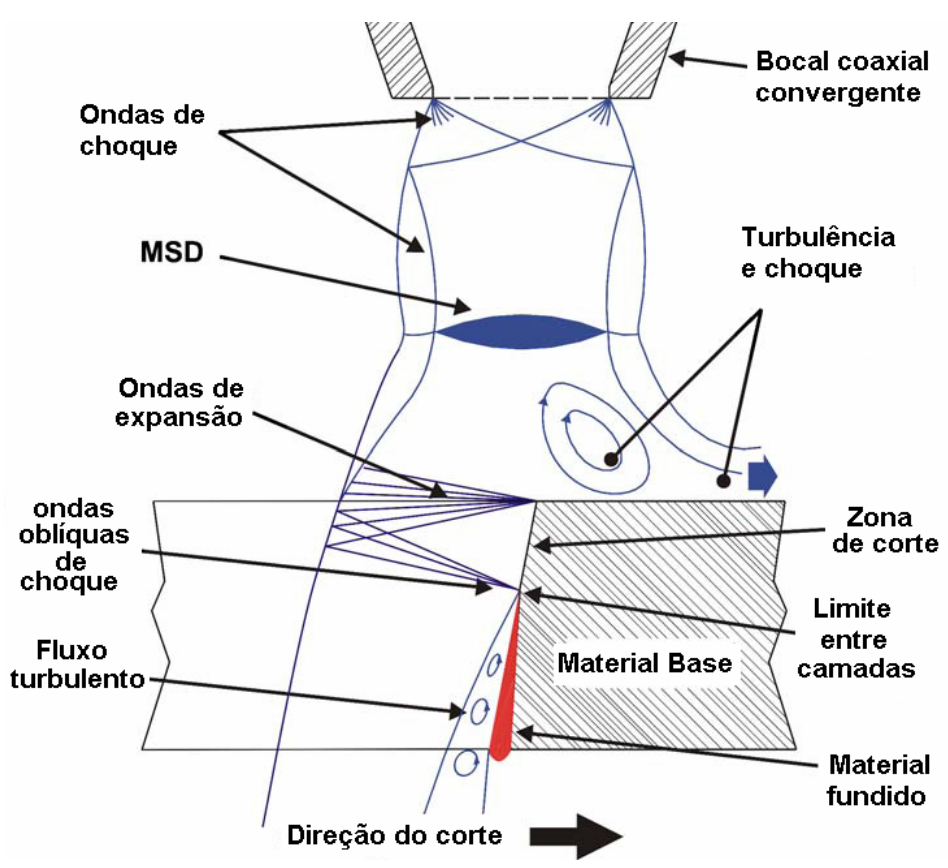

Figura 23 -Interações aerodinâmicas do fluxo de gás no processo de corte a laser. 
$\mathrm{Na}$ tentativa de eliminar ou reduzir estes problemas, várias investigações referentes à utilização de bocais supersônicos estão sendo realizadas. Vários resultados insatisfatórios foram relatados ${ }^{96}$, contudo Riveiro ${ }^{100,101}$ descreveu que obteve êxito ao processar ligas de alumínio com um laser de $\mathrm{CO}_{2}$, assistido por um sistema de fluxo supersônico, adicionado sob uma certa inclinação ao lado do bocal coaxial.

Neste trabalho, um bocal foi projetado e confeccionado, com geometria semelhante ao bocal de Laval para mensurar o efeito de um sistema supersônico em comparação ao bocal tradicional utilizado. Entretanto, diversos problemas, como exemplo: a dificuldade técnica de reproduzir com precisão o perfil geométrico e a definição do correto posicionamento (coaxial e/ou sistema auxiliar de injeção independente do eixo do feixe laser), resultaram na drástica redução da velocidade e da qualidade do processo. Assim, os testes foram abortados em decorrência da ineficiência do corte em comparação ao bocal convencional e o tema fica como sugestão de futuros trabalhos.

\section{Interações entre parâmetros}

Como visto, o corte a laser envolve uma gama muito grande de parâmetros, os quais podem ter uma influência decisiva nos diversos aspectos relacionados ao processo. Assim, a escolha do melhor conjunto de parâmetros torna-se uma tarefa extremamente complexa, e depende dos objetivos propostos. Portanto, o primeiro passo é determinar qual o objetivo principal: a qualidade do acabamento, precisão dimensional, velocidade de processo, custos, etc. Esta tarefa é realizada principalmente com base na experiência dos operadores e na exigência da peça. 
Muitas vezes a melhor condição não é atendida em função de uma maior velocidade de processo ou de configuração operacional do equipamento - set up. Se a mudança do ressonador, por exemplo, para se conseguir um modo espacial mais adequado requerer um tempo demasiado, então, isto somente é feito se a peça assim o exigir. Se a quantidade de rebarba for maior para uma velocidade de processo maior, às vezes prefere-se um re-trabalho na peça para que o sistema esteja livre para um próximo processo.

De maneira geral, um operador experiente sabe qual o efeito de um parâmetro sobre o resultado do processo. Contudo, ninguém pode afirmar nada sobre a interação dos diversos parâmetros envolvidos e como cada um age sobre o outro. Surgem assim várias questões para serem analisadas:

O que é melhor usar, uma energia baixa e uma taxa de repetição alta, ou o oposto, uma energia alta e uma taxa de repetição baixa?

No primeiro caso temos uma retirada de material feita aos poucos, com remoção de uma pequena quantidade por pulso, requerendo diversos pulsos para atravessar toda a espessura do material. No segundo caso, cada pulso tem energia suficiente para vazar a chapa e aí o problema torna-se o de escolher a melhor taxa de sobreposição.

O que é mais adequado, uma lente de comprimento focal curto ou mais longo?

No primeiro caso temos uma maior intensidade e em princípio maior evaporação com conseqüente diminuição do material fundido. Neste caso, a rebarba deveria ser menor; contudo, se a largura do corte (kerf) é menor, a dificuldade de se retirar o material também será maior. Desta forma, como alternativa pode-se aumentar a pressão do gás; isto, além de aumentar o custo, também pode modificar a dinâmica do seu fluxo e não fornecer o resultado esperado. 


\section{É melhor utilizar uma largura temporal menor, e dessa forma obter uma intensidade maior?}

Este caso é semelhante à situação da lente de comprimento focal curto, e pode conduzir a uma menor quantidade de rebarbas, como também, a uma menor zona afetada pelo calor. Aqui, devido às limitações da fonte de alimentação, a diminuição da largura temporal do pulso laser, leva necessariamente à diminuição da energia por pulso, a qual pode então não ser suficiente para a penetração da espessura em um único pulso. Isto implica na diminuição da velocidade, com conseqüente variação da taxa de sobreposição, aumento do aporte de calor, e aumento da zona afetada pelo calor.

Este tipo de análise parece ser imenso e demonstra como são complexas as interações entre os parâmetros do processo. Por este motivo, não existe uma teoria que aborde completamente os mecanismos envolvidos no corte de metais com laser pulsado. Existem somente algumas teorias aproximadas para furação que fornecem parâmetros básicos. Assim, a otimização de um processo deve ser dedicada ao particular caso e o sucesso desta é alcançado pelo pré-estabelecimento do resultado que se busca. Métodos estatísticos são então os meios utilizados para este tipo de otimização. 


\subsection{Projeto de experimentos - DOE}

\subsubsection{Projeto e Análise de Experimentos}

O cenário atual de severa competitividade exerce grande pressão no setor industrial, a qual precisa estabelecer metas para vencer a concorrência e apresentar produtos com melhor qualidade. Dessa forma, torna-se imprescindível desenvolver ferramentas para obter um controle rigoroso dos seus processos.

Muitos sistemas dos mais diferentes setores são projetados para realizar funções específicas e normalmente essas funções são passíveis de medição e controle, dentro de uma determinada tolerância. Diversos modelos matemáticos foram desenvolvidos para conhecer as variáveis do sistema, exercer pleno controle sobre estes parâmetros e assim alcançar melhores resultados.

Geralmente, os modelos matemáticos são extremamente complexos e exigem um amplo conhecimento teórico multidisciplinar para seu desenvolvimento, o que implica em um estudo exaustivo de longa duração, consequentemente oneroso. Portanto, antes de iniciar uma modelagem matemática, é interessante delimitar um campo inicial, como também, estimar as faixas de valores dos principais parâmetros do projeto. Isto é possível por meio da aplicação de ferramentas estatísticas e do planejamento experimental com métodos de otimização.

Em um trabalho pioneiro, Ronald Fischer realizou este tipo de abordagem estatística aplicada na pesquisa agrícola em 1920, introduzindo vários aspectos, como o teste de hipóteses, a estimativa de parâmetros, o planejamento experimental entre outros ${ }^{102}$. Atualmente, as técnicas de análise estatística e o planejamento DOE são amplamente utilizados para estudos de simulação. Alguns exemplos destes estudos são encontrados: no controle de rotas dos taxistas (Bailey e Clark, 1992) ${ }^{103}$, 
na simulação do controle de uma nave espacial (Gordon, 1994) ${ }^{104}$, no controle de um sistema hídrico (Kuei e Madu, 1994) ${ }^{105}$.

O estudo e a aplicação das teorias de planejamento experimental e de técnicas de otimização para a melhoria de produtos e sistemas são amplamente utilizadas nas áreas da química e da engenharia de alimentos, mas na engenharia mecânica sua difusão ainda é pequena, o que gera uma lacuna de conhecimento e uma escassez de técnicas aplicadas aos desenvolvimentos de projetos e produtos ${ }^{106}$.

Entretanto, o crescimento substancial das tecnologias aplicadas ao processamento dos metais contribuiu para despertar o interesse no desenvolvimento e na implementação de processos efetivos de controle operacional da usinagem, em busca de um balanço entre custo e qualidade.

Independentemente do tipo de usinagem, a otimização dos parâmetros operacionais requer a modelagem das variáveis de entrada e de saída com suas interações para determinar a melhor condição ou próxima desta.

Para atingir essa meta, vários modelos são propostos, como: regressão estatística (Montgomery e Peck, 1992) ${ }^{107}$, rede neural artificial - RNA (Fu, 2003) ${ }^{108}$, teoria dos conjuntos fuzzy (Zadeh, 1973) ${ }^{109}$, em conjunto com técnicas, como: método Taguchi (Ross, 1989) ${ }^{110}$, metodologia da superfície de resposta - MSR (Montgomery, 2001) ${ }^{17}$, programação matemática (Hillier e Liebermann, 1999) ${ }^{111}$, entre outras. Apesar do grande número de estudos realizados, não existe um modelo universal que correlacione a influência e as interações das variáveis (entrada/saída), especialmente na usinagem de corte de metais ${ }^{112,113}$.

Na análise estatística define-se o termo robustez quando à aplicação de um procedimento resulta em dados satisfatórios, mesmo ao apresentar transgressão em algumas hipóteses pré-estabelecidas. Isto ocorre dentro do planejamento 
experimental por meio das suposições definidas pelo projetista, pois mesmo que estas escolhas não estejam exatamente corretas, ainda assim podem fornecer respostas robustas. No entanto, estas escolhas exercem uma profunda influência na construção do projeto e a fim de estabelecer um bom planejamento é necessário: deter um pré-conhecimento do assunto a ser investigado; saber de que maneira os dados serão coletados e ter uma idéia qualitativa de como estes dados deverão ser analisados. Além disso, reunir o maior número de informações sobre as variáveis de entrada é essencial para obter uma ampla abordagem do tema. Para isso ocorrer com o menor índice de erros, deve-se evitar coletar as informações de um único indivíduo e sim obtê-las dos profissionais de diferentes áreas (engenharia, controle de qualidade, produção, técnicos de operação e manutenção, entre outras) envolvidos no processo.

$\mathrm{Na}$ Tabela 7 foram descritos os passos para o desenvolvimento de um planejamento experimental, segundo as regras apresentadas por Montgomery ${ }^{17}$.

Tabela 7 - Guia para a construção do planejamento experimental.

\section{Regras gerais}

1) Estabelecer o problema e o objetivo de estudo.

2) Escolher os fatores (variáveis de entrada que se tem controle).

3) Escolher as variáveis de saída (resposta que se tem interesse).

4) Determinar a região de operação (faixa de valores para cada fator em que o sistema pode operar).

5) Especificar a região de interesse (uma sub-região do campo operacional dentro do qual é possível realizar o experimento).

6) Escolher o modelo estatístico (ANOVA, regressão, correlação espacial).

7) Selecionar o critério para escolher o DOE (por exemplo: variância mínima).

8) Escolher um projeto experimental apropriado (Latin square - quadrado latino, fatorial, composição central).

9) Selecionar os níveis dos fatores para cada teste.

10) Realizar os testes e coletar os dados.

11) Analisar os dados e verificar a adequação do modelo estatístico.

12) Conclusões e recomendações. 


\subsubsection{Projeto Fatorial}

Muitos experimentos envolvem a análise dos efeitos de dois ou mais fatores sobre uma variável que se quer estudar. O método de variar um dos fatores de cada vez e manter fixo os demais não se mostra adequado quando existe a possibilidade da influência de um fator sobre o outro. Neste caso, o mais adequado é a utilização de projetos fatoriais, pois em cada medida completa de um experimento, todas as combinações possíveis dos níveis dos fatores são investigadas. Por exemplo, se existem a níveis para o fator $A$ e $b$ níveis para o fator $B$, então cada réplica contém todas as ab combinações de tratamentos. Desta maneira, quando os fatores são arranjados em um projeto fatorial, eles são considerados cruzados.

O efeito de um fator é definido como sendo a mudança na resposta produzida por uma mudança no nível deste fator. Isto é comumente chamado de efeito principal, porque se refere aos fatores primários de interesse no experimento. Muitas vezes, a diferença na resposta entre os níveis de um fator não é a mesma para todos os níveis dos outros fatores. Quando isto ocorre, existe uma interação entre os fatores.

Se os fatores do projeto são todos quantitativos, é possível então, construir a representação de modelo de regressão para o caso de um experimento fatorial de dois fatores pela equação (8):

$$
y=\beta_{0}+\beta_{1} X_{1}+\beta_{2} X_{2}+\beta_{12} X_{1} X_{2}+\varepsilon .
$$

Onde, y é a variável de resposta, os $\beta$ s são parâmetros a determinar, $x_{1}$ é a variável que representa o fator $A, x_{2}$ é a variável que representa o fator $B$ e $\varepsilon$ é um termo que representa o erro aleatório. O termo $x_{1} x_{2}$ representa a interação entre $x_{1} \mathrm{e}$ $x_{2}$. 
Com a comparação dos valores médios dos termos $\beta_{1}, \beta_{2}$ e $\beta_{12}$ pode-se estimar a influência que cada fator tem naquele determinado experimento, bem como, se é importante ou não a interação entre eles. Isto é bastante útil quando existem muitos fatores e não se conhece bem a importância de cada um deles. Desta maneira, determina-se quais os fatores devem ser variados e quais os que podem permanecer fixos do experimento, em que se deseja otimizar alguma variável de saída. Para um projeto fatorial de dois fatores, o arranjo geral é o representado na Tabela 8.

Tabela 8 - Arranjo geral para projeto fatorial com 2 fatores ${ }^{17}$.

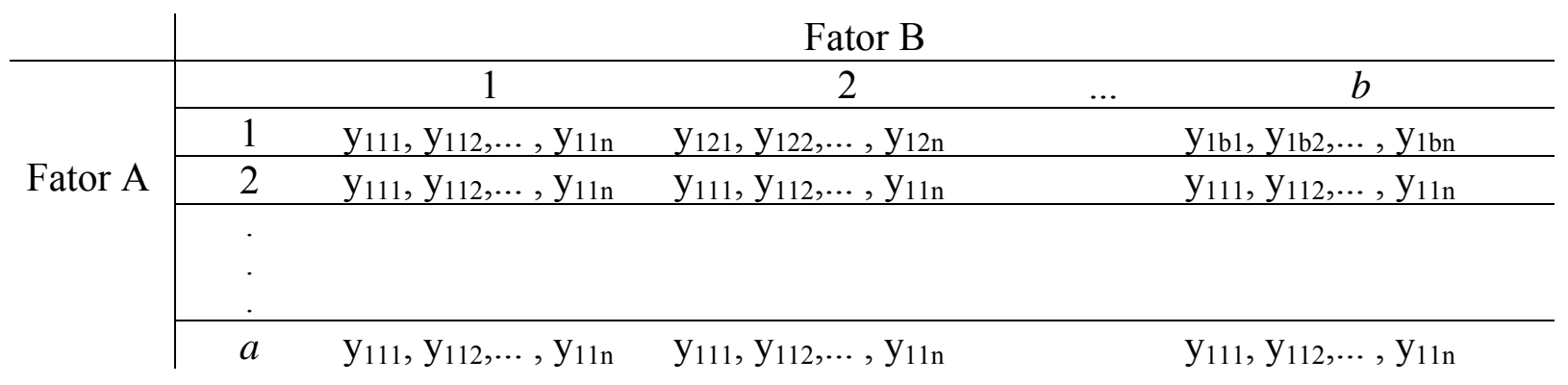

Onde: $(\mathrm{i}=1,2, \ldots, a) ;(\mathrm{j}=1,2, \ldots, b) ;(\mathrm{k}=1,2, \ldots, \mathrm{n}) ; \mathrm{a}$ e $\mathrm{b}$ o número de níveis e $\mathrm{n}$ é o número de réplicas.

Outro modelo, freqüentemente, utilizado para o caso de um experimento fatorial é o modelo dos efeitos. Neste caso, os fatores são admitidos como fixos, e os efeitos do tratamento (e das interações entre eles) são definidos como desvios da média total. Assim, os testes de hipóteses são feitos com base na análise de variância para o caso de $\mathbf{n}$-fatores.

O modelo dos efeitos pode ser escrito como:

$$
\mathbf{y}_{\mathrm{ijk}}=\mu+\tau_{\mathrm{i}}+\beta_{\mathrm{j}}+(\tau \beta)_{\mathrm{ij}}+\varepsilon_{\mathrm{ijk}}
$$

onde $\mu$ é o efeito médio total, $\tau_{\mathrm{i}}$ é o efeito do i-ésimo nível do fator da linha $\mathrm{A}$, $\beta_{\mathrm{j}}$ é o efeito do j-ésimo nível do fator da coluna $\mathrm{B},(\tau \beta)_{\mathrm{ij}}$ é o efeito da interação entre $\tau_{\mathrm{i}}$ e $\beta_{\mathrm{j}}$ e $\varepsilon_{\mathrm{ijk}}$ é um componente de erro aleatório. 
O teste de hipóteses ou teste de significância permite a comparação entre duas formulações em bases objetivas, com o conhecimento dos riscos associados de se chegar a uma conclusão errada. A hipótese estatística reflete alguma conjectura acerca da situação do problema, isto é descrito por:

$$
\begin{aligned}
& H_{0}: \mu_{1}=\mu_{2} \text { (hipótese nula) } \\
& H_{1}: \mu_{1} \neq \mu_{2} \text { (hipótese alternativa) }
\end{aligned}
$$

Ao realizar o teste de hipóteses, dois tipos de erros podem ser cometidos (Tabela 9):

a) Erro do tipo I - ocorre quando se rejeita $\left(H_{0}\right)$, sendo que a hipótese nula $\left(H_{0}\right)$ é verdadeira.

b) Erro do tipo II - ocorre quando se aceita $\left(H_{0}\right)$, uma vez que a hipótese nula $\left(H_{0}\right)$ é falsa.

Tabela 9 - Tipo de erros para o teste de hipóteses ${ }^{106}$.

\begin{tabular}{c|cc} 
Decisão & $\left(H_{0}\right)$ é verdadeira & $\left(H_{0}\right)$ é falsa \\
\hline Aceitar $\left(H_{0}\right)$ & Não há erro & Erro Tipo II $(\beta)$ \\
Rejeitar $\left(H_{0}\right)$ & Erro Tipo I $(\alpha)$ & Não há erro
\end{tabular}

\section{Análise estatística para o modelo de efeitos fixos.}

A análise de variância para os diversos fatores é feita com base na soma dos quadrados (variável de saída) de cada tratamento (ou fator) e de suas interações. Assim, a soma dos quadrados total corrigida $\left(\mathrm{SS}_{\mathrm{T}}\right)$, para um experimento com dois fatores, pode ser escrita como:

$$
S S_{T}=\sum_{i=1}^{a} \sum_{j=1}^{b} \sum_{k=1}^{n} y_{i j k}^{2}-\frac{y^{2}}{a b n}
$$


As somas dos quadrados dos fatores $A\left(S S_{A}\right), B\left(S S_{B}\right)$, da interação $A B\left(S S_{A B}\right)$ e do erro $\left(S S_{E}\right)$ são descritas pelas equações:

$$
\begin{aligned}
& S S_{A}=\frac{1}{b n} \sum_{i=1}^{a} y_{i}^{2}-\frac{y^{2}}{a b n} \\
& S S_{B}=\frac{1}{a n} \sum_{j=1}^{b} y_{i}^{2}-\frac{y^{2}}{a b n} \\
& S S_{\text {Subtotal }}=\frac{1}{n} \sum_{i=1}^{a} \sum_{j=1}^{b} y_{i j}^{2}-\frac{y^{2}}{a b n} \\
& \mathrm{SS}_{\mathrm{AB}}=\mathrm{SS}_{\text {Subtotal }}-\mathrm{SS}_{\mathrm{A}}-\mathrm{SS}_{\mathrm{B}} \\
& \mathrm{SS}_{\mathrm{E}}=\mathrm{SS}_{\mathrm{T}}-\mathrm{SS}_{\mathrm{A}}-\mathrm{SS}_{\mathrm{B}}-\mathrm{SS}_{\mathrm{AB}}
\end{aligned}
$$

Cada soma de quadrados dividida pelos seus graus de liberdade é um quadrado médio (MS); o valor esperado para o quadrado médio do erro é simplesmente a variância $\left(\sigma^{2}\right)$, que é a medida da dispersão de uma distribuição de probabilidade. Assim, cada uma das razões dos quadrados médios $M S_{A} / M S_{E}$, $\mathrm{MS}_{\mathrm{B}} / \mathrm{MS}_{\mathrm{E}}$ e $\mathrm{MS}_{\mathrm{AB}} / \mathrm{MS}_{\mathrm{E}}$ são distribuídas como $\mathrm{F}$ (distribuição) e sua análise fornece informações sobre o grau de significância para cada tratamento para este experimento. O procedimento de teste é normalmente resumido num diagrama de análise de variância como mostrado na Tabela 10. Esta tabela também representa um quadro de saída típico de um programa estatístico como, por exemplo, o MiniTab.

\subsubsection{Projeto Fatorial Fracionado}

Uma situação que pode tornar o projeto fatorial $2^{k}$ impraticável é um número muito grande de fatores (k). Por exemplo, para 6 fatores o teste terá 64 casos e neste caso, somente 6 dos 63 graus de liberdade correspondem ao efeito principal, como também somente 15 são correspondentes a interação de dois fatores, 
sobrando 42 graus de liberdade associados às altas ordens de interação. Para resolver este problema, Finney em 1945, propôs o planejamento fatorial fracionado que proporciona uma boa estimativa dos efeitos principais e das interações de baixa ordem de vários fatores com um número menor de experimentos em relação ao planejamento fatorial completo, sacrificando por outro lado interações de alta ordem. As interações de alta ordem, geralmente apresentam valores pequenos e sem muita importância ${ }^{114}$, o que possibilita aplicar o projeto fatorial fracionado a fim de se obter o máximo de informação com a menor quantidade de dados e dessa forma reduzir o tempo, os custos e a quantidade de recursos na realização dos experimentos.

Tabela 10 - Análise de variância baseado na soma dos quadrados ${ }^{17}$.

\begin{tabular}{ccccc}
\hline $\begin{array}{c}\text { Fonte de } \\
\text { variação }\end{array}$ & $\begin{array}{c}\text { Soma dos } \\
\text { Quadrados }\end{array}$ & $\begin{array}{c}\text { Graus de } \\
\text { Liberdade }\end{array}$ & $\begin{array}{c}\text { Quadrado } \\
\text { Médio }\end{array}$ & $\mathrm{F}_{0}$ \\
\hline Fator A & $\mathrm{SS}_{\mathrm{A}}$ & $\mathrm{a}-1$ & $\mathrm{MS}_{\mathrm{A}}=\mathrm{SS}_{\mathrm{A}} /(\mathrm{a}-1)$ & $\mathrm{F}_{0}=\mathrm{MS}_{\mathrm{A}} / \mathrm{MS}_{\mathrm{E}}$ \\
Fator B & $\mathrm{SS}_{\mathrm{B}}$ & $\mathrm{b}-1$ & $\mathrm{MS}_{\mathrm{B}}=\mathrm{SS}_{\mathrm{B}} /(\mathrm{b}-1)$ & $\mathrm{F}_{0}=\mathrm{MS}_{\mathrm{B}} / \mathrm{MS}_{\mathrm{E}}$ \\
& & & & \\
Interação & $\mathrm{SS}_{\mathrm{AB}}$ & $(\mathrm{a}-1)(\mathrm{b}-1)$ & $\mathrm{MS}_{\mathrm{AB}}=\mathrm{SS}_{\mathrm{AB}} /(\mathrm{a}-1)(\mathrm{b}-1)$ & $\mathrm{F}_{0}=\mathrm{MS}_{\mathrm{AB}} / \mathrm{MS}_{\mathrm{E}}$ \\
& & & & \\
Erro & $\mathrm{SS}_{\mathrm{E}}$ & $\mathrm{ab}(\mathrm{n}-1)$ & $\mathrm{MS}_{\mathrm{E}}=\mathrm{SS}_{\mathrm{E}} / \mathrm{ab}(\mathrm{n}-1)$ & \\
Total & $\mathrm{SS}_{\mathrm{T}}$ & $\mathrm{abn}-1$ & & \\
\hline
\end{tabular}

O sucesso do uso do projeto fatorial fracionado está baseado em três princípios:

1) A dispersão do efeito principal: geralmente nos sistemas e/ou processos que apresentam um grande número de fatores (variáveis de entrada) caracterizamse por sofrer mais influência dos efeitos principais de cada fator e da interação de baixa ordem.

2) A propriedade de projeção: o projeto fatorial fracionado pode ser aplicado em maiores projetos sobre a configuração dos fatores mais significativos. 
3) Seqüência do experimento: é possível combinar testes de dois ou mais projetos fatoriais fracionados para construir uma seqüência maior do modelo que possibilite estimar os efeitos principais e pontos de interesse.

O projeto fatorial fracionado é representado pela forma $2^{(k-p)}$, em que $k$ é o número de fatores e $\mathrm{p}$ é o grau de fracionamento do experimento fatorial. Para exemplificar um fracionamento considere uma situação de um planejamento completo de 3 fatores $\left(2^{(3)}\right)$, o que resultaria em 8 combinações. Ao aplicar o fracionamento, denominado como fração-meia (one-half fraction), o número de combinações se tornaria 4, ou seja, a metade.

A seleção das combinações a, b, c e abc determinaria a fração principal fracionada sobre a construção da matriz $2^{(3)}$ para realização do teste, conforme verifica-se na Tabela 11 e na Figura 24.

Nota-se que o projeto fatorial fracionado é constituído somente pela combinação de tratamentos que apresentam sinal positivo (+) da coluna ABC. Esta coluna é chamada de gerador para este caso $\mathrm{I}=\mathrm{ABC}$. Os quatro ensaios restantes do projeto fatorial completo, que não foram empregados, também constituem uma metade (meia fração), ou seja, o outro gerador da fração alternativa, somente com sinal trocado (-).

Tabela 11 - Exemplo da Tabela (+/-) do projeto fatorial $2^{(3)}$.

\begin{tabular}{cccccccccc}
\hline $\begin{array}{c}\mathrm{N}^{\circ} \text { de } \\
\text { testes }\end{array}$ & Combinações & $\mathrm{I}$ & $\mathrm{A}$ & $\mathrm{B}$ & $\mathrm{C}$ & $\mathrm{AB}$ & $\mathrm{AC}$ & $\mathrm{BC}$ & $\mathrm{ABC}$ \\
\hline 1 & $\mathrm{a}$ & + & + & - & - & - & - & + & + \\
2 & $\mathrm{~b}$ & + & - & + & - & - & + & - & + \\
3 & $\mathrm{c}$ & + & + & - & + & + & - & - & + \\
4 & $\mathrm{abc}$ & + & - & + & + & + & + & + & + \\
\hline 5 & $\mathrm{ab}$ & + & + & + & - & + & - & - & - \\
6 & $\mathrm{ac}$ & + & - & - & + & - & + & - & - \\
7 & $\mathrm{bc}$ & + & + & + & + & - & - & + & - \\
8 & $(1)$ & + & - & - & - & + & + & + & - \\
\hline
\end{tabular}




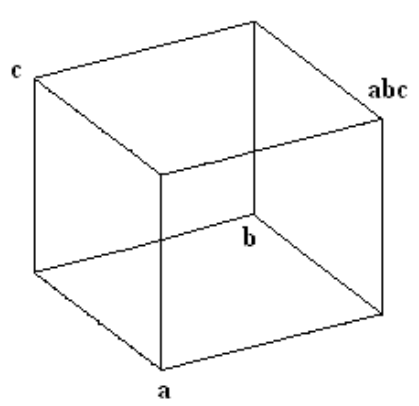

$I=+\mathrm{ABC}$ a) fração principal

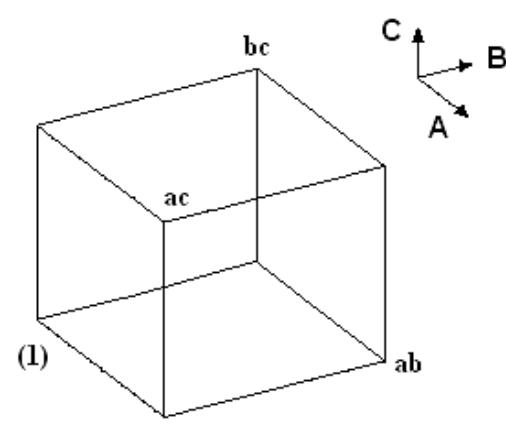

$\mathrm{I}=-\mathrm{ABC}$

b) fração alternativa

Figura 24 - Representação das combinações do Projeto Fatorial Fracionado $2^{(3-1)}$.

tratamento das combinações do projeto fatorial fracionado $2^{(3-1)}$ gera 3 graus de liberdade para estimar os efeitos principais e as interações de dois fatores, com a seguintes combinações lineares, apresentada na Tabela 12:

Tabela 12 - Combinações lineares para projeto fatorial fracionado $2^{(3-1)}$.

\begin{tabular}{|c|c|}
\hline Efeitos principais & Interações de dois fatores \\
\hline$\ell_{A}=1 / 2(a-b-c+a b c)$ & $\ell_{B C}=1 / 2(a-b-c+a b c)$ \\
\hline$\ell_{B}=1 / 2(-a+b-c+a b c)$ & $\ell_{A C}=1 / 2(-a+b-c+a b c)$ \\
\hline$\ell_{C}=1 / 2(-a-b+c+a b c)$ & $\ell_{A B}=1 / 2(-a-b+c+a b c)$ \\
\hline
\end{tabular}

Observa-se que cada efeito principal de A, B, C é idêntico à interação de dois fatores. Esta propriedade é chamada de idêntica ou de sinônimo (aliases).

Assim, o valor do contraste no projeto fatorial fracionado de $A, B, C$ é na verdade a estimativa da soma dos dois efeitos que corresponde ao efeito principal de cada fator em um planejamento fatorial e são representados desta forma: $\ell_{A}=\ell_{B C}$ $\ell_{A} \rightarrow A+B C ; \ell_{B}=\ell_{A C}, \ell_{B} \rightarrow B+A C$ e $\ell_{C}=\ell_{A B}, \ell_{C} \rightarrow C+A B$.

O exemplo abordado de projeto fatorial fracionado $2^{(3-1)}$ é classificado projeto de resolução III, isto significa que neste tipo de modelo os efeitos principais são idênticos com as interações de dois fatores. 
A resolução dos projetos é classificada em três tipos:

a) Resolução III - Um efeito principal não é idêntico aos outros efeitos principais, contudo superpõe com interações de dois fatores.

b) Resolução IV - Um efeito principal não é idêntico aos outros efeitos principais, e nem com as interações de dois fatores, mas as interações de dois fatores se confundem entre si. Um projeto do tipo $2^{(4-1)}$ com gerador I= ABCD.

c) Resolução V: - Um efeito principal não é idêntico aos outros efeitos principais, e nem com as interações de dois fatores, mas as interações de dois fatores se confundem com as interações de três fatores. Um projeto do tipo $2^{(5-1)}$ com gerador $\mathrm{I}=\mathrm{ABCDE}$.

Geralmente, na aplicação dos planejamentos experimentais fracionados devese preferir a maior resolução possível, pois quanto maior é a resolução, menor será o número de restrições das interações e consequentemente um menor número de interações é negligenciado.

Neste trabalho foram aplicados: o projeto fatorial completo $2^{(4)}$ (4 fatores a 2 níveis - Resolução: IV com 2 réplicas), como também o projeto fatorial fracionado $2^{(6-}$ 2) ( $1 / 4$ de 6 fatores a 2 níveis - Resolução: IV com 2 réplicas) escolhidos para avaliação de seis e quatro parâmetros correspondentes as variáveis consideradas mais influentes no processamento a laser. 


\section{MATERIAIS E MÉTODOS}

\subsection{Materiais}

\subsubsection{Metais}

Os materiais empregados no desenvolvimento deste estudo foram:

- Titânio comercialmente puro - Ti c.p. (grau 2);

- $\quad$ Liga de titânio Ti-6Al-4V (grau 5);

Estes materiais foram adquiridos da empresa Realum, na forma de chapas laminadas com espessuras de $0,5 \mathrm{~mm}$ e de $1,0 \mathrm{~mm}$, nas dimensões de $300 \mathrm{~mm} \times$ $600 \mathrm{~mm}$. A composição química nominal fornecida pelo fabricante e algumas propriedades destes materiais estão apresentadas na Tabela 13 e na Tabela 14, respectivamente.

Tabela 13 - Composição química dos materiais ${ }^{115}$.

\begin{tabular}{lcccccccc}
\hline & \multicolumn{8}{c}{ Elementos (\%) máxima } \\
\hline Material & $\mathrm{N}$ & $\mathrm{C}$ & $\mathrm{H}$ & $\mathrm{Fe}$ & $\mathrm{O}$ & $\mathrm{Al}$ & $\mathrm{V}$ & $\mathrm{Ti}$ \\
\hline $\begin{array}{l}\text { Ti-c.p. } \\
\text { (Grau 2) }\end{array}$ & 0,03 & 0,08 & 0,015 & 0,30 & 0,25 & - & - & balanço \\
\hline $\begin{array}{l}\text { Ti-6Al-4V } \\
\text { (Grau 5) }\end{array}$ & 0,05 & 0,08 & 0,015 & 0,40 & 0,20 & $\begin{array}{c}5,5 \\
\text { a }\end{array}$ & $\begin{array}{c}3,5 \\
\text { a }\end{array}$ & balanço \\
\hline
\end{tabular}

Tabela 14 - Propriedades físico-químicas, térmicas e mecânicas do Ti c.p. (grau 2) e da liga Ti-6Al-4V (grau 5) ${ }^{116,117}$.

\begin{tabular}{l|cc}
\hline Propriedades & Ti c.p & Ti-6Al-4V \\
\hline Ponto de fusão ${ }^{\circ} \mathrm{C}$ & \multicolumn{2}{|c}{$1604-1660$} \\
Densidade do sólido a $20^{\circ} \mathrm{C}\left(\mathrm{g} \cdot \mathrm{cm}^{-3}\right)$ & 4,51 & 4,43 \\
Dureza Vickers (HV) & $145(+/-20)$ & $349(+/-20)$ \\
Resistência à tração (MPa) & 344 & 950 \\
Resistência à fadiga (MPa) & $300-425$ & $240-510$ \\
Módulo de elasticidade (GPa) & 105 & 114 \\
Tensão de escoamento (MPa) & $275-410$ & 880 \\
Condutividade térmica $\left(\mathrm{W} \cdot \mathrm{m}^{-1} \cdot \mathrm{K}^{-1}\right)$ & 16 & 7 \\
\hline
\end{tabular}




\subsubsection{Gases}

Nas aplicações de laser em processamento de materiais é necessário o uso de gás de assistência para se obter um resultado otimizado. Assim, neste trabalho foram investigados os seguintes gases de assistência:

- Nitrogênio;

- Argônio;

- Hélio;

- Mistura argônio e hélio em diferentes proporções;

O laboratório de processamento de materiais a laser do IPEN dispõe de um sistema de distribuição com linhas (de cobre) independentes para cada tipo de gás. Cada cilindro de $9 \mathrm{~m}^{3}$ está conectado em um circuito autônomo.

$\mathrm{Na}$ Figura 25 são apresentadas as especificações técnicas de fornecimento dos gases investigados e algumas de suas características.

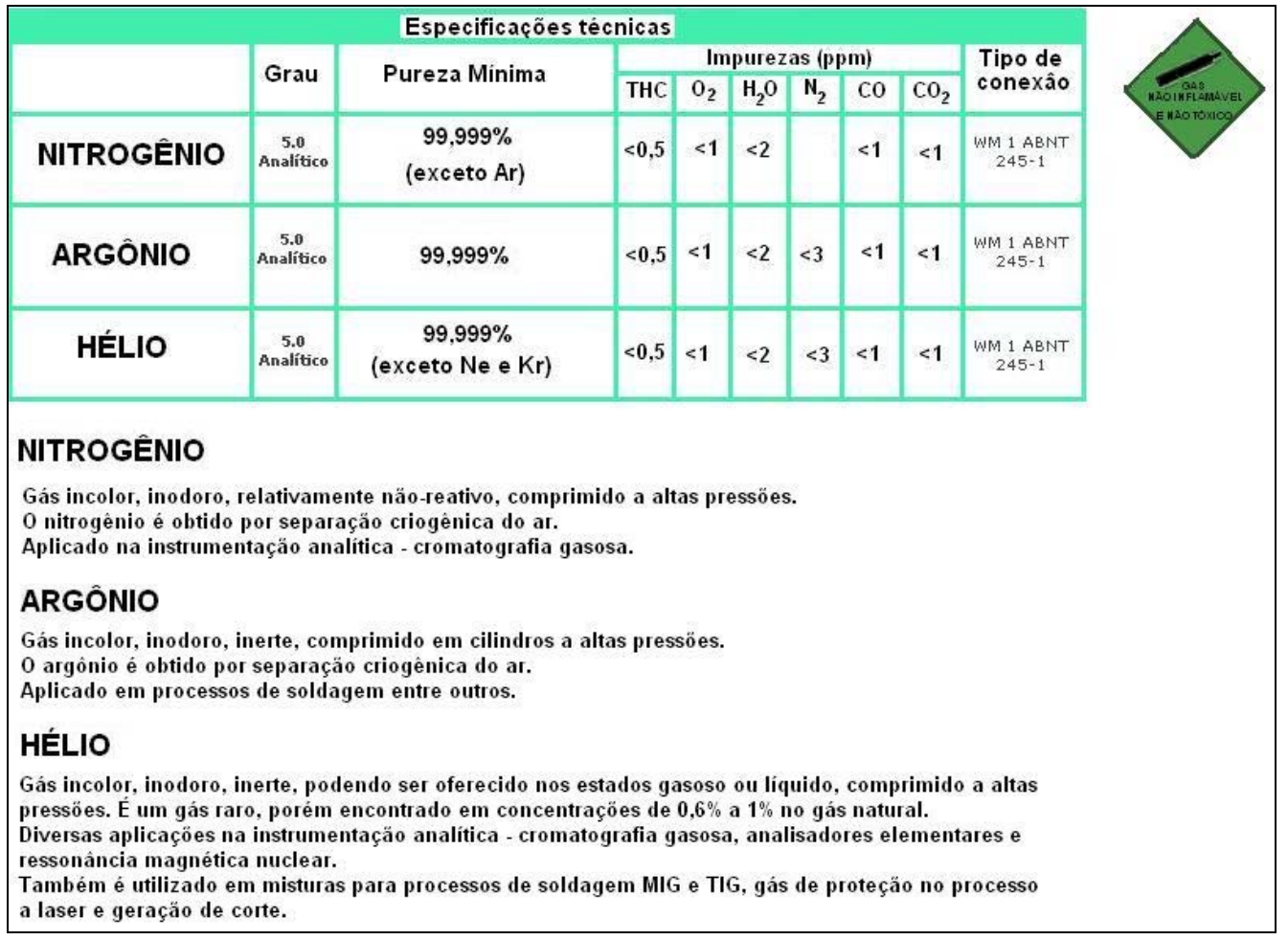

Figura 25 - Especificações e características dos gases ${ }^{118}$. 


\subsection{Métodos}

\subsubsection{Geração das amostras}

Previamente à geração do conjunto de amostras foi realizada a análise da composição química dos materiais para confirmá-la com as especificações das normas técnicas. Os materiais foram analisadas com o uso do equipamento marca Rigaku, modelo RIX-3000 do Laboratório de Fluorescência de Raios-X no CQMA/IPEN, pela técnica de espectrometria de fluorescência de Raios-X. O material recebido atende as especificações e os valores desta análise estão indicados na Tabela 15.

Tabela 15 - Composição química dos materiais analisados no IPEN e as normas ASTM.

\begin{tabular}{|c|c|c|c|c|}
\hline Elemento & $\begin{array}{c}\text { Limites max. } \\
\text { de composição } \\
\%(\mathrm{~m} / \mathrm{m}) \\
\text { Norma ASTM } \\
\text { F67 }\end{array}$ & $\begin{array}{c}\text { Composição real } \\
\%(\mathrm{~m} / \mathrm{m}) \\
\\
\text { Ti c.p. }\end{array}$ & $\begin{array}{c}\text { Limites max. } \\
\text { de composição } \\
\%(\mathrm{~m} / \mathrm{m}) \\
\text { Norma ASTM } \\
\text { F136 }\end{array}$ & $\begin{array}{c}\text { Composição real } \\
\%(\mathrm{~m} / \mathrm{m}) \\
\text { Ti-6AI-4V }\end{array}$ \\
\hline Nitrogênio & 0,03 & 0,03 & 0,05 & 0,048 \\
\hline Carbono & 0,10 & 0,08 & 0,08 & 0,08 \\
\hline Hidrogênio & 0,015 & 0,010 & 0,012 & 0,01 \\
\hline Ferro & 0,30 & 0,23 & 0,25 & 0,24 \\
\hline Oxigênio & 0,25 & 0,18 & 0,13 & 0,10 \\
\hline Alumínio & $x$ & $x$ & 5,5 a 6,5 & 6,30 \\
\hline Vanádio & $x$ & $x$ & 3,5 a 4,5 & 3,90 \\
\hline Titânio & \multicolumn{4}{|c|}{ Balanço } \\
\hline
\end{tabular}

Todos os lotes de amostras foram projetados e distribuídos sobre a área útil das chapas metálicas por um sistema de computação gráfica (CAD/CAM "Computer Aided Desing" - Projeto Assistido por Computador e "Computer Aided Manufacturing" - Fabricação Assistida por Computador).

Com o software Mastercam Mill (versão 8$)^{119}$, gerou-se um programa executável, composto pelos comandos e posicionamentos necessários para realizar 
o contorno dimensional das amostras. Um exemplo do arranjo gráfico está apresentado na Figura 26.
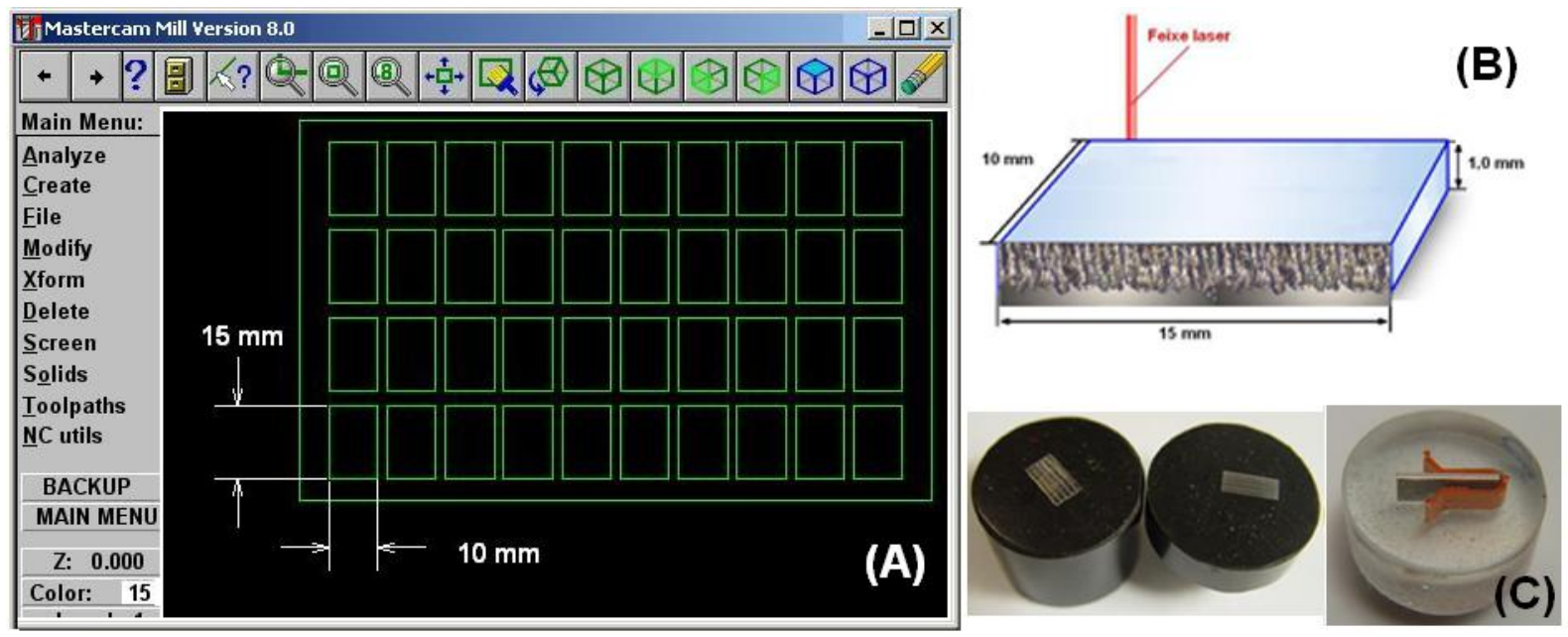

Figura 26 - Representação: A) do arranjo de amostras no software Mastercam, B) Dimensões do corte de cada amostra, C) amostras embutidas.

Os programas executáveis de contorno são transferidos por uma porta de comunicação ao equipamento de processamento a laser, para assim executar o corte das amostras com geometria retangular de $10 \times 15 \mathrm{~mm}^{2}$.

Desenvolvido pelos pesquisadores do CLA/IPEN e denominado por "Central de Processamento de Materiais a Laser" (CPML), este equipamento consiste em um laser de estado sólido pulsado de Nd:YAG acoplado a um centro de usinagem vertical de comando numérico (CNC - marca Heidenhain / Diadur 630 ) ${ }^{120}$;(Figura 27). Na Tabela 16 estão descritas as principais características deste equipamento.

Tabela 16 - Características da CPML.

\begin{tabular}{|c|c|}
\hline Laser & Fresadora Rocco (CNC) \\
\hline Energia por pulso - máx. $10 \mathrm{~J}$ & $\begin{array}{l}3 \text { eixos com possibilidade de acoplamento } \\
\text { do } 4^{\circ} \text { eixo }\end{array}$ \\
\hline Freqüência - máx. $500 \mathrm{~Hz}$ & Curso dos eixos X780 mm, Y390 mm, Z400 mm. \\
\hline Duração temporal do pulso - 0,2 a $10 \mathrm{~ms}$ & Programação ISO \\
\hline Potência média de saída - Max. 120 W & Avanço rápido - $20.000 \mathrm{~mm} \cdot \mathrm{min}^{-1}$ \\
\hline Potência Pico - 3 kW & Precisão 0,02 mm \\
\hline Lentes de focalização $50 \mathrm{~mm}$ e $100 \mathrm{~mm}$ & $\begin{array}{l}\text { Câmera CCD e Monitor para visualização do } \\
\text { processo }\end{array}$ \\
\hline Variação da Posição focal máx. 10 mm & $\begin{array}{l}\text { Controle computacional dos parâmetros laser e } \\
\text { transferência de dados para processamento. }\end{array}$ \\
\hline
\end{tabular}




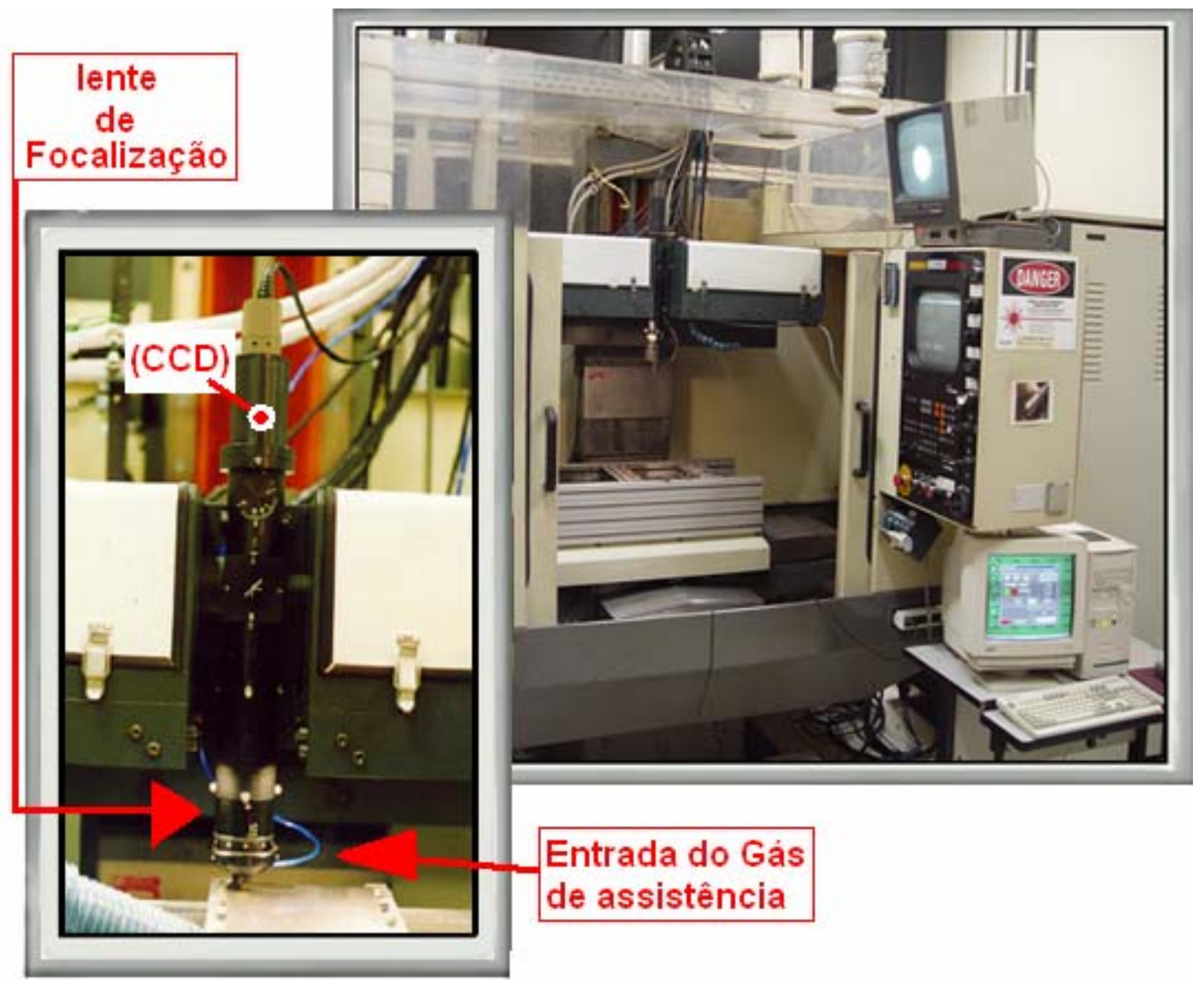

Figura 27 - Vista panorâmica da Central de Processamento de Materiais a Laser, no detalhe o sistema de entrega do feixe.

Neste trabalho, a investigação da influência dos parâmetros de processo do corte a laser foi conduzida de maneira progressiva em razão da ocorrência dos resultados.

Fase 1 - Processamento do Ti c.p. e da Liga Ti-6Al-4V com gás nitrogênio.

Baseado na experiência anterior em processamento de materiais a laser do grupo de pesquisadores do Centro de Aplicações a Laser (CLA - IPEN/CNEN), selecionou-se um conjunto de parâmetros de processo. Estes dados, utilizados para delimitar uma configuração básica de processo, estão descritos na Tabela 17.

Nesta fase inicial das investigações, empregou-se o nitrogênio industrial como gás de assistência do processo ${ }^{121}$ para avaliar seus efeitos sobre o acabamento superficial do corte. O nitrogênio é um gás abundante e pode ser adquirido por 
tarifas inferiores aos gases inertes mais nobres. Assim, o fator custo de gás também foi considerado para seleção do nitrogênio como gás de assistência. Para focalização do feixe laser utilizou-se lentes com comprimento focal de $50 \mathrm{~mm}$ e 100 $\mathrm{mm}$.

Tabela 17 - Seleção inicial dos parâmetros fixos e variáveis.

\begin{tabular}{|c|c|c|c|}
\hline \multicolumn{4}{|c|}{ Parâmetros } \\
\hline \multicolumn{2}{|c|}{ Fixos } & \multicolumn{2}{|c|}{ Variáveis } \\
\hline $\begin{array}{l}\text { Polarização da luz } \\
\text { Distância focal }\end{array}$ & $\begin{array}{l}\text { não polarizada } \\
100 \mathrm{~mm}\end{array}$ & $\begin{array}{l}\text { Energia do pulso } \\
\text { laser }\end{array}$ & $\begin{array}{l}\text { Fornecida pelo sistema; } \\
\text { Variação: dezenas de } \\
\text { milijoules a Joules. }\end{array}$ \\
\hline Modo transversal & Multimodo & $\begin{array}{l}\text { Duração temporal } \\
\text { do pulso laser }\end{array}$ & $\begin{array}{l}\text { Variação na escala } \\
\text { de } 0,2 \text { a } 10 \mathrm{~ms} \text {. }\end{array}$ \\
\hline $\begin{array}{l}\text { Geometria } \\
\text { do bocal }\end{array}$ & $\begin{array}{l}\text { Formato cônico; } \\
\qquad \varnothing=0,7 \mathrm{~mm}\end{array}$ & $\begin{array}{l}\text { Taxa de repetição } \\
\text { dos pulsos } \\
\text { (Freqüência) }\end{array}$ & Variação máxima $500 \mathrm{~Hz}$ \\
\hline Geometria de corte & $\begin{array}{l}\text { Linhas retas } \\
(10 \mathrm{~mm} \times 15 \mathrm{~mm})\end{array}$ & $\begin{array}{l}\text { Velocidade do } \\
\text { processo }\end{array}$ & $\begin{array}{l}\text { Controle contínuo pelo CNC; } \\
\text { Variação: centenas de } \\
\text { mm.min-1 }\end{array}$ \\
\hline Tipo de gás & Nitrogênio & $\begin{array}{l}\text { Posição focal da } \\
\text { lente }\end{array}$ & Variação de 0 a 10 mm \\
\hline $\begin{array}{l}\text { Distância } \\
\text { Bocal/Peça }\end{array}$ & $\mathrm{wz}=0,6 \mathrm{~mm}$ & Pressão de gás & $\begin{array}{l}\text { Controlado pelas válvulas do } \\
\text { sistema de injeção; } \\
\text { Limite: } 14 \text { bar. }\end{array}$ \\
\hline \multicolumn{4}{|c|}{$\begin{array}{c}\text { Observação.- O significado para sigla wz é working zone que representa a distância entre o boca } \\
\text { e o material }\end{array}$} \\
\hline
\end{tabular}

Precedente à execução do corte das amostras, estabeleceu-se uma seqüência de passos para determinar uma configuração inicial de usinagem.

Na primeira abordagem determinou-se a posição exata do ponto focal sobre a placa de titânio. O método consiste em executar uma seqüência de pulsos únicos sobre o material, variando-se a posição focal da lente. Cada pulso aplicado sobre a superfície gera uma "cratera" e pela observação da sua dimensão geométrica (com a ajuda de um microscópio estereoscópico) é possível estabelecer o ponto de maior 
intensidade. Este ponto define a melhor posição focal sobre a placa de titânio. A Figura 28 ilustra a técnica empregada.

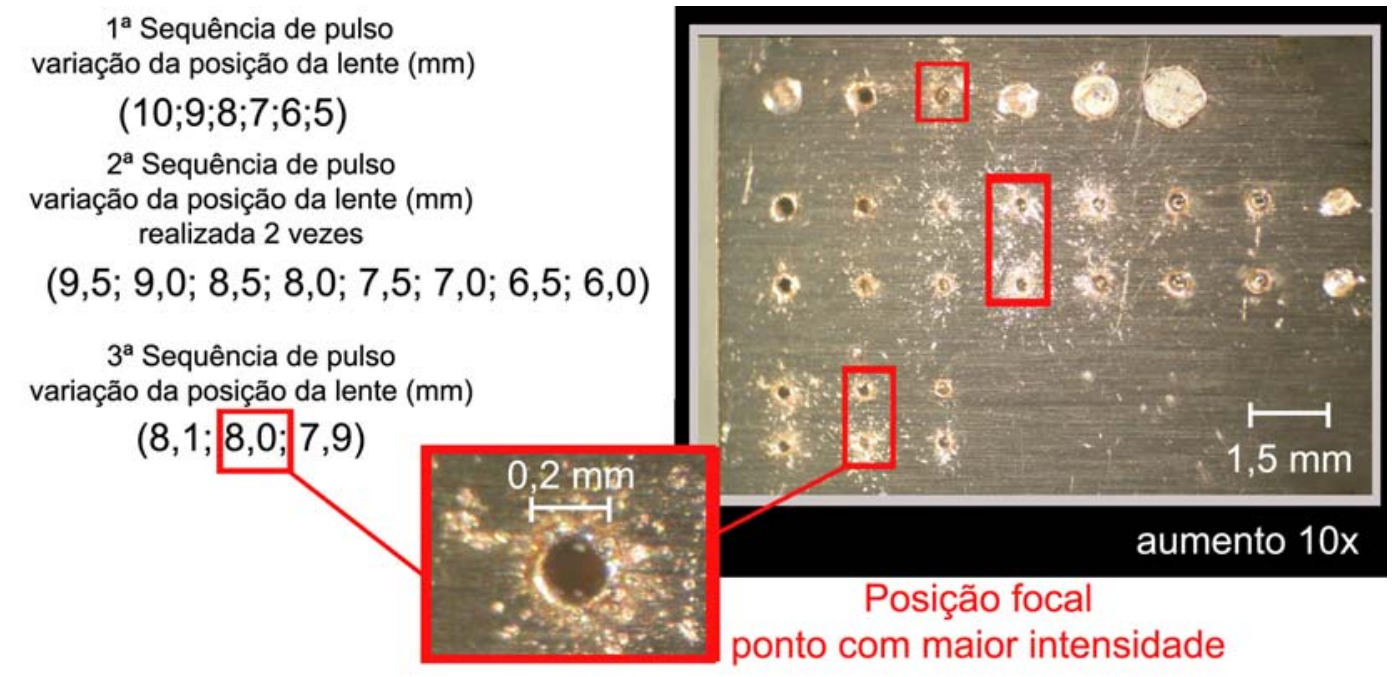

Figura 28 - llustração da técnica para determinar o ponto focal.

Com o ponto focal fixado é necessário determinar uma velocidade máxima de processo em função da taxa de sobreposição desejada para os pulsos laser. Se no corte a laser pulsado a sobreposição destes pulsos ultrapassar a dimensão do diâmetro do feixe (pulsos tangentes), a execução do mesmo é inviabilizada.

A velocidade máxima $\left(\mathrm{v}_{\max } \equiv \mathrm{mm} . \mathrm{s}^{-1}\right)$ pode ser estimada pelo produto entre $\mathrm{o}$ diâmetro do furo $(\varnothing \equiv \mathrm{mm})$ e a freqüência [taxa de repetição dos pulsos ( $f \equiv \mathrm{Hz})$ ], conforme a equação (16).

$$
\mathrm{V}_{\max }=\phi . f
$$

Os parâmetros variáveis selecionados para definir o diâmetro do furo foram a energia por pulso e a taxa de repetição. Assim sendo, escolheu-se a mínima energia por pulso $(E \equiv J)$ capaz de realizar um único furo homogêneo no material. Uma energia menor não seria suficiente para haver a penetração na espessura total da 
chapa, e uma energia maior praticamente não aumentaria o diâmetro do furo, levando a um desperdício de energia.

Com base na energia por pulso determina-se a freqüência ( $f \equiv H z$ ) máxima possível, por meio da equação (17). A potência média $(\mathrm{Pm} \equiv \mathrm{W})$ é mantida constante para a alimentação da lâmpada do laser e é a máxima possível para este sistema. O fato de sempre se conservar a mesma potencia média, garante a estabilidade da lente térmica do elemento laser, evitando-se assim que esta venha influenciar nas características do feixe laser, principalmente na sua divergência, o que poderia modificar o diâmetro e a posição do ponto focal.

$$
P_{m}=E . f
$$

Onde: $P_{m}$ é a potência média real de saída do feixe laser, $(E)$ é a energia contida em cada pulso laser e (f) é a taxa de repetição dos pulsos, ou seja, o número de pulsos laser por segundo.

A duração do pulso [largura temporal do pulso laser (tp $\equiv \mathrm{ms})$ ] e a potência média de alimentação da lâmpada foram fixados em 0,6 ms e 5300 Watts, respectivamente. Nestas condições, a máxima potência média de saída, medida com um detector de potência, foi de 43,2 W. Essa potência foi medida após a lente de focalização, ou seja, após a passagem do feixe por todo o sistema de guiamento deste.

Nota-se também, que para manter esta potência constante, é preciso haver uma relação constante entre a energia e a taxa de repetição para os pulsos laser, conforme a equação (17).

Assim, têm-se duas condições limites para o corte: uma na qual a energia é baixa e a taxa de repetição é alta, e outra que a energia é alta e a taxa de repetição 
é baixa. No primeiro caso, é possível remover uma pequena quantidade de material em cada pulso laser, ou seja, diversos pulsos seriam necessários para a completa penetração da sua espessura total. No segundo caso, a energia de um único pulso pode vazar todo o material e a velocidade máxima seria aquela para a qual os furos ficassem tangentes entre si.

Desta maneira, têm-se as duas condições bastante extremas, e a princípio não se pode dizer qual delas proporcionaria o melhor resultado em relação a qualidade de acabamento e de velocidade de processo.

Nesta investigação preliminar, definiram-se alguns parâmetros iniciais com base no segundo caso descrito acima. Na Tabela 18 podem ser visualizados os valores dos diâmetros de cada furo, obtidos em função da energia do pulso laser, juntamente com a taxa de repetição do laser. Note que, para se garantir a qualidade do corte aplicou-se um fator de $5 \%$ de redução nas velocidades máximas obtidas.

Tabela 18 - Variação dos parâmetros do laser, dimensão dos furos obtidos e $\mathrm{v}_{\max }$ corte.

\begin{tabular}{cccccc}
\hline Condição & $\begin{array}{c}\text { Freqüência } \\
(\mathrm{Hz})\end{array}$ & Energia $(\mathrm{J})$ & $\begin{array}{c}\text { Diâmetro } \\
\text { do furo } \\
(\mathrm{mm})\end{array}$ & $\begin{array}{c}\text { Velocidade } \\
\text { Max. de corte } \\
\left(\mathrm{mm}_{\mathrm{min}} \mathrm{m}^{-1}\right)\end{array}$ & $\begin{array}{c}\text { Velocidade de } \\
\text { corte 5\% menor } \\
\left(\mathrm{mm}_{\mathrm{min}}{ }^{-1}\right)\end{array}$ \\
\hline A & 89 & 0,460 & 0,135 & 720,90 & 684 \\
B & 73 & 0,592 & 0,167 & 731,50 & 700 \\
C & 48 & 0,925 & 0,286 & 823,70 & 782 \\
\hline
\end{tabular}

Para a garantia da qualidade do corte aplicou-se um fator de $5 \%$ de redução nas velocidades máximas obtidas.

Desta forma, a primeira série de amostras foi cortada em três condições diferentes para a análise da superfície de corte em função da formação de rebarbas e da rugosidade. Também, variaram-se as velocidades das três condições e seus valores foram reduzidos em $80 \%, 60 \%$ e $40 \%$ da inicial, proporcionando assim a variação na sobreposição dos pulsos (S) em 5\%, 24\%, 43\% e 62\%, conforme demonstrado na Tabela 19. 
Tabela 19 - Grupo de amostras, suas velocidades e taxa de sobreposição para três condições diferentes de corte.

\begin{tabular}{cccc}
\hline Condição & $\mathrm{N}^{0}$ amostra & Velocidade $\left(\mathrm{mm} \cdot \mathrm{min}^{-1}\right)$ & $\mathrm{S}(\%)$ \\
\hline \multirow{3}{*}{$\mathrm{A}$} & 1 & 684 & 5 \\
& 2 & 548 & 24 \\
& 3 & 410 & 43 \\
& 4 & 274 & 62 \\
$\mathrm{~B}$ & 5 & 700 & 5 \\
& 6 & 560 & 24 \\
& 7 & 420 & 43 \\
$\mathrm{C}$ & 8 & 280 & 62 \\
& 9 & 782 & 5 \\
& 10 & 626 & 24 \\
& 11 & 470 & 43 \\
\end{tabular}

\section{Análise da qualidade superficial do corte}

Para avaliar a qualidade superficial do corte, dois fatores foram escolhidos: a rugosidade e a quantidade de rebarba formada.

\section{Método para avaliação da quantidade de Rebarba}

A quantidade de rebarbas foi obtida pela digitalização da imagem da superfície usinada. Cada imagem da superfície de corte foi capturada digitalmente e tratada graficamente e desta forma extrairam-se as áreas da formação de rebarbas. A Figura 29 ilustra o método gráfico utilizado para a determinação desta área de material não expelido.

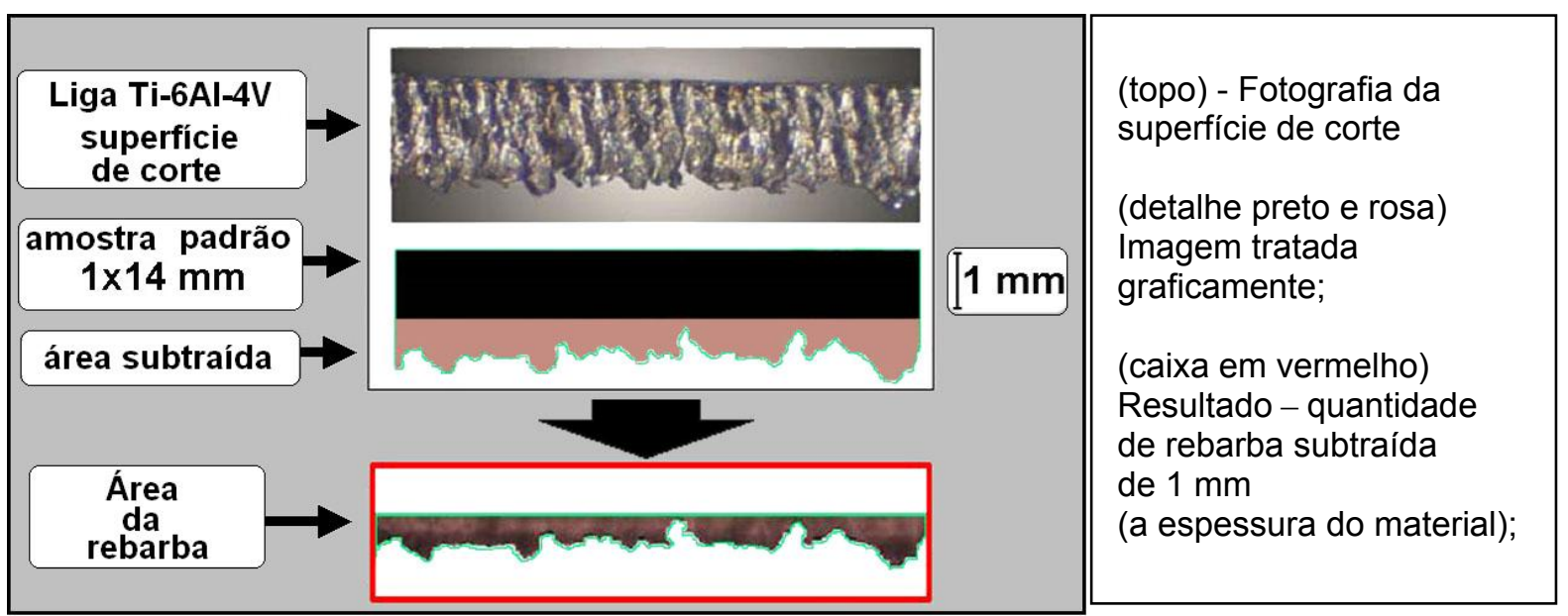

Figura 29 - Metodologia de captura da imagem digital. 
Os valores da área das rebarbas de cada amostra foram adicionados no modelo de análise experimental (ANOVA) para gerar o gráfico dos efeitos de cada parâmetro e suas interações.

Para validar os dados referentes à área da formação de rebarbas e estimar o erro experimental da metodologia de tratamento gráfico das imagens digitalizadas foram executados dois tipos de teste.

No primeiro teste, uma única amostra foi fotografada utilizando-se uma câmera fotográfica digital acoplada a um microscópio estereoscópico marca Nikon, modelo SMZ-2. Em seguida, um único operador processou essa imagem via software (Imageproplus), por três vezes nas mesmas condições e calcularam-se os desvios em função da área resultante. No segundo teste, realizou-se a captura da imagem de três diferentes amostras. Cada imagem foi tratada graficamente no mesmo software, por um único operador e comparou-se cada resultado obtido.

Os valores verificados nos testes estão apresentados na Figura 30 e indicam uma margem de erro experimental de até $10 \%$.

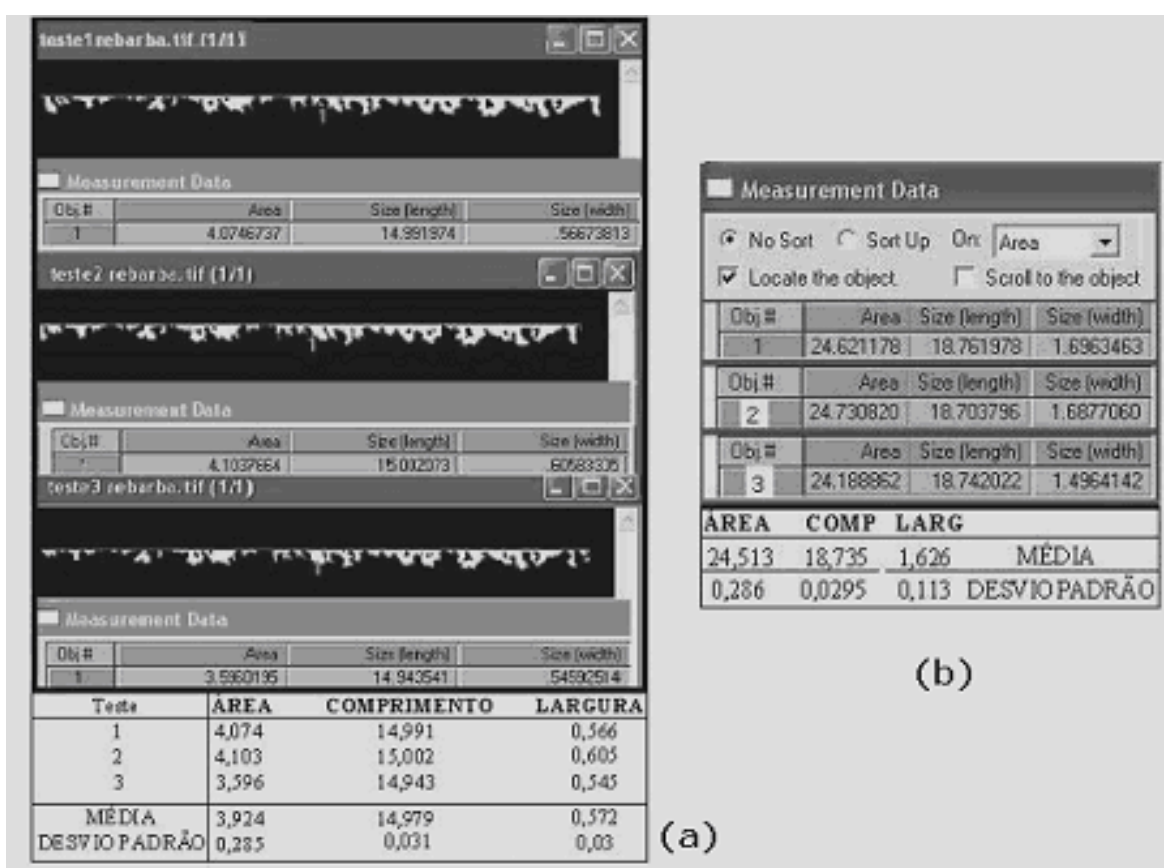

Figura 30 - Dados comparativos entre: (a) imagens de uma única amostra. (b) três amostras distintas A unidade das dimensões em $\mathrm{mm}$. 
A configuração da montagem da câmera fotográfica digital acoplada ao microscópio pode ser observada na Figura 31.

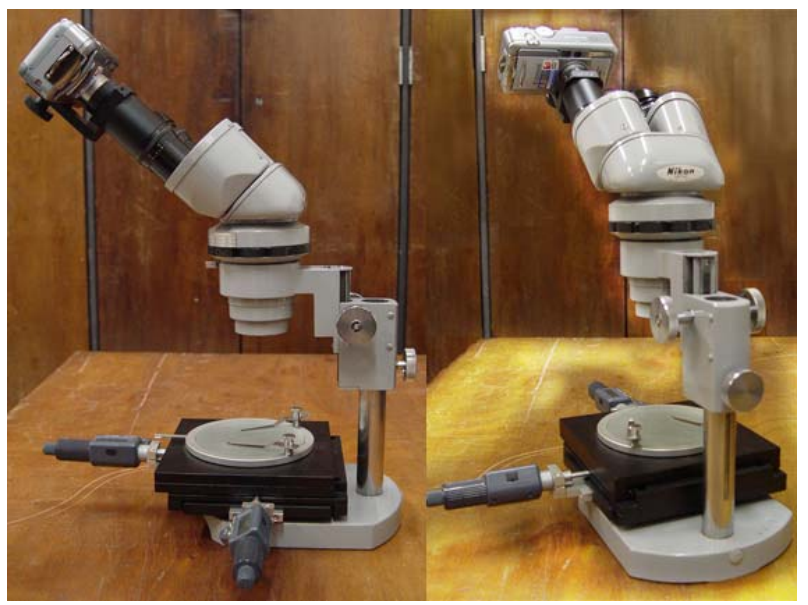

Figura 31 - Foto da configuração do equipamento para capturar a imagem das amostras.

\section{Método para avaliação da rugosidade superficial}

$\mathrm{Na}$ análise de inspeção superficial de cada amostra foram coletadas 3 medidas no sentido longitudinal da superfície de corte sempre com o número de identificação das amostras para frente do operador e adotando os pontos 1, 2 e 3 da esquerda para direita, conforme demonstrados na Figura 32.

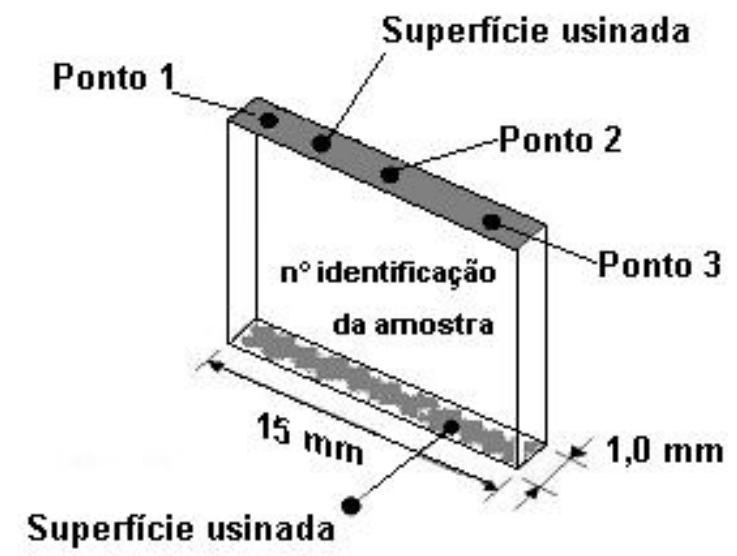

Figura 32 - llustração da análise de inspeção superficial. 
Na Tabela 20 estão relacionados os locais de realização dos ensaios, como também os equipamentos utilizados no levantamento dos dados de rugosidade e da quantidade de formação de rebarbas.

Tabela 20 - Tipo de análise, equipamento e instituição.

\begin{tabular}{|c|c|c|c|}
\hline Análise & Equipamento & $\begin{array}{l}\text { Parâmetros de } \\
\text { análise }\end{array}$ & Instituição \\
\hline \multirow{2}{*}{$\begin{array}{c}\text { Inspeção } \\
\text { superficial } \\
\text { (Rugosidade) }\end{array}$} & $\begin{array}{l}\text { Rugosímetro } \\
\text { Marca: Mitutoyo } \\
\text { Modelo: Surftest } 211\end{array}$ & \multirow{2}{*}{$\begin{array}{l}\text { Cutt-off }-0,8 \mathrm{~mm} \\
\text { Norma DIN } \\
\text { Parâmetros Ra } \\
\text { Raio de ponta }-5 \mu \mathrm{m} \\
\text { Unidade de medida } \mu \mathrm{m}\end{array}$} & $\begin{array}{c}\text { Lab. de Análises } \\
\text { Metrológicas } \\
\text { Centro do Combustível } \\
\text { Nuclear - (CCN) } \\
\text { (IPEN/CNEN) }\end{array}$ \\
\hline & $\begin{array}{l}\text { Rugosímetro } \\
\text { Marca: Taylor /Hobson } \\
\text { Modelo: Surtronic 3P }\end{array}$ & & $\begin{array}{c}\text { LADICON } \\
\text { Centro Tecnológico da } \\
\text { Marinha em São Paulo } \\
\text { (CTMSP) }\end{array}$ \\
\hline \multirow{2}{*}{$\begin{array}{l}\text { Formação } \\
\text { de } \\
\text { rebarbas }\end{array}$} & $\begin{array}{l}\text { Captura da imagem por } \\
\text { câmera fotográfica digita } \\
\text { Marca: Cânon } 4 \text { Mega Pixels } \\
\text { Modelo: Powershot S40 } \\
\text { Acoplado ao microscópio Nikon }\end{array}$ & \multirow[t]{2}{*}{ Aumento $10 x$} & $\begin{array}{c}\text { Central de } \\
\text { Processamento de } \\
\text { Materiais a Laser } \\
\text { (CPML) } \\
\text { Centro de Laser e }\end{array}$ \\
\hline & $\begin{array}{l}\text { Software de tratamento gráfico } \\
\text { ImageProplus versão demo }\end{array}$ & & $\begin{array}{c}\text { Aplicações - (CLA) } \\
\text { (IPEN/CNEN) }\end{array}$ \\
\hline
\end{tabular}

\section{Fase 2 - Processamento da Liga Ti-6Al-4V com diferentes gases.}

A partir da evidência da formação de nitreto de titânio (TiN) na superfície de corte decidiu-se por direcionar a investigação para a aplicação de diferentes gases.

Um novo grupo de amostras foi processado com o uso dos gases argônio, hélio e três misturas destes (em uma combinação proporcional a $75 \% \mathrm{He}-25 \% \mathrm{Ar}, 25 \% \mathrm{He}-$ $75 \%$ Ar e $50 \%$ de cada um). Reproduziu-se o corte dez vezes, para cada tipo de gás.

A identificação utilizada no grupo das amostras e suas condições de usinagem estão apresentadas na Tabela 21. 
Tabela 21 - Processamento da liga Ti-6Al-4V com diferentes gases inertes.

\begin{tabular}{|c|c|c|c|}
\hline Tipo de gás & $\begin{array}{l}\text { Identificação } \\
\text { da amostra }\end{array}$ & $\begin{array}{c}\text { Quantidade } \\
\text { de } \\
\text { amostras }\end{array}$ & $\begin{array}{c}\text { Condições do } \\
\text { Processamento a Laser }\end{array}$ \\
\hline Hélio & 6804- A & 10 & \multirow{6}{*}{$\begin{array}{l}\text { Potência média }-5300 \mathrm{~W} \\
\text { Freqüência }-49 \mathrm{~Hz} \\
\text { Largura temporal }-0,6 \mathrm{~ms} \\
\text { Pressão do Gás }-100 \mathrm{psi}\left(690 \times 10^{3} \mathrm{~Pa}\right) \\
\text { Velocidade de corte }-200 \mathrm{~mm} \cdot \mathrm{min}^{-1} \\
\text { Lente } 100 \mathrm{~mm} \\
\text { Potência de saída no detector }-43,2 \mathrm{~W}\end{array}$} \\
\hline Nitrogênio & 6804- B & 10 & \\
\hline Argônio & 6804- C & 10 & \\
\hline $\begin{array}{l}\text { Argônio } 50 \% \\
\text { Hélio } 50 \%\end{array}$ & 6804- D & 10 & \\
\hline $\begin{array}{c}\text { Argônio } 25 \% \\
\text { Hélio } 75 \%\end{array}$ & 6804- E & 10 & \\
\hline $\begin{array}{l}\text { Argônio } 75 \% \\
\text { Hélio } 25 \%\end{array}$ & $6804-F$ & 10 & \\
\hline
\end{tabular}

\section{Análise Estatística da influência dos parâmetros no processamento a laser.}

Com o objetivo de investigar outros parâmetros envolvidos na usinagem estruturou-se um planejamento fatorial de experimentos (DOE) para assim estabelecer uma otimização do processo. A realização desta análise permitiu avaliar os parâmetros e as interações estatisticamente significantes no processamento a laser pulsado.

A análise fatorial foi fundamentada em um arranjo utilizando-se como fatores os parâmetros do processo a laser, selecionados previamente entre aqueles que conceitualmente provocam os maiores efeitos na usinagem. Assim, os parâmetros de energia por pulso; largura temporal; pressão do gás; velocidade de corte; tipo de lente; posição focal foram dispostos em uma matriz fatorial fracionada $1 / 4$ de 6 fatores a 2 níveis - Resolução: IV com 2 réplicas. A configuração do planejamento fatorial de experimentos e os valores dos fatores podem ser observados na Tabela 22. 
Tabela 22 - Configuração do Projeto fatorial fracionado de 6 fatores.

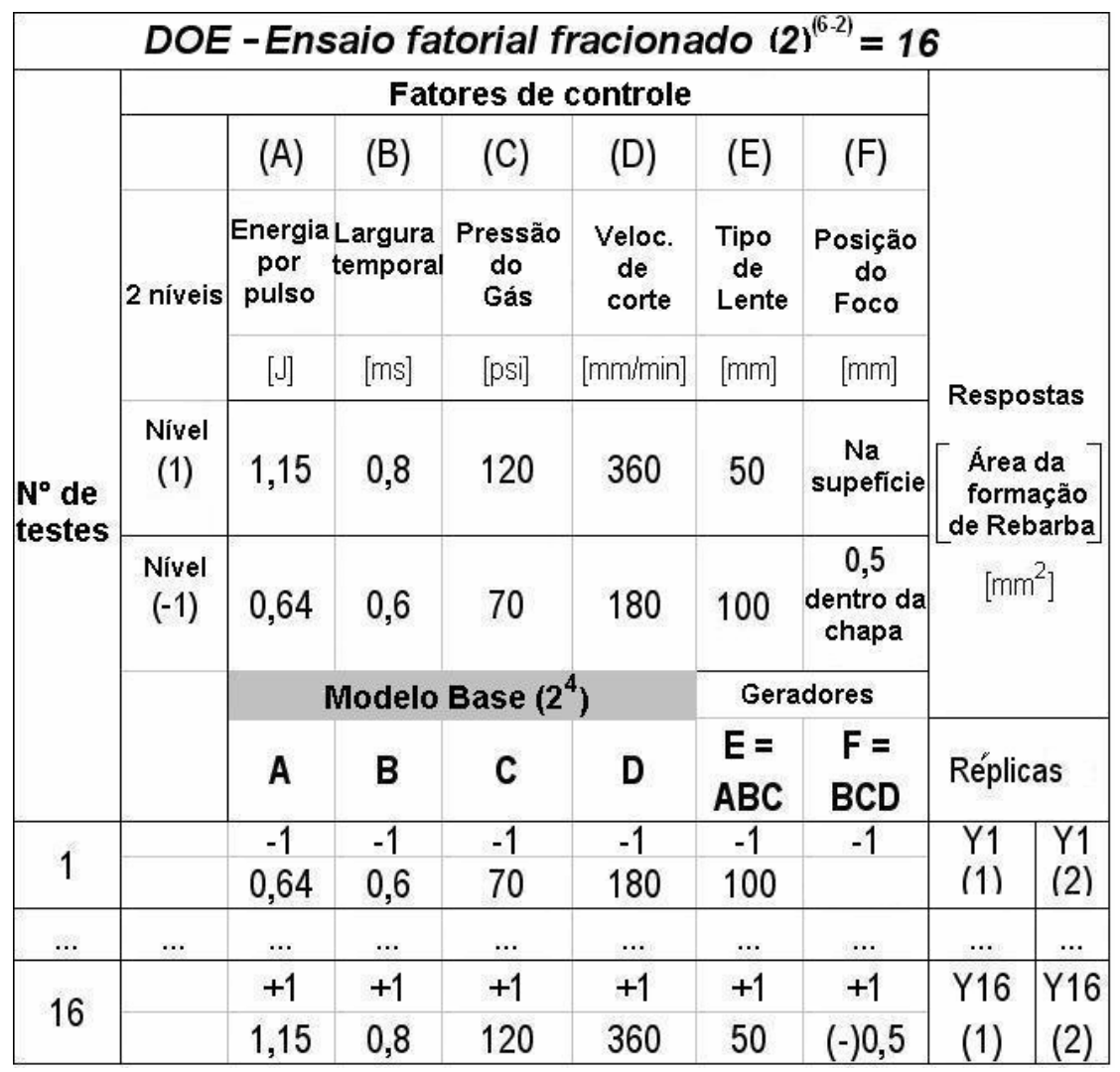

Com o planejamento experimental estabelecido obteve-se um total de 32 amostras, cortadas ao fluxo do gás argônio. A nomenclatura desse conjunto de réplicas foi definida como: CPML - Y(1) a CPML - Y(32).

Empregou-se o software Minitab - 12 versão educacional, uma ferramenta estatística, para auxiliar na estruturação dos gráficos e diagramas de influência das variáveis investigadas. A interpretação dos dados gerados graficamente permitiu confrontar o efeito de cada variável, e assim verificar a viabilidade de otimização do processamento a laser do titânio.

O resultado exeqüível possibilitou a construção de um segundo modelo DOE, combinando somente os fatores mais significativos do arranjo anterior. Com isso constituiu-se uma matriz de 4 fatores a 2 níveis - Resolução: IV com 2 réplicas, conforme indicada na Tabela 23. 
Tabela 23 - Configuração do Projeto fatorial de 4 fatores.

\begin{tabular}{|c|c|c|c|c|c|c|c|}
\hline & \multicolumn{7}{|c|}{ DOE - Ensaio fatorial $(2)^{4}=16$} \\
\hline \multirow{6}{*}{$\begin{array}{l}N^{\circ} \text { de } \\
\text { testes }\end{array}$} & \multicolumn{5}{|c|}{ Fatores de controle } & \multirow{5}{*}{\multicolumn{2}{|c|}{$\begin{array}{l}\text { Respostas } \\
{\left[\begin{array}{c}\text { Área da } \\
\text { formação } \\
\text { de Rebarba }\end{array}\right.}\end{array}$}} \\
\hline & \multirow{3}{*}{2 níveis } & (A) & (B) & (C) & (D) & & \\
\hline & & $\begin{array}{l}\text { Energia } \\
\text { por } \\
\text { pulso }\end{array}$ & $\begin{array}{l}\text { Largura } \\
\text { temporal }\end{array}$ & $\begin{array}{l}\text { Pressão } \\
\text { do } \\
\text { Gás }\end{array}$ & $\begin{array}{c}\text { Veloc. } \\
\text { de } \\
\text { corte }\end{array}$ & & \\
\hline & & {$[\cdot]$} & [ms] & [psi] & [mm/min] & & \\
\hline & $\begin{array}{l}\text { Nivel } \\
\text { (1) }\end{array}$ & 1,2 & 0,9 & 120 & 300 & & \\
\hline & $\begin{array}{c}\text { Nivel } \\
(-1)\end{array}$ & 0,6 & 0,5 & 80 & 180 & {$[\mathrm{mn}$} & \\
\hline & & & Modelo & Base $(2$ & & & \\
\hline & & A & B & C & D & Réplic & \\
\hline 1 & & -1 & -1 & -1 & -1 & $\mathrm{Y1}$ & Y1 \\
\hline 1 & & 0,6 & 0,5 & 80 & 180 & (1) & (2) \\
\hline$\ldots$ & $\ldots$ & $\ldots$ & $\ldots$ & $\ldots$ & $\ldots$ & $\ldots$ & $\ldots$ \\
\hline 10 & & +1 & +1 & +1 & +1 & Y16 & Y16 \\
\hline 10 & & 1,2 & 0,9 & 120 & 300 & (1) & (2) \\
\hline
\end{tabular}

Nesta nova disposição, a lente com comprimento focal de $50 \mathrm{~mm}$, juntamente com a variável da posição focal, na superfície e dentro dela, foram suprimidas. Alterou-se o intervalo das variáveis: velocidade de corte, pressão de gás e largura temporal para ampliar o campo de estudo.

Classificaram-se as réplicas pela identificação: CPML - Z(1) a Z(32).

Obtenção de réplicas por meio de um equipamento laser industrial.

Para comparar possíveis divergências entre os resultados obtidos em laboratório com um outro equipamento industrial, realizou-se o corte de novas réplicas no centro de usinagem a laser da empresa Lasertools ${ }^{122}$. Este equipamento também foi montado pelos pesquisadores do Centro de Lasers e Aplicações do IPEN, numa colaboração entre este instituto e a empresa, com o apoio financeiro da FAPESP. 
Esta nova etapa de testes objetivou validar a técnica, visto que aqui o equipamento industrial empregado, é largamente utilizado em todo o mundo e apresenta características diferentes do feixe laser. Assim, além de se verificar a importância destas diferenças no processo estudado, também poderia o trabalho ser aproveitado em casos reais de produção de corte do titânio.

O laser utilizado foi o modelo KLS 246 da marca LASAG, cuja principal diferença com relação ao laser do IPEN é a sua potência média bem maior de até 80 Watts. Isto pode, por exemplo, possibilitar uma maior taxa de repetição para uma dada energia, o que leva a uma velocidade de processo proporcionalmente maior. Assim, mesmo com uma energia por pulso exatamente igual àquela utilizada com o laser do IPEN, uma velocidade de processo maior pode modificar toda a dinâmica de formação da poça fundida e provocar resultados diferentes, quanto ao acabamento superficial do corte.

Além disso, obviamente, o feixe deve apresentar uma estrutura espacial diferente, pois esta depende de inúmeros fatores construtivos do equipamento, como tipo da cavidade bombeadora, tipo e condições de refrigeração, desenho da lâmpada de bombeamento, entre outros. Por sua vez, esta distribuição espacial da energia do pulso laser, também pode influenciar na dinâmica de formação da poça líquida e resultar em um outro acabamento da superfície.

Apesar da semelhança entre os dois lasers, as pequenas diferenças construtivas de cada equipamento podem influenciar decisivamente em algumas características do feixe laser e consequentemente vir a alterar a qualidade do resultado de um determinado processo. Por este motivo, foi decidido acrescentar mais esta etapa neste trabalho. 
O vínculo de cooperação com a empresa Lasertools favoreceu a realização dos testes, que foram aplicados com a mesma metodologia do planejamento de experimentos de 4 fatores. Esta análise propiciou assim estimar relações entre os testes laboratoriais com os resultados obtidos em uma máquina com características e confiabilidade comercial.

Os dados referentes ao equipamento e suas características estão demonstrados na Figura 33.
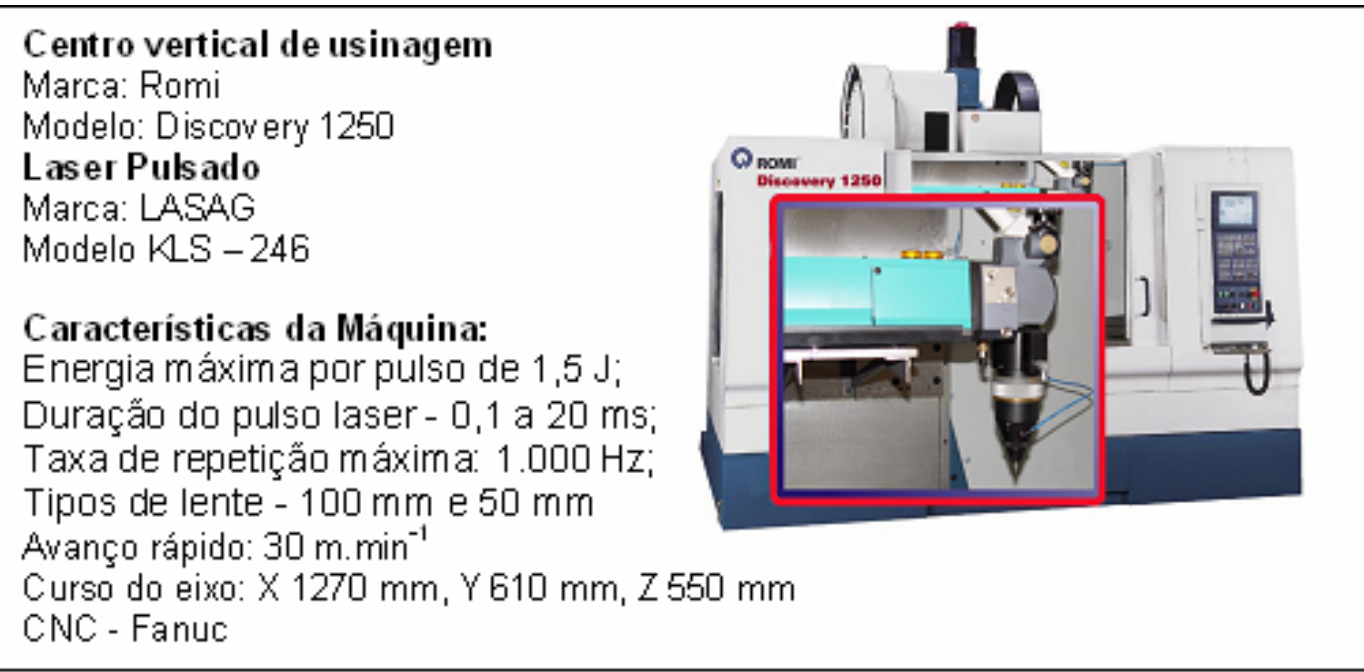

Figura 33 - Centro de usinagem industrial.

\section{Metalografia do Titânio}

O exame metalográfico proporciona o embasamento para a análise e descrição da microestrutura dos metais. Portanto, este ensaio é importante e deve ser cuidadosamente realizado, especialmente para o titânio e suas ligas ${ }^{123,124,125}$.

Durante a preparação, as amostras metalográficas deste material são suscetíveis à deformação mecânica e térmica. O superaquecimento das superfícies, pelo lixamento e polimento distorce completamente as microestruturas, prejudicando a correta identificação das fases. 
Neste trabalho, as áreas de corte, analisadas por microscopia ótica e pelo microscópio eletrônico de varredura (MEV), foram levemente lixadas e polidas para preservar as camadas termicamente afetadas e ressolidificadas com possível incorporação de elementos da atmosfera.

Lixamento - Para planificar a superfície e remover as irregularidades, utilizou-se lixa de grana 600 e 1000, por um período de 10 e 30 segundos, respectivamente. A operação foi refrigerada com fluxo constante de água.

Polimento Mecânico - Obteve-se resultado satisfatório ao dividir o polimento em duas etapas. No intermediário empregou-se como abrasivo pasta de diamante de $3 \mu \mathrm{m}$ por 5 minutos, com velocidade do disco de $250 \mathrm{rpm}$ e média pressão. No polimento final aplicou-se sílica coloidal com base aquosa por 10 minutos, com velocidade do disco 250 rpm e média pressão.

Ambos processos foram executados no Laboratório de Metalurgia do Pó localizado no Centro de Ciências e Tecnologia de Materiais (CCTM) do IPEN, em uma politriz motorizada marca Fortel, modelo PFL.

Montagem da amostra - Para facilitar a observação microscópica e a aplicação do ensaio de dureza, os materiais foram embutidos em baquelite ou resina poliéster (cura a frio) em moldes plásticos com 30 mm de diâmetro.

Ataque químico - O procedimento usado para revelar as estruturas consistiuse em imergir a superfície no reagente Kroll ${ }^{126,127,128}$, que contém $2 \%$ de $\mathrm{HF}, 10 \%$ de $\mathrm{HNO}_{3}$ e $88 \%$ de $\mathrm{H}_{2} \mathrm{O}$, por 40 segundos. As amostras do titânio comercialmente puro passaram pelo ataque de uma variante do reagente Weck ${ }^{129}$ composto de $3 \mathrm{~g}$ de bifluoreto de amônia (NH4F-HF), 4 ml de ácido hidroclorídrico (HCl-25\%) e $100 \mathrm{ml}$ 
de água destilada. No laboratório do grupo Lasers e Aplicações, divisão de fotônica (EFO) do Instituto de Estudos Avançados (IEAv/CTA), o titânio c.p. foi submetido a este reagente, que gera uma revelação colorida da estrutura do material, facilitando a identificação das fases.

\section{Ensaio de Microdureza}

As técnicas de caracterização mecânica, como o ensaio de dureza, auxiliam na análise das propriedades dos materiais. A dureza permite comparar superfícies conforme sua resistência à deformação permanente ou plástica localizada, como também, serve de indicativo para identificação microestrutural.

Um dos métodos utilizados para determiná-la é o teste de dureza Vickers, desenvolvido por Smith e Sandland, em 1925. O ensaio é baseado na relação entre a impressão gerada por um penetrador e a carga aplicada sobre o material.

Neste trabalho, algumas das amostras processadas a laser foram submetidas ao ensaio de microdureza convencional e dinâmico, realizado no Laboratório de Fenômenos de Superfície (LFS) do Departamento de Engenharia Mecânica da Escola Politécnica da Universidade de São Paulo.

Na Tabela 24 estão identificadas as amostras selecionadas para cada tipo de ensaio, o equipamento utilizado e as condições do teste.

Tabela 24 - Condições dos Ensaios de microdureza.

\begin{tabular}{|c|c|c|c|}
\hline Amostras & $\begin{array}{c}\text { Tipo de ensaio } \\
\text { de dureza }\end{array}$ & Equipamento & Condições \\
\hline $\begin{array}{c}\text { Ticp,Ti64 laser } \\
\text { e } \\
\text { Série } 6804\end{array}$ & convencional & $\begin{array}{c}\text { Microdurômetro } \\
\text { Marca: Buehler } \\
\text { Modelo: Micromet } 2100\end{array}$ & Carga: $980,7 \mathrm{mN}$ \\
\hline $\begin{array}{c}\text { Somente duas: } \\
\text { 6804- C } \\
\text { e } \\
\text { CPML - Y(30) }\end{array}$ & instrumentada & $\begin{array}{c}\text { Microdurômetro } \\
\text { Marca: Fischer } \\
\text { Modelo: } \\
\text { FischerscopeHV100 }\end{array}$ & $\begin{array}{c}\text { Carga de } 200 \mathrm{mN} \\
\text { Aplicação da carga máx: } \\
\text { em } 60 \text { passos com intervalo de } 0,1 \mathrm{~s} \\
\text { Manutenção da carga máx: } 10 \mathrm{~s} ; \\
\text { Remoção da carga: } \\
\text { em } 100 \text { passos com intervalo } 0,1 \mathrm{~s}\end{array}$ \\
\hline
\end{tabular}


A relação das amostras submetidas ao ensaio de microdureza dinâmico, assim como a descrição do modo em que o ensaios foram configurados, podem ser visualizados na Tabela 25.

Tabela 25 - Relação das amostras submetidas ao ensaio de microdureza dinâmico.

\begin{tabular}{|c|c|c|c|c|c|c|}
\hline Amostra & Descrição & $\begin{array}{c}\text { Face } \\
\text { analisada }\end{array}$ & \begin{tabular}{|c|}
$N^{\circ}$ \\
do \\
ensaio
\end{tabular} & $\begin{array}{c}\mathrm{N}^{0} \text { de } \\
\text { indentação }\end{array}$ & $\begin{array}{l}\text { Posição relativa } \\
\text { na superfície }\end{array}$ & nomenclatura \\
\hline \multirow{5}{*}{$\begin{array}{l}\text { CPML } \\
\text { Y(30) }\end{array}$} & \multirow{5}{*}{$\begin{array}{c}\text { Dimensão } \\
\text { 10x15 mm; } \\
\text { Usinada } \\
\text { a laser } \\
\text { com gás } \\
\text { argônio. } \\
\\
\text { Relativa } \\
\text { à menor } \\
\text { rebarba no } \\
\text { DOE } \\
6 \text { fatores } \\
\text { (CPML) }\end{array}$} & \multirow{5}{*}{$\begin{array}{l}\text { Corte } \\
\text { transversal }\end{array}$} & $1^{\circ}$ & 6 & $\begin{array}{c}\text { Extremidade (borda) } \\
\text { Região clara zona } \\
\text { fundida }\end{array}$ & $\mathrm{CY}$ \\
\hline & & & $2^{\circ}$ & 5 & $\begin{array}{c}\text { Partindo da borda em } \\
\text { direção ao material } \\
\text { base (centro) }\end{array}$ & CY perfil \\
\hline & & & $3^{\circ}$ & 6 & $\begin{array}{c}\text { Na região limite entre } \\
\text { a zona fundida (clara) } \\
\text { e o material base } \\
\text { na (ZTA) }\end{array}$ & $\begin{array}{l}\text { CY perfil } \\
\text { sub }\end{array}$ \\
\hline & & & $4^{\circ}$ & 10 & $\begin{array}{c}\text { Somente na região do } \\
\text { material base }\end{array}$ & CYMB \\
\hline & & & $5^{\circ}$ & 29 & $\begin{array}{c}\text { Repetição do } \\
4^{\circ} \text { ensaio com maior } \\
n^{\circ} \text { de pontos }\end{array}$ & CYMB REP \\
\hline \multirow{3}{*}{ 6804- C } & \multirow{3}{*}{$\begin{array}{c}\text { Dimensão } \\
\text { 10x15 mm; } \\
\text { Usinada } \\
\text { a laser } \\
\text { com gás } \\
\text { argônio } \\
\text { 100\% }\end{array}$} & \multirow{3}{*}{$\begin{array}{l}\text { Área da } \\
\text { superfície de } \\
\text { corte }\end{array}$} & $1^{\circ}$ & 13 & $\begin{array}{l}\text { Na região limite entre } \\
\text { a zona fundida (clara) } \\
\quad \text { e os vales } \\
\text { (partes não afetadas } \\
\text { pelo lixamento) }\end{array}$ & CAR \\
\hline & & & $2^{\circ}$ & 7 & $\begin{array}{c}\text { Na região abaixo da } \\
\text { zona fundida (clara) } \\
\text { em direção ao } \\
\text { material base } \\
\text { (meio da amostra) }\end{array}$ & CAR1 \\
\hline & & & $3^{\circ}$ & 7 & $\begin{array}{l}\text { Partindo da borda } \\
\text { zona fundida em } \\
\text { direção do material } \\
\text { base (centro) }\end{array}$ & CAR2 \\
\hline
\end{tabular}

Os pontos de micro-indentação foram distribuídos de modo a abranger uma heterogeneidade das amostras e assim propiciar comparações entre as diferentes regiões. O arranjo de aplicação das indentações está representado na Figura 34. 

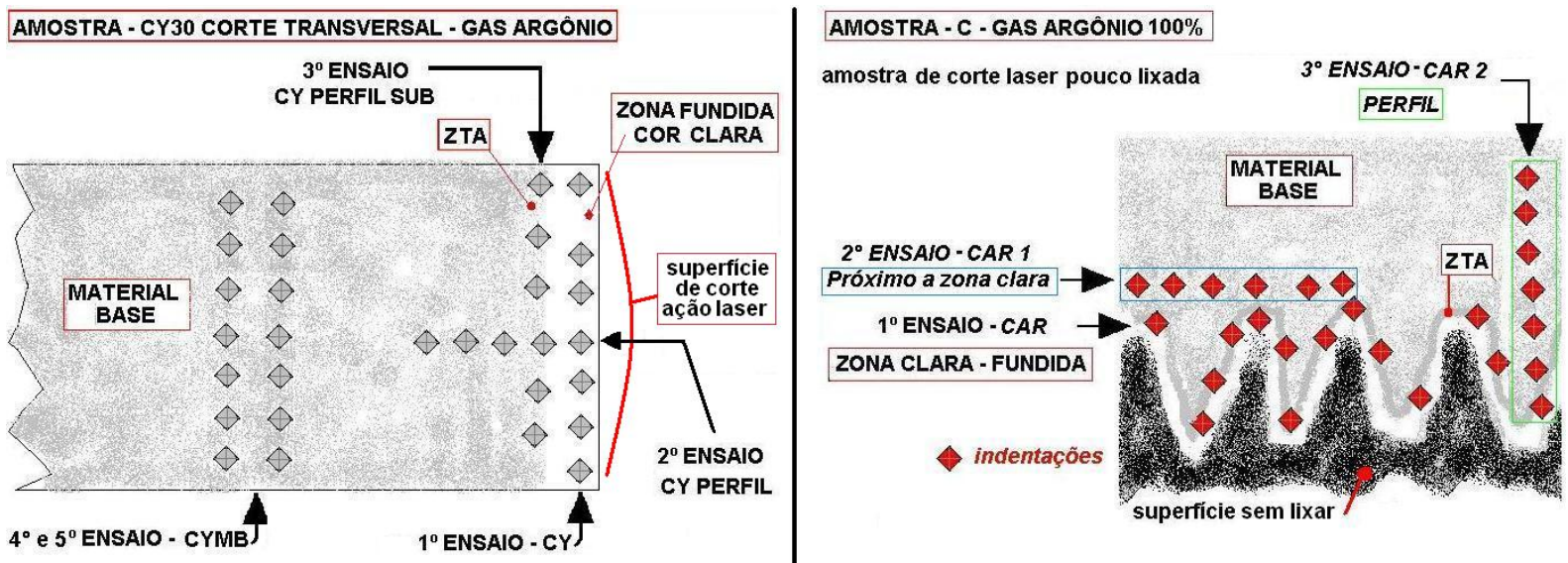

Figura 34 - llustração dos pontos de indentação do ensaio de microdureza dinâmica. Vista transversal da região de corte (esquerda); vista de topo da superfície de corte (direita) com lixamento parcial.

A finalidade da análise de microdureza dinâmica (instrumentada) foi comparar os efeitos entre as diferentes configurações de processamento. Aplicou-se a metodologia de Oliver \& Pharr ${ }^{130}$, conforme ISO/FDIS $14577-1$ de 2002 que calcula por meio das curvas de regressão os valores de dureza e módulo de elasticidade, conforme indicado na Figura 35.

|Carga

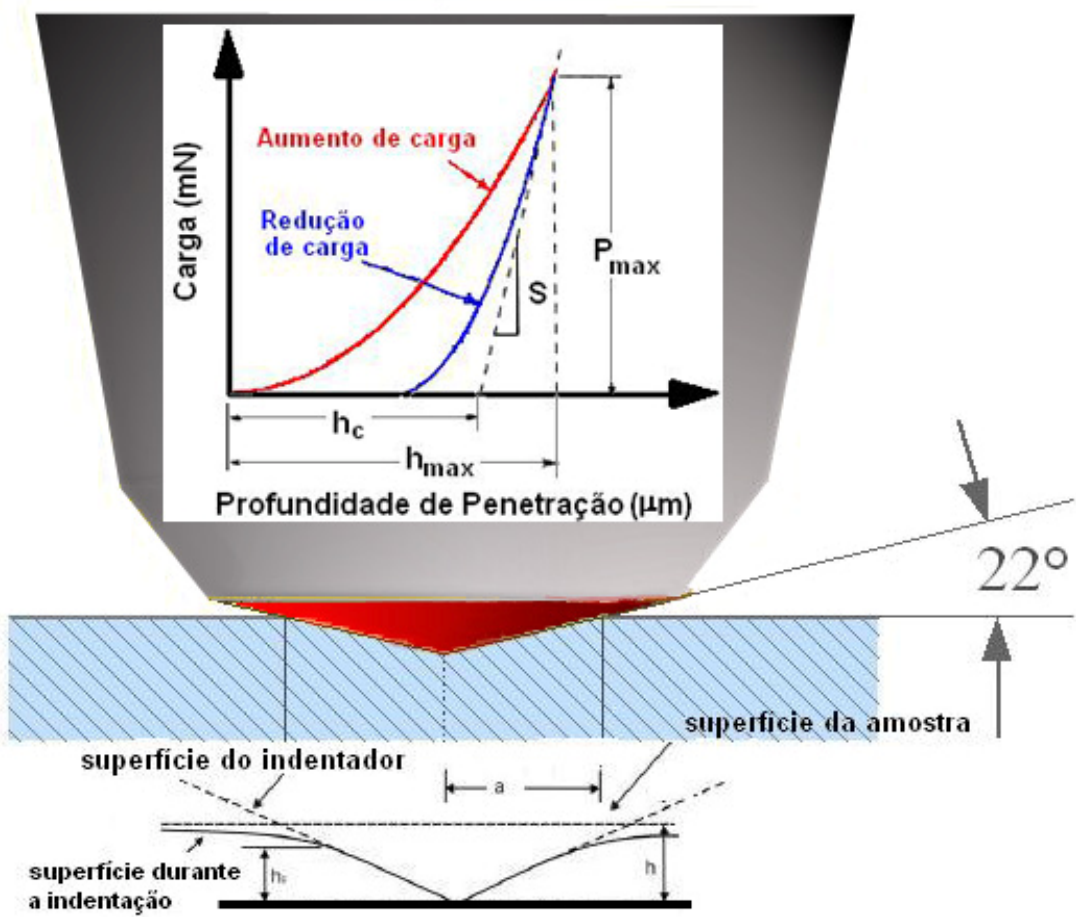

Figura 35 - Esquema ilustrativo do gráfico da carga pela profundidade de penetração em um ensaio de microdureza dinâmica. 


\section{Microscopia Ótica e Microscopia Eletrônica de Varredura (MEV)}

Os instrumentos de microscopia ótica e eletrônica de varredura, empregados na observação dos materiais processados, auxiliaram na identificação das fases, como também, na caracterização das microestruturas obtidas.

A visualização das micrografias permitiu diferenciar as diversas superfícies de corte usinadas com diferentes gases e investigar as seguintes características: a formação de precipitados de nitrogênio, a transformação martensítica com uso do argônio, a profundidade da zona termicamente afetada (ZTA) e da zona de material ressolidificado, as diferenças do acabamento superficial, assim como quantificar a formação de rebarbas.

Os equipamentos usados foram um microscópio ótico da marca Olympus, modelo BX60MF5 e um microscópio eletrônico de varredura (MEV) da marca Philips, modelo XL30 do CCTM - Centro de Ciências e Tecnologia dos Materiais do IPEN.

\section{Análise por Difração de raios-X}

A análise por difração de raios-X foi de grande importância na comparação entre as diversas configurações de processamento, e contribuiu para verificar a formação de nitretos de titânio nas amostras cortadas a laser com nitrogênio.

Realizou-se a análise de varredura simples por meio do difratômetro de raiosX, marca Philips, modelo MPD1880 com tubo de cobre no Laboratório de Caracterização Tecnológica (LCT - EPUSP), conforme visto na Figura 36

As condições aplicadas foram: tensão de $40 \mathrm{kV}$, corrente $40 \mathrm{~mA}$, faixa de observação $20^{\circ} \leq 2 \theta \leq 120^{\circ}$ e alvo de Cu-Ka que fornece-se raios-X com comprimento de onda $\lambda=1,5406 \AA$. 


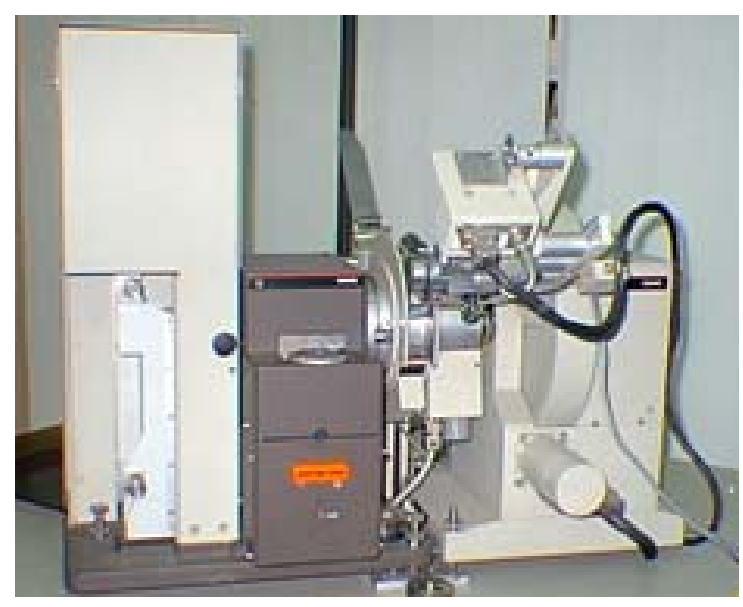

Figura 36 - Difratômetro de raios-X, marca Philips, modelo MPD1880 utilizado neste trabalho. 


\section{RESULTADOS E DISCUSSÃO}

Conforme abordado em outros capítulos, o processamento a laser é basicamente um processo termomecânico, no qual um feixe de luz focalizado e pontual atua como fonte de aquecimento, ao mesmo tempo em que um fluxo de gás exerce forças mecânicas expelindo o material fundido para fora do canal de corte.

A definição anterior é uma forma simplista de abordar o tema, pois na realidade o resultado final do corte com laser pulsado está associado à ocorrência de inúmeros fenômenos físicos, que se alteram em virtude das diferentes combinações dos parâmetros de processamento.

Devido a essa complexidade, várias abordagens podem ser pesquisadas, o que implicaria na geração de uma enorme soma de resultados. Para delimitar uma região menor, procurou-se direcionar as investigações gradativamente em decorrência de cada configuração aplicada, para assim delinear uma otimização do processo. Os resultados estão apresentados em conseqüência das alterações e adequações das variáveis de estudo no transcurso das fases do trabalho.

Inicialmente, a usinagem do titânio pela aplicação do laser em conjunto com gás nitrogênio propiciou a formação de nitretos de titânio (TiN), presente em uma fina camada na zona de ressolidificação ${ }^{131}$.

Para verificar a transferência de nitrogênio para o volume do material, realizouse uma série de análises por microscopia ótica, ensaios de dureza e difração de raios-X. Na micrografia ótica da superfície usinada do Ti c.p., indicada na Figura 37, observa-se à formação de precipitados (pontos escuros) dispersos na zona ressolidificada (parte clara da micrografia). 


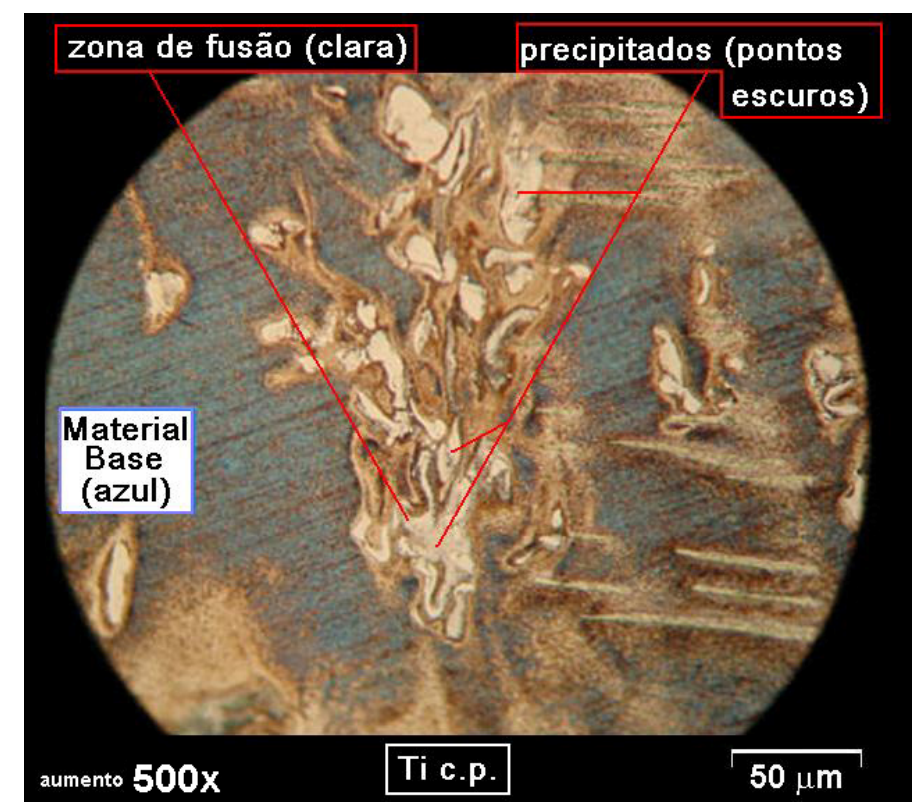

Figura 37 - Micrografia ótica da superfície de corte doTi c.p (ataque com reagente weck).Nota-se a presença de precipitados de nitrogênio (pontos escuros) na região de fusão (área clara).

$\mathrm{Na}$ liga Ti-6Al-4V, processada a laser com nitrogênio e mesma configuração de usinagem, também se nota a presença de nitreto de titânio. Próximo da borda de corte, onde o laser incide sobre o material, percebe-se que o pulso promove a fusão do metal e permite a penetração do nitrogênio, conforme apresentada na Figura 38.

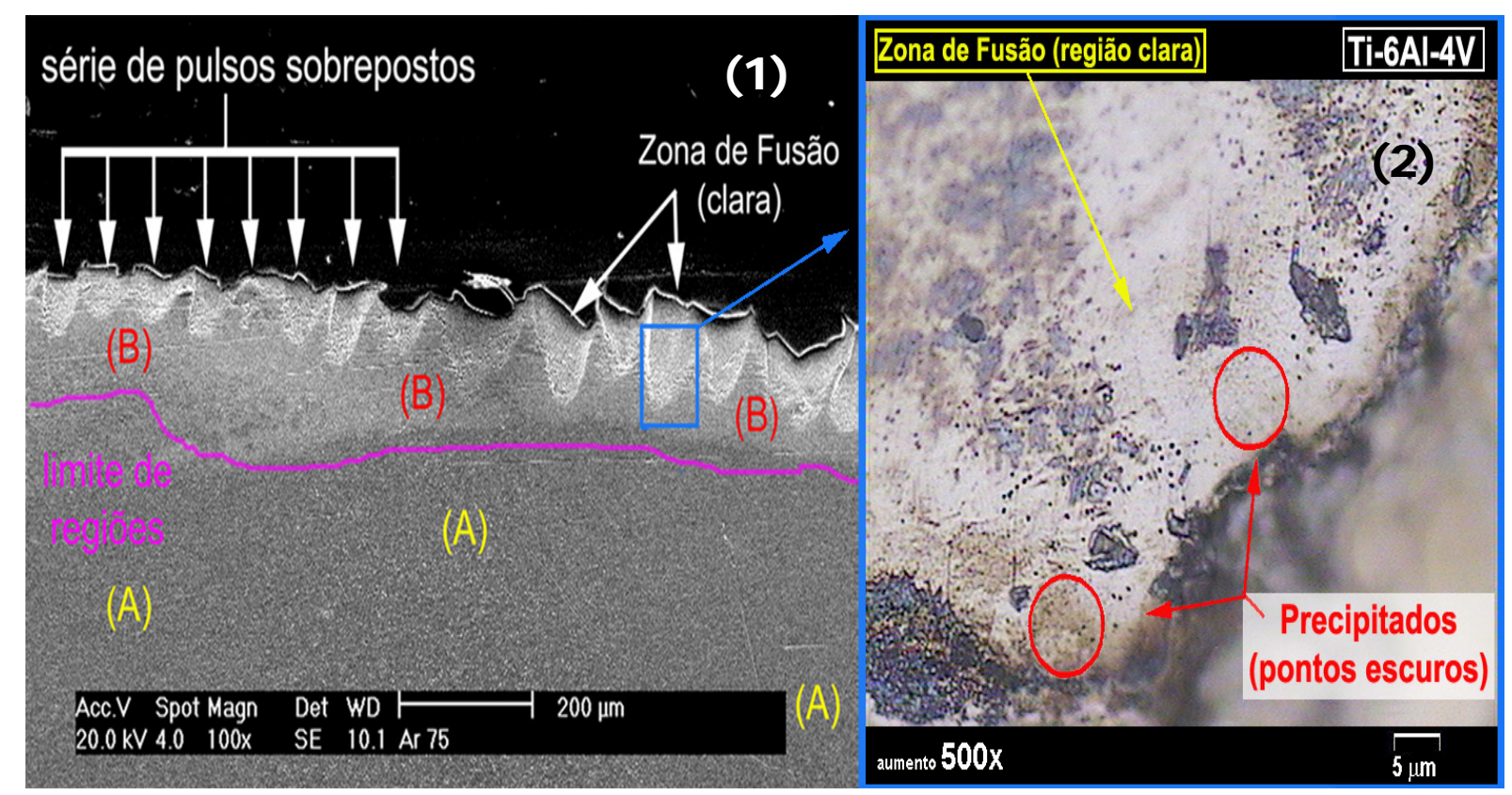

Figura 38 - (1) MEV da superfície de corte com pulsos aparentes. Região marcada com (A) é material base, com (B) zona termicamente afetada. (2) Detalhe da superfície de corte, observa-se precipitados de nitrogênio (pontos escuros) na região de fusão (área clara). 
Eventualmente, a dispersão das partículas de nitreto de titânio em $\alpha$-Ti propicia a formação de finas dendritas ${ }^{132}$. Na Figura 39 , nota-se um indício desta formação na zona de fusão da superfície de corte do Ti c.p. (grau 2).

Nas condições normais de corte, a taxa típica de resfriamento do processamento a laser está em torno de centenas a milhares de graus por segundo, o que caracteriza uma alta taxa de variação. Com este resfriamento rápido, usualmente de forma irregular e abrupta, espera-se uma grande alteração da microestrutura da zona fundida e a possibilidade da formação de dendritas de TiN e alfa -Ti rico em nitrogênio.

Os veios escuros nas zonas ressolidificadas, verificados na Figura 40, podem ser um indicativo da penetração do nitrogênio. $O$ aquecimento sobre o titânio provocado pela ação do laser gera um gradiente térmico, contendo regiões onde há fusão do material. Este material base na forma líquida apresenta diferentes tensões superficiais que propiciam a transferência de massa pelas correntes formadas no seio do fluido.

Assim a penetração do nitrogênio pode ocorrer e resultar na alteração da matriz Ti. Além da difusão do nitrogênio, existe a chance da formação de nitretos pela reação exotérmica com o titânio.

Conforme o diagrama binário de fases, visto anteriormente, a variação da temperatura do material matriz fundido em relação ao ponto de fusão do TiN influencia nas condições de dissociação da fase TiN, Nesta situação, a viscosidade da poça líquida e a morfologia da superfície podem ser alteradas ${ }^{133}$.

Baseado nas evidências de alta taxa de resfriamento, na concentração de dentritas e na presença de precipitados, conduziu-se o ensaio de dureza, para investigar um possível endurecimento na zona de corte. 


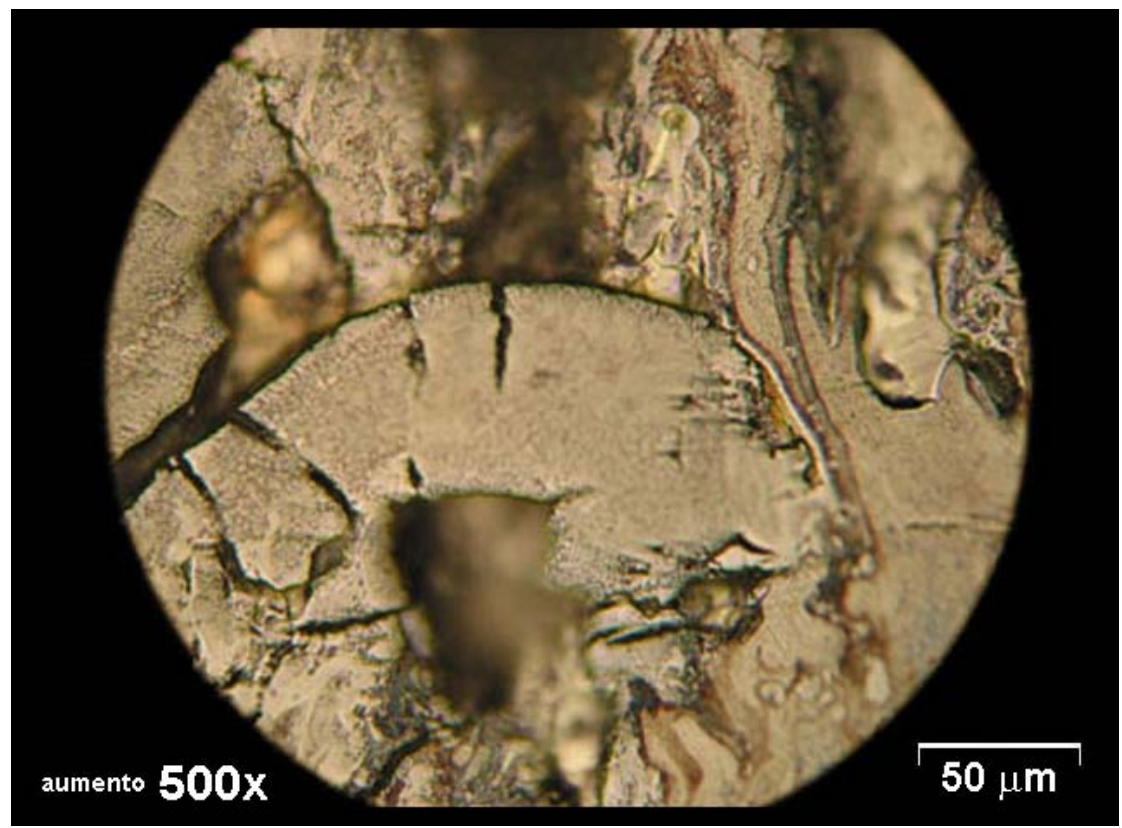

Figura 39 - Micrografia ótica da superfície de corte da liga Ti c.p. (grau 2) usinada a laser com gás nitrogênio. Zona de fusão e dendritas. (amostra Ticp_laser).

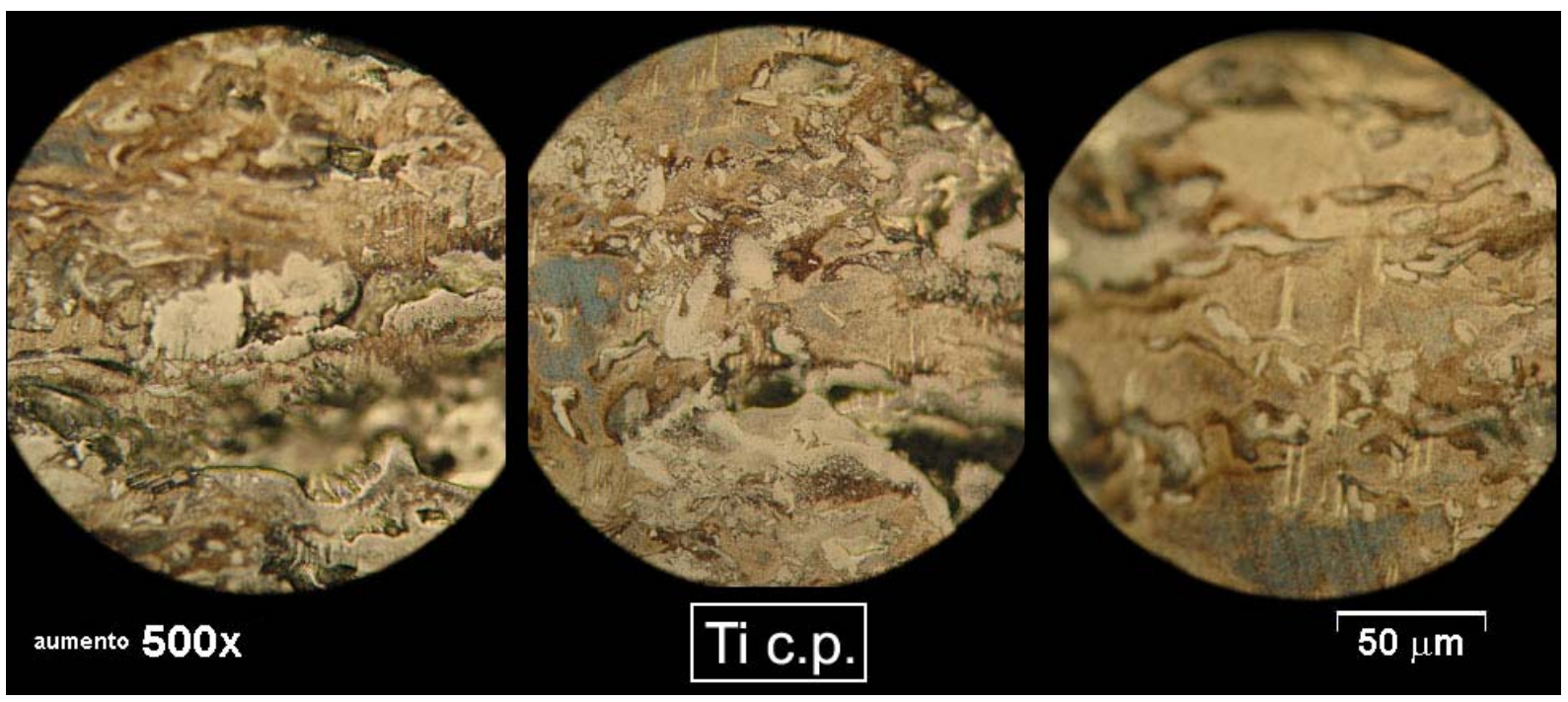

Figura 40 - Detalhe da superfície de corte da liga Ti c.p. (grau 2) usinada a laser com gás nitrogênio. Três micrografias da zona de fusão.

Com o ensaio convencional de microdureza Vickers comparou-se os valores da superfície de corte com os do material base. Um significativo aumento de dureza foi verificado na superfície ressolidificada. De acordo com os resultados obtidos, observou-se na superfície usinada do Ti c.p., um acréscimo de aproximadamente duas vezes do valor médio da chapa laminada e um valor três vezes maior para a superfície ressolidificada na liga Ti-6Al-4V (Grau 5) ${ }^{134}$. Estes valores estão apresentados da figura 41 a figura 44 . 

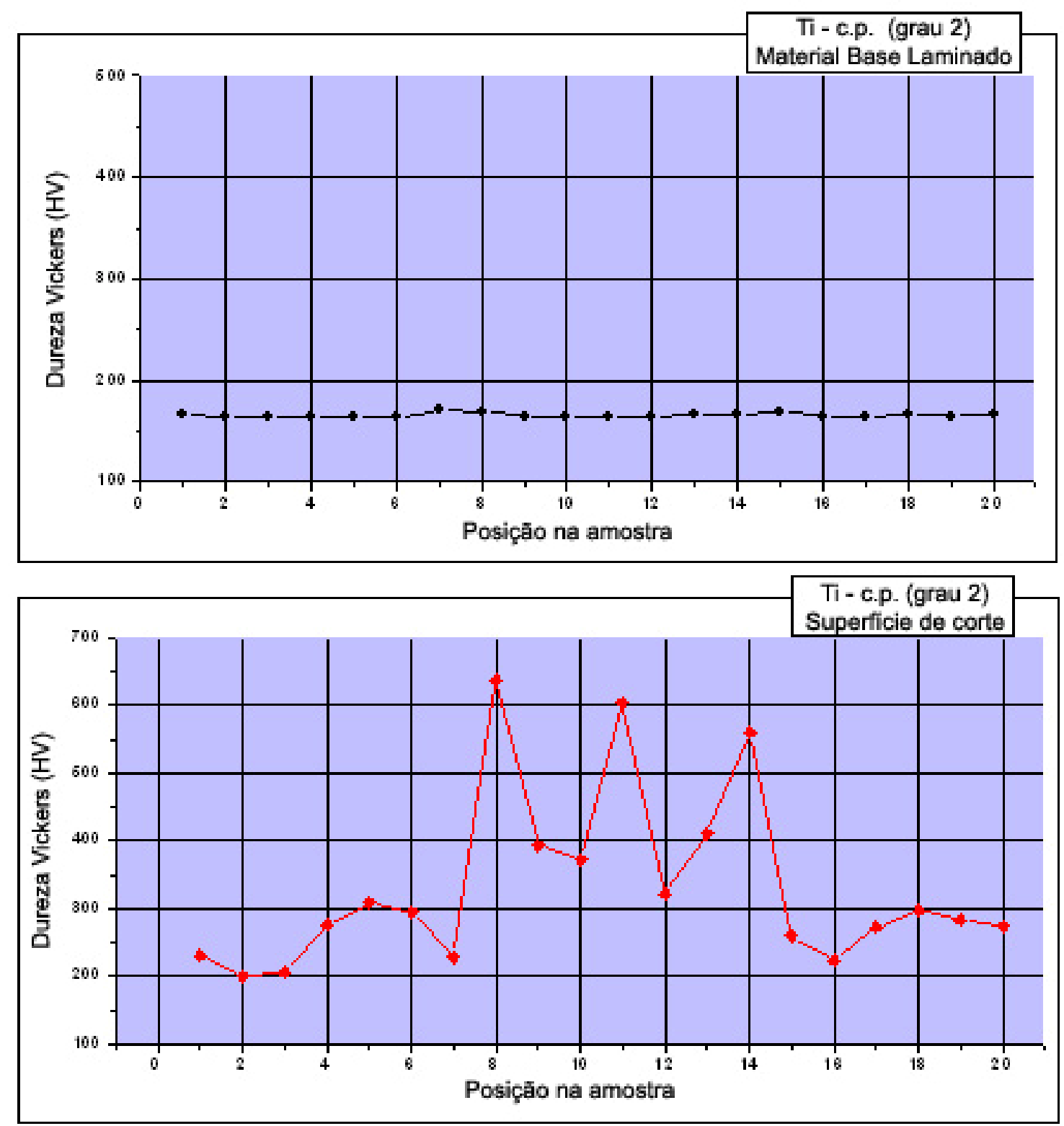

Figura 41 - Ensaio de microdureza convencional - comparação entre os valores de dureza do material base laminado e superfície usinada a laser do Titânio puro (grau 2).

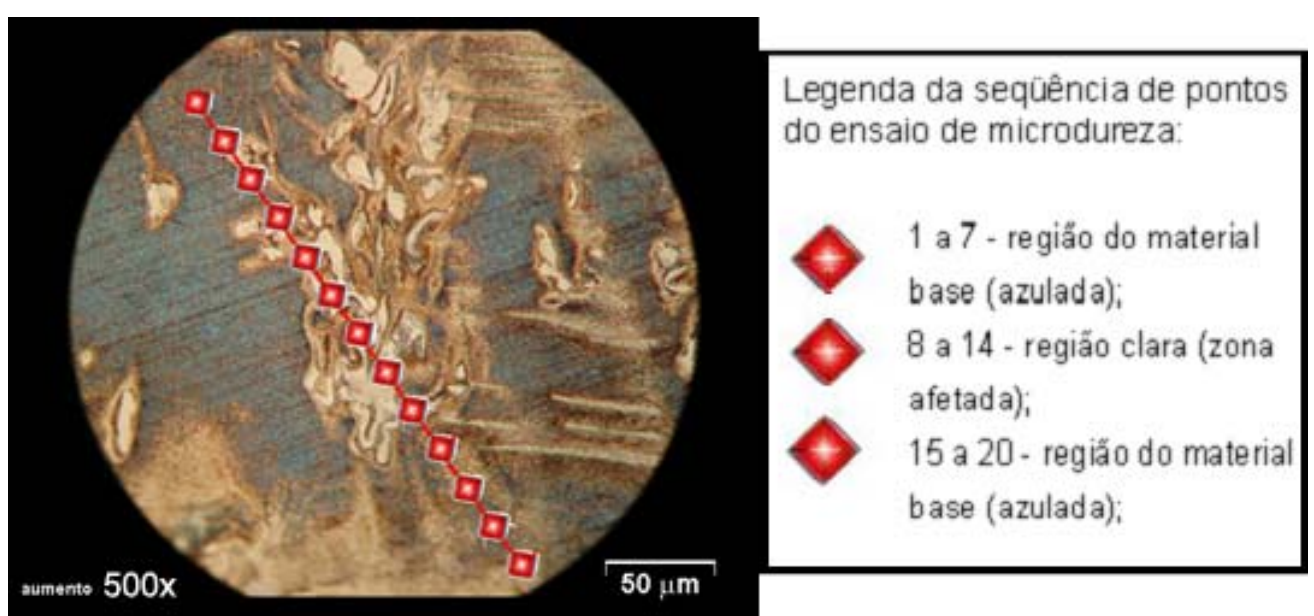

Figura 42 - llustração da seqüência de pontos realizados na superfície de corte do Ti-cp (grau 2) usinada a laser com gás nitrogênio (amostra Ticp_laser). 

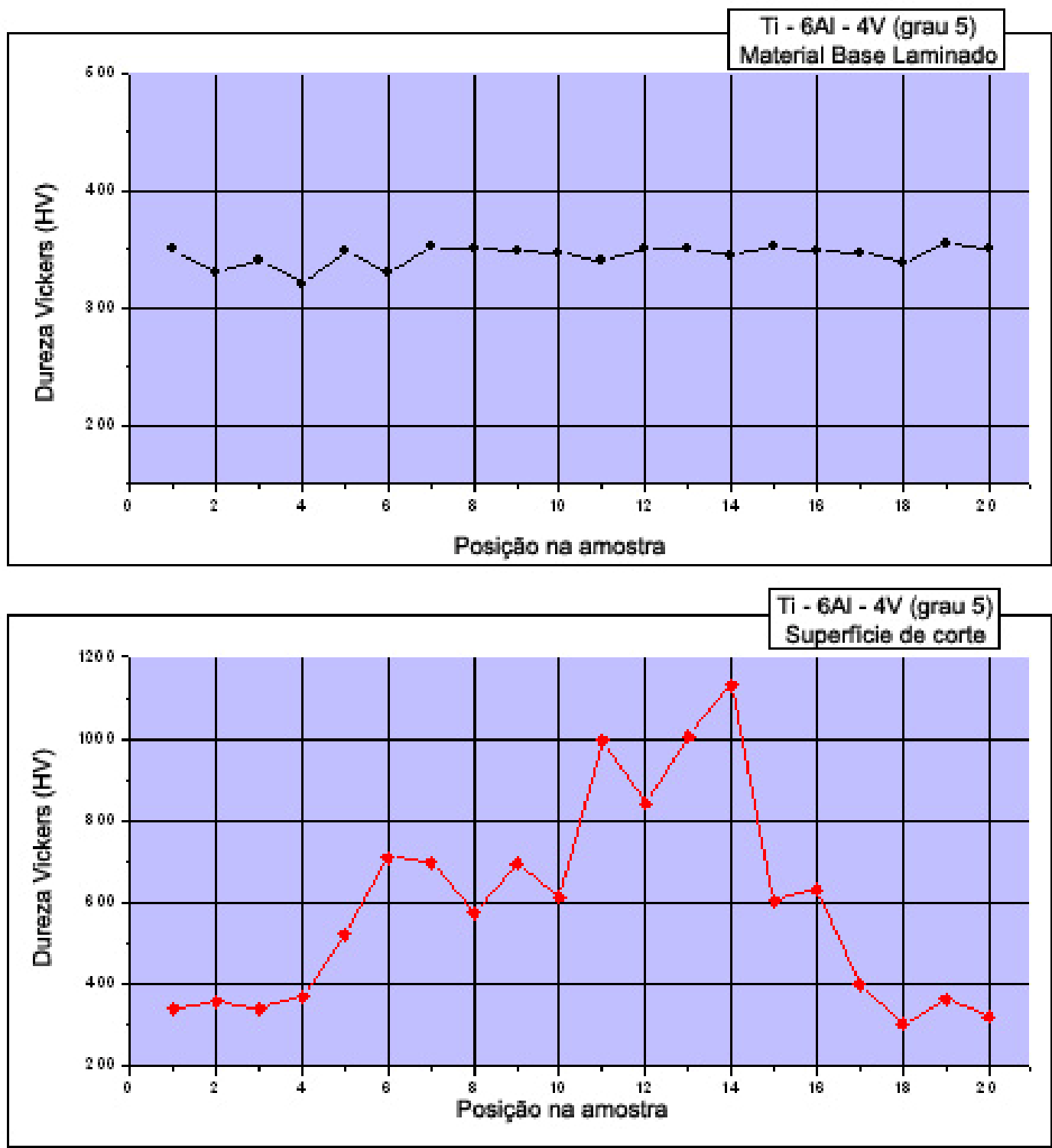

Figura 43 - Ensaio de microdureza convencional - comparação entre os valores de dureza do material base laminado e superfície usinada a laser da Liga Ti-6Al-4V (grau 5).
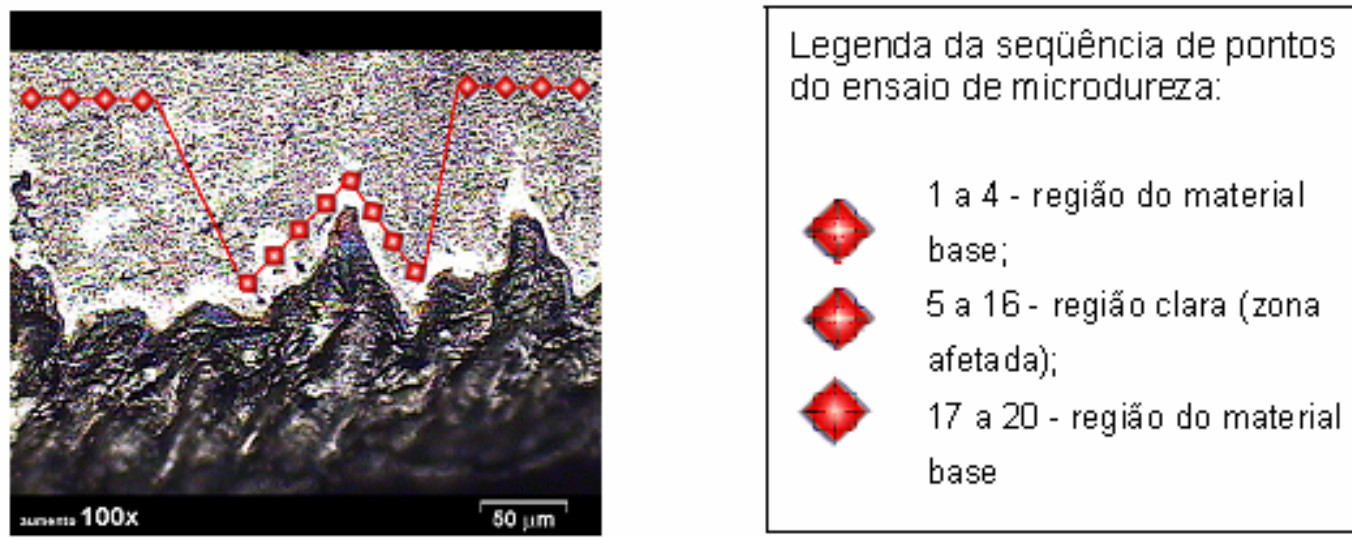

Figura 44 - llustração da seqüência de pontos realizados na superfície de corte da liga Ti-6Al-4V usinada a laser com gás nitrogênio (amostra Ti64laser). 
O endurecimento superficial verificado pelo ensaio de microdureza é significativo, e provavelmente, esta alteração é proveniente da formação de nitretos (TiN). Este fato, também foi descrito nas investigações de Akgun and Inal (1992; 1994), na qual os autores concluíram que o endurecimento superficial da liga Ti-6Al4V pela ação do laser em atmosfera de nitrogênio, está associado à formação de $\operatorname{TiN}^{135}$.

Para verificar a presença de nitreto de titânio na superfície de fusão realizou-se a análise de difração por raios-X. Os difratogramas obtidos são apresentados da figura 45 até figura 49.

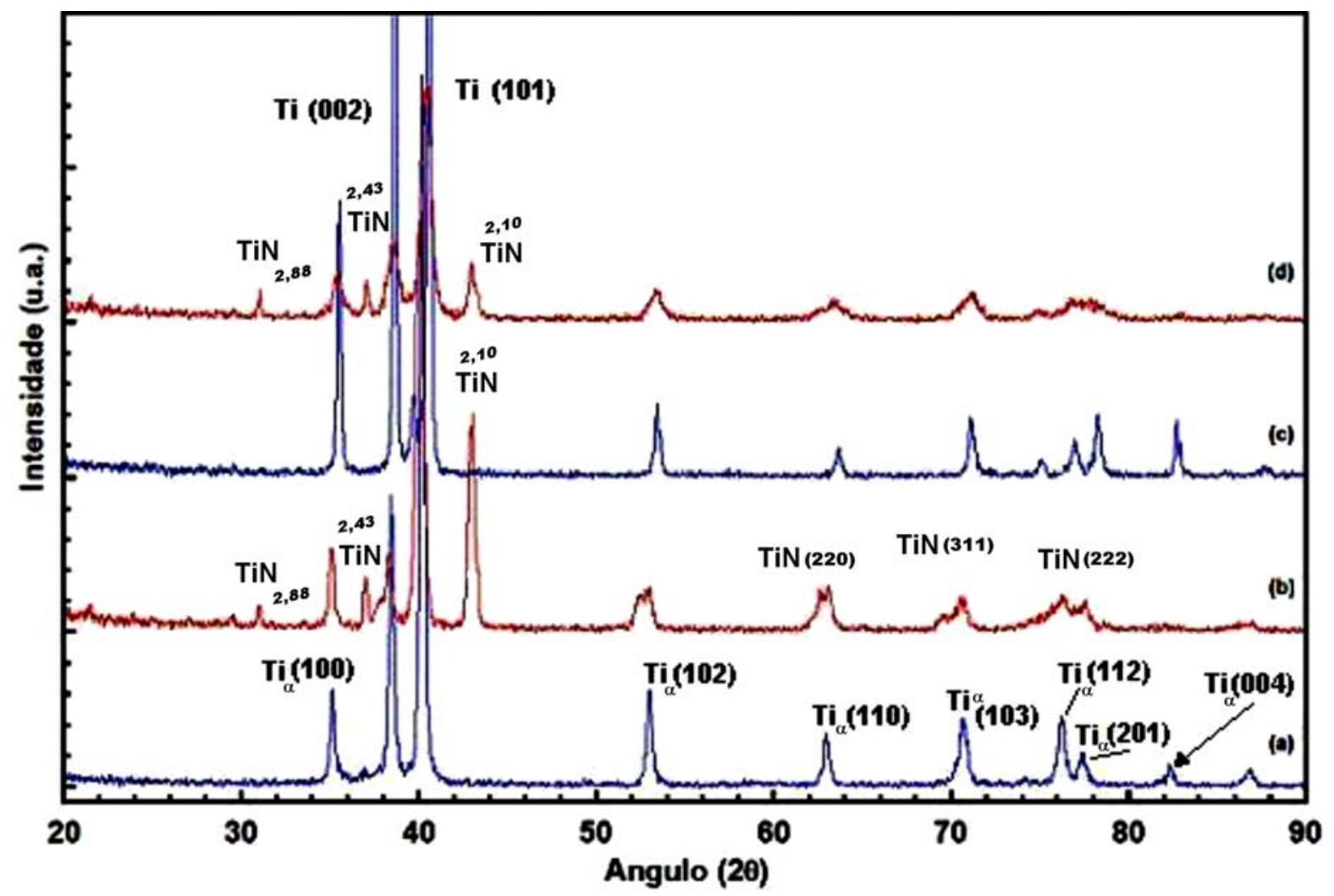

Figura 45 - Sobreposição dos difratogramas de raios-X, alguns picos de TiN e Ti estão demarcados:

(a) material base laminado -Ti c.p. (grau 2);

(b) superfície usinada a Laser - Ti c.p. (grau 2);

(c) material base laminado - Liga Ti-6Al-4V (grau 5);

(d) superfície usinada a Laser - Liga Ti-6Al-4V (grau 5); 
Os picos de TiN apresentados no diagrama de análise cristalográfica na Figura 45 foram confirmados por Xue et all ${ }^{136}$ (1997), como também no trabalho de Etaqqi et al. (1998) ${ }^{132}$. No difratograma do Ti c.p. laminado corresponde a $\mathrm{Ti}-\alpha$ (hexagonal) e no caso do Ti c.p. usinado a laser verifica-se nitreto de titânio (TiN cúbico).

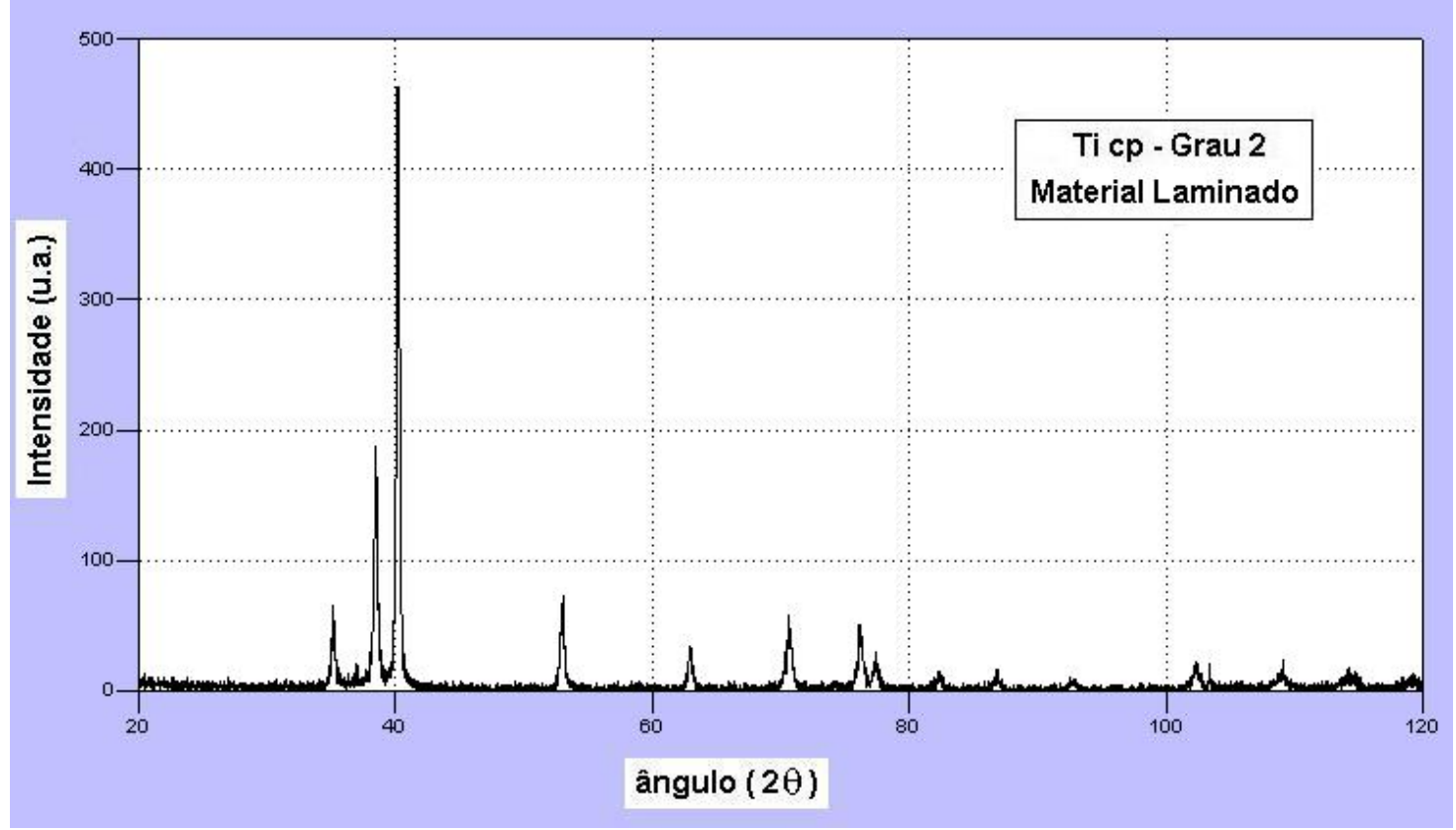

Figura 46 - Difratograma de raios-X do titânio puro grau 2 laminado.

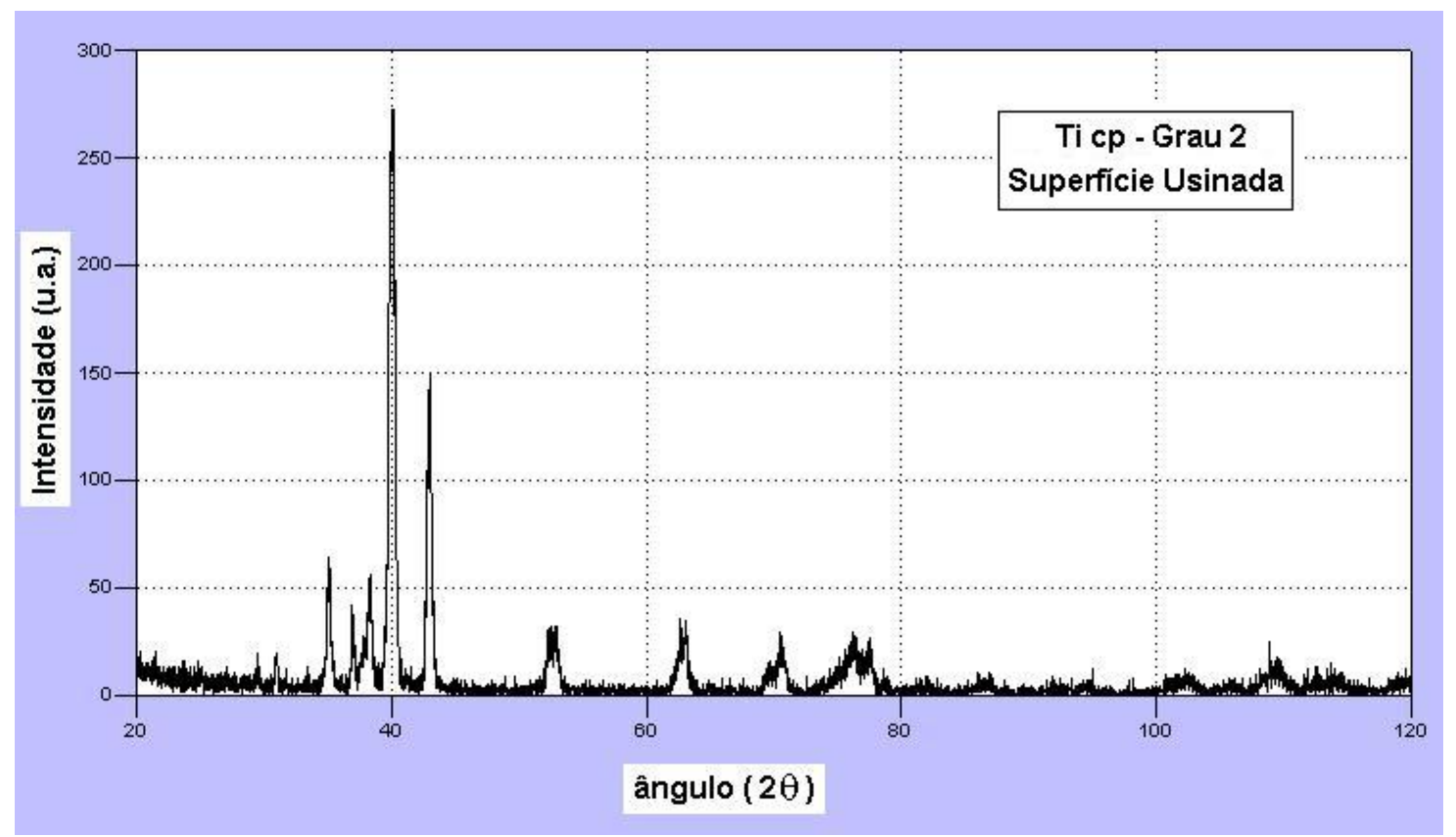

Figura 47 - Difratograma de raios-X da superfície usinada a laser do titânio puro grau 2. 


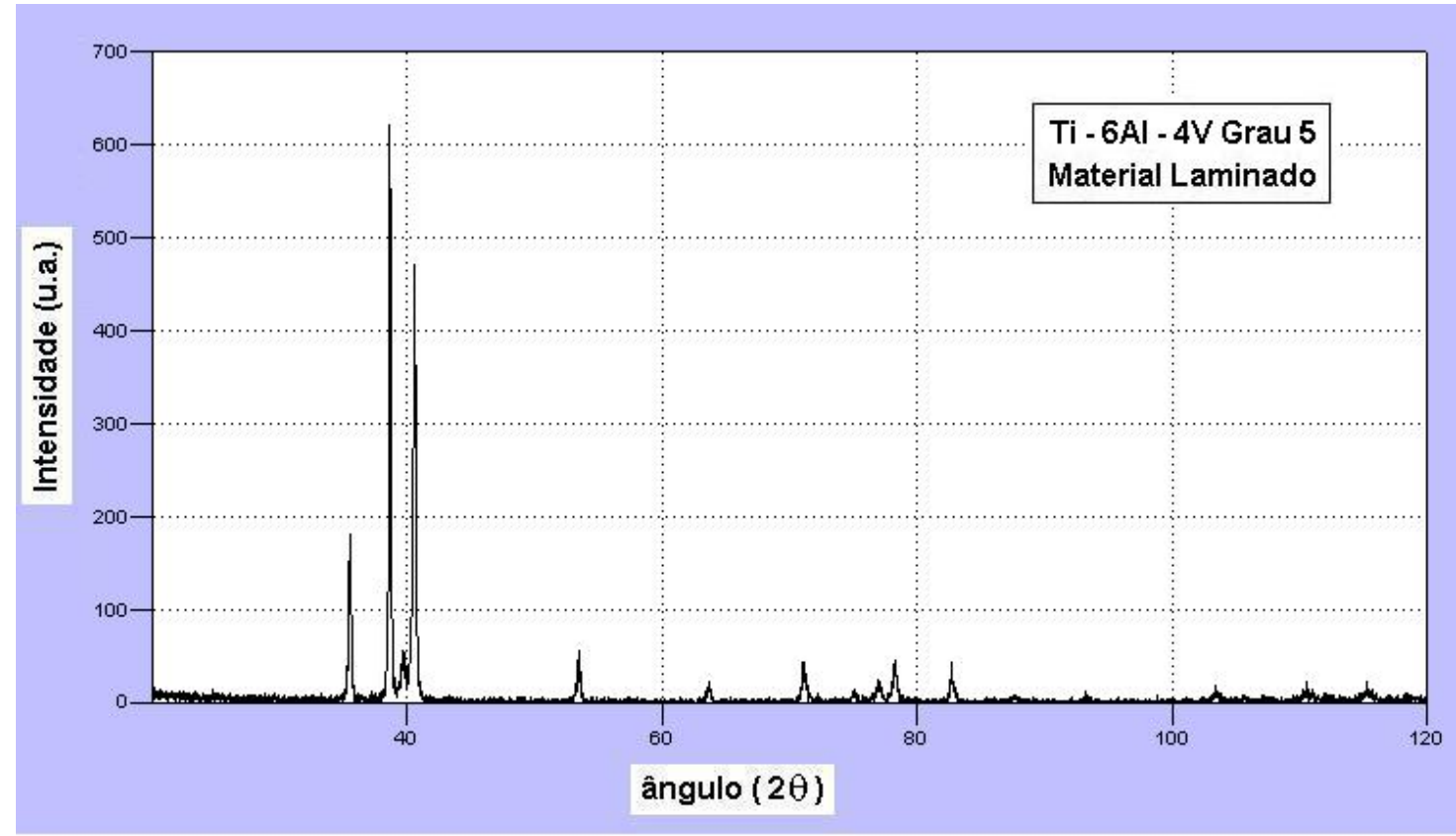

Figura 48 - Difratograma de raios-X material laminado da liga Ti-6Al-4V grau 5.

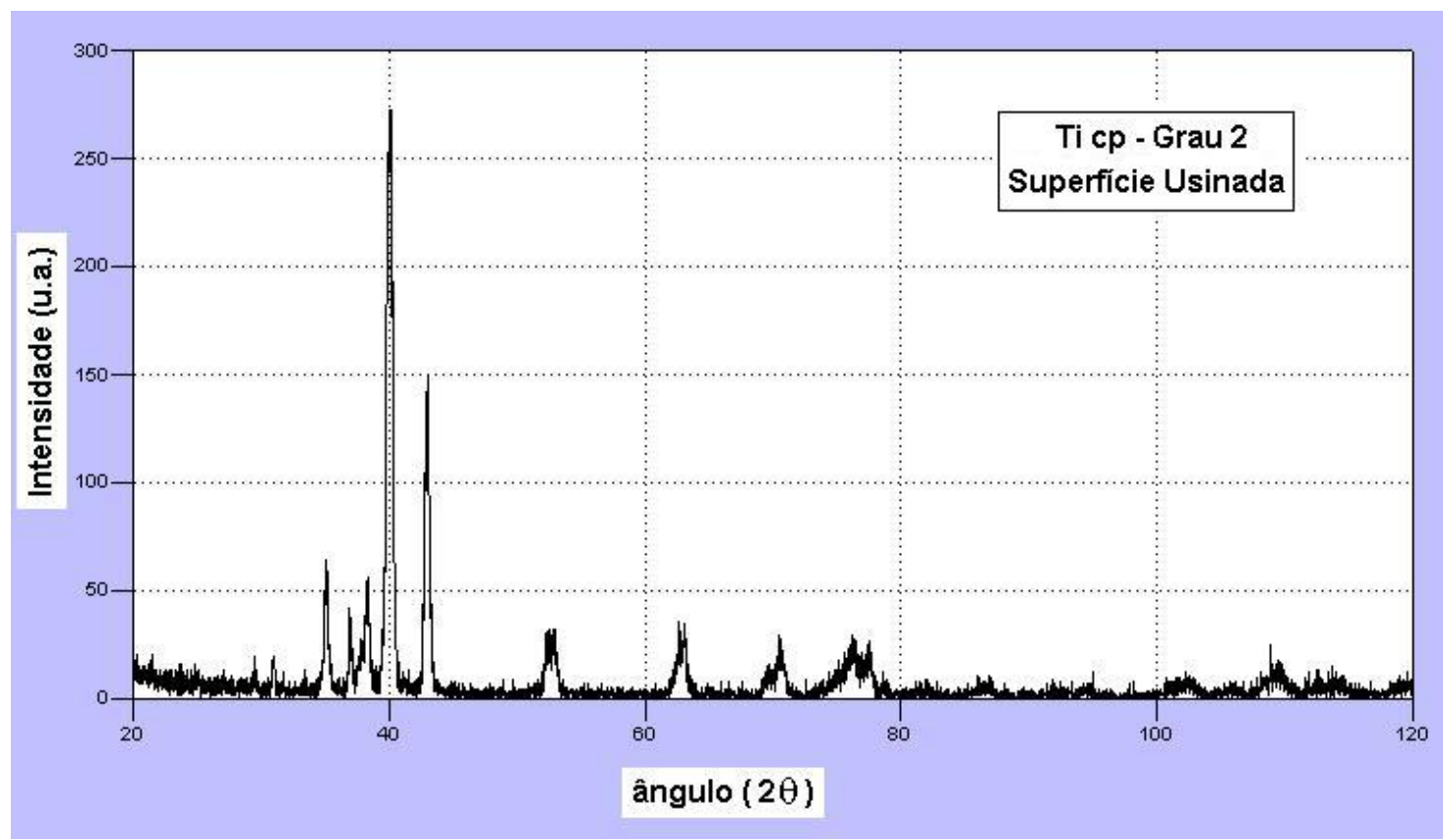

Figura 49 - Difratograma de raios-X superfície usinada a laser da liga Ti-6Al-4V grau 5.

Os diagramas da análise cristalográfica indicam que as fases formadas na zona ressolidificada foram amplamente influenciadas pela presença do nitrogênio.

Fases de TiN metaestável, classificadas como $\mathrm{TiN}_{0,3}$ e $\mathrm{TiN}_{0,9}$, são formadas por causa da rápida solidificação, particularmente nos processos a laser sem controle de pulso ${ }^{137,138}$ (pulse-shaping). Entretanto, a distinção dos padrões de 
difração entre $\mathrm{Ti}-\alpha$ e as fases metaestáveis $\left(\mathrm{TiN}_{0,3}\right.$ e $\left.\mathrm{TiN}_{0,9}\right)$ é extremamente difícil, pois são muito similares.

Um estado desordenado entre o titânio e nitrogênio é gerado pela rápida solidificação, e o curto espaço de tempo da interação entre os elementos impede a formação estequiométrica do TiN. Geralmente, as condições de corte do titânio sob a ação do laser com nitrogênio geram uma significativa redução da ductibilidade e da resistência à fadiga. Nesta situação, tensões provenientes do processo e a baixa tenacidade da fase de nitreto podem conduzir à formação de trincas ${ }^{139,140}$.

Especialmente na confecção de implantes, estas trincas nas camadas superficiais limitam a utilização deste material, pois tendem a propagar fraturas. Um evento como a falha em implantes é inadmissível e o controle deve ser rígido para assim evitar inúmeras complicações.

Fatores como a ocorrência de falhas nos implantes, a fragilização estrutural pela absorção dos gases de processo e o desgaste prematuro de ferramentas na usinagem de peças pós-processadas a laser com o uso de nitrogênio (como já mencionado em métodos), motivaram a execução de novas investigações com a utilização de diferentes gases inertes.

Nestas novas considerações, também foi ponderado o emprego exclusivo da liga Ti-6Al-4V, visto que atualmente, uma grande parcela da produção mundial do titânio é direcionada à fabricação desta liga ${ }^{141}$.

Conforme a nova adequação, um conjunto de amostras (série-6804) foi processado a laser sob diferentes gases na liga Ti-6Al-4V. Os resultados referentes ao ensaio de microdureza convencional são observados na Tabela 26 e na Figura 50. 
Tabela 26 - Relação dos valores de dureza convencional do conjunto 6804 .

\begin{tabular}{ccccccc} 
Amostra & $\mathbf{6 8 0 4 - A}$ & $\mathbf{6 8 0 4 - B}$ & $\mathbf{6 8 0 4 - C}$ & $\mathbf{6 8 0 4 - D}$ & $\mathbf{6 8 0 4 - E}$ & $\mathbf{6 8 0 4 - F}$ \\
\hline Gás & $\begin{array}{c}\text { Hélio } \\
\mathbf{( 1 0 0 \% )}\end{array}$ & $\begin{array}{c}\text { Nitrogênio } \\
\mathbf{( 1 0 0 \% )}\end{array}$ & $\begin{array}{c}\text { Argônio } \\
\mathbf{( 1 0 0 \% )}\end{array}$ & $\begin{array}{c}\text { Argônio } \\
\text { Hélio } \\
\mathbf{( 5 0 \% )}\end{array}$ & $\begin{array}{c}\text { Argônio (25\%) } \\
\text { Hélio (75\%) }\end{array}$ & $\begin{array}{c}\text { Argônio(75\%) } \\
\text { Hélio (25\%) }\end{array}$ \\
& \multicolumn{5}{c}{$\begin{array}{c}\text { Dureza } \\
\text { Vickers (HV) }\end{array}$} \\
& 306,4 & 303,0 & 320,6 & 262,0 & 284,0 & 324,6 \\
& 299,0 & 323,8 & 317,9 & 293,2 & 270,0 & 326,0 \\
& 314,5 & 366,2 & 315,3 & 290,8 & 288,5 & 317,9 \\
& 304,6 & 341,5 & 319,2 & 301,5 & 289,7 & 319,2 \\
& 283,2 & 334,7 & 317,9 & 293,1 & 288,5 & 330,1 \\
& 300,2 & 350,2 & 316,6 & 297,8 & 290,8 & 316,6 \\
& 335,7 & 384,8 & 320,1 & 305,1 & 314,0 & 319,2 \\
& 303,0 & 395,6 & 316,2 & 274,0 & 312,7 & 306,4 \\
& 298,7 & 381,4 & 318,4 & 289,6 & 311,4 & 330,1 \\
& 301,3 & 420,4 & 321,0 & 310,2 & 305,7 & 311,4 \\
& 300,8 & 357,6 & 317,5 & 285,4 & 301,9 & 321,9 \\
& 283,0 & 383,1 & 318,3 & 299,1 & 320,8 & 319,2 \\
& 294,5 & 371,2 & 315,9 & 303,0 & 304,0 & 332,6 \\
& 298,6 & 350,7 & 322,6 & 301,9 & 295,7 & 329,5 \\
& 320,5 & 355,3 & 319,3 & 289,8 & 287,6 & 309,5 \\
& 310,6 & 353,4 & 330,4 & 297,9 & 299,4 & 310,9 \\
& 299,5 & 349,7 & 321,3 & 309,5 & 306,2 & 299,5 \\
& 302,9 & 360,2 & 317,7 & 300,8 & 319,9 & 310,2 \\
& 287,0 & 356,9 & 310,9 & 279,3 & 318,5 & 328,5 \\
& 290,4 & 339,4 & 316,9 & 276,9 & 320,2 & 317,4 \\
\hline
\end{tabular}

Verifica-se que os valores médios de dureza são muito próximos em todas as amostras. Somente, a amostra 6804B apresentou um acréscimo de $18 \%$ da menor média obtida. Provavelmente, esta diferença está associada à absorção de nitrogênio.

As amostras geradas com a utilização dos gases hélio, argônio e a mistura destes apresentaram uma usinagem caracterizada pela redução da formação de rebarbas e também pela eliminação dos precipitados de nitrogênio. Os resultados obtidos por difratometria de raios-X mostram que somente o corte com gás nitrogênio induz a fase TiN nas superfícies de corte. Os picos referentes a esta fase não são observados no corte feito com hélio e argônio, conforme indicados na Figura 51. 


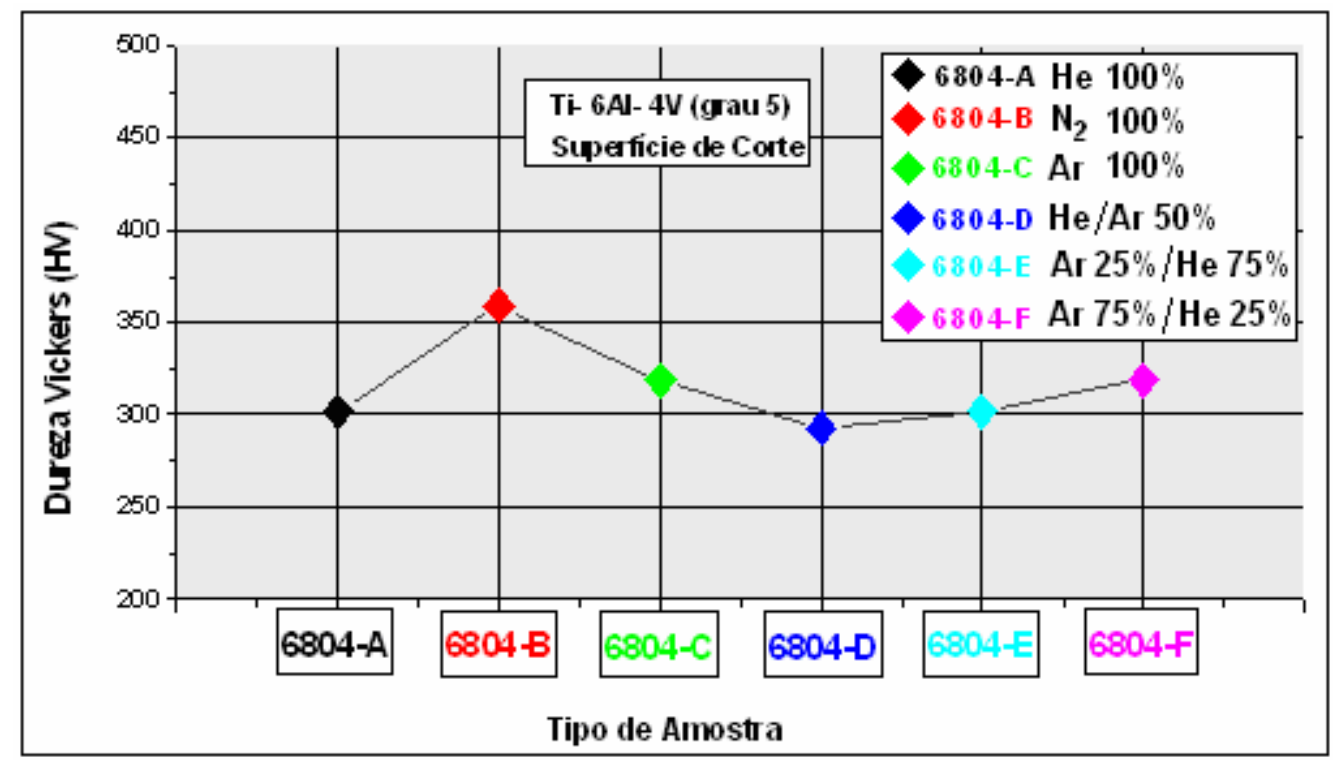

Figura 50 - Ensaio de microdureza convencional - comparação entre os valores de dureza da superfície de corte usinada a laser sob diferentes gases (série 6804 amostras).

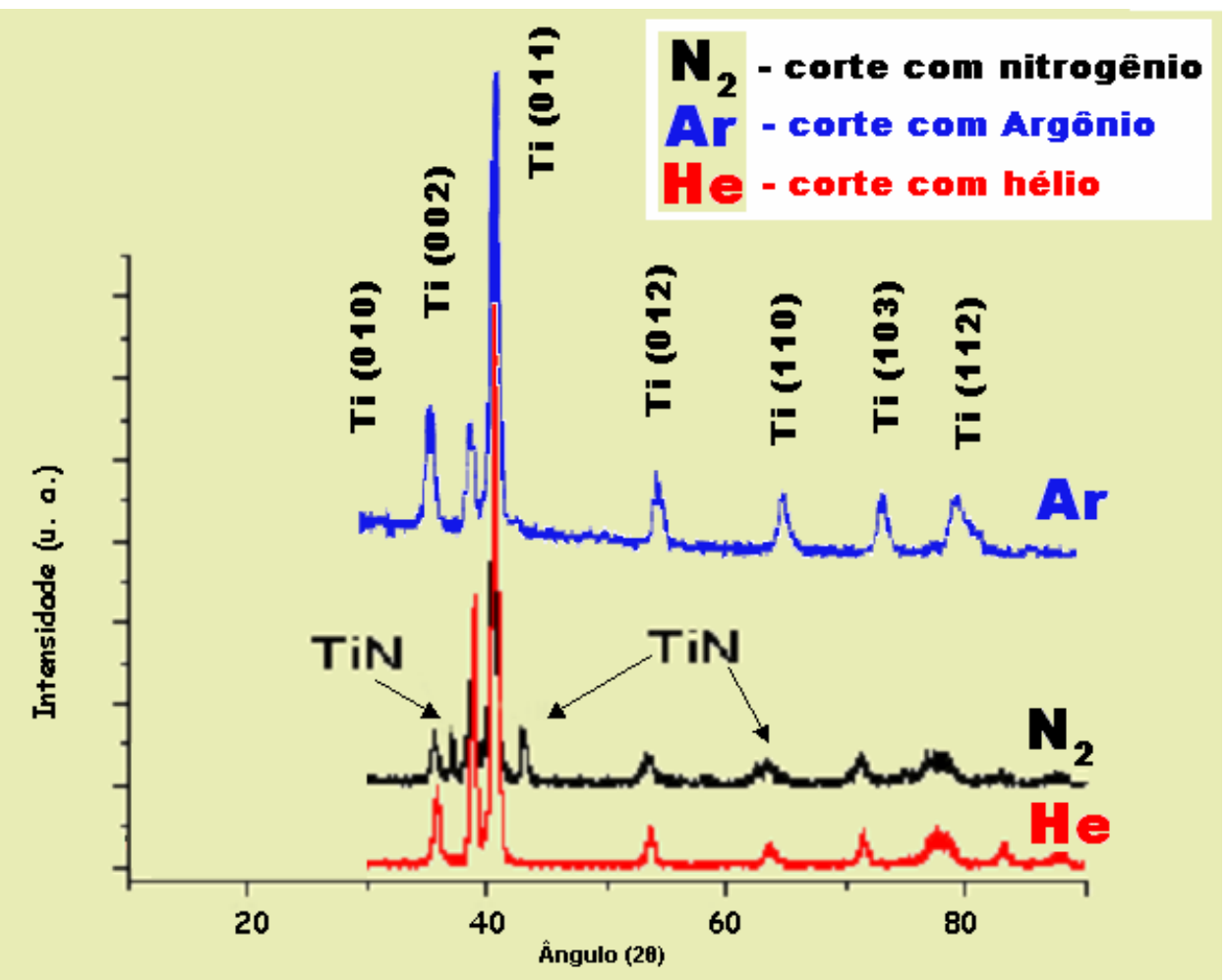

Figura 51 - Diagrama cristalográfico: comparação entre cortes com gás nitrogênio, argônio e hélio.

A pequena divergência na média da dureza superficial, entre as diferentes amostras, assim como os resultados do diagrama cristalográfico, indicam que o expressivo mecanismo de endurecimento superficial está associado à formação de TiN. 
As regiões entre a zona de fusão e a zona termicamente afetada das superfícies de corte foram observadas por meio da microscopia ótica e da eletrônica. Diferenciou-se as fases da microestrutura, mediante comparações com a literatura disponível, em formação de fase $\alpha$ equiaxial nas áreas claras com fase $\beta$ retida intragranular nas áreas escuras e transformação martensítica fina nas zonas ressolidificadas. Os detalhes das fases estão indicados na Figura 52 e na Figura 53.

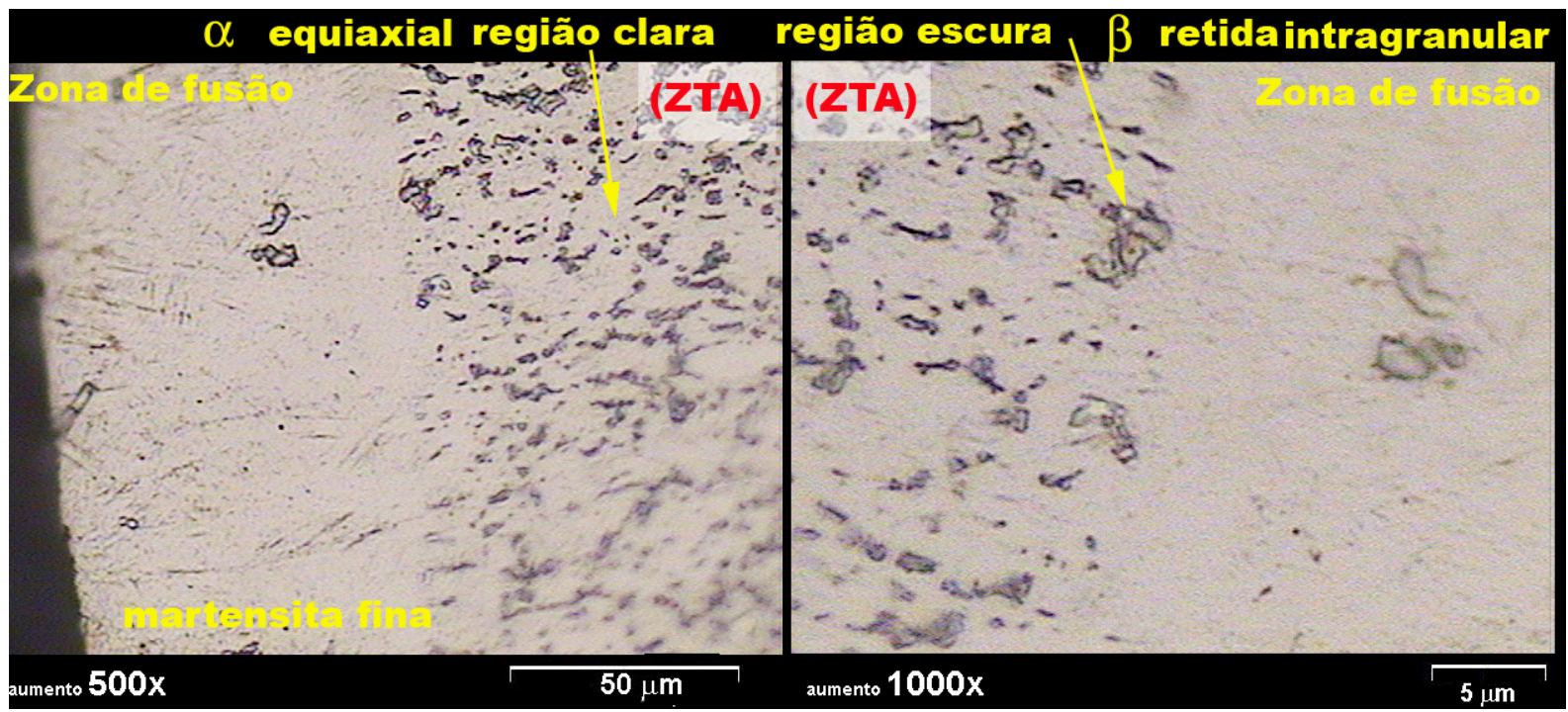

Figura 52 - Micrografia da zona de ressolidificação e ZTA - formação de martensita.

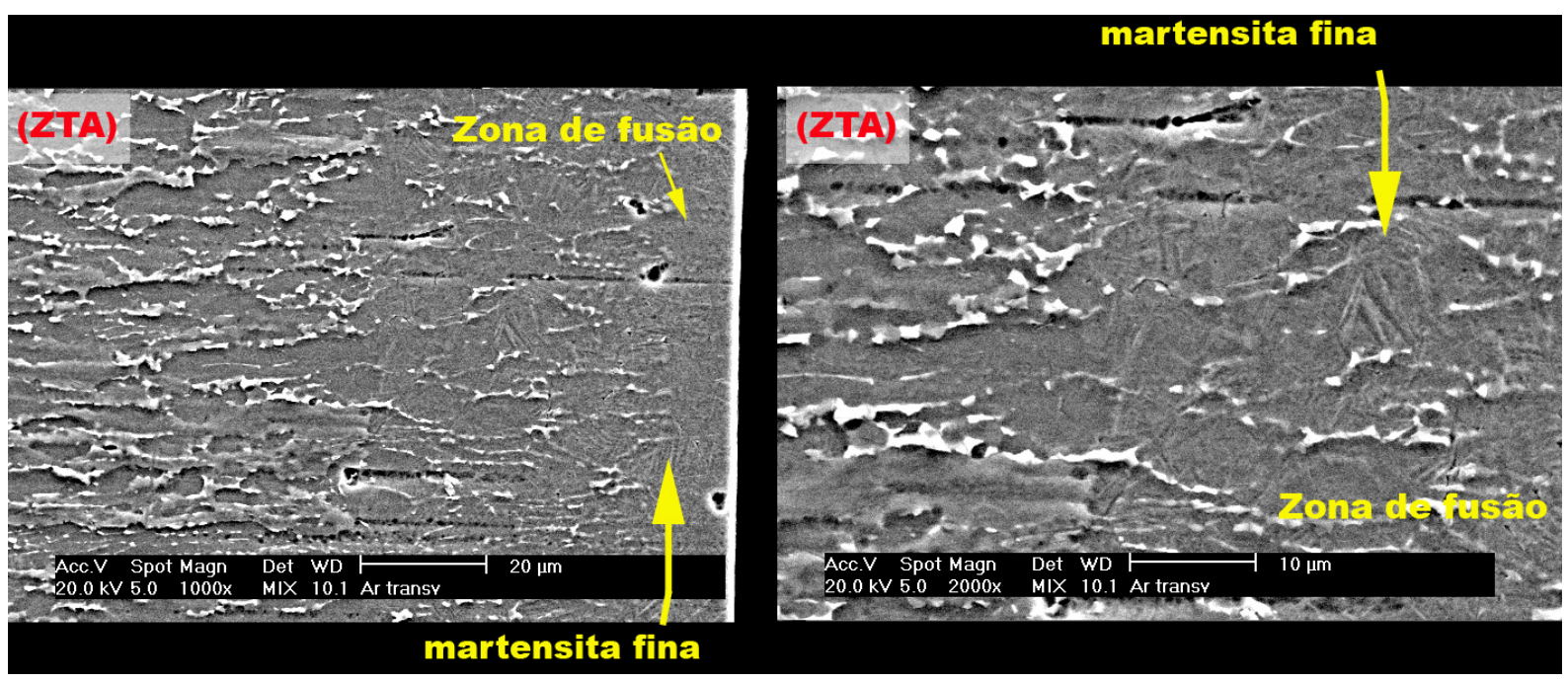

Figura 53 - MEV da zona de ressolidificação e ZTA - formação de martensita. 
A transformação martensítica nos aços gera o aumento da dureza e da rigidez, em grandes proporções, resultado das severas distorções no arranjo de distribuição atômico. No caso da liga Ti-6Al-4V esta transformação propicia um leve aumento da dureza $^{12}$. Este resultado é observado na Figura 54 , que compara os valores de dureza no material base com os da zona ressolidificada e da zona afetada pelo calor. A Figura 55 é uma ilustração para situar a região onde foram realizadas as indentações.

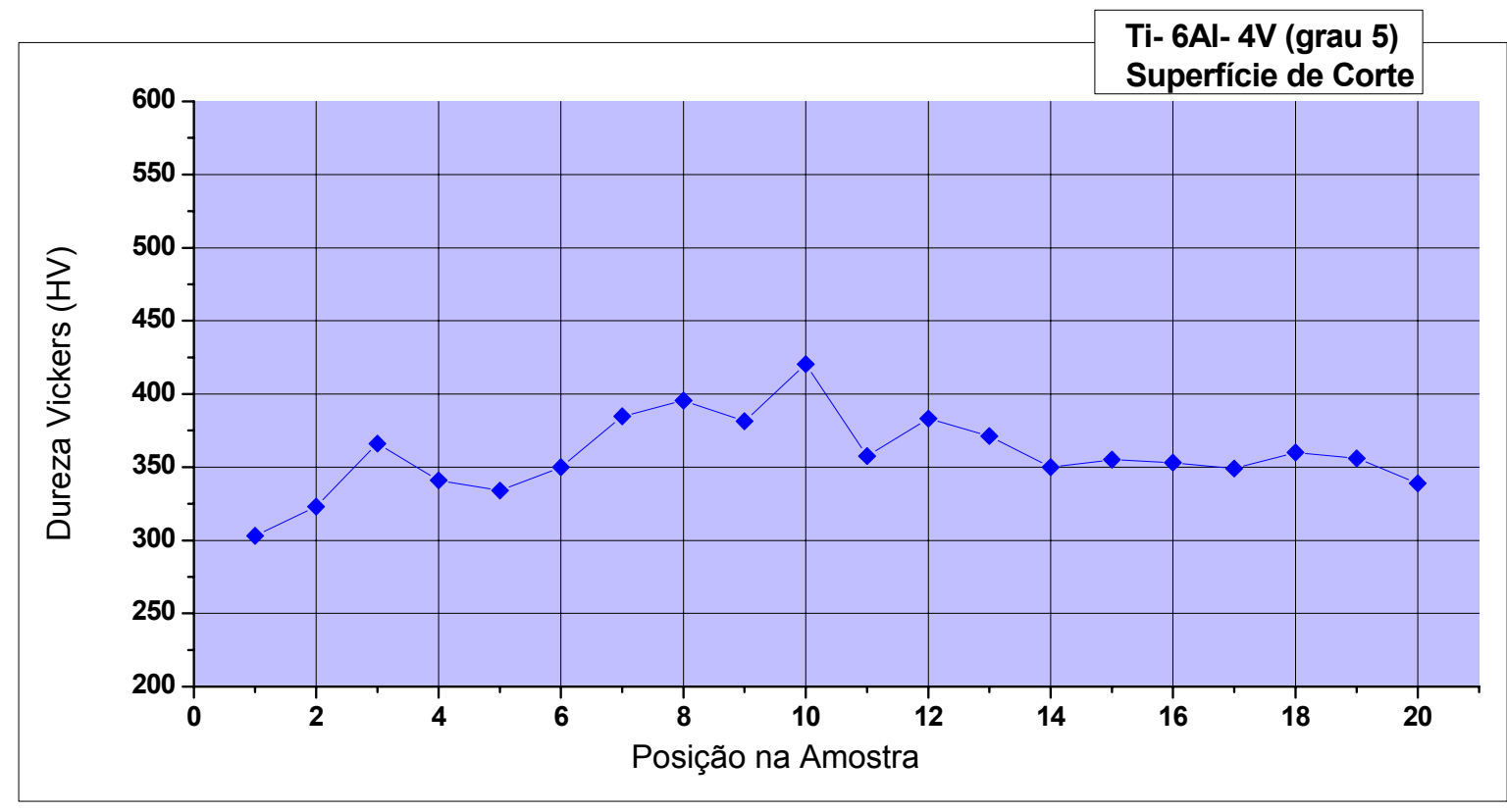

Figura 54 - Ensaio de microdureza convencional da superfície usinada a laser da Liga Ti-6Al-4V (amostra 6804-B).

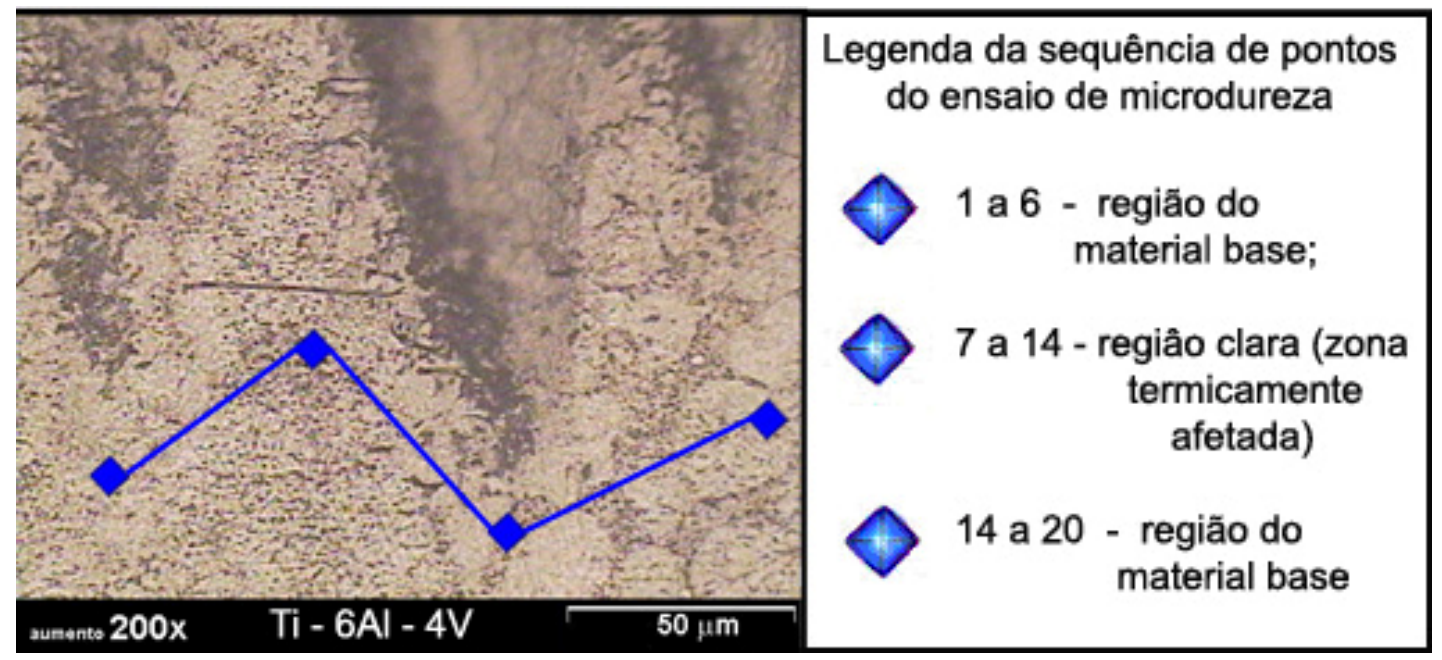

Figura 55 - Ilustração da seqüência de pontos realizados na superfície de corte da liga Ti-6Al-4V usinada a laser com gás nitrogênio (amostra 6804-B). 
Realizou-se o ensaio de microdureza instrumentada na amostra 6804 - C, para examinar possível relação entre as mudanças microestruturais em diferentes áreas da superfície usinada com o endurecimento superficial. Os resultados referentes aos testes indicam uma relativa uniformidade nos valores das médias de dureza, entre as diversas regiões da zona de corte, conforme apresentados na Tabela 27, na Figura 56e Figura 57.

Tabela 27 - Valores do ensaio de microdureza instrumentada na amostra 6804 - C.

\begin{tabular}{|c|c|c|c|c|c|c|c|c|}
\hline Amostra & $\begin{array}{c}\text { Dureza } \\
(\mathrm{GPa})\end{array}$ & $\begin{array}{c}\text { Dureza } \\
\text { Vickers } \\
(\mathrm{HV})\end{array}$ & Amostra & $\begin{array}{c}\text { Dureza } \\
(\mathrm{GPa})\end{array}$ & $\begin{array}{c}\text { Dureza } \\
\text { Vickers } \\
(\mathrm{HV})\end{array}$ & Amostra & $\begin{array}{c}\text { Dureza } \\
\text { (GPa) }\end{array}$ & $\begin{array}{c}\text { Dureza } \\
\text { Vickers } \\
(\mathrm{HV})\end{array}$ \\
\hline \multirow{11}{*}{ CAR } & 3,059 & 311,946 & \multirow{11}{*}{ CAR1 } & & & \multirow{11}{*}{ CAR2 } & & \\
\hline & $\begin{array}{l}3,406 \\
3,045\end{array}$ & $\begin{array}{l}34 t, 346 \\
310,463\end{array}$ & & 3,071 & 313,147 & & 3.05 & 315.278 \\
\hline & 3,362 & 342,814 & & 3,215 & 327,817 & & 3,252 & 331,590 \\
\hline & 3,121 & 318,230 & & 3,311 & 337,631 & & 2,601 & 265,183 \\
\hline & 3,023 & 308,224 & & 3,418 & 348,500 & & 2,571 & 262,157 \\
\hline & 2,961 & 301,898 & & 3,450 & 351,823 & & 3,565 & 363,564 \\
\hline & 3,147 & 320,869 & & 3,285 & 334,916 & & 3,307 & 337,193 \\
\hline & 3,426 & 349,326 & & \multirow[t]{4}{*}{3,491} & \multirow[t]{4}{*}{356,020} & & 3,243 & 330,679 \\
\hline & 3,248 & 331,180 & & & & & & \\
\hline & 3,194 & 325,688 & & & & & & \\
\hline & 3,276 & 334,089 & & & & & & \\
\hline Média & & 325 & & & 339 & & & 315 \\
\hline Desvio & & 15,92 & & & 15,03 & & & 37,96 \\
\hline
\end{tabular}

Observação: o equipamento fornece os valores na unidade (GPa), a coluna Dureza Vickers foi adicionada como conversão dos dados para facilitar a compreensão.
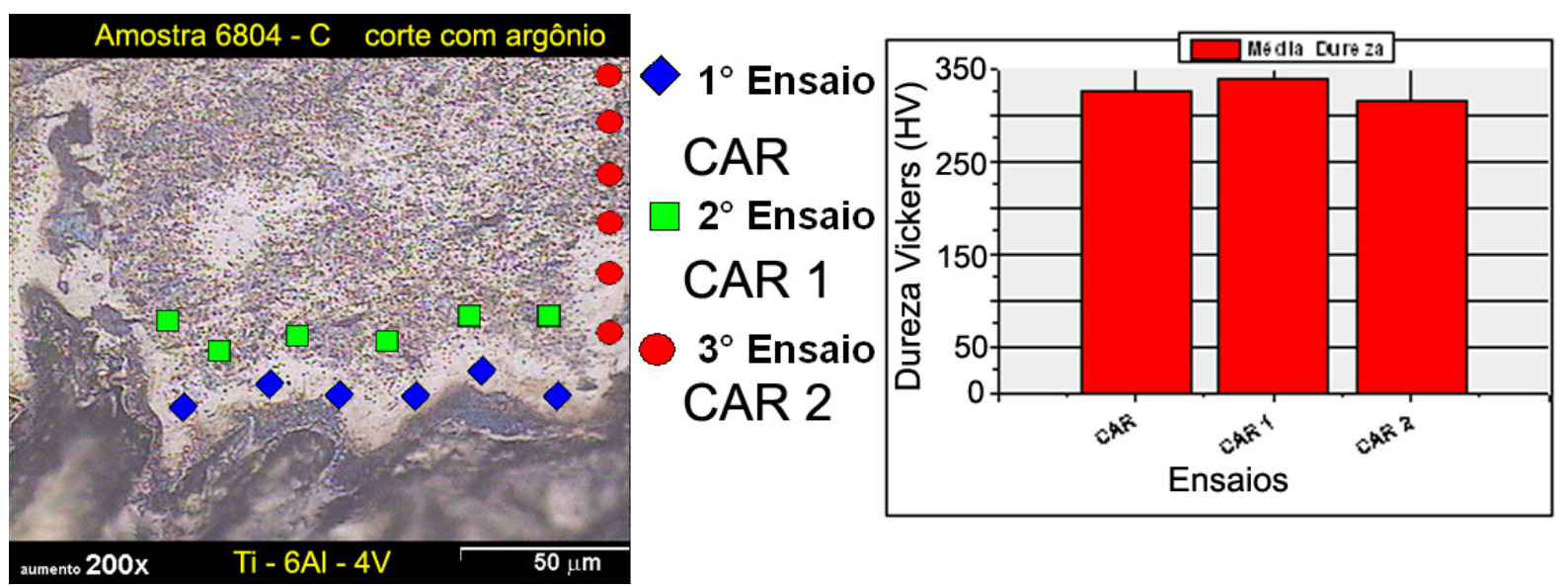

Figura 56 - Micrografia com a seqüência do teste e os valores médios de dureza da liga Ti-6Al-4V usinada a laser com gás argônio [amostra (6804-C)]. 
Nota-se uma variação nos valores referentes ao ensaio CAR2, o que pode ser uma indicação da alteração microestrutural ao longo da superfície, em conseqüência da transformação martensítica, propiciada pelo gradiente térmico.
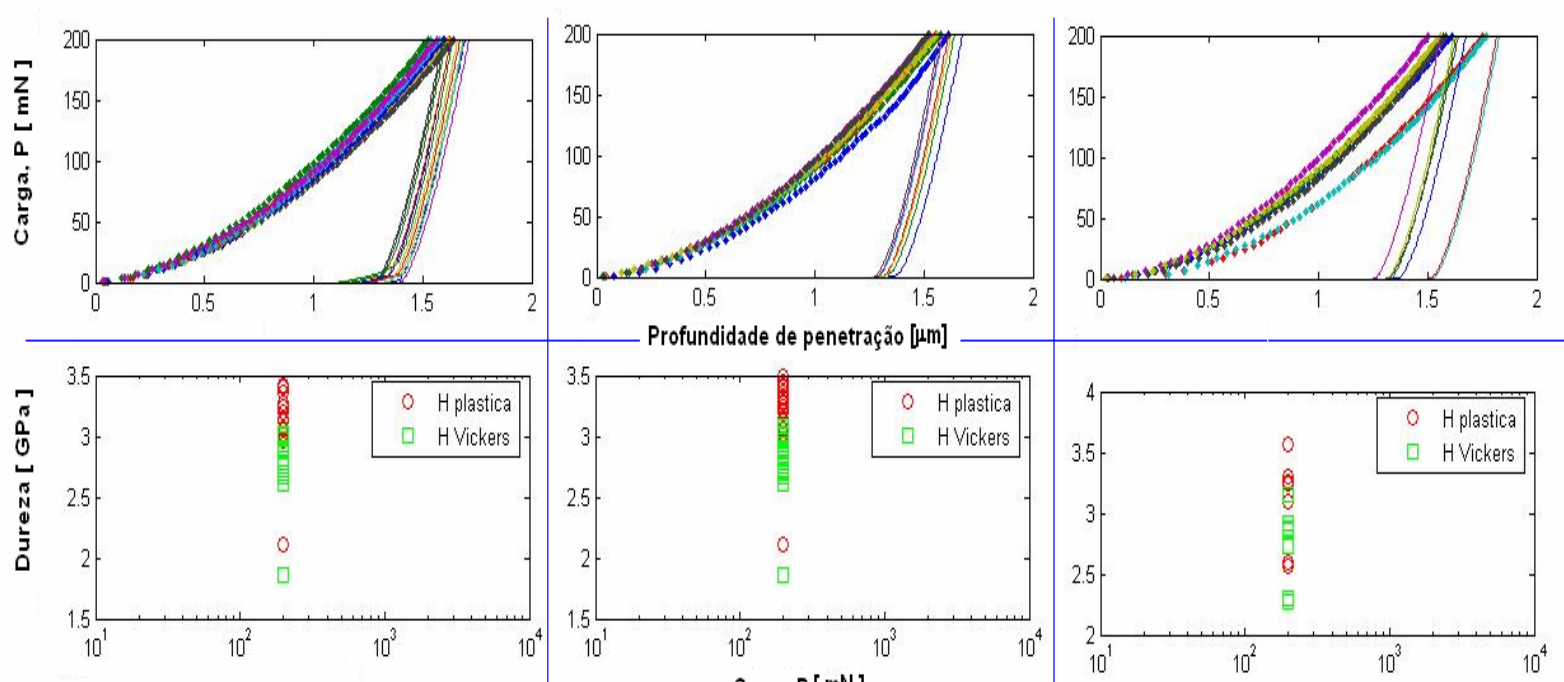

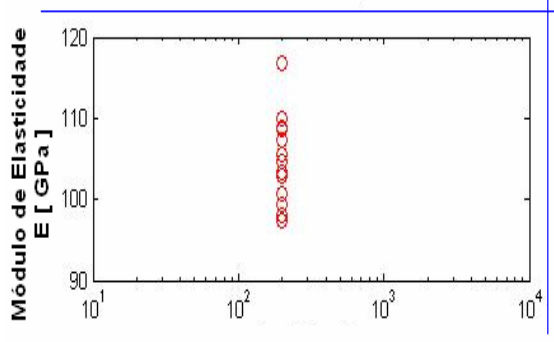

CAR

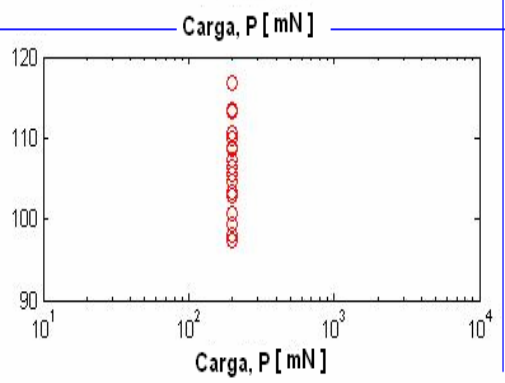

CAR1

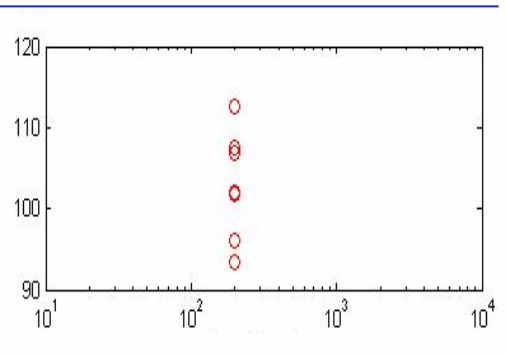

CAR2

Figura 57 - Gráficos da carga pela profundidade de penetração, Dureza pela carga e Módulo de Elasticidade pela carga para o ensaio de microdureza instrumentada (amostra $6804-C$ ).

A significativa diferença observada entre os valores obtidos de dureza na amostra Ti64laser (figura 43 e 44) e na amostra 6804-B (figura 54 e 55), ambas processadas com fluxo de nitrogênio, indica uma situação paradoxal. Acredita-se que este fato esteja associado à complexidade da dinâmica do processo a laser pulsado.

Os mecanismos de interação entre energia disponível e material são regidos pelo fenômeno de absorção dos fótons. Essa absorção da energia incidente é alterada durante a ação termodinâmica do laser em razão de diversos fatores, alguns associados ao material e outros ao feixe. 
Desta forma, qualquer alteração no material como sua rugosidade superficial, os defeitos da rede cristalina, as impurezas presentes (óxidos, óleos, poros entre outros) poderiam gerar diferenças na refletividade do material, na formação do plasma, influenciando assim a absorção da energia e por fim afetar o resultado obtido.

Outro fator perturbador do processamento é a ejeção do metal fundido. A ineficiente ejeção do material líquido altamente viscoso pelos gases inertes, durante o processo de corte, permite a formação de rebarbas na borda de saída. A dissipação de calor na superfície de corte é reduzida em razão do acúmulo de rebarbas em alta temperatura e do estreitamento do Kerf.

O equilíbrio termodinâmico sofre mudanças e o material fica exposto a maiores temperaturas por mais tempo. Esta ocorrência favorece uma reação indesejada do material com os gases da atmosfera. Isto, também poderia influenciar na absorção dos gases de assistência na superfície de corte.

A variação nas condições do sistema ótico implicaria em distorções do feixe laser e na sua propagação. Fatores como, a divergência do feixe e o fator de qualidade do feixe $\left(\mathrm{M}^{2}\right)$ seriam modificados, provocando alterações na intensidade do feixe e deste modo comprometer o processo.

O primeiro passo para iniciar o modelamento do processo e assim otimizar o corte a laser pulsado foi verificar a influência da intensidade do feixe pela relação entre energia do feixe e taxa de sobreposição dos pulsos.

Essa análise foi realizada com a finalidade de avaliar a interferência destes parâmetros sobre a qualidade do acabamento superficial, pela verificação da quantidade acumulada de rebarbas e da rugosidade das superfícies de corte. 
Os resultados referentes às medidas de rebarba e de rugosidade, em cada caso, estão relacionados na Tabela 28 e na Tabela 29, respectivamente.

Tabela 28 - Quantidade de rebarba $\left(\mathrm{mm}^{2}\right)$ medida para três energias e quatro taxas de sobreposição diferentes.

\begin{tabular}{|c|c|c|c|}
\hline \multirow{3}{*}{$\begin{array}{c}\text { Taxa de } \\
\text { Sobreposição } \\
\text { de pulsos }\end{array}$} & \multicolumn{3}{|c|}{ Energia $(J)$} \\
\hline & $E_{1}-0,460$ & $E_{2}-0,592$ & $E_{3}-0,925$ \\
\hline & \multicolumn{3}{|c|}{ Quantidade de rebarba aderida nas amostras $\left(\mathrm{mm}^{2}\right)$} \\
\hline S1 - 5\% & $0,2290,246 \quad 0,300$ & $0,2940,2220,203$ & $0,2830,278 \quad 0,250$ \\
\hline S2 - $24 \%$ & $0,3780,483 \quad 0,445$ & $0,431 \quad 0,480 \quad 0,465$ & $0,3230,3330,338$ \\
\hline S3 - $43 \%$ & $0,316 \quad 0,362 \quad 0,407$ & $0,693 \quad 0,591 \quad 0,655$ & $0,505 \quad 0,558 \quad 0,484$ \\
\hline$S 4-62 \%$ & $\begin{array}{llll}0,557 & 0,475 & 0,538\end{array}$ & $\begin{array}{lll}0,686 & 0,676 & 0,712\end{array}$ & \begin{tabular}{|lll}
0,452 & 0,497 & 0,478
\end{tabular} \\
\hline
\end{tabular}

Observar que o grupo dos doze valores acima (Tabela 28), dividido em três colunas é a referência da área da quantidade de rebarba obtida nas amostras. Já na Tabela 29, os valores são referentes à medida de rugosidade média da superfície de corte.

Tabela 29 - Rugosidade $(\mu \mathrm{m})$ medida para três energias e quatro taxas de sobreposição diferentes.

\begin{tabular}{|c|c|c|c|}
\hline \multirow{3}{*}{$\begin{array}{l}\text { Taxa de } \\
\text { Sobreposição } \\
\text { de pulsos }\end{array}$} & \multicolumn{3}{|c|}{ Energia (J) } \\
\hline & $E_{1}-0,460$ & $E_{2}-0,592$ & $E_{3}-0,925$ \\
\hline & \multicolumn{3}{|c|}{ Rugosidade média $(\mathrm{Ra}-\mu \mathrm{m})$} \\
\hline S1- $5 \%$ & $4,72 \quad 5,73 \quad 8,67$ & $7,21 \quad 6,98 \quad 7,29$ & $\begin{array}{llll}19,15 & 18,57 & 16,70\end{array}$ \\
\hline S2 - $24 \%$ & $6,13 \quad 4,34 \quad 3,71$ & $7,07 \quad 5,91 \quad 8,62$ & $\begin{array}{lll}12,09 & 17,28 & 16,38\end{array}$ \\
\hline$S 3-43 \%$ & $3,07 \quad 5,13 \quad 4,25$ & $9,51 \quad 6,37 \quad 8,11$ & $7,79 \quad 5,32 \quad 8,75$ \\
\hline$S 4-62 \%$ & $2,67 \quad 4,58 \quad 5,62$ & $2,69 \quad 3,92 \quad 3,95$ & $7,08 \quad 5,29 \quad 9,00$ \\
\hline
\end{tabular}


Estes valores apresentados nas tabelas acima são referentes aos dados coletados pelos ensaios de inspeção superficial e de captura digital e foram empregados para a realização da análise de variância.

Pela aplicação da metodologia ANOVA gerou-se a Tabela 30 , na qual é possível observar alguns dos resultados desta análise. $\mathrm{O}$ valor $\mathrm{P}$ indica que existe uma forte interação entre os parâmetros avaliados (energia e taxa de sobreposição de pulsos). Portanto, cada um dos fatores interfere no resultado (acabamento superficial) de modo independente, como também exercem influência entre si. Defini-se grau de liberdade (DF); soma dos quadrados (SS); média quadrática (MS); razão entre médias (Fo).

Tabela 30 - Análise de variância para acabamento superficial das peças usinadas de titânio.

\begin{tabular}{|c|c|c|c|c|c|c|}
\hline & Fonte & DF & SS & MS & Fo & $\begin{array}{c}\text { Valor } \\
\text { P }\end{array}$ \\
\hline \multirow{5}{*}{$\begin{array}{c}\text { ANOVA } \\
\text { para } \\
\text { Quantidade } \\
\text { de } \\
\text { rebarbas }\end{array}$} & Sobreposição & 3 & 0.490617 & 0.163539 & 119.74 & 0.000 \\
\hline & Energia & 2 & 0.101402 & 0.050701 & 37.12 & 0.000 \\
\hline & Sobreposição*Energia & 6 & 0.126438 & 0.021073 & 15.43 & 0.000 \\
\hline & Erro & 24 & 0.032780 & 0.001366 & & \\
\hline & Total & 35 & 0.751237 & & & \\
\hline \multirow{5}{*}{$\begin{array}{l}\text { ANOVA } \\
\text { para } \\
\text { rugosidade }\end{array}$} & Sobreposição & 3 & 170.093 & 56.698 & 22.78 & 0.000 \\
\hline & Energia & 2 & 329.853 & 164.927 & 66.27 & 0.000 \\
\hline & Sobreposição*Energia & 6 & 158.185 & 26.364 & 10.59 & 0.000 \\
\hline & Erro & 24 & 59.730 & 2.489 & & \\
\hline & Total & 35 & 717.862 & & & \\
\hline
\end{tabular}

As variações da rugosidade e da quantidade de rebarba pela taxa de sobreposição de pulsos e energia estão apresentadas na Figura 58 e na Figura 59. 


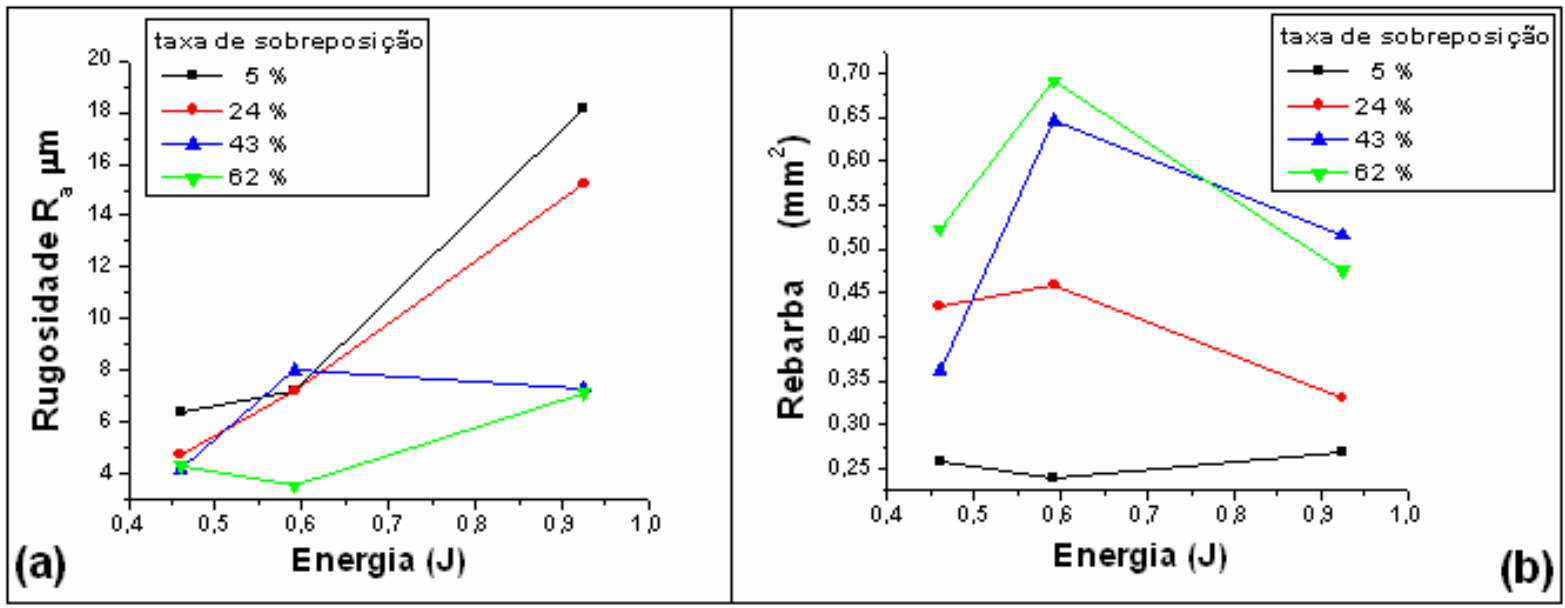

Figura 58 - Variação Rugosidade x Energia (a). Variação Rebarba x Energia (b).

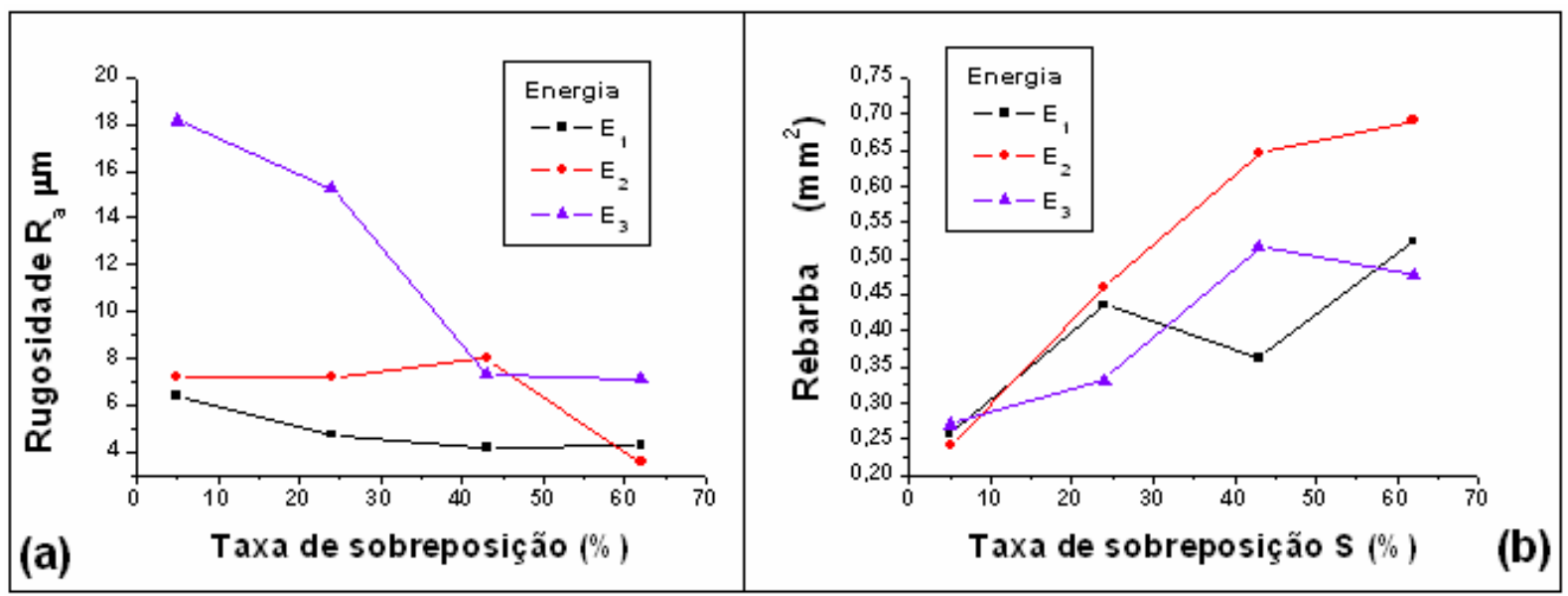

Figura 59 - Variação Rugosidade x Taxa de sobreposição de pulsos (a).

Variação Rebarba $x$ taxa de sobreposição de pulsos (b).

$\mathrm{Na}$ investigação da interferência dos parâmetros (energia e sobreposição de pulsos) na qualidade da superfície, verificou-se que o aumento da taxa de sobreposição, pulsos mais próximos, i.e. menor velocidade de processo, ocasiona a diminuição da rugosidade e o aumento da quantidade de rebarbas.

Esta condição de melhor acabamento superficial deve estar associada a uma maior transferência térmica do processo que, por um lado aumenta a quantidade de líquido expelido, e por outro permite um aplainamento maior da superfície do titânio.

Quanto à energia, nota-se que a rugosidade permanece quase inalterada para os menores valores, mas sofre um grande acréscimo para o maior valor de energia. No entanto, o comportamento da quantidade de rebarbas, formada em razão da 
energia do pulso laser, é ambíguo, pois apresenta um valor intermediário de energia que conduz o aumento de rebarbas ${ }^{142,143}$. O mecanismo da formação de rebarbas ${ }^{144}$ é influenciado pela combinação de vários fatores que podem interagir de forma heterogênea com certas condições, como nesta faixa de energia.

\subsection{Análise da formação de rebarba pela aplicação do DOE}

Em conseqüência de todos os resultados anteriores apresentados, substituiuse o gás nitrogênio pelo argônio e selecionaram-se seis parâmetros do processo para prosseguir nas investigações pelo método de Planejamento Experimental (DOE).

Nesta etapa, aplicou-se o modelo experimental de seis fatores em matriz fatorial fracionada de $1 / 4$ a dois níveis para duas réplicas, como proposto anteriormente. Com base nesta configuração, executou-se a usinagem tendo em vista gerar as amostras e coletar os dados de rebarba aderida na borda de corte. Os valores obtidos estão dispostos na Tabela 31 (coluna Resposta - Réplicas)

A estruturação dos gráficos e diagramas de influência dos parâmetros investigados em virtude da quantidade de rebarbas proporcionou avaliar a interferência relativa a cada um destes. Conforme observa-se na Figura 60, cada variável exerce um fator de influência que pode ser verificado pela inclinação das retas apresentadas nos gráficos.

Os maiores ângulos formados com a linha horizontal significam um maior efeito, como nos casos dos fatores: pressão de gás(C), Tipo de lente [comprimento focal $(E)]$ e velocidade de corte (D). Esta grande inclinação é um indicativo que esses parâmetros são importantes no processo de corte a laser. 
Tabela 31 - Modelo experimental ensaio DOE para 6 fatores a 2 níveis(Rebarba).

\begin{tabular}{|c|c|c|c|c|c|c|c|c|c|}
\hline \multicolumn{10}{|c|}{$\begin{array}{c}\text { Ensaio fatorial fracionado } 2^{(6-2)}=16 \\
\text { DOE realizado na CPML }\end{array}$} \\
\hline \multirow{7}{*}{$\begin{array}{c}\mathrm{N}^{\circ} \\
\text { do } \\
\text { teste }\end{array}$} & \multicolumn{7}{|c|}{\begin{tabular}{|l|} 
Fatores de Controle \\
\end{tabular}} & \multirow{6}{*}{\multicolumn{2}{|c|}{$\begin{array}{l}\text { Resposta } \\
\text { Área de } \\
\text { Rebarba } \\
\quad\left(\mathrm{mm}^{2}\right)\end{array}$}} \\
\hline & \multirow[t]{2}{*}{2 niveis } & \begin{tabular}{|c|}
$\begin{array}{c}\text { Energia } \\
\text { do } \\
\text { Pulso }\end{array}$ \\
\end{tabular} & \begin{tabular}{|c|} 
Largura \\
Temporal \\
do Pulso \\
\end{tabular} & \begin{tabular}{|c|}
$\begin{array}{c}\text { Pressão } \\
\text { Gás }\end{array}$ \\
\end{tabular} & $\begin{array}{l}\text { Vel. de } \\
\text { Corte }\end{array}$ & $\begin{array}{c}\text { Lente } \\
\text { Compr. } \\
\text { Focal } \\
\end{array}$ & $\begin{array}{l}\text { Posição } \\
\text { do Foco }\end{array}$ & & \\
\hline & & {$[\boldsymbol{J}]$} & [ms] & [psi] & {$[\mathrm{mm} / \mathrm{min}]$} & [mm] & [mm] & & \\
\hline & nível (1) & 1,15 & 0,8 & 120 & 360 & 50 & $\begin{array}{c}\mathrm{Na} \\
\text { superficie }\end{array}$ & & \\
\hline & nivel (-1) & 0,64 & 0,6 & 70 & 180 & 100 & $\begin{array}{c}0,5 \mathrm{~mm} \\
\text { dentro da } \\
\text { chapa }\end{array}$ & & \\
\hline & \multirow{2}{*}{\begin{tabular}{c|} 
Ordem \\
aleatória
\end{tabular}} & \multicolumn{4}{|c|}{ Modelo Base 2 (a quarta) } & \multicolumn{2}{|c|}{ Geradores } & & \\
\hline & & A & $\mathbf{B}$ & $\mathbf{C}$ & $\mathbf{D}$ & $\begin{array}{c}\mathbf{E}= \\
\mathrm{ABC}\end{array}$ & $\begin{array}{c}\mathbf{F}= \\
\mathbf{B C D}\end{array}$ & \multicolumn{2}{|c|}{ Réplicas } \\
\hline \multirow{2}{*}{1} & \multirow{2}{*}{7 e 9} & -1 & -1 & -1 & -1 & -1 & -1 & Y1 (1) & $Y 17(2)$ \\
\hline & & 0,64 & 0,6 & 70 & 180 & 100 & 6,7 & 3,638 & 3,8715 \\
\hline \multirow{2}{*}{2} & \multirow{2}{*}{28 e 30} & +1 & -1 & -1 & -1 & +1 & -1 & $Y 2(1)$ & $Y 18(2)$ \\
\hline & & 1,15 & 0,6 & 70 & 180 & 50 & 6,7 & 7,263 & 7,3735 \\
\hline \multirow{2}{*}{3} & \multirow{2}{*}{23 e 27} & -1 & +1 & -1 & -1 & +1 & +1 & Y3 (1) & Y19(2) \\
\hline & & 0,64 & 0,8 & 70 & 180 & 50 & 6,2 & 6,01 & 5,501 \\
\hline \multirow{2}{*}{4} & \multirow{2}{*}{8 e 13} & +1 & +1 & -1 & -1 & -1 & +1 & Y4 (1) & Y20 (2) \\
\hline & & 1,15 & 0,8 & 70 & 180 & 100 & 6,2 & 4,525 & 4,8065 \\
\hline \multirow{2}{*}{5} & \multirow{2}{*}{21 e 32} & -1 & -1 & +1 & -1 & +1 & +1 & Y5 (1) & Y21 (2) \\
\hline & & 0,64 & 0,6 & 120 & 180 & 50 & 6,2 & 6,074 & 6,1285 \\
\hline \multirow{2}{*}{6} & \multirow{2}{*}{1 e 16} & +1 & -1 & +1 & -1 & -1 & +1 & Y6 (1) & Y22 (2) \\
\hline & & 1,15 & 0,6 & 120 & 180 & 100 & 6,2 & 5,024 & 4,1225 \\
\hline \multirow{2}{*}{7} & $2 \cdot 11$ & -1 & +1 & +1 & -1 & -1 & -1 & $Y 7$ (1) & Y23 (2) \\
\hline & 3 e 11 & 0,64 & 0,8 & 120 & 180 & 100 & 6,7 & 3,7975 & 1,3465 \\
\hline 0 & $17-25$ & +1 & +1 & +1 & -1 & +1 & -1 & Y8 (1) & Y24 (2) \\
\hline 8 & $17 \mathrm{e} 25$ & 1,15 & 0,8 & 120 & 180 & 50 & 6,7 & 3,688 & 5,1155 \\
\hline & & -1 & -1 & -1 & +1 & -1 & +1 & Y9 (1) & Y25 (2) \\
\hline 9 & 4 e 15 & 0,64 & 0,6 & 70 & 360 & 100 & 6,2 & 3,8355 & 3,435 \\
\hline & & +1 & -1 & -1 & +1 & +1 & +1 & Y10 (1) & Y26 (2) \\
\hline 10 & 24 e 29 & 1,15 & 0,6 & 70 & 360 & 50 & 6,2 & 4,764 & 4,8085 \\
\hline 11 & 2621 & -1 & +1 & -1 & +1 & +1 & -1 & Y11(1) & $Y 27$ (2) \\
\hline 11 & $26 \mathrm{e} 31$ & 0,64 & 0,8 & 70 & 360 & 50 & 6,7 & 7,985 & 7,9 \\
\hline & & +1 & +1 & -1 & +1 & -1 & -1 & Y12 (1) & Y28 (2) \\
\hline 12 & 2 e 6 & 1,15 & 0,8 & 70 & 360 & 100 & 6,7 & 5,4165 & 5,5385 \\
\hline 12 & 10 & -1 & -1 & +1 & +1 & +1 & -1 & Y13(1) & Y29(2) \\
\hline 13 & 18 e 22 & 0,64 & 0,6 & 120 & 360 & 50 & 6,7 & 4,335 & 4,608 \\
\hline 1 & - $\quad 1$ & +1 & -1 & +1 & +1 & -1 & -1 & Y14 (1) & Y30 (2) \\
\hline 14 & 5 e 14 & 1,15 & 0,6 & 120 & 360 & 100 & 6,7 & 1,487 & 1,205 \\
\hline & & -1 & +1 & +1 & +1 & -1 & +1 & Y15 (1) & Y31 (2) \\
\hline 15 & 10 e 12 & 0,64 & 0,8 & 120 & 360 & 100 & 6,2 & 2,2735 & 1,731 \\
\hline & & +1 & +1 & +1 & +1 & +1 & +1 & $Y 16(1)$ & Y32(2) \\
\hline 16 & 19 e 20 & 1,15 & 0,8 & 120 & 360 & 50 & 6,2 & 3,113 & 3,0925 \\
\hline
\end{tabular}


Verifica-se no diagrama de Pareto (Figura 61) que algumas interações, tais como; a energia do pulso (A) com Tipo de lente [comprimento focal] (E) e entre a energia do pulso (A) com velocidade de corte (D), também devem ser consideradas.

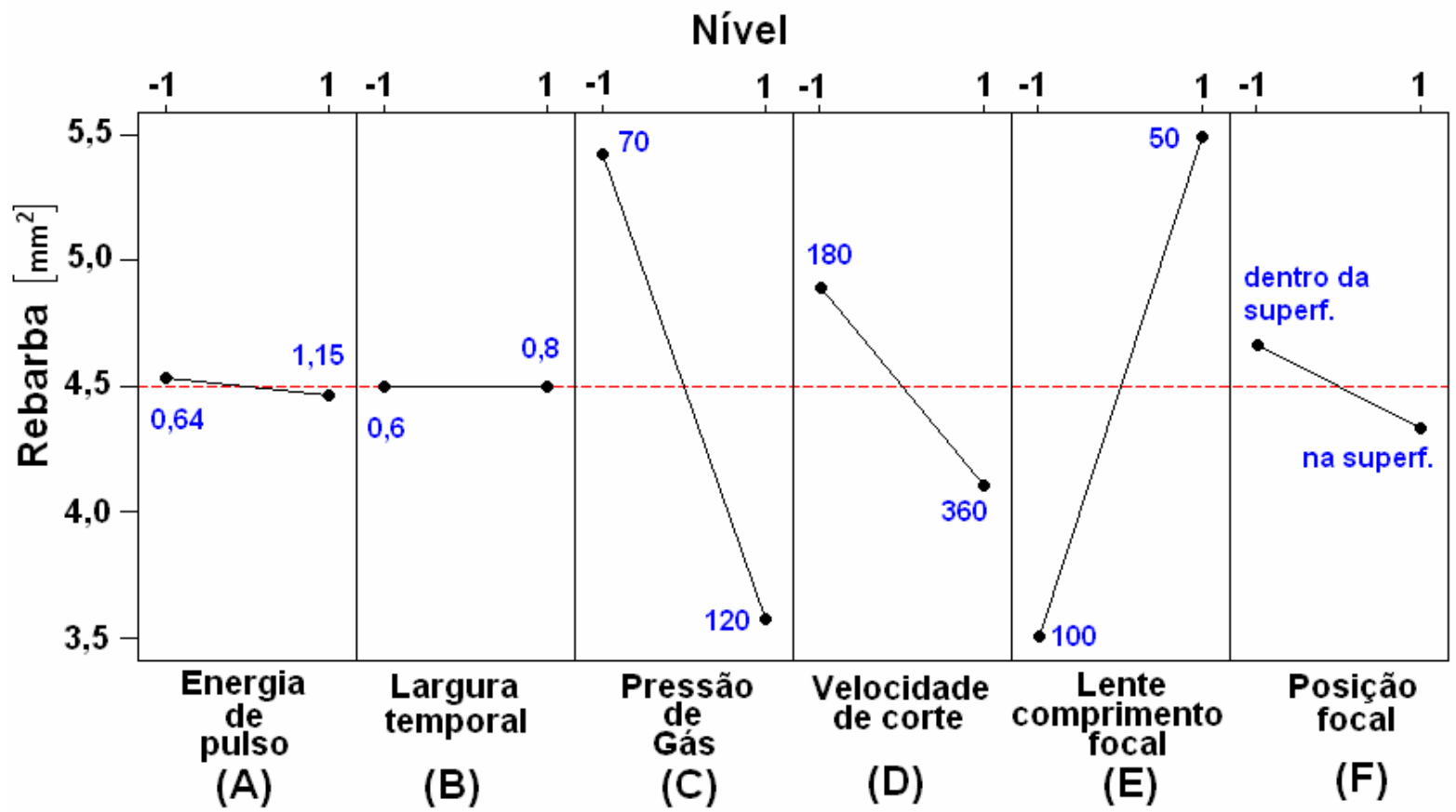

Figura 60 - Gráfico de influência para cada parâmetro em resposta a rebarba - (6 fatores).

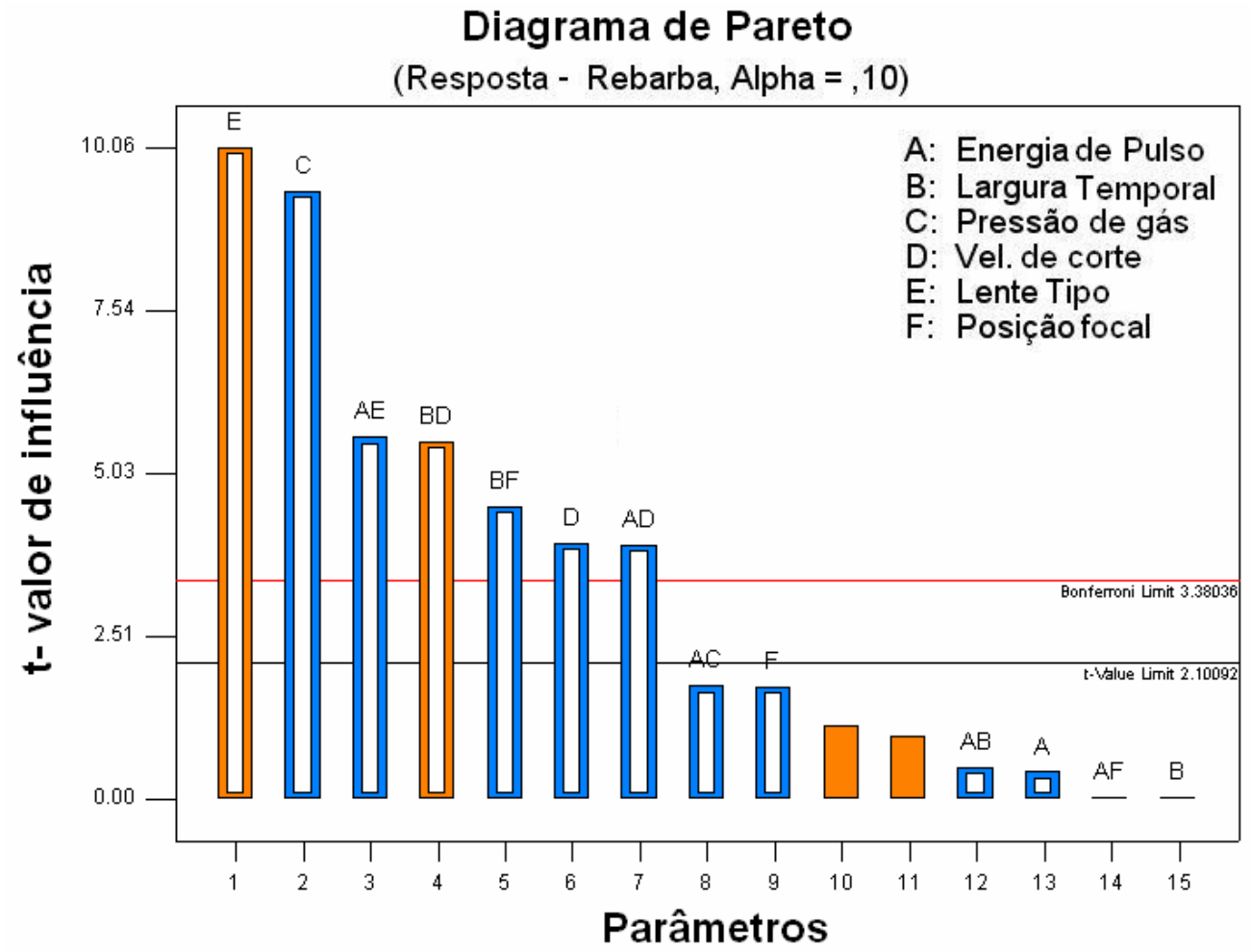

Figura 61 - Diagrama de influência individual e das interações para DOE com 6 fatores. 
A concentração de rebarbas foi reduzida à proporção que se aumentaram os valores de pressão do gás (C) e da velocidade de corte (D). Essa configuração pode proporcionar uma condição de melhor acabamento superficial, contudo acarretaria um acréscimo de custos ao processo, em virtude do alto consumo de gás.

Em relação à taxa de velocidade é possível inferir que seu aumento está limitado pelo próprio deslocamento do feixe. Um avanço maior que o limite tangencial entre pulsos, ou seja, sem uma sobreposição, resultaria em uma operação ineficaz.

Os parâmetros energia (A), largura temporal (B) e posição focal (F) apresentaram quase nenhum efeito segundo a inclinação verificada nos seus respectivos gráficos.

Na variação do comprimento focal da lente $(E)$ observou-se uma redução do material ressolidificado aderido na borda de corte. O uso da lente de comprimento focal de $100 \mathrm{~mm}$ indica ser a melhor escolha por gerar a menor quantidade de rebarbas.

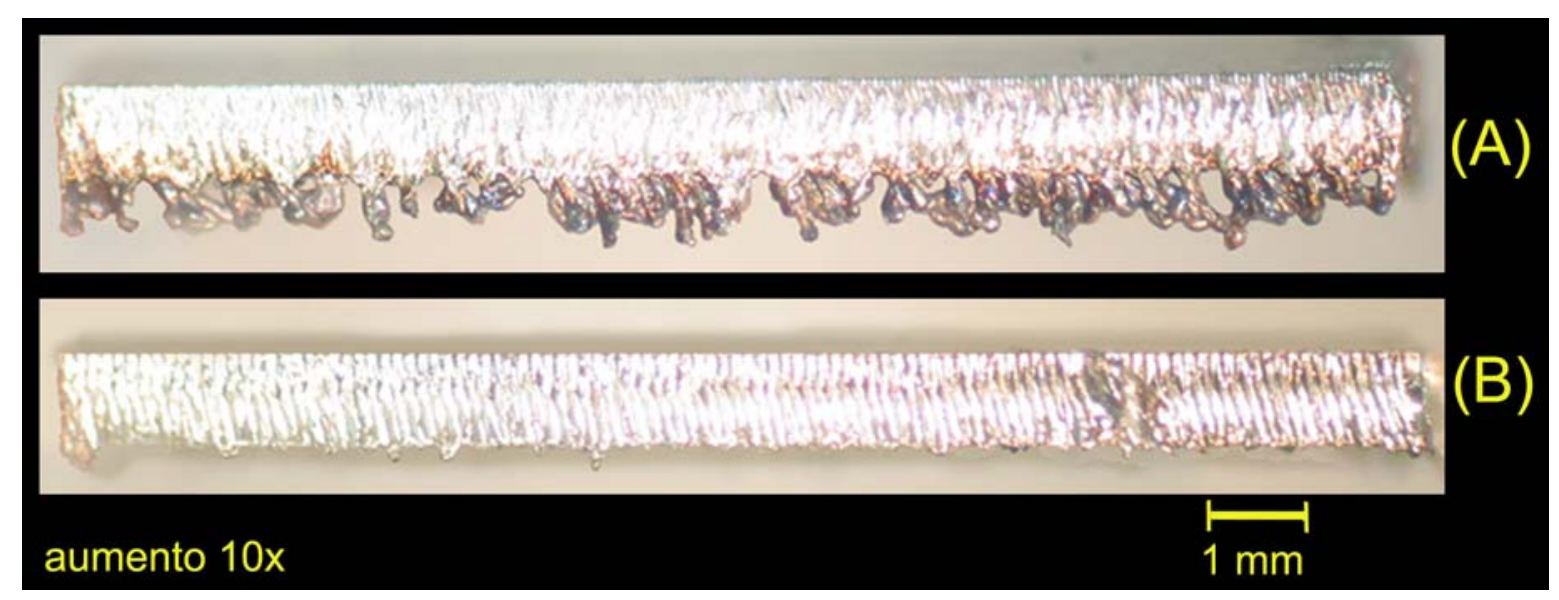

Figura 62 - Aderência de rebarba na borda de corte (a) na pior condição (b) melhor resultado para DOE com 6 fatores.

Por meio das imagens visualizadas na Figura 62, verifica-se o contraste das usinagens na pior e melhor condição de processo. Essa diferença é um indicativo que a aplicação do DOE auxilia, como também possibilita otimizar o corte a laser. 
Com base nesses indícios, optou-se por prosseguir com a metodologia do planejamento experimental a fim de se aprimorar e obter um acabamento superior ao alcançado.

Estabeleceu-se um novo arranjo fatorial com apenas quatro fatores a dois níveis, no qual os parâmetros comprimento focal da lente $(E)$ e posição do foco $(F)$ foram suprimidos, conforme indicado na Tabela 32.

Desta forma, fixou-se a variável (E) com o uso da lente de $100 \mathrm{~mm}$ por apresentar melhores resultados, como também a taxa de influência da posição do foco foi desconsiderada pelo pouco efeito observado.

As faixas de valores para nível alto (1) e baixo (-1) dos três parâmetros: velocidades de corte, pressão de gás e largura temporal, foram redefinidas para ampliar o campo de investigação.

Teoricamente, ao contrário do que se verificou no gráfico de influência, a intensidade do feixe laser sobre a superfície do material é um fator muito importante na dinâmica de formação da poça líquida na região de corte. Quanto mais curto é o pulso (e consequentemente mais intenso), maiores são as taxas de evaporação ${ }^{145}$, o que resulta em menor quantidade de material fundido.

Além da consideração inicial relativa aos parâmetros de energia e diâmetro do pulso, é imperativa a análise da possível influência exercida pela variação da largura temporal. Diante disso, selecionou-se uma largura temporal de $0,5 \mathrm{~ms}$ e $0,9 \mathrm{~ms}$.

Verificou-se que o efeito no nível baixo (-1) para os fatores velocidade de corte e pressão de gás foi desfavorável, ocasionando acúmulo de rebarba. Em virtude disso, as escalas foram alteradas para os novos níveis baixo e alto, para velocidade de (180 e $300 \mathrm{~mm} \cdot \mathrm{min}^{-1}$ ) e para gás de assistência de (80 e 120 psi). 
Tabela 32 - Modelo experimental ensaio DOE para 4 fatores a 2 níveis (Rebarba).

\begin{tabular}{|c|c|c|c|c|c|c|c|}
\hline \multicolumn{8}{|c|}{ Ensaio fatorial $\mathbf{2}^{(4)}=16$ (DOE realizado na CPML) } \\
\hline \multirow{7}{*}{$\begin{array}{c}N^{\circ} \text { do } \\
\text { teste }\end{array}$} & \multirow{3}{*}{2 níveis } & \multicolumn{4}{|c|}{ Fatores de Controle } & \multirow{7}{*}{\multicolumn{2}{|c|}{$\begin{array}{c}\text { Resposta } \\
\text { área } \\
\text { de } \\
\text { rebarbas } \\
\left(\mathbf{m m}^{2}\right)\end{array}$}} \\
\hline & & $\begin{array}{l}\text { Energia } \\
\text { do Pulso }\end{array}$ & $\begin{array}{l}\text { Largura } \\
\text { Temporal } \\
\text { do Pulso }\end{array}$ & $\begin{array}{c}\text { Pressão } \\
\text { Gás }\end{array}$ & $\begin{array}{l}\text { Vel. de } \\
\text { Corte }\end{array}$ & & \\
\hline & & {$[\boldsymbol{J}]$} & [ms] & [psi] & [mm/min] & & \\
\hline & nível (1) & 1,2 & 0,9 & 120 & 300 & & \\
\hline & $\mid$ nível (-1) & 0,6 & 0,5 & 80 & 180 & & \\
\hline & Ordem & & odelo Base & 2 (a quar & ta) & & \\
\hline & aleatória & $\mathbf{A}$ & $\mathbf{B}$ & $\mathbf{C}$ & $\mathbf{D}$ & & \\
\hline 1 & $2=24$ & -1 & -1 & -1 & -1 & Y1 (1) & Y17(2) \\
\hline 1 & 2 e 24 & 0,6 & 0,5 & 80 & 180 & 0,781 & 0,604 \\
\hline 2 & $12 \quad 21$ & +1 & -1 & -1 & -1 & Y2 (1) & Y18(2) \\
\hline 2 & $13 \mathrm{e} 31$ & 1,2 & 0,5 & 80 & 180 & 2,518 & 2,235 \\
\hline$a$ & $16 \quad 30$ & -1 & +1 & -1 & -1 & Y3 (1) & Y19(2) \\
\hline 3 & 16 e 30 & 0,6 & 0,9 & 80 & 180 & 0,699 & 2,259 \\
\hline & & +1 & +1 & -1 & -1 & Y4 (1) & Y2O(2) \\
\hline 4 & 20 e 27 & 1,2 & 0,9 & 80 & 180 & 2,534 & 2,295 \\
\hline 5 & $9=23$ & -1 & -1 & +1 & -1 & Y5 (1) & Y21 (2) \\
\hline & $9=23$ & 0,6 & 0,5 & 120 & 180 & 0,387 & 0,379 \\
\hline 6 & 5 & +1 & -1 & +1 & -1 & Y6 (1) & Y22 (2) \\
\hline 0 & $3 e 14$ & 1,2 & 0,5 & 120 & 180 & 2,374 & 2,388 \\
\hline 7 & $7=1$ & -1 & +1 & +1 & -1 & Y7 (1) & Y23 (2) \\
\hline$f$ & 7 e 10 & 0,6 & 0,9 & 120 & 180 & 0,134 & 0,137 \\
\hline 0 & $18=28$ & +1 & +1 & +1 & -1 & Y8 (1) & Y24 (2) \\
\hline 8 & $18 \mathrm{e} 28$ & 1,2 & 0,9 & 120 & 180 & 0,522 & 0,471 \\
\hline 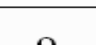 & $11=8$ & -1 & -1 & -1 & +1 & Y9 (1) & Y25 (2) \\
\hline 9 & $11 \mathrm{e} 22$ & 0,6 & 0,5 & 80 & 300 & 1,409 & 1,429 \\
\hline 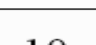 & 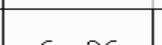 & +1 & -1 & -1 & +1 & Y10(1) & Y26 (2) \\
\hline 10 & 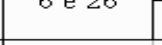 & 1,2 & 0,5 & 80 & 300 & 0,726 & 0,709 \\
\hline 1 & 100 & -1 & +1 & -1 & +1 & Y11 (1) & Y27 (2) \\
\hline 11 & $12 \mathrm{e} 21$ & 0,6 & 0,9 & 80 & 300 & 0,724 & 0,654 \\
\hline 12 & $=25$ & +1 & +1 & -1 & +1 & Y12(1) & Y28(2) \\
\hline 12 & $3 \mathrm{e} 20$ & 1,2 & 0,9 & 80 & 300 & 3,331 & 3,419 \\
\hline 12 & $4-15$ & -1 & -1 & +1 & +1 & Y13 (1) & Y29 (2) \\
\hline 13 & 4 e 15 & 0,6 & 0,5 & 120 & 300 & 1,008 & 0,864 \\
\hline 14 & 8017 & +1 & -1 & +1 & +1 & Y14 (1) & Y30 (2) \\
\hline 14 & $8 \mathrm{e} 17$ & 1,2 & 0,5 & 120 & 300 & 0,565 & 0,499 \\
\hline 15 & 1020 & -1 & +1 & +1 & +1 & Y15(1) & Y31 (2) \\
\hline 15 & $1 \mathrm{e} 29$ & 0,6 & 0,9 & 120 & 300 & 0,175 & 0,160 \\
\hline & & +1 & +1 & +1 & +1 & Y16 (1) & Y32 (2) \\
\hline 16 & 19 e 32 & 1,2 & 0,9 & 120 & 300 & 0,685 & 0,729 \\
\hline
\end{tabular}

Como no experimento anterior de seis fatores, após dispor dos valores da quantidade de rebarba (coluna Resposta - Réplicas) para cada situação, analisou-se 
o conjunto dos gráficos e diagramas de influência dos quatro parâmetros, representados na Figura 63 e na Figura 64.

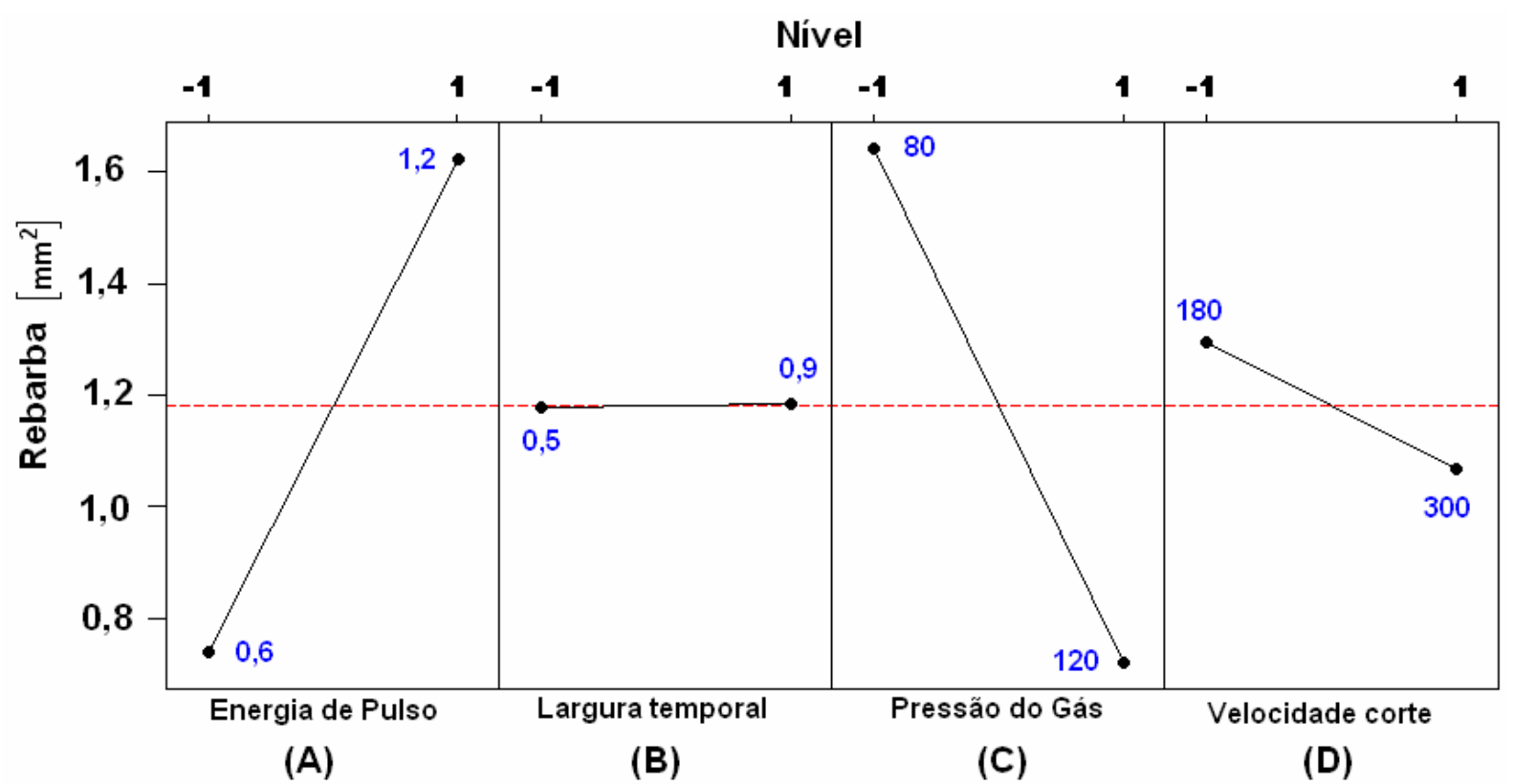

Figura 63 - Gráfico de influência para cada parâmetro em resposta a rebarba - (4 fatores).

Diagrama de Pareto

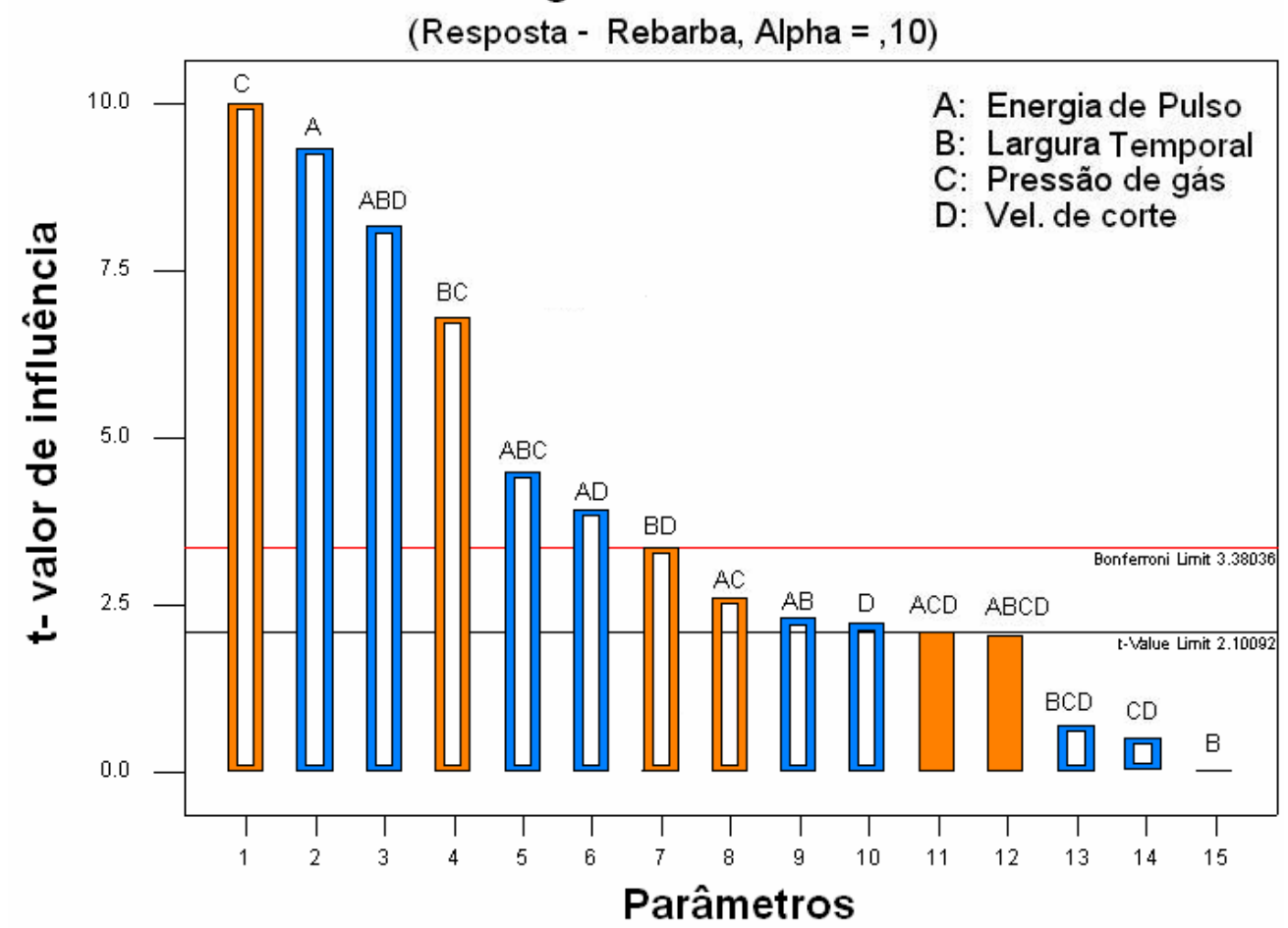

Figura 64 - Diagrama de influência individual e das interações para DOE com 4 fatores. 
Verificou-se a mesma tendência da análise DOE - (6 fatores) em relação aos parâmetros de pressão do gás (C) e da velocidade de corte (D), ou seja, a concentração de rebarbas foi reduzida mediante o aumento de seus valores.

Pelo gráfico de Pareto (Figura 64), observa-se que a pressão do gás está entre as variáveis de maior influência no processo, como já visto no modelo anterior. $\mathrm{O}$ ângulo de abertura da reta para energia (A) é acentuado, o que indicaria um efeito de elevada significância. Entretanto, os testes referentes aos dois arranjos fatoriais (6 fatores e 4 fatores) quando comparados, permitem uma avaliação com maior coerência. A comparação entre os quatro parâmetros das duas análises está representada na Figura 65.

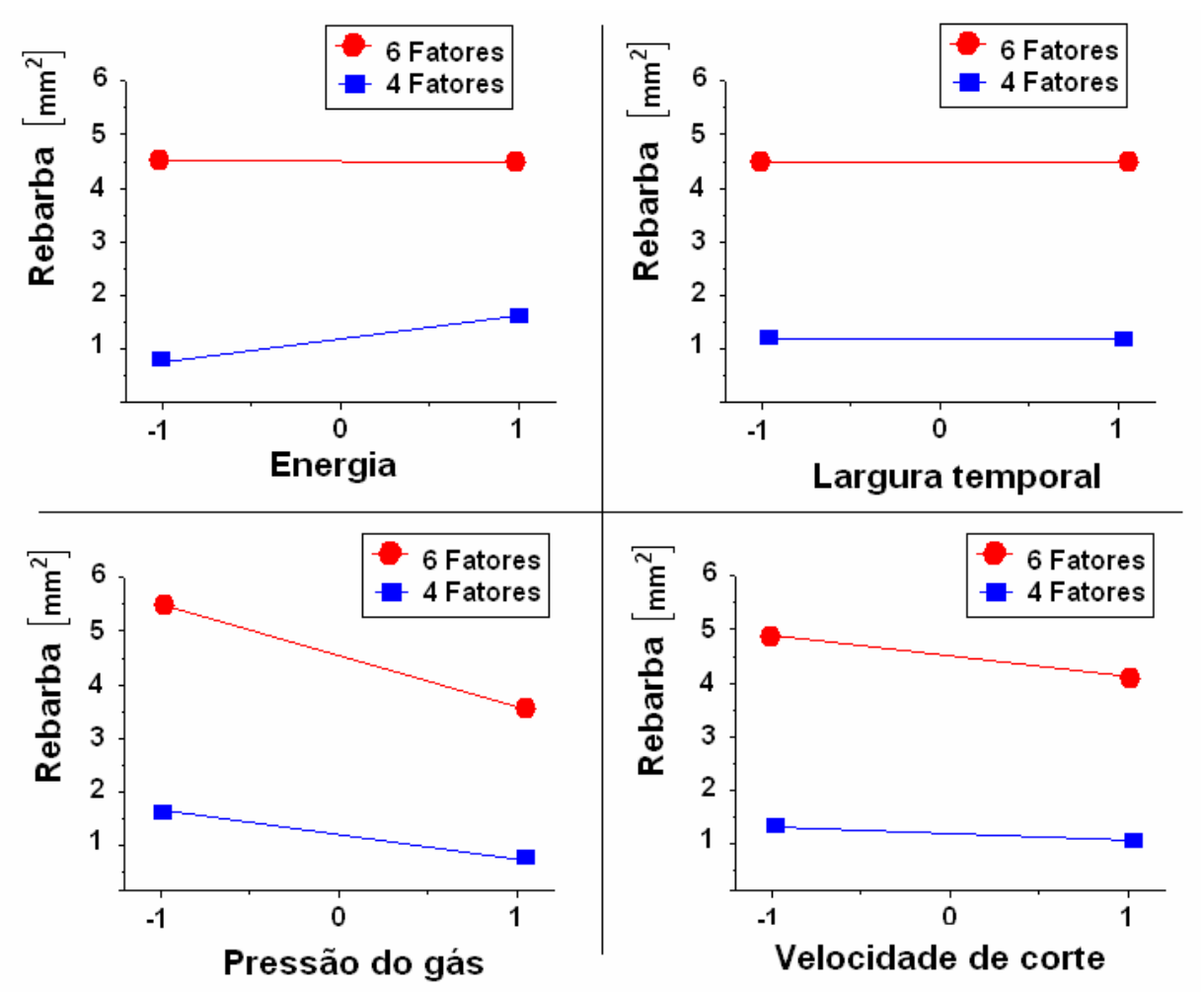

Figura 65 - Comparação entre planejamento experimental de 6 e 4 fatores.

Apesar da divergência entre alguns resultados relativos a interação entre fatores e ao grau de influência de cada um, nota-se ao examinar os gráficos, uma mesma inclinação das variáveis do processo de cada planejamento proposto. 
Essa semelhança pode apontar que por meio da metodologia DOE, atingiu-se um patamar de otimização dos parâmetros em benefício da qualidade do acabamento superficial de corte.

Destaca-se na Figura 66 a evidente variação de aderência das rebarbas entre as duas amostras usinadas em conformidade as diferentes configurações do planejamento experimental.

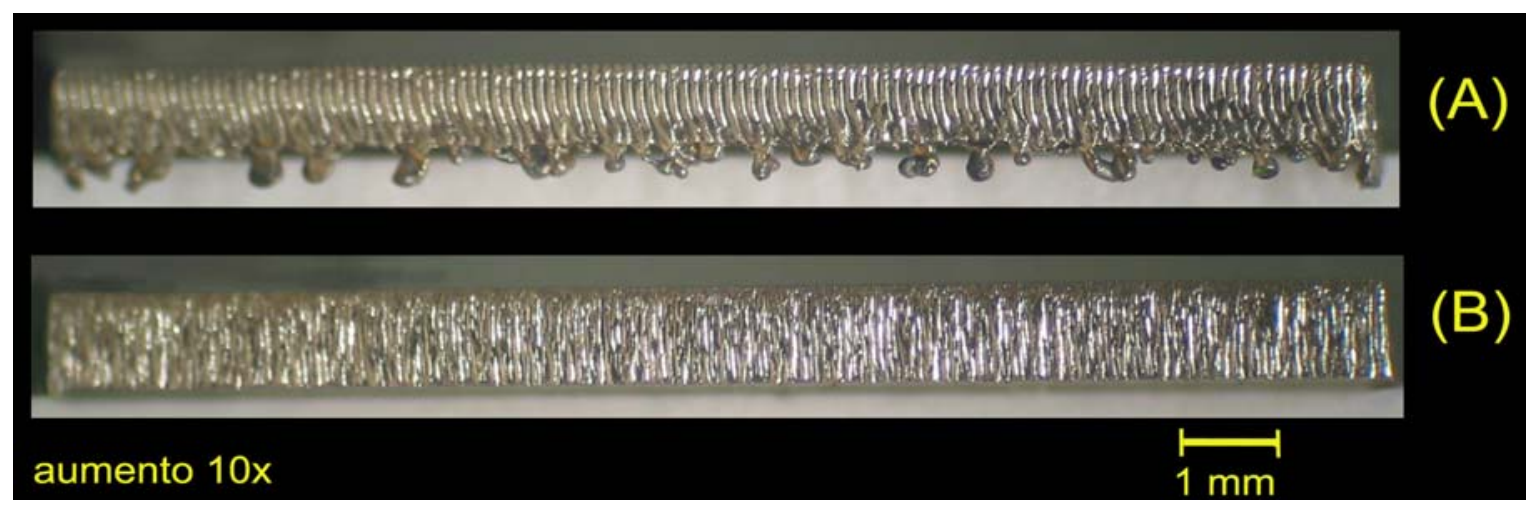

Figura 66 - Fotografia da superfície de corte (a) na pior condição (b) melhor resultado para DOE com 4 fatores.

Ao se calcular a média entre os valores da formação de rebarbas, obtidos pelo arranjo fatorial inicial com seis fatores e o último realizado com quatro variáveis, verificou-se uma taxa de redução do material ressolidificado na borda de corte, aproximadamente quatro vezes menor, conforme apresentado na Figura 67.

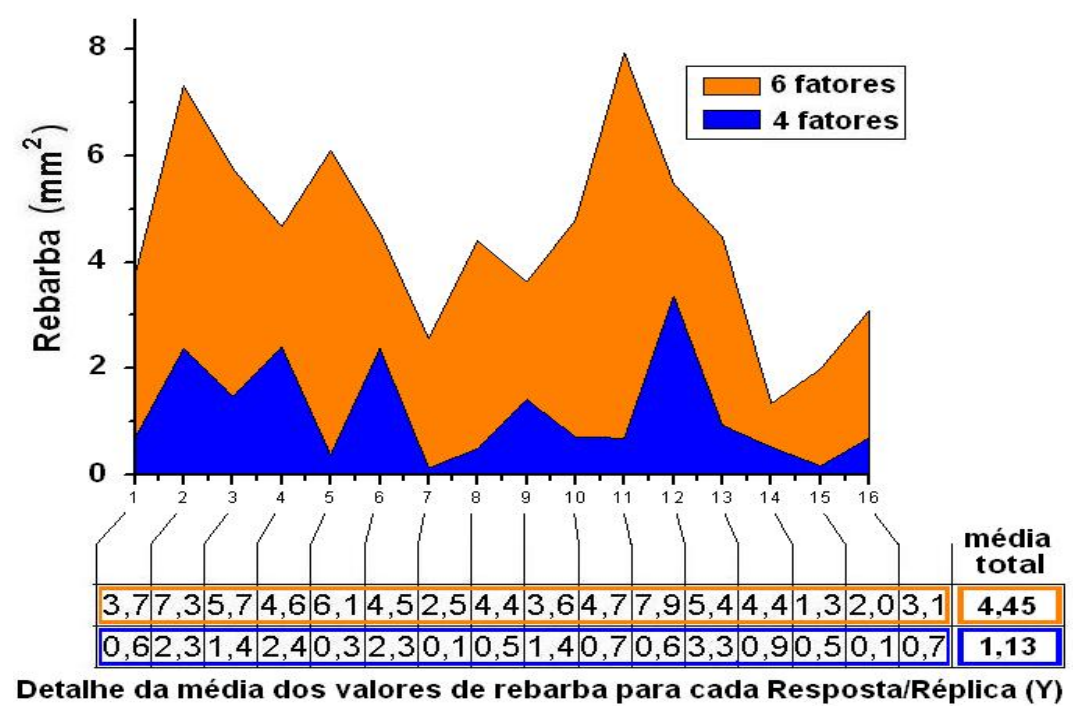

Figura 67 - Gráfico comparativo da quantidade de rebarbas entre DOE com 6 e 4 fatores. 
O gráfico também fornece um perfil da orientação de ambos planejamentos, descrito pelas inclinações das retas, demonstrando uma similaridade entre picos e vales. Isso pode caracterizar uma coerência do método aplicado em situar uma região de convergência ao resultado desejado.

Como já citado no capítulo anterior, procurou-se validar a técnica DOE pela obtenção de réplicas por meio de um equipamento laser industrial. Os testes foram executados valendo-se das averiguações realizadas, mediante o modelo de análise fatorial de quatro fatores.

Nessa investigação, procurou-se manter os valores equivalentes ao realizado na CPML, assim como a mesma seleção de parâmetros, procurando parametrizar os ensaios. Contudo, necessitou-se adequar as escalas por serem sistemas diferentes.

Ajustaram-se as faixas de valores do nível alto (1) e baixo $(-1)$ para os quatro parâmetros em: energia de [0,65 e 1,05 (J)]; largura temporal de $[0,4$ e 0,5 (ms)]; pressão do gás de [80 e 120 (psi)]; velocidade de [(300 e 500 mm.min $\left.\left.{ }^{-1}\right)\right]$. Esses dados, como também os valores da quantidade de rebarba, estão dispostos na Tabela 33.

Os dados obtidos revelaram uma divergência entre os lados opostos da superfície de usinagem de uma mesma amostra. Em conseqüência disso, estabeleceu-se uma distribuição diferenciada, adequando as tabelas e gráficos, para melhor investigar essas alterações. 
Tabela 33 - Modelo experimental ensaio DOE para 4 fatores a 2 níveis (LASAG- Rebarba).

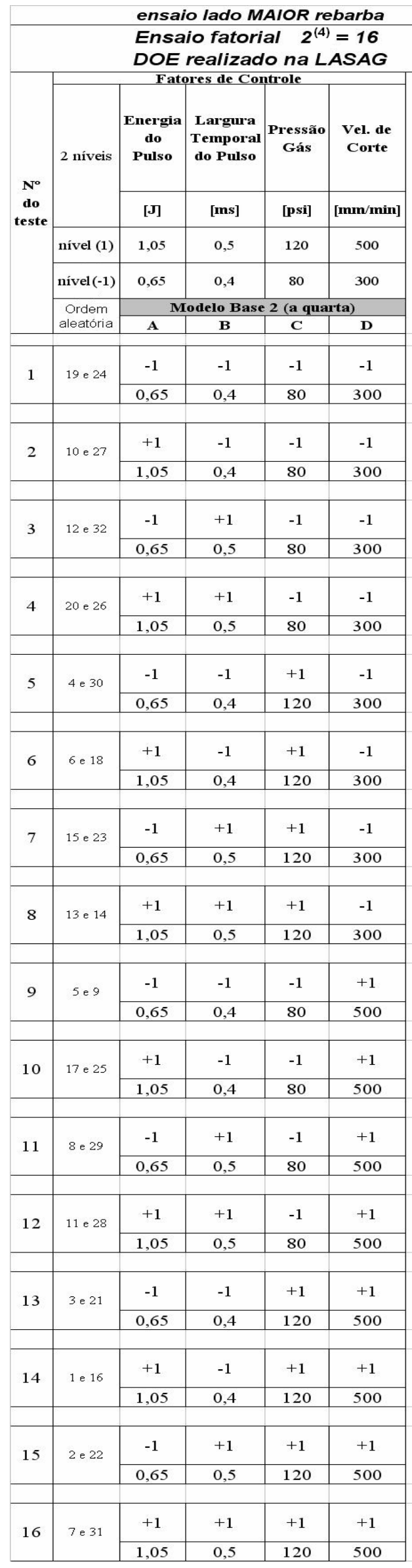

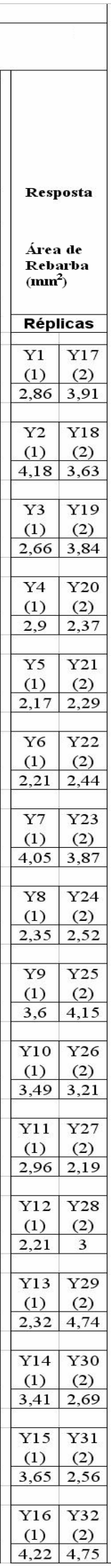

\begin{tabular}{|c|c|c|c|c|c|c|c|}
\hline & & ensai & io lado $\mathrm{m}$ & enor re & barba & & \\
\hline & & $\begin{array}{l}\text { Ensa } \\
\text { DOE }\end{array}$ & $\begin{array}{l}\text { io fatori } \\
\text { realizad }\end{array}$ & $\begin{array}{l}\text { al } 2^{(4)} \\
\text { o na } L\end{array}$ & $\begin{array}{c}=16 \\
A S A G\end{array}$ & & \\
\hline & & Fato & ores de Con & trole & & & \\
\hline & 2 níveis & $\begin{array}{c}\text { Energia } \\
\text { do } \\
\text { Pulso }\end{array}$ & \begin{tabular}{|c|} 
Largura \\
Temporal \\
do Pulso
\end{tabular} & $\begin{array}{c}\text { Pressão } \\
\text { Gás }\end{array}$ & $\begin{array}{c}\text { Vel. de } \\
\text { Corte }\end{array}$ & & \\
\hline do & & [J] & {$[\mathrm{ms}]$} & [psi] & {$[\mathbf{m m} / \mathbf{m i n}]$} & Resp & osta \\
\hline & nível (1) & 1,05 & 0,5 & 120 & 500 & & \\
\hline & nível (-1) & 0,65 & 0,4 & 80 & 300 & Reb: & $\begin{array}{l}\text { arba } \\
\left.2^{2}\right)\end{array}$ \\
\hline & Ordem & & [odelo Base & 2 (a qua & Irta) & & \\
\hline & aleatória & $\mathbf{A}$ & \begin{tabular}{|c|}
$\mathbf{B}$ \\
\end{tabular} & C & D & Répl & icas \\
\hline 1 & 16 e 17 & -1 & -1 & -1 & -1 & $\begin{array}{l}\text { Y1 } \\
\text { (1) }\end{array}$ & $\begin{array}{l}\text { Y17 } \\
\text { (2) }\end{array}$ \\
\hline & & 0,65 & 0,4 & 80 & 300 & 2,16 & 2,44 \\
\hline & & & & & & & \\
\hline 2 & 10 e 22 & +1 & -1 & -1 & -1 & $\begin{array}{l}\text { Y2 } \\
\text { (1) }\end{array}$ & $\begin{array}{l}\text { Y18 } \\
(2)\end{array}$ \\
\hline & & 1,05 & 0,4 & 80 & 300 & 2,52 & 2,42 \\
\hline & & & & & & & \\
\hline 3 & 18 e 32 & -1 & +1 & -1 & -1 & $\begin{array}{l}\text { Y3 } \\
\text { (1) }\end{array}$ & $\begin{array}{l}\text { Y19 } \\
\text { (2) }\end{array}$ \\
\hline & & 0,65 & 0,5 & 80 & 300 & 2,03 & 3,46 \\
\hline & & & & & & & \\
\hline 4 & 11 e 24 & +1 & +1 & -1 & -1 & $\begin{array}{l}\text { Y4 } \\
(1)\end{array}$ & $\begin{array}{l}\text { Y20 } \\
(2)\end{array}$ \\
\hline & & 1,05 & 0,5 & 80 & 300 & 2,38 & 1,86 \\
\hline & & & & & & & \\
\hline 5 & 7 e 30 & -1 & -1 & +1 & -1 & $\begin{array}{l}\text { Y5 } \\
(1)\end{array}$ & $\begin{array}{l}\text { Y21 } \\
(2)\end{array}$ \\
\hline & & 0,65 & 0,4 & 120 & 300 & 1,74 & 1,87 \\
\hline & & & & & & & \\
\hline 6 & 15 e 27 & +1 & -1 & +1 & -1 & $\begin{array}{l}\text { Y6 } \\
(1)\end{array}$ & $\begin{array}{l}\text { Y22 } \\
(2)\end{array}$ \\
\hline & & 1,05 & 0,4 & 120 & 300 & 1,97 & 1,86 \\
\hline & & & & & & & \\
\hline 7 & 2 e 3 & -1 & +1 & +1 & -1 & $\begin{array}{l}\mathrm{Y} 7 \\
(1)\end{array}$ & $\begin{array}{l}\text { Y23 } \\
(2)\end{array}$ \\
\hline & & 0,65 & 0,5 & 120 & 300 & 3,29 & 3,37 \\
\hline & & & & & & & \\
\hline 8 & 25 e 31 & +1 & +1 & +1 & -1 & $\begin{array}{l}\text { Y8 } \\
(1)\end{array}$ & $\begin{array}{l}\text { Y24 } \\
\text { (2) }\end{array}$ \\
\hline & & 1,05 & 0,5 & 120 & 300 & 1,69 & 1,67 \\
\hline & & & & & & & \\
\hline 9 & 8 e 26 & -1 & -1 & -1 & +1 & $\begin{array}{l}\text { Y9 } \\
\text { (1) }\end{array}$ & $\begin{array}{l}\text { Y25 } \\
\text { (2) }\end{array}$ \\
\hline & & 0,65 & 0,4 & 80 & 500 & 2,99 & 2,61 \\
\hline & & & & & & & \\
\hline 10 & $6 e 23$ & +1 & -1 & -1 & +1 & $\begin{array}{c}\text { Y10 } \\
(1)\end{array}$ & $\begin{array}{l}\text { Y26 } \\
(2)\end{array}$ \\
\hline & & 1,05 & 0,4 & 80 & 500 & 2,57 & 2,57 \\
\hline & & & & & & & \\
\hline 11 & 4 e 14 & -1 & +1 & -1 & +1 & $\begin{array}{l}\text { Y11 } \\
(1)\end{array}$ & $\begin{array}{l}\text { Y27 } \\
\text { (2) }\end{array}$ \\
\hline & & 0,65 & 0,5 & 80 & 500 & 1,9 & 2,08 \\
\hline & & & & & & & \\
\hline 12 & 1 e 9 & +1 & +1 & -1 & +1 & $\begin{array}{l}\text { Y12 } \\
(1)\end{array}$ & $\begin{array}{l}\text { Y28 } \\
(2)\end{array}$ \\
\hline & & 1,05 & 0,5 & 80 & 500 & 1,82 & 1,67 \\
\hline & & & & & & & \\
\hline 13 & 19 e 29 & -1 & -1 & +1 & +1 & $\begin{array}{l}\text { Y13 } \\
(1)\end{array}$ & $\begin{array}{l}\text { Y29 } \\
(2)\end{array}$ \\
\hline & & 0,65 & 0,4 & 120 & 500 & 2,17 & 2,33 \\
\hline & & & & & & & \\
\hline 14 & 12 e 28 & +1 & -1 & +1 & +1 & $\begin{array}{l}\text { Y14 } \\
(1)\end{array}$ & $\begin{array}{l}\text { Y30 } \\
\text { (2) }\end{array}$ \\
\hline & & 1,05 & 0,4 & 120 & 500 & 3,2 & 2,03 \\
\hline & & & & & & & \\
\hline 15 & 13 e 21 & -1 & +1 & +1 & +1 & $\begin{array}{l}\text { Y15 } \\
\text { (1) }\end{array}$ & $\begin{array}{l}\text { Y31 } \\
\text { (2) }\end{array}$ \\
\hline & & 0,65 & 0,5 & 120 & 500 & 2,29 & 1,91 \\
\hline & & & & & & & \\
\hline 16 & 5 e 20 & +1 & +1 & +1 & +1 & $\begin{array}{l}\text { Y16 } \\
(1)\end{array}$ & $\begin{array}{l}\text { Y32 } \\
(2)\end{array}$ \\
\hline & & 1,05 & 0,5 & 120 & 500 & 2,53 & 2,49 \\
\hline
\end{tabular}


Realizou-se a análise do grau de influência individual e das interações entre as variáveis seguindo os mesmos padrões de avaliação. Os gráficos gerados podem ser visualizados na Figura 68.

Gráfico de influência para cada parâmetro em resposta a Rebarba

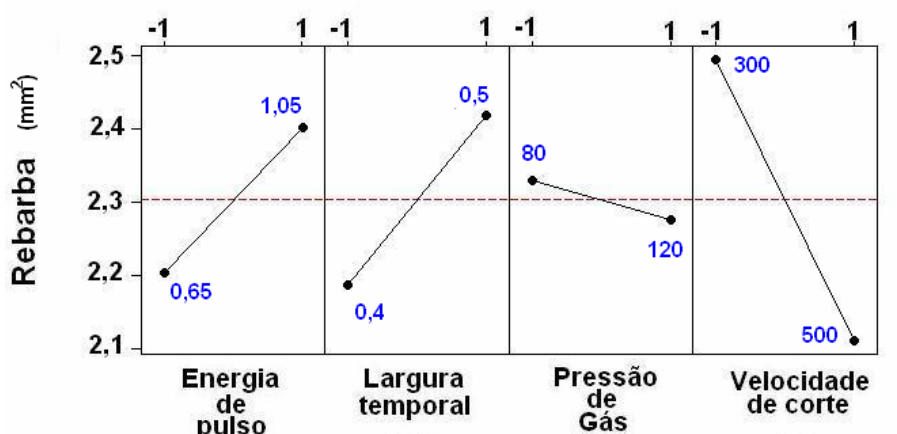

(A)
(B)

Lado de menor rebarba
Diagrama de Pareto para as influências dos parâmetros e suas interações

(Resposta - Rebarba, Alpha $=, 10)$

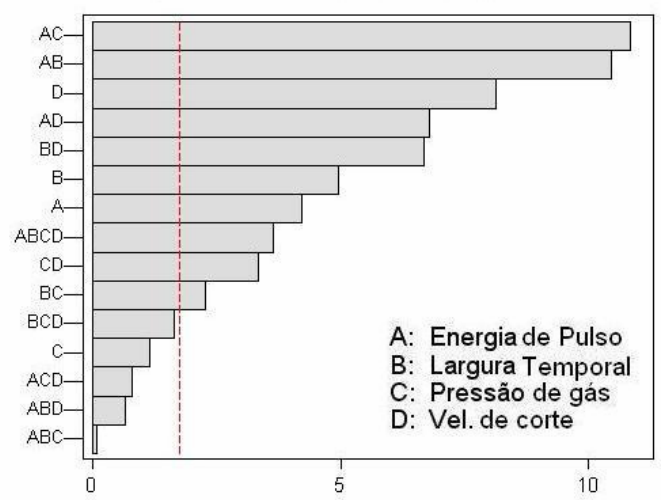

Gráfico de influência para cada parâmetro em resposta a Rebarba Diagrama de Pareto para as influências

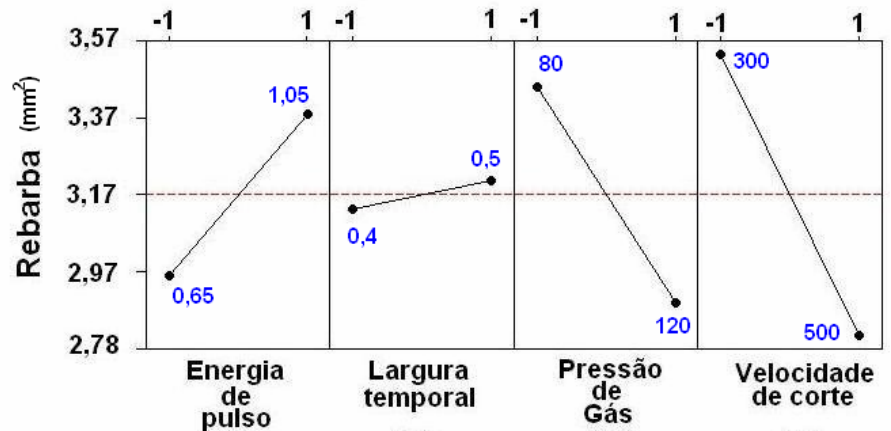

(A)

(B)

(C)

(D)

Lado de maior rebarba

(B)

Figura 68 - Diagramas de influência para DOE 4 fatores na LASAG:

(A) lado de menor rebarba $(B)$ lado de maior rebarba

Nota-se que apesar da diferença na inclinação das retas relativas aos parâmetros largura temporal e pressão do gás, existe uma semelhança em ambos gráficos. Provavelmente, essa irregularidade ocasionou uma discrepância dos efeitos das variáveis e suas interações, distorcendo a seqüência apresentada no diagrama de Pareto entre os lados de maior e menor rebarba. 
Entretanto, a interação entre os fatores energia de pulso (A) e largura temporal (B) está evidenciada em ambos diagramas, como de ampla influência sob a resposta rebarba. Esse fato corrobora a teoria de redução da quantidade de material fundido ao empregar-se um processo com pulsos mais curtos.

O modo de operação do laser pulsado e contínuo provoca diferentes efeitos na dinâmica de distribuição térmica no processo. Uma característica do regime contínuo é o alto nível de potência média, que proporciona velocidades de usinagem mais altas. Por outro lado a qualidade do corte é comprometida em virtude do maior aquecimento para remoção do material.

No sistema pulsado é possível manter uma alta potência pico, concomitantemente, com uma potência média baixa, graças ao maior numero de parâmetros disponíveis para controle. Isso permite irradiar um alvo com uma alta potência sobre uma pequena área em um curto espaço de tempo, reduzindo-se a dissipação do calor pelo metal a fim de evitar-se a aderência do material fundido.

Portanto, a intensidade que é função da energia do pulso (fator A), largura temporal (fator B) e o diâmetro do foco, conforme descrita na equação (7) da página 64, é um aspecto importante no mecanismo de interação do laser com a matéria.

Todos os fatos relatados, como os resultados obtidos tornam evidente a complexidade no controle do balanço energético para configurar uma otimização do processo.

Para apurar as variações introduzidas pelo próprio sistema de processamento a laser foram executados cortes idênticos de um contorno retangular para dez amostras sob as mesmas condições de usinagem e dessa maneira aferir a margem de erros. Estes valores estão descritos na Tabela 34. 
Tabela 34 - Margem de erro no processo de captura da rebarba.

\begin{tabular}{|c|c|c|c|c|c|c|c|c|c|}
\hline \multicolumn{10}{|c|}{ Margem de erro na captura da área das rebarbas } \\
\hline \multicolumn{5}{|c|}{ CPML } & \multicolumn{5}{|c|}{ LASAG } \\
\hline $\begin{array}{c}\mathrm{N}^{\circ} \text { da } \\
\text { Amostra }\end{array}$ & Descriçäo & $\begin{array}{l}\text { Área } \\
\left(\mathrm{mm}^{2}\right)\end{array}$ & $\begin{array}{c}\text { Comprimento } \\
\text { via software } \\
(\mathrm{mm})\end{array}$ & $\begin{array}{c}\text { Largura } \\
\text { (mm) }\end{array}$ & $\begin{array}{c}\mathrm{N}^{\circ} \text { da } \\
\text { Amostra }\end{array}$ & Descrição & $\begin{array}{l}\text { Área } \\
\left(\mathrm{mm}^{2}\right)\end{array}$ & $\begin{array}{c}\text { Comprimento } \\
\text { via software } \\
(\mathrm{mm})\end{array}$ & $\begin{array}{c}\text { Largura } \\
\text { (mm) }\end{array}$ \\
\hline \multirow{2}{*}{1} & Lado 1a & 2,806 & 14,699 & 0,507 & \multirow{2}{*}{1} & Lado 1a & 3,191 & 13,805 & 0,413 \\
\hline & Lado 1b & 2,876 & 14,632 & 0,513 & & Lado 1b & 3,953 & 13,853 & 0,569 \\
\hline \multirow{2}{*}{2} & Lado 2a & 2,231 & 14,807 & 0,353 & \multirow{2}{*}{2} & Lado 2a & 3,022 & 13,87 & 0,472 \\
\hline & Lado 2b & 2,793 & 14,894 & 0,457 & & Lado 2b & 4,05 & 13,771 & 0,483 \\
\hline \multirow{2}{*}{3} & Lado 3a & 2,293 & 14,679 & 0,411 & \multirow{2}{*}{3} & Lado 3a & 2,7 & 13,979 & 0,489 \\
\hline & Lado 3b & 2,348 & 14,72 & 0,406 & & Lado 3b & 4,478 & 13,787 & 0,641 \\
\hline \multirow{2}{*}{4} & Lado 4a & 2,761 & 14,825 & 0,38 & \multirow{2}{*}{4} & Lado 4a & 3,119 & 13,663 & 0,561 \\
\hline & Lado 4b & 2,816 & 14,632 & 0,455 & & Lado 4b & 3,922 & 13,787 & 0,609 \\
\hline \multirow{2}{*}{5} & Lado 5a & 2,509 & 14,757 & 0,443 & \multirow{2}{*}{5} & Lado 5a & 2,622 & 13,862 & 0,441 \\
\hline & Lado 5b & 2,522 & 14,757 & 0,488 & & Lado $5 b$ & 3,42 & 13,747 & 0,518 \\
\hline \multirow{2}{*}{6} & Lado 6a & 2,986 & 14,544 & 0,484 & \multirow{2}{*}{6} & Lado 6a & 3,372 & 13,558 & 0,509 \\
\hline & Lado 6b & 2,781 & 14,719 & 0,4 & & Lado 6b & 4,003 & 13,647 & 0,542 \\
\hline \multirow{2}{*}{7} & Lado 7a & 2,403 & 14,437 & 0,345 & \multirow{2}{*}{7} & Lado 7a & 3,088 & 13,82 & 0,52 \\
\hline & Lado 7b & 2,6057 & 14,612 & 0,449 & & Lado $7 b$ & 4,911 & 13,837 & 0,602 \\
\hline \multirow[b]{2}{*}{8} & Lado 8a & 2,2497 & 14,729 & 0,368 & \multirow{2}{*}{8} & Lado 8a & 2,944 & 13,713 & 0,541 \\
\hline & Lado 8b & 2,487 & 14,709 & 0,461 & & Lado 8b & 3,869 & 13,746 & 0,703 \\
\hline & & & & & & & & & \\
\hline \multirow{2}{*}{9} & Lado 9a & 2,782 & 14,786 & 0,458 & \multirow{2}{*}{9} & Lado 9a & 2,868 & 13,927 & 0,442 \\
\hline & Lado 9b & 2,55 & 14,651 & 0,427 & & Lado 9b & 3,681 & 13,762 & 0,538 \\
\hline \multirow[b]{2}{*}{10} & Lado 10a & 2,294 & 14,835 & 0,373 & \multirow[b]{2}{*}{10} & Lado 10a & 3,259 & 13,705 & 0,493 \\
\hline & Lado 10b & 2,273 & 14,796 & 0,369 & & Lado 10b & 4,144 & 13,797 & 0,615 \\
\hline & Média & & $\overline{\overline{\text { Desvio padrẫo }}}$ & 0,278 & & Média & & Desvio padrẵo & 0,24 \\
\hline & Amostras a & 2,531 & amostra a & $10,9 \%$ & & Amostras a & 3,019 & lado a & $7,90 \%$ \\
\hline & Média & 2605 & Desvio padrẫo & 0,207 & & Média & 4043 & Desvio padrẫo & 0,41 \\
\hline & Amostras b & 2,605 & amostra b & $7,9 \%$ & & Amostras b & 4,043 & lado b & $10 \%$ \\
\hline & Média & & Desvio padrẵo & 0,242 & & Média & & Desvio padrẫo & 0,62 \\
\hline & entre todas & 2,568 & amostra a & $9,4 \%$ & & entre todas & 3,531 & amostras & $23 \%$ \\
\hline
\end{tabular}

Nota-se ao examinar os dados gerados no processamento do laser LASAG (Tabela 34) que há uma grande variação entre os valores de cada lado das amostras, como já citado. 
Analisando a média calculada referente a cada lado das amostras independentemente, verifica-se um valor aproximado de 10\%, o qual está dentro da margem de erro do sistema. Ao examinar o valor percentual na soma entre todas as áreas de rebarba, sem considerar a diferença entre seus lados, observa-se um valor de $23 \%$ sobre a área total da média, mais que o dobro da análise diferenciada, ou seja, uma ampla margem de erro.

Essa divergência pode ser um indicativo de que o feixe deste laser apresenta uma polarização preferencial, ou seja, não se trata de um feixe perfeitamente "não polarizado" como especificado no catálogo do equipamento. Isto afetaria o corte provocando alterações na formação das rebarbas nos diferentes sentidos do contorno dos eixos (x, y). Este fato foi confirmado pelo fabricante (LASAG).

\section{Avaliação da microdureza nas amostras cortadas com argônio na CPML.}

Para investigar possíveis alterações na microestrutura das superfícies usinadas em conformidade com o planejamento DOE, aplicou-se o ensaio de microdureza dinâmica instrumentada na amostra que apresentou menor quantidade de rebarba no primeiro lote. Os resultados referentes aos testes indicam uma relativa uniformidade nos valores das médias de dureza, entre as diversas regiões da zona de corte. O primeiro ensaio $(\mathrm{CY})$ destaca-se pelo maior valor medido, provavelmente em razão da transformação martensítica na zona de ressolidificação. Esses valores são observados na Tabela 35 e nas figuras de 69 a 71. 
Tabela 35 - Valores de microdureza instrumentada da amostra CPML- Y(30).

\begin{tabular}{l|cccc}
\hline $\begin{array}{c}\text { Amostra: menor rebarba } \\
\text { CPML - Y(30) } \\
\text { Argônio - 100\% }\end{array}$ & Ensaio & $\begin{array}{c}\text { Dureza } \\
\text { Média } \\
(\mathrm{GPa})\end{array}$ & $\begin{array}{c}\text { Dureza } \\
\text { Média } \\
\text { Vickers (HV) }\end{array}$ & $\begin{array}{c}\text { Módulo de } \\
\text { Elasticidade, E } \\
(\mathrm{GPa})\end{array}$ \\
\hline CY & $1^{\circ}$ & 3,505 & 357 & 90,910 \\
CY perfil & $2^{\circ}$ & 3,125 & 319 & 105,5 \\
CY perfil sub & $3^{\circ}$ & 3,032 & 309 & 93,8 \\
CYMB & $4^{\circ}$ & 3,069 & 313 & 111,9 \\
CYMB REP & $5^{\circ}$ & 3,14 & 320 & 117,3 \\
\hline
\end{tabular}
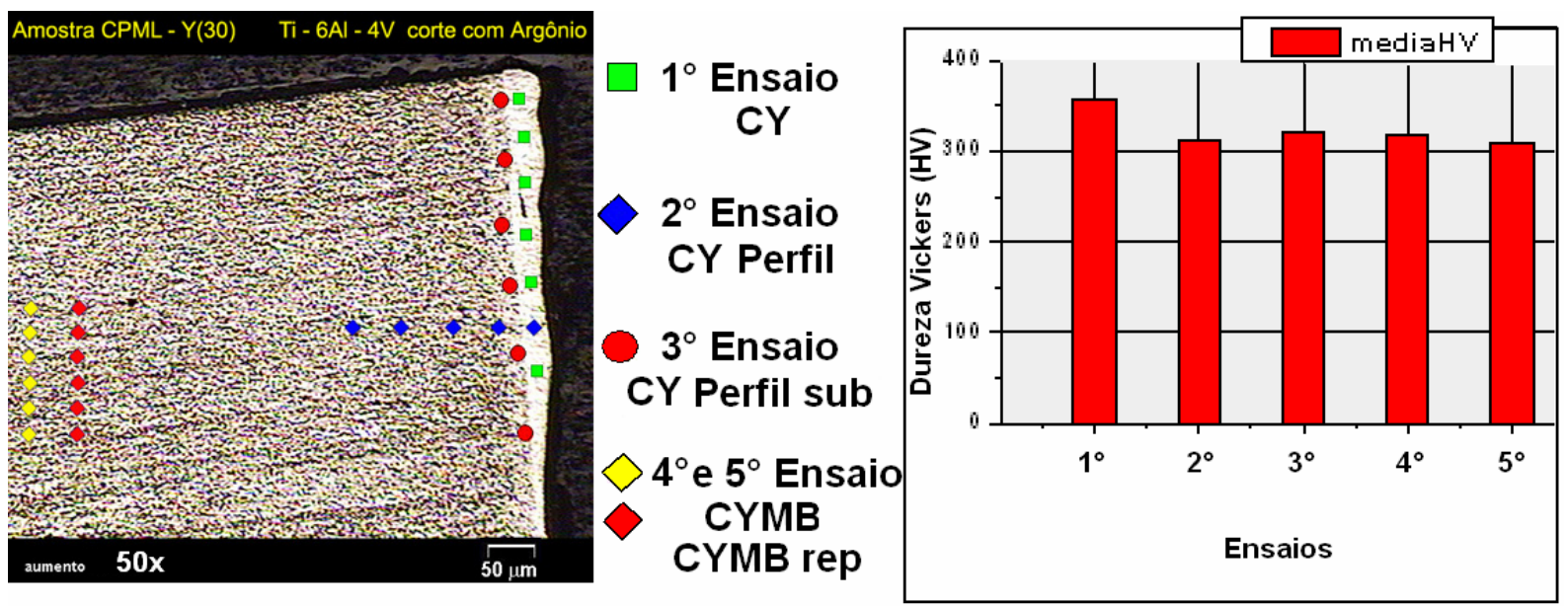

Figura 69 - Micrografia com a seqüência do teste e os valores médios de dureza da liga Ti-6Al-4V usinada a laser com gás argônio [amostra CPML Y(30)].

A amostra CPML $Y(30)$ apresentou um valor médio de dureza de aproximadamente $323 \mathrm{HV}$. Esse endurecimento superficial é bem inferior, quase $50 \%$ menor, em comparação ao valor médio de 600 HV obtido na amostra Ti64laser (corte a laser com uso de nitrogênio). Contudo, verificou-se um valor muito próximo da média de dureza das amostras do conjunto 6804 (aproximadamente $315 \mathrm{HV}$ ), que indica um leve endurecimento superficial. 

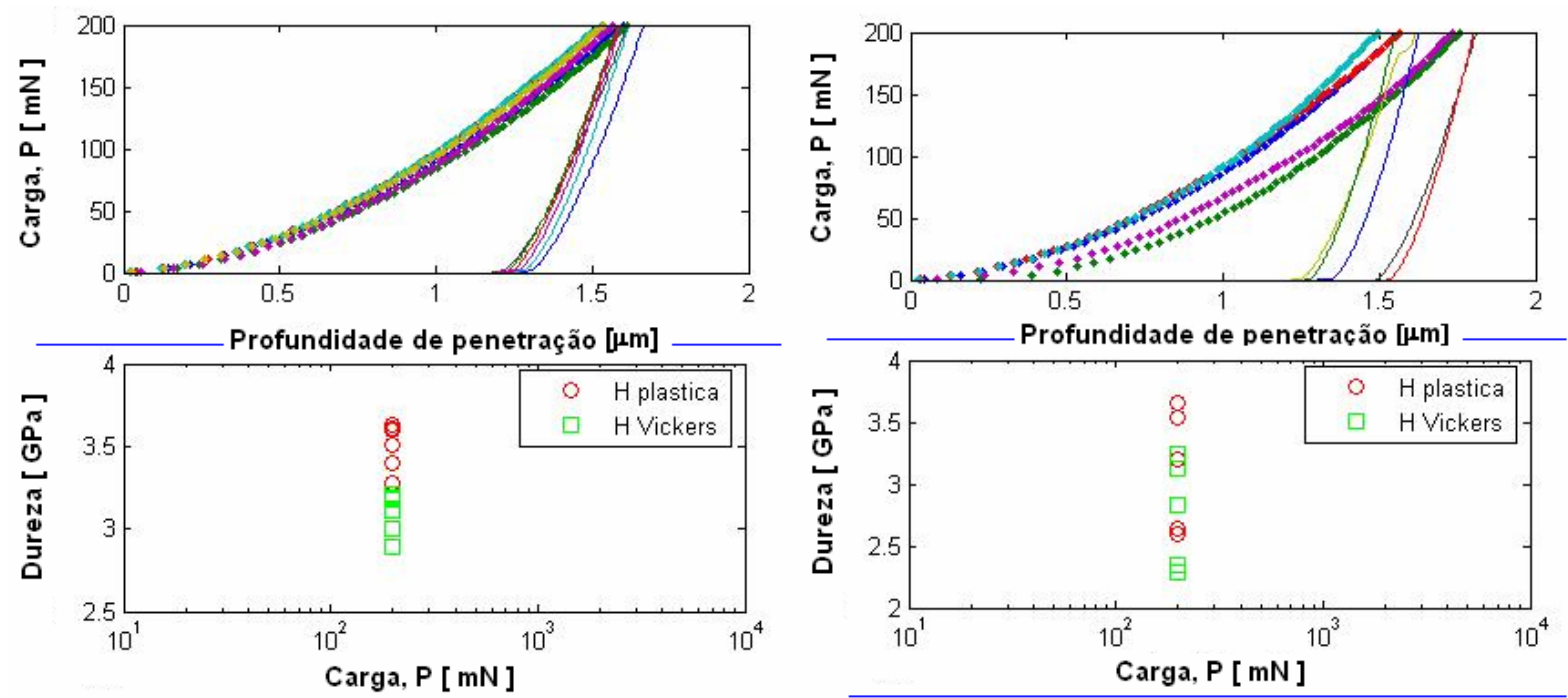

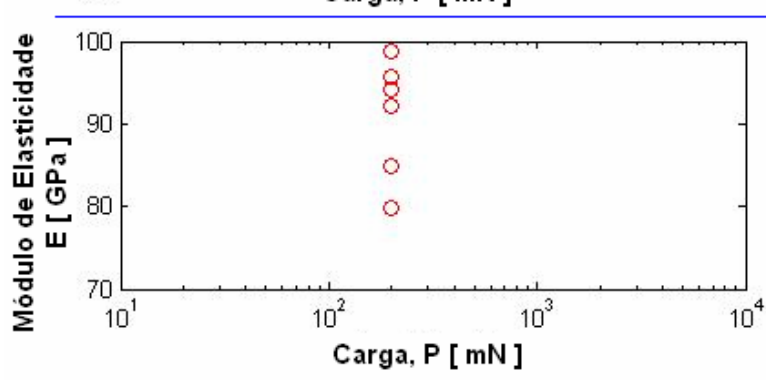

CY

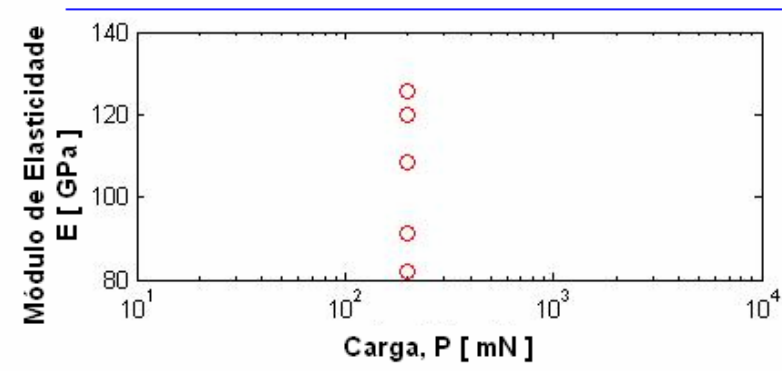

CYperfil

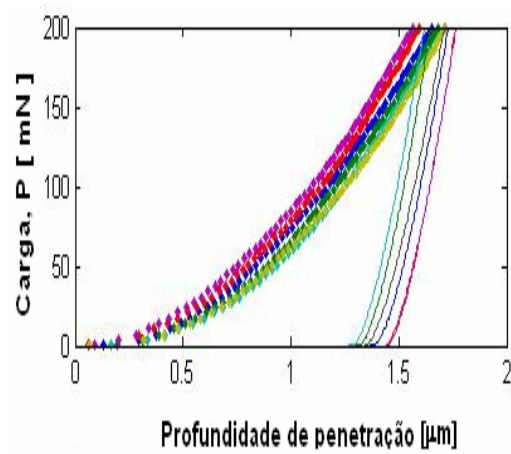

Profundidade de penetração [um]

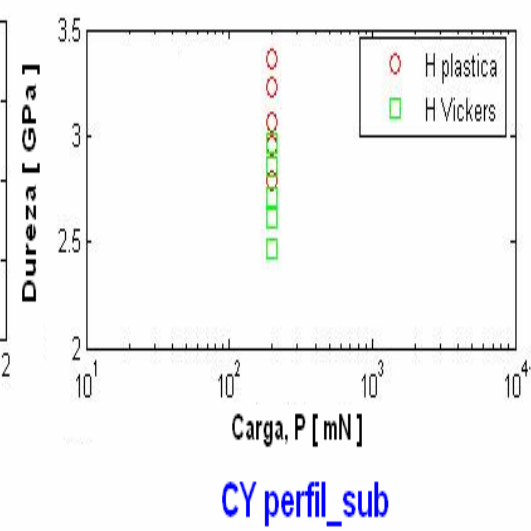

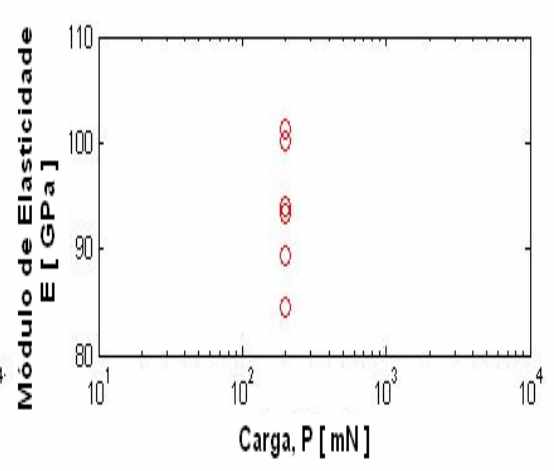

Carga, $P[\mathrm{mN}]$

Figura 70- Gráficos da carga pela profundidade de penetração, Dureza pela carga e Módulo de Elasticidade pela carga do $1^{\circ}$ ao $3^{\circ}$ ensaio de microdureza instrumentada [amostra CPML Y(30)]. 

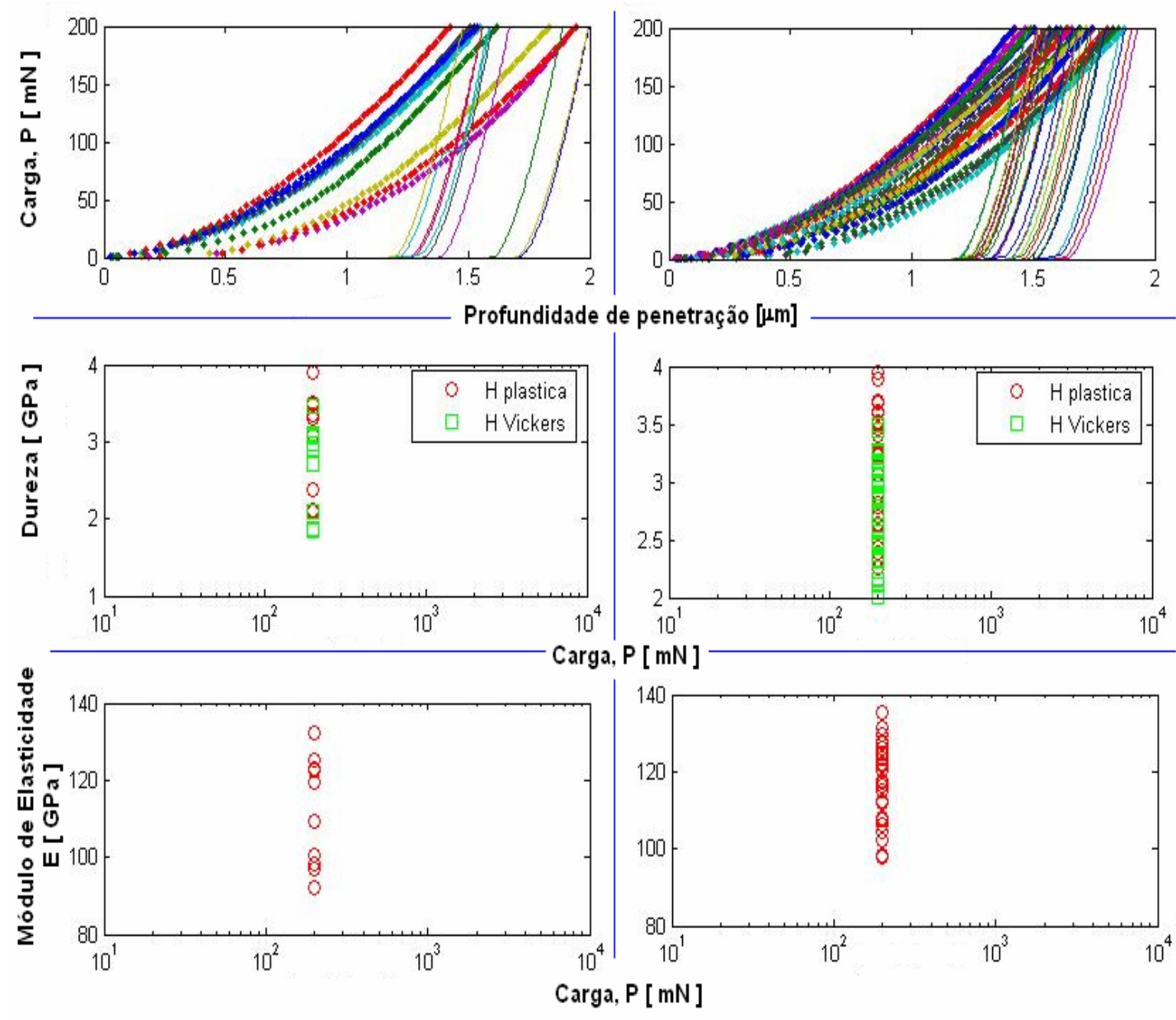

CYMB

\section{CYMB_rep}

Figura 71- Gráficos da carga pela profundidade de penetração, Dureza pela carga e Módulo de Elasticidade pela carga para o $4^{\circ}$ e $5^{\circ}$ ensaio de microdureza instrumentada [amostra CPML Y(30)].

A superfície de corte do titânio processada a laser, relativa à aderência de rebarbas diferenciou-se com a seqüência de aplicação do planejamento fatorial em até seis vezes. Esse fato está indicado na seqüência da figura 72 até figura 76.

Observa-se uma diferença de aproximadamente 4 vezes no dimensional de material ressolidificado aderido nas bordas das amostras CPML Y(30) e CPML Z(7), condição com maior e menor rebarba, respectivamente(Figura 72 e Figura 73). No detalhe da Figura 74 [lado esquerdo - CPML Y(30)], observa-se uma grande formação de rebarba com a presença de martensita fina na zona de fusão. A formação de martensita, também pode ser verificada na Figura 76. 

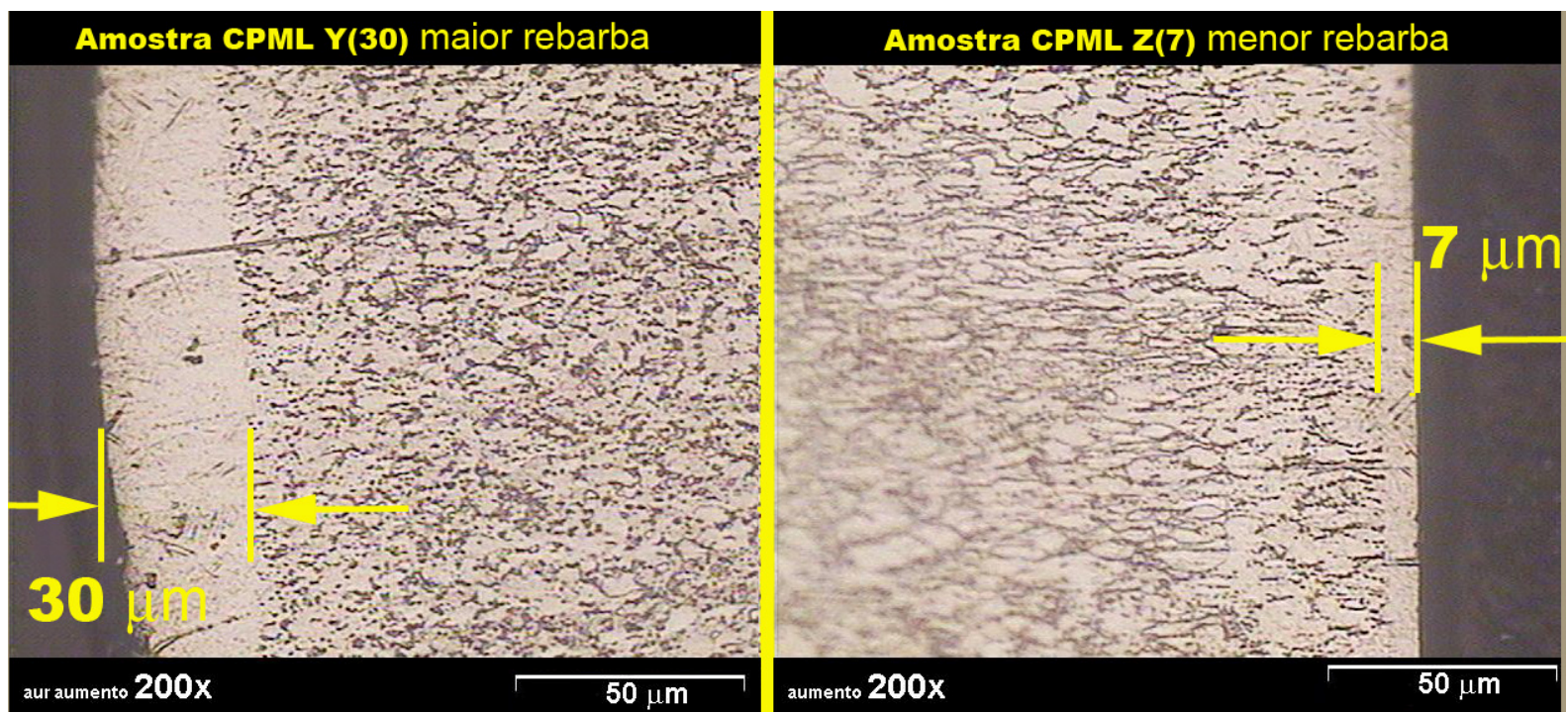

Figura 72 - Comparação entre pior e melhor condição de material ressolidificado aderido (Borda a).
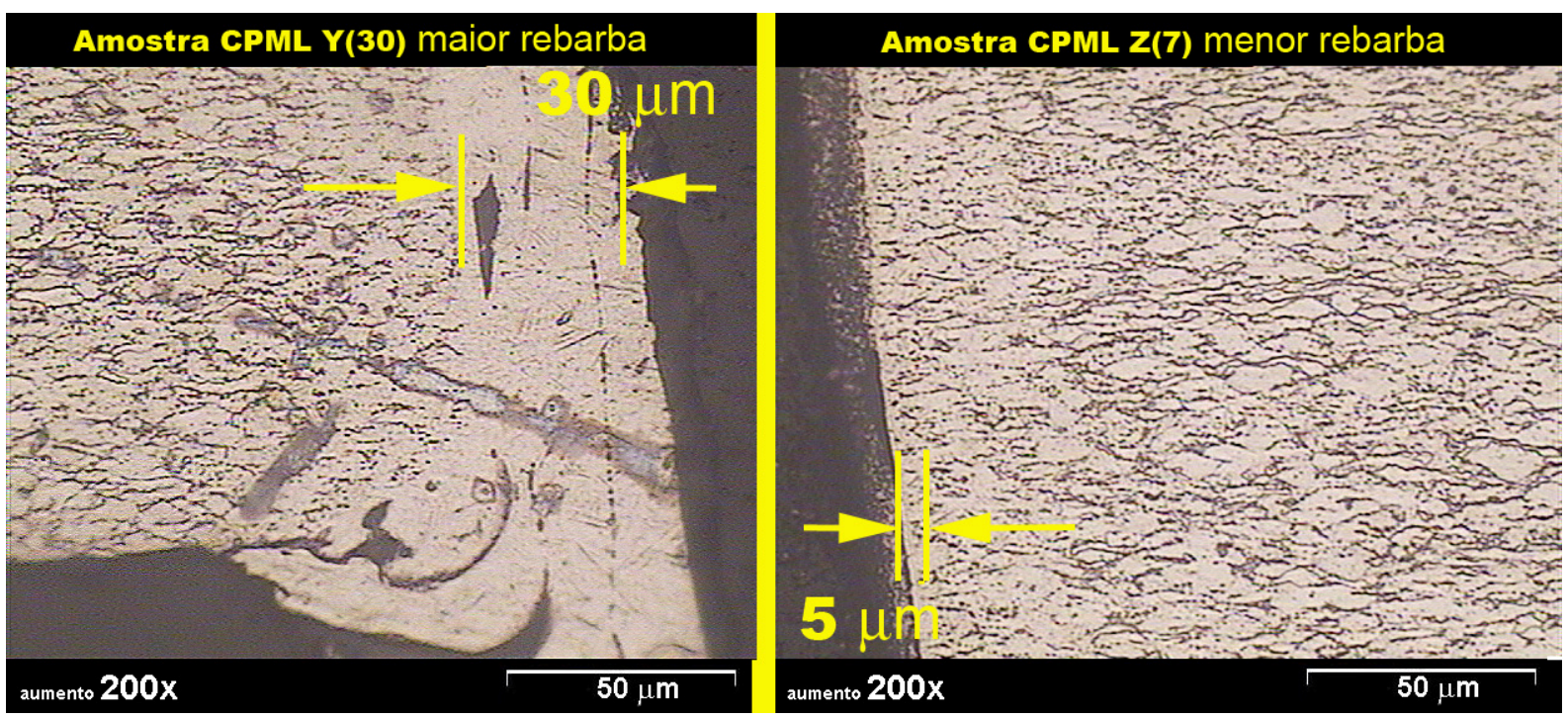

Figura 73 - Material ressolidificado aderido (Borda b) entre pior e melhor condição de corte.
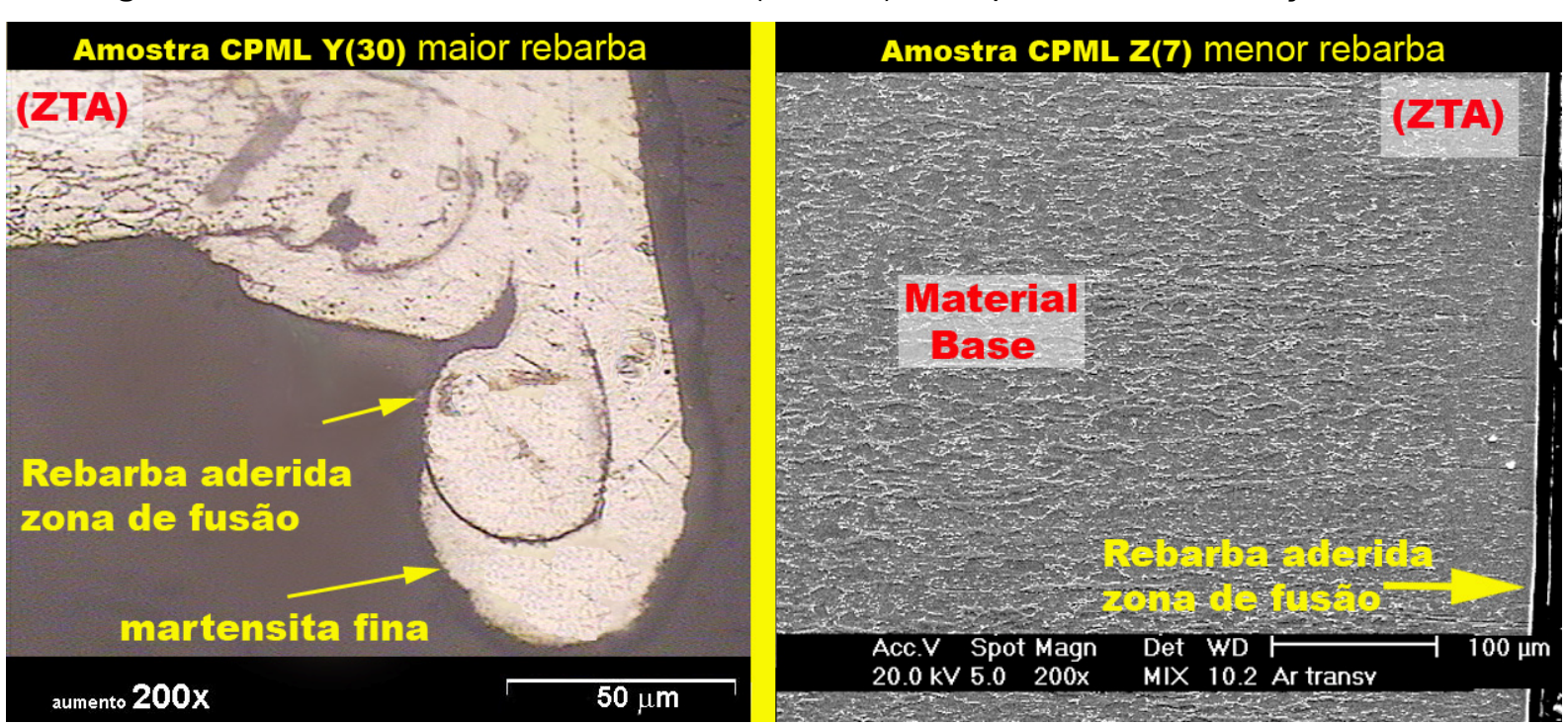

Figura 74 - Detalhe da rebarba aderida entre pior e melhor condição de corte. 
Evidentemente a combinação diferenciada dos parâmetros de corte para cada amostra interfere de foram significativa provocando uma acentuada diferença na adesão de material fundido.

Indiferente da configuração empregada é possível notar uma zona termicamente afetada variando entre $100 \mu \mathrm{m}$ a $200 \mu \mathrm{m}$, como também a transformação martensitíca na zona de fusão e uma microestrutura apresentando as fases $\alpha$ equiaxial $+\beta$ intragranular, característica de uma liga Ti-6Al-4V., conforme verifica-se na Figura 75

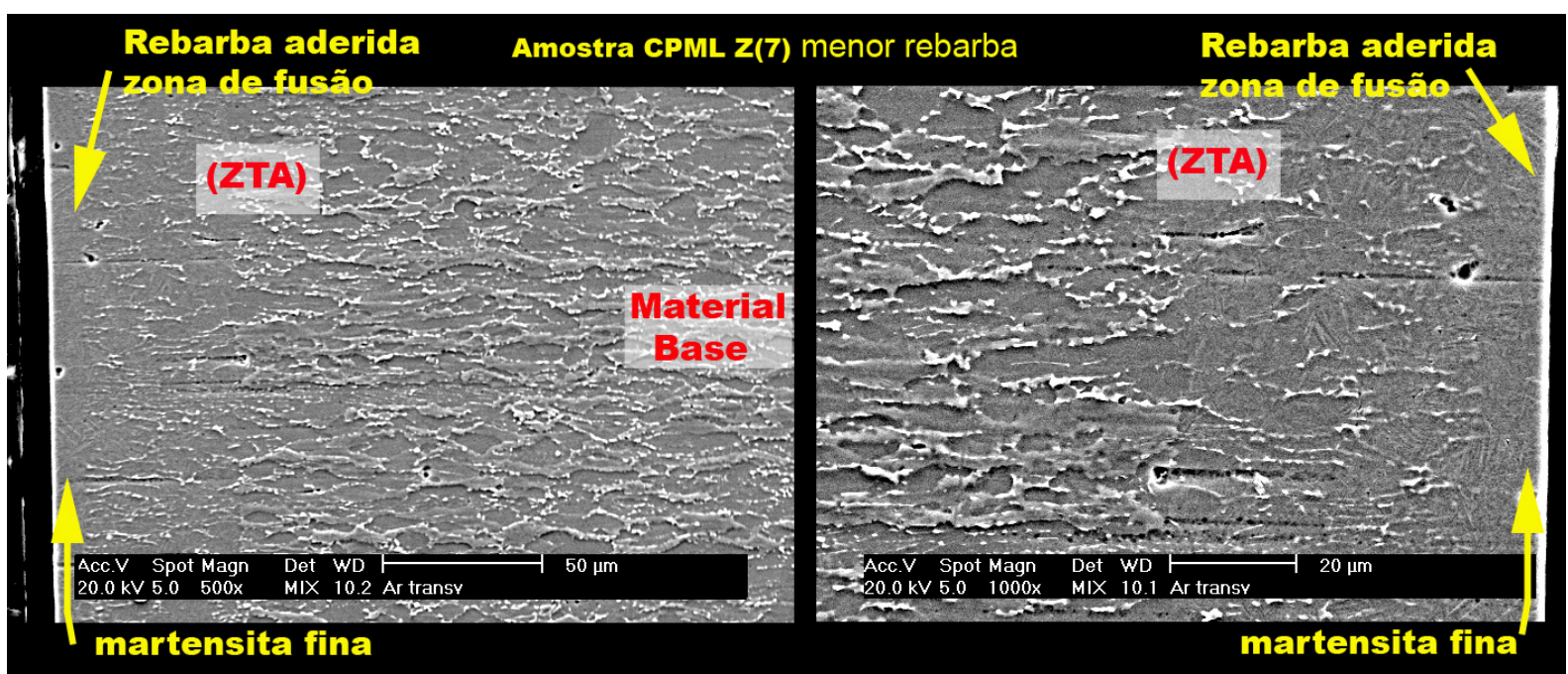

Figura 75 - (MEV) Detalhe da microestrutura na amostra de menor rebarba.

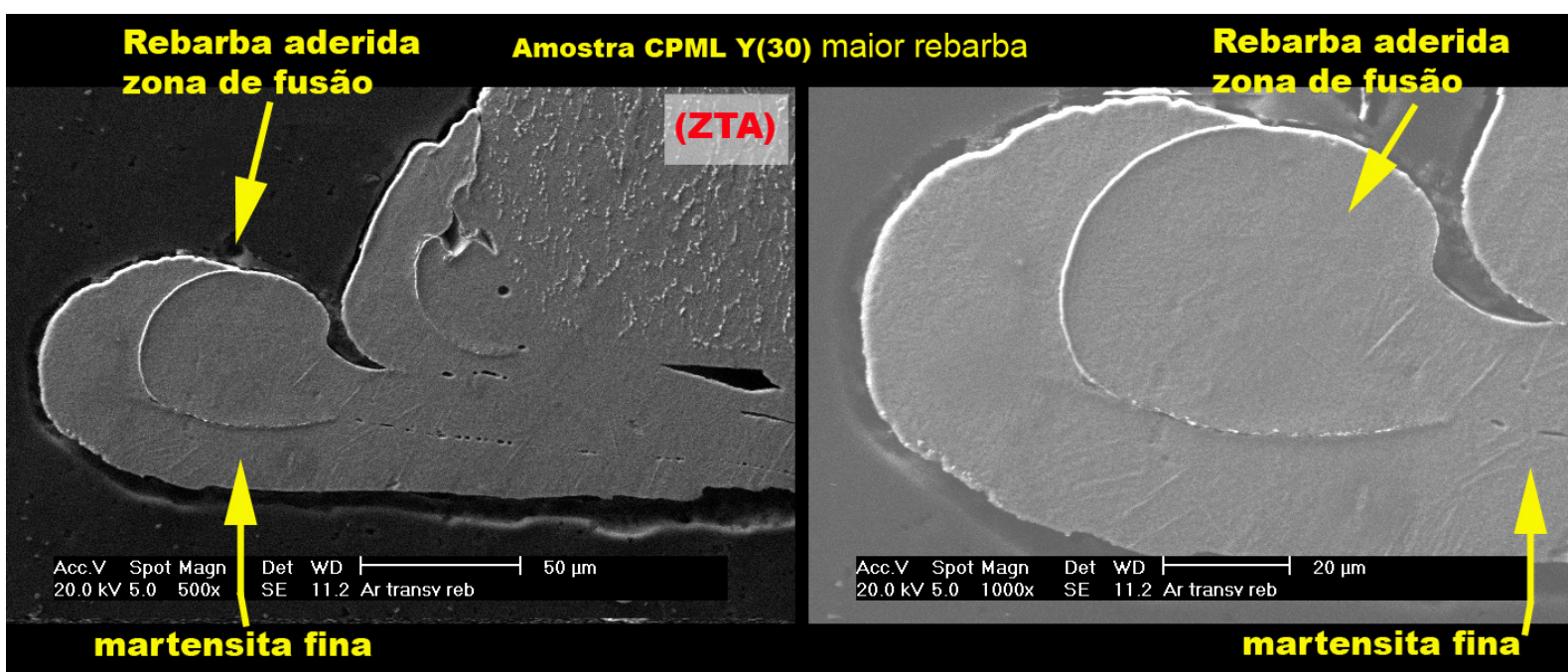

Figura 76 - (MEV) Detalhe da microestrutura na amostra de maior rebarba. 


\section{Análise da rugosidade pela aplicação do DOE}

Nesta parte das investigações, aplicou-se a mesma estratégia do modelo experimental de seis fatores em matriz fatorial fracionada de $1 / 4$ a dois níveis com duas réplicas e DOE fatorial de quatro fatores, como apresentado para o caso da formação de rebarbas, para analisar a qualidade superficial do corte em relação à rugosidade das amostras.

Os dados obtidos na análise de inspeção superficial, igualmente aos da aderência de material fundido, revelaram uma ampla variação entre os lados opostos da superfície de usinagem, como também sobre um único plano de uma mesma amostra. Essa desconformidade foi considerada parte dos erros do ensaio e intrínseca ao processo térmico do corte a laser que gera superfícies irregulares na parede do metal. Pelo ajuste dos valores entre as três medidas coletadas equalizouse a diferença das rugosidades em um valor coerente com as médias calculadas.

As análises do grau de influência individual e das interações entre as variáveis seguiram os mesmos padrões de investigação, baseado no exame dos gráficos gerados. Na seqüência das tabelas de 36 a 38 estão dispostos os valores resultantes da análise de inspeção superficial utilizados na composição do arranjo fatorial.

Tabela 36 - Dados coletados de rugosidade para ensaio DOE para 6 fatores a 2 níveis (CPML).

\begin{tabular}{|c|c|c|c|c|c|c|c|c|c|c|c|c|c|c|c|}
\hline \multirow{2}{*}{ teste } & \multirow{2}{*}{$\begin{array}{c}\text { corpo de } \\
\text { prova }\end{array}$} & \multicolumn{3}{|c|}{$\mathrm{Ra}$ (microns) } & \multirow[t]{2}{*}{ MÉDIA } & \multirow[t]{2}{*}{ desvio } & \multirow[t]{2}{*}{ ajuste } & \multirow{2}{*}{ teste } & \multirow{2}{*}{$\begin{array}{c}\text { corpo de } \\
\text { prova }\end{array}$} & \multicolumn{3}{|c|}{$\mathrm{Ra}$ (microns) } & \multirow[t]{2}{*}{ MÉDIA } & \multirow[t]{2}{*}{ desvio } & \multirow[t]{2}{*}{ ajuste } \\
\hline & & $1^{\circ}$ & $2^{\circ}$ & $3^{\circ}$ & & & & & & $1^{\circ}$ & $2^{\circ}$ & $3^{\circ}$ & & & \\
\hline 1 & CY1 & 5,01 & 5,55 & 4,62 & 5,06 & 0,467 & 5,06 & 17 & $\mathrm{cY} 17$ & 2,51 & 3,53 & 4,41 & 3,48 & 0,951 & 3,02 \\
\hline 2 & $\mathrm{C} Y 2$ & 4,98 & 6,5 & 7,27 & 6,25 & 1,165 & 6,50 & 18 & CY18 & 4,99 & 4,73 & 4,4 & 4,71 & 0,296 & 4,71 \\
\hline 3 & $\mathrm{CY} 3$ & 4,85 & 6,44 & 6,81 & 6,03 & 1,041 & 6,60 & 19 & CY19 & 5,4 & 6,2 & 5,14 & 5,58 & 0,552 & 5,58 \\
\hline 4 & CY4 & 3,04 & 4,54 & 6,15 & 4,58 & 1,555 & 3,80 & 20 & CY20 & 4,22 & 4,29 & 4,49 & 4,33 & 0,140 & 4,33 \\
\hline 5 & CY5 & 3,1 & 5,13 & 9,74 & 5,99 & 3,403 & 4,00 & 21 & CY21 & 2,56 & 5,93 & 7 & 5,16 & 2,317 & 6,00 \\
\hline 6 & CY6 & 3,35 & 2,54 & 2,89 & 2,93 & 0,406 & 2,93 & 22 & $\mathrm{CY} 22$ & 4,73 & 6,4 & 6,06 & 5,73 & 0,883 & 6,10 \\
\hline 7 & $\mathrm{C} Y 7$ & 4,62 & 3,77 & 4,19 & 4,19 & 0,425 & 4,19 & 23 & CY23 & 2,32 & 3,15 & 3,38 & 2,95 & 0,558 & 2,95 \\
\hline 8 & CY8 & 3,92 & 3,77 & 6,56 & 4,75 & 1,569 & 3,80 & 24 & CY24 & 8,14 & 4,94 & 4,38 & 5,82 & 2,029 & 4,50 \\
\hline 9 & c/9 & 3,91 & 3,82 & 3,4 & 3,71 & 0,272 & 3,71 & 25 & $\mathrm{CY} 25$ & 3,31 & 5,6 & 5,87 & 4,93 & 1,407 & 5,60 \\
\hline 10 & CY10 & 8,96 & 4,93 & 4,89 & 6,26 & 2,338 & 4,90 & 26 & CY26 & 5,72 & 7,48 & 4,79 & 6 & 1,366 & 5,10 \\
\hline 11 & CY11 & 7,02 & 6,85 & 7,99 & 7,29 & 0,615 & 7,20 & 27 & $\mathrm{CY} 27$ & 5,41 & 6,45 & 5,62 & 5,83 & 0,550 & 5,83 \\
\hline 12 & CY12 & 6,92 & 5,55 & 4,62 & 5,7 & 1,157 & 5,20 & 28 & CY28 & 5,29 & 4,78 & 4,09 & 4,72 & 0,602 & 4,50 \\
\hline 13 & CY13 & 7,35 & 9,5 & 9,05 & 8,63 & 1,134 & 9,00 & 29 & CY29 & 2,6 & 5,52 & 5,44 & 4,52 & 1,663 & 5,45 \\
\hline 14 & CY14 & 6,54 & 7,16 & 7,51 & 7,07 & 0,491 & 7,07 & 30 & CY30 & 5,25 & 5,17 & 4,49 & 4,97 & 0,222 & 4,97 \\
\hline 15 & CY15 & 2,51 & 1,95 & 2,64 & 2,37 & 0,367 & 2,37 & 31 & CY31 & 3,48 & 3,91 & 3,6 & 3,66 & 0,222 & 3,66 \\
\hline 16 & CY16 & 5,95 & 7,09 & 6,7 & 6,58 & 0,579 & 6,58 & 32 & CY32 & 6,75 & 8,03 & 6,43 & 7,07 & 0,847 & 6,50 \\
\hline
\end{tabular}


Tabela 37 - Dados coletados de rugosidade para ensaio DOE para 4 fatores a 2 níveis (CPML).

\begin{tabular}{|c|c|c|c|c|c|c|c|c|c|c|c|c|c|c|c|}
\hline \multirow{2}{*}{$\begin{array}{l}\text { corpo de } \\
\text { prova }\end{array}$} & \multirow{2}{*}{ Lado } & \multicolumn{3}{|c|}{ Ra (microns) } & \multirow[t]{2}{*}{ Média } & \multirow[t]{2}{*}{ desvio } & \multirow[t]{2}{*}{ Ajuste } & \multirow{2}{*}{$\begin{array}{l}\text { corpo de } \\
\text { prova }\end{array}$} & \multirow{2}{*}{ Lado } & \multicolumn{3}{|c|}{$\mathrm{Ra}$ (microns) } & \multirow[t]{2}{*}{ Média } & \multirow[t]{2}{*}{ desvio } & \multirow[t]{2}{*}{ Ajuste } \\
\hline & & $1^{\circ}$ & $2^{\circ}$ & $3^{\circ}$ & & & & & & $1^{\circ}$ & $2^{\circ}$ & $3^{\circ}$ & & & \\
\hline \multirow{2}{*}{$Y 1$} & 1 & 1,34 & 1,37 & 1,57 & 1,43 & 0,125 & 1,43 & \multirow{2}{*}{ Y17 } & 1 & 2,89 & 2,45 & 2,67 & 2,74 & 0,220 & 2,74 \\
\hline & 2 & 2,74 & 2,33 & 2,37 & 2,48 & 0,226 & 2,48 & & 2 & 1,3 & 1,4 & 1,31 & 1,34 & 0,055 & 1,34 \\
\hline \multirow{2}{*}{$Y_{2}$} & 1 & 2,08 & 2,05 & 1,95 & 2,03 & 0,068 & 2,03 & \multirow{2}{*}{ Y18 } & 1 & 1,87 & 2,77 & 2,66 & 2,43 & 0,491 & 2,43 \\
\hline & 2 & 3,02 & 2,45 & 2,88 & 2,78 & 0,297 & 2,78 & & 2 & 3,64 & 2,25 & 2,75 & 2,88 & 0,704 & 2,50 \\
\hline \multirow{2}{*}{ Y3 } & 1 & 1,97 & 1,89 & 1,9 & 1,92 & 0,044 & 1,92 & \multirow{2}{*}{ Y19 } & 1 & 2,21 & 1,84 & 2,05 & 2,03 & 0,186 & 2,03 \\
\hline & 2 & 1,63 & 1,75 & 2,45 & 1,94 & 0,443 & 1,94 & & 2 & 2,26 & 2,64 & 3,32 & 2,74 & 0,537 & 2,74 \\
\hline \multirow{2}{*}{$Y_{4}$} & 1 & 2,77 & 2,04 & 2,27 & 2,36 & 0,373 & 2,36 & \multirow{2}{*}{$Y 20$} & 1 & 2,08 & 2,11 & 2,39 & 2,19 & 0,171 & 2,19 \\
\hline & 2 & 2,26 & 2,05 & 2,25 & 2,19 & 0,118 & 2,19 & & 2 & 2,38 & 2,2 & 2,24 & 2,27 & 0,095 & 2,27 \\
\hline \multirow{2}{*}{$Y_{5}$} & 1 & 1,3 & 1,23 & 1,13 & 1,22 & 0,085 & 1,22 & \multirow{2}{*}{$Y 21$} & 1 & 1,38 & 1,22 & 1,53 & 1,38 & 0,155 & 1,38 \\
\hline & 2 & 1,12 & 1,55 & 1,12 & 1,26 & 0,248 & 1,26 & & 2 & 1,21 & 1,15 & 1,24 & 1,20 & 0,046 & 1,20 \\
\hline \multirow{2}{*}{ Y6 } & 1 & 2,71 & 2,3 & 2,63 & 2,55 & 0,217 & 2,55 & \multirow{2}{*}{$Y 22$} & 1 & 2,1 & 2,45 & 2,2 & 2,25 & 0,180 & 2,25 \\
\hline & 2 & 2,52 & 2,17 & 2,16 & 2,28 & 0,205 & 2,28 & & 2 & 2,8 & 2,98 & 2,38 & 2,72 & 0,308 & 2,72 \\
\hline & 1 & 1,68 & 1,71 & 1,88 & 1,76 & 0,108 & 1,76 & & 1 & 1,2 & 1,41 & 1,63 & 1,41 & 0,215 & 1,41 \\
\hline$\gamma /$ & 2 & 2,3 & 2,48 & 2,55 & 2,44 & 0,129 & 2,44 & $Y 23$ & 2 & 2,35 & 2,54 & 2,74 & 2,54 & 0,195 & 2,54 \\
\hline Yo & 1 & 2,9 & 2,81 & 3,11 & 2,94 & 0,154 & 2,94 & & 1 & 2,19 & 2,46 & 2,3 & 2,32 & 0,136 & 2,32 \\
\hline Yo & 2 & 2,17 & 2,09 & 2 & 2,09 & 0,085 & 2,09 & 924 & 2 & 2,94 & 2,4 & 2,94 & 2,76 & 0,312 & 2,76 \\
\hline & 1 & 2,07 & 1,32 & 1,81 & 1,73 & 0,381 & 1,73 & & 1 & 2,07 & 1,87 & 1,82 & 1,92 & 0,132 & 1,92 \\
\hline Yy & 2 & 1,43 & 2,36 & 1,28 & 1,69 & 0,585 & 1,30 & $Y 25$ & 2 & 2,02 & 2,11 & 2,05 & 2,06 & 0,046 & 2,06 \\
\hline & 1 & 6,58 & 5,66 & 6,06 & 6,10 & 0,461 & 6,10 & & 1 & 6,64 & 7,15 & 9,56 & 7,78 & 1,560 & 6,90 \\
\hline YTO & 2 & 4,11 & 5,03 & 3,06 & 4,07 & 0,986 & 3,60 & $Y \angle b$ & 2 & 5,35 & 4,84 & 3,8 & 4,66 & 0,790 & 4,66 \\
\hline & 1 & 1,51 & 1,54 & 1,4 & 1,48 & 0,074 & 1,48 & & 1 & 1,84 & 1,55 & 1,29 & 1,56 & 0,275 & 1,56 \\
\hline YT & 2 & 1,6 & 1,98 & 1,31 & 1,63 & 0,336 & 1,63 & $Y 27$ & 2 & 1,62 & 1,98 & 1,44 & 1,68 & 0,275 & 1,68 \\
\hline 12 & 1 & 3,39 & 3,68 & 3,8 & 3,62 & 0,211 & 3,62 & Yo8 & 1 & 3,9 & 3,22 & 3,21 & 3,44 & 0,396 & 3,44 \\
\hline$Y 12$ & 2 & 2,39 & 2,9 & 2,76 & 2,68 & 0,264 & 2,68 & 128 & 2 & 3,23 & 3,02 & 3,81 & 3,35 & 0,409 & 3,35 \\
\hline$Y_{13}$ & 1 & 1,69 & 1,8 & 1,96 & 1,82 & 0,136 & 1,82 & & 1 & 2,14 & 2,06 & 2,06 & 2,09 & 0,046 & 2,09 \\
\hline 813 & 2 & 1,38 & 1,53 & 3,23 & 2,05 & 1,028 & 1,45 & $r 29$ & 2 & 2,05 & 1,9 & 1,81 & 1,92 & 0,121 & 1,92 \\
\hline & 1 & 4,44 & 5,12 & 5,53 & 5,03 & 0,551 & 5,03 & & 1 & 3,35 & 3,52 & 4,48 & 3,78 & 0,609 & 3,45 \\
\hline$Y 14$ & 2 & 7,44 & 6,78 & 7,16 & 7,13 & 0,331 & 7,13 & Y 30 & 2 & 8,62 & 8,94 & 9,35 & 8,97 & 0,366 & 8,97 \\
\hline$\gamma_{15}$ & 1 & 1,9 & 1,48 & 1,56 & 1,65 & 0,223 & 1,65 & $y_{31}$ & 1 & 1,46 & 1,35 & 1,21 & 1,34 & 0,125 & 1,34 \\
\hline 15 & 2 & 1,14 & 1,36 & 1,44 & 1,31 & 0,155 & 1,31 & 131 & 2 & 1,17 & 1,31 & 1,71 & 1,40 & 0,280 & 1,40 \\
\hline & 1 & 4,33 & 3,79 & 3,68 & 3,93 & 0,348 & 3,93 & & 1 & 4,17 & 3,8 & 4,76 & 4,24 & 0,484 & 4,24 \\
\hline$Y 1$ & 2 & 3,04 & 4,18 & 3,58 & 3,40 & 0,570 & 3,20 & $\mathrm{Y} 32$ & 2 & 4,38 & 3,61 & 3,43 & 3,81 & 0,505 & 3,81 \\
\hline
\end{tabular}

\section{Rugosidade - CPML 4 fatores}

Tabela 38 - Dados coletados de rugosidade para ensaio DOE para 4 fatores a 2 níveis (LASAG).

\begin{tabular}{|c|c|c|c|c|c|c|c|c|c|c|c|c|c|c|c|}
\hline \multirow{2}{*}{ teste } & & \multicolumn{3}{|c|}{$\mathrm{Ra}$ (microns) } & \multirow[t]{2}{*}{ MÉDIA } & \multirow[t]{2}{*}{ desvio } & \multirow[t]{2}{*}{ Ajuste } & \multirow{2}{*}{ teste } & & \multicolumn{3}{|c|}{$\mathrm{Ra}$ (microns) } & \multirow[t]{2}{*}{ MÉDIA } & \multirow[t]{2}{*}{ desvio } & \multirow[t]{2}{*}{ Ajuste } \\
\hline & & $1^{\circ}$ & $2^{\circ}$ & $3^{\circ}$ & & & & & & $1^{\circ}$ & $2^{\circ}$ & $3^{\circ}$ & & & \\
\hline \multirow{2}{*}{1} & Lado 1 & 2,4 & 2,56 & 2,13 & 2,36 & 0,217 & 2,36 & \multirow{2}{*}{17} & Lado 1 & 6,26 & 4,74 & 5,76 & 5,59 & 0,775 & 5,59 \\
\hline & Lado 2 & 4,34 & 3,93 & 2,6 & 3,62 & 0,910 & 4,14 & & Lado 2 & 4,7 & 3,76 & 3,15 & 3,87 & 0,781 & 3,50 \\
\hline \multirow{2}{*}{2} & Lado 1 & 2,63 & 3,83 & 6,12 & 4,19 & 1,773 & 3,50 & \multirow{2}{*}{18} & Lado 1 & 2,78 & 6,22 & 6,32 & 5,11 & 2,016 & 6,20 \\
\hline & Lado 2 & 10,63 & 10,56 & 5,68 & 8,96 & 2,838 & 10,60 & & Lado 2 & 5,48 & 3,45 & 6,51 & 5,15 & 1,557 & 5,50 \\
\hline \multirow{2}{*}{3} & Lado 1 & 4,04 & 5,02 & 5,62 & 4,89 & 0,798 & 5,30 & \multirow{2}{*}{19} & Lado 1 & 4,81 & 2,87 & 4,58 & 4,09 & 1,060 & 4,60 \\
\hline & Lado 2 & 6,48 & 7,39 & 5,79 & 6,55 & 0,803 & 6,55 & & Lado 2 & 3,7 & 5,39 & 8,88 & 5,99 & 2,642 & 4,80 \\
\hline \multirow{2}{*}{4} & Lado 1 & 6,76 & 3,2 & 4,76 & 4,91 & 1,785 & 3,98 & \multirow{2}{*}{20} & Lado 1 & 6,3 & 4,72 & 4,63 & 5,22 & 0,939 & 4,65 \\
\hline & Lado 2 & 4,86 & 4,66 & 3,86 & 4,46 & 0,529 & 4,46 & & Lado 2 & 4,18 & 6,16 & 4,33 & 4,89 & 1,102 & 4,20 \\
\hline \multirow{2}{*}{5} & Lado 1 & 1,66 & 3,4 & 2,59 & 2,55 & 0,871 & 2,50 & \multirow{2}{*}{21} & Lado 1 & 2,36 & 3,27 & 1,93 & 2,52 & 0,684 & 2,20 \\
\hline & Lado 2 & 2,66 & 2,71 & 1,92 & 2,43 & 0,442 & 2,43 & & Lado 2 & 3,38 & 3,88 & 4,23 & 3,83 & 0,427 & 3,83 \\
\hline \multirow{2}{*}{6} & Lado 1 & 3,1 & 1,99 & 2,29 & 2,46 & 0,574 & 2,46 & \multirow{2}{*}{22} & Lado 1 & 3,08 & 2,1 & 1,98 & 2,39 & 0,603 & 2,00 \\
\hline & Lado 2 & 2,47 & 2,52 & 2,41 & 2,47 & 0,055 & 2,47 & & Lado 2 & 2,82 & 1,87 & 3,15 & 2,61 & 0,665 & 2,61 \\
\hline \multirow{2}{*}{7} & Lado 1 & 4,27 & 4,12 & 5,23 & 4,54 & 0,602 & 4,20 & \multirow{2}{*}{23} & Lado 1 & 4,39 & 3,96 & 4,16 & 4,17 & 0,215 & 4,17 \\
\hline & Lado 2 & 2,02 & 2,85 & 1,92 & 2,26 & 0,511 & 2,26 & & Lado 2 & 3,75 & 3,83 & 4,46 & 4,01 & 0,389 & 4,01 \\
\hline & Lado 1 & 4,16 & 3,84 & 3,57 & 3,86 & 0,295 & 3,86 & & Lado 1 & 4,05 & 3,69 & 3,63 & 3,79 & 0,227 & 3,79 \\
\hline 8 & Lado 2 & 3,02 & 3,55 & 4,63 & 3,73 & 0,821 & 3,25 & 24 & Lado 2 & 2,14 & 2,75 & 3,84 & 2,91 & 0,861 & 2,50 \\
\hline 9 & Lado 1 & 5,47 & 4,98 & 5,44 & 5,3 & 0,275 & 5,30 & & Lado 1 & 5,43 & 8,44 & 7,27 & 7,05 & 1,517 & 7,20 \\
\hline$y$ & Lado 2 & 2,69 & 2,52 & 3,69 & 2,97 & 0,632 & 2,60 & 25 & Lado 2 & 5,63 & 7,66 & 5,38 & 6,22 & 1,250 & 5,40 \\
\hline & Lado 1 & 3,65 & 4,25 & 3,79 & 3,9 & 0,314 & 3,90 & & Lado 1 & 5,84 & 10,02 & 4,47 & 6,78 & 2,891 & 5,00 \\
\hline 10 & Lado 2 & 3,55 & 4,51 & 4,86 & 4,31 & 0,678 & 4,70 & 26 & Lado 2 & 6,33 & 8,35 & 11,55 & 8,74 & 2,632 & 7,00 \\
\hline & Lado 1 & 4,96 & 5,19 & 8,53 & 6,23 & 1,998 & 5,10 & & Lado 1 & 5,05 & 4,93 & 4,39 & 4,79 & 0,352 & 4,79 \\
\hline 11 & Lado 2 & 4,87 & 5,47 & 5,07 & 5,14 & 0,306 & 5,14 & 27 & Lado 2 & 3,54 & 7,74 & 10,99 & 7,42 & 3,735 & 5,64 \\
\hline & Lado 1 & 10,78 & 10,07 & 11,55 & 10,8 & 0,740 & 10,20 & & Lado 1 & 6,55 & 7,68 & 15,63 & 9,95 & 4,948 & 6,80 \\
\hline 12 & Lado 2 & 6,91 & 6,75 & 5,93 & 6,53 & 0,526 & 6,53 & 28 & Lado 2 & 8,02 & 10,89 & 11,51 & 10,14 & 1,862 & 10,90 \\
\hline & Lado 1 & 2,12 & 3,74 & 3,25 & 3,04 & 0,831 & 3,50 & & Lado 1 & 4,02 & 4,69 & 5,06 & 4,59 & 0,527 & 4,52 \\
\hline 13 & Lado 2 & 3,03 & 4,58 & 6,02 & 4,54 & 1,495 & 4,54 & 29 & Lado 2 & 4,54 & 3,58 & 6,16 & 4,76 & 1,304 & 4,10 \\
\hline 14 & Lado 1 & 3,04 & 2,93 & 4,01 & 3,33 & 0,594 & 3,33 & & Lado 1 & 8,63 & 6,69 & 5,13 & 6,82 & 1,753 & 6,00 \\
\hline & Lado 2 & 3,85 & 4,74 & 3,82 & 4,14 & 0,523 & 4,14 & 30 & Lado 2 & 5,51 & 4,28 & 6,2 & 5,33 & 0,973 & 5,50 \\
\hline & Lado 1 & 3,4 & 4,08 & 7,35 & 4,94 & 2,112 & 3,70 & & Lado 1 & 5,37 & 6,57 & 4,37 & 5,44 & 1,102 & 5,00 \\
\hline 15 & Lado 2 & 5,34 & 4,74 & 4,14 & 4,74 & 0,600 & 4,50 & 31 & Lado 2 & 5,12 & 4,81 & 3,88 & 4,6 & 0,645 & 4,60 \\
\hline & Lado 1 & 10,84 & 7,56 & 9,57 & 9,32 & 1,654 & 10,20 & & Lado 1 & 7,66 & 6,67 & 7 & 7,11 & 0,504 & 7,11 \\
\hline & Lado 2 & 8,75 & 6,57 & 5,64 & 6,99 & 1,596 & 5,80 & 32 & Lado 2 & 8,3 & 9,07 & 7,69 & 8,35 & 0,692 & 7,80 \\
\hline
\end{tabular}


Cada rugosidade medida foi adicionada ao experimento fatorial correspondente e dessa forma estabeleceram-se as tabelas com seus respectivos dados, conforme apresentado a seguir nas tabelas de 39 até 41.

Os gráficos de influência para cada parâmetro e os diagramas de Pareto com as interações das variáveis do planejamento experimental com seis e quatro fatores, realizados na CPML, estão condensados na Figura 77.

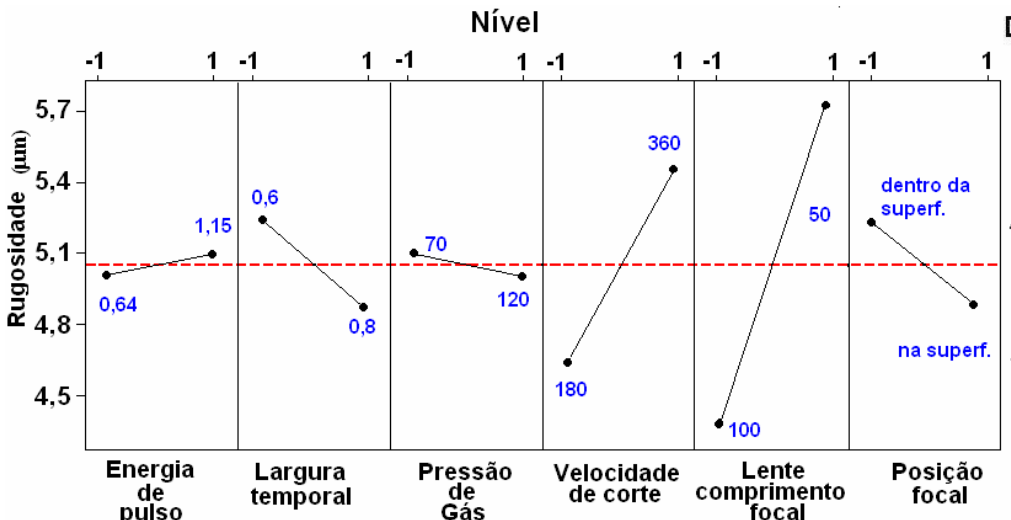

(A)

(B)

(C)

(D)

(E)

(F)

Gráfico de influência para cada parâmetro em resposta a Rugosidade

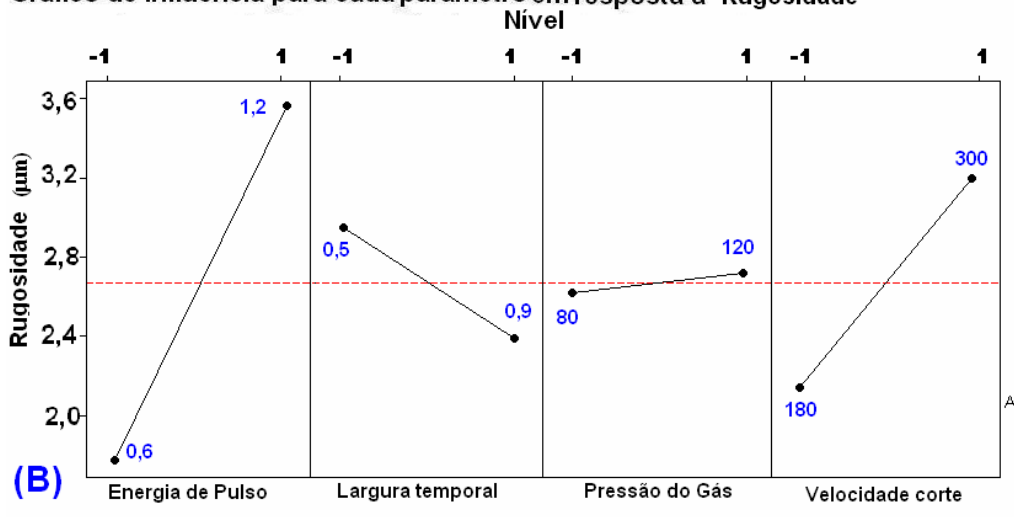

(A)

(C)
Diagrama de Pareto para as influências dos parâmetros e suas interações

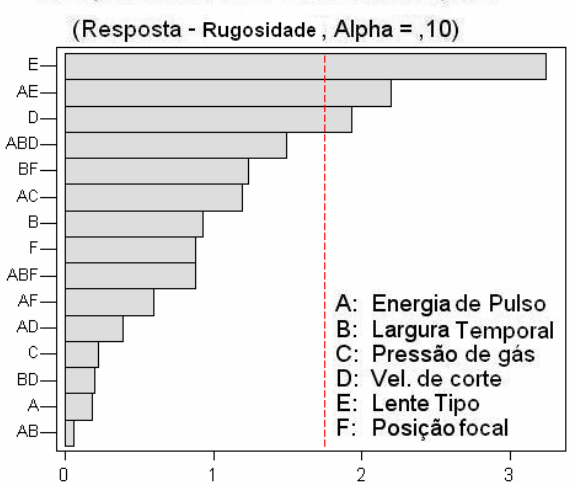

Diagrama de Pareto para as influências dos parâmetros e suas interações

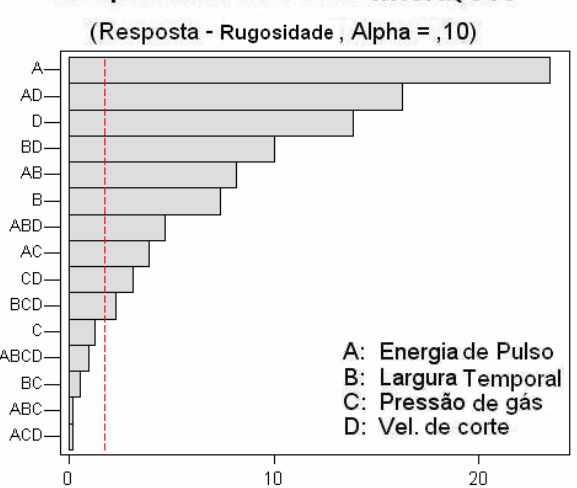

Figura 77 - Diagramas de influência para DOE: (A) 6 fatores; (B) 4 fatores (CPML).

Segundo a inclinação das retas visualizadas no gráfico $(A)$ da Figura 77 , a velocidade de corte (D) e o tipo de lente [comprimento focal (E)], dos seis parâmetros analisados, foram os que maior efeito causaram no aumento da rugosidade. Com menor intensidade a posição focal (F) e largura temporal (B), também influenciam na qualidade superficial. 
Tabela 39 - Modelo experimental ensaio DOE para 6 fatores a 2 níveis (Rugosidade).

\begin{tabular}{|c|c|c|c|c|c|c|c|c|c|}
\hline \multicolumn{10}{|c|}{$\begin{array}{c}\text { Ensaio fatorial fracionado } 2^{(6-2)}=16 \quad \text { Rugosidade } \\
\text { DOE realizado na CPML }\end{array}$} \\
\hline \multirow{7}{*}{$\begin{array}{l}N^{\circ} \text { do } \\
\text { teste }\end{array}$} & \multicolumn{7}{|c|}{$\begin{array}{ll}\text { Fatores de Controle } \\
\end{array}$} & \multirow{6}{*}{\multicolumn{2}{|c|}{$\begin{array}{c}\text { Resposta } \\
\text { Rugosidade (mm) }\end{array}$}} \\
\hline & \multirow[t]{2}{*}{2 niveis } & \begin{tabular}{|c|} 
Energia \\
do \\
Pulso \\
\end{tabular} & $\begin{array}{c}\text { Largura } \\
\text { Temporal } \\
\text { do Pulso } \\
\end{array}$ & $\begin{array}{l}\text { Pressão } \\
\text { Gás }\end{array}$ & $\begin{array}{l}\text { Vel. de } \\
\text { Corte }\end{array}$ & \begin{tabular}{|c|} 
Lente \\
Compr. \\
Focal \\
\end{tabular} & \begin{tabular}{|c|} 
Posição \\
do \\
Foco \\
\end{tabular} & & \\
\hline & & {$[\boldsymbol{J}]$} & [ms] & [psi] & {$[\mathbf{m m} / \mathbf{m i n}]$} & [mm] & [mm] & & \\
\hline & nível (1) & 1,15 & 0,8 & 120 & 360 & 50 & $\begin{array}{c}\text { Na } \\
\text { superf. }\end{array}$ & & \\
\hline & $\begin{array}{c}\text { nível } \\
(-1)\end{array}$ & 0,64 & 0,6 & 70 & 180 & 100 & $\begin{array}{l}0,5 \mathrm{~mm} \\
\text { dentro } \\
\text { da } \\
\text { chapa }\end{array}$ & & \\
\hline & \multirow[b]{2}{*}{$\begin{array}{l}\text { Ordem } \\
\text { aleatória }\end{array}$} & \multicolumn{4}{|c|}{ Modelo Base 2 (a quarta) } & \multicolumn{2}{|c|}{ Geradores } & & \\
\hline & & $\mathbf{A}$ & $\mathbf{B}$ & C & $\mathbf{D}$ & $\begin{array}{c}\mathbf{E}= \\
\mathbf{A B C}\end{array}$ & $\begin{array}{c}\mathbf{F}= \\
\mathbf{B C D}\end{array}$ & Rép & licas \\
\hline \multirow{2}{*}{1} & \multirow{2}{*}{7 e 9} & -1 & -1 & -1 & -1 & -1 & -1 & Y1 (1) & Y17 (2) \\
\hline & & 0,64 & 0,6 & 70 & 180 & 100 & 6,7 & 5,06 & 3,02 \\
\hline \multirow{2}{*}{2} & \multirow{2}{*}{28 e 30} & +1 & -1 & -1 & -1 & +1 & -1 & Y2 (1) & Y18 (2) \\
\hline & & 1,15 & 0,6 & 70 & 180 & 50 & 6,7 & 6,50 & 4,71 \\
\hline \multirow{2}{*}{3} & \multirow{2}{*}{23 e 27} & -1 & +1 & -1 & -1 & +1 & +1 & Y3 (1) & Y19(2) \\
\hline & & 0,64 & 0,8 & 70 & 180 & 50 & 6,2 & 6,60 & 5,58 \\
\hline \multirow{2}{*}{4} & \multirow{2}{*}{8 e 13} & +1 & +1 & -1 & -1 & -1 & +1 & Y4 (1) & Y20 (2) \\
\hline & & 1,15 & 0,8 & 70 & 180 & 100 & 6,2 & 3,80 & 4,33 \\
\hline \multirow{2}{*}{5} & \multirow{2}{*}{21 e 32} & -1 & -1 & +1 & -1 & +1 & +1 & Y5 (1) & Y21 (2) \\
\hline & & 0,64 & 0,6 & 120 & 180 & 50 & 6,2 & 4,00 & 6,00 \\
\hline \multirow{2}{*}{6} & \multirow{2}{*}{1 e 16} & +1 & -1 & +1 & -1 & -1 & +1 & Y6 (1) & Y22 (2) \\
\hline & & 1,15 & 0,6 & 120 & 180 & 100 & 6,2 & 2,93 & 6,10 \\
\hline \multirow{2}{*}{7} & \multirow{2}{*}{3 e 11} & -1 & +1 & +1 & -1 & -1 & -1 & Y7 (1) & Y23 (2) \\
\hline & & 0,64 & 0,8 & 120 & 180 & 100 & 6,7 & 4,19 & 2,95 \\
\hline \multirow{2}{*}{8} & \multirow{2}{*}{17 e 25} & +1 & +1 & +1 & -1 & +1 & -1 & Y8 (1) & Y24 (2) \\
\hline & & 1,15 & 0,8 & 120 & 180 & 50 & 6,7 & 3,80 & 4,50 \\
\hline 0 & $4 \mathrm{e} 15$ & -1 & -1 & -1 & +1 & -1 & +1 & Y9 (1) & Y25 (2) \\
\hline 9 & 4 e 15 & 0,64 & 0,6 & 70 & 360 & 100 & 6,2 & 3,71 & 5,60 \\
\hline 10 & 24 e 29 & +1 & -1 & -1 & +1 & +1 & +1 & $\mathrm{Y10(1)}$ & Y26 (2) \\
\hline 10 & $24=29$ & 1,15 & 0,6 & 70 & 360 & 50 & 6,2 & 4,90 & 5,10 \\
\hline & & -1 & +1 & -1 & +1 & +1 & -1 & Y11(1) & Y27 (2) \\
\hline 11 & 26 e 31 & 0,64 & 0,8 & 70 & 360 & 50 & 6,7 & 7,20 & 5,83 \\
\hline & & +1 & +1 & -1 & +1 & -1 & -1 & Y12 (1) & Y28 (2) \\
\hline 12 & 2 e 6 & 1,15 & 0,8 & 70 & 360 & 100 & 6,7 & 5,20 & 4,50 \\
\hline 13 & 18 e 22 & -1 & -1 & +1 & +1 & +1 & -1 & Y13(1) & Y29 (2) \\
\hline 13 & $18 \mathrm{e} 22$ & 0,64 & 0,6 & 120 & 360 & 50 & 6,7 & 9,00 & 5,45 \\
\hline & & +1 & -1 & +1 & +1 & -1 & -1 & Y14(1) & Y30 (2) \\
\hline 14 & 5 e 14 & 1,15 & 0,6 & 120 & 360 & 100 & 6,7 & 7,07 & 4,97 \\
\hline & & -1 & +1 & +1 & +1 & -1 & +1 & Y15(1) & Y31 (2) \\
\hline 15 & 10 e 12 & 0,64 & 0,8 & 120 & 360 & 100 & 6,2 & 2,37 & 3,66 \\
\hline 16 & 19 e 20 & +1 & +1 & +1 & +1 & +1 & +1 & Y16(1) & Y32 (2) \\
\hline 10 & & 1,15 & 0,8 & 120 & 360 & 50 & 6,2 & 6,58 & 6,50 \\
\hline
\end{tabular}


Tabela 40 - Modelo experimental ensaio DOE para 4 fatores a 2 níveis (Rugosidade).

\begin{tabular}{|c|c|c|c|c|c|c|c|}
\hline \multicolumn{8}{|c|}{$\begin{array}{r}\text { Ensaio fatorial } 2^{(4)}=16 \text { Rugosidade } \\
\text { DOE realizado na CPML }\end{array}$} \\
\hline \multirow{7}{*}{$\begin{array}{l}N^{\circ} \text { do } \\
\text { teste }\end{array}$} & \multirow{3}{*}{2 níveis } & Fat & & & & \multirow{2}{*}{\multicolumn{2}{|c|}{ Resposta }} \\
\hline & & $\begin{array}{l}\text { Energia } \\
\text { do Pulso }\end{array}$ & $\begin{array}{l}\text { Largura } \\
\text { Temporal } \\
\text { do Pulso }\end{array}$ & $\begin{array}{c}\text { Pressão } \\
\text { Gás }\end{array}$ & $\begin{array}{l}\text { Vel. de } \\
\text { Corte }\end{array}$ & & \\
\hline & & [J] & [ms] & [psi] & [mm/min] & \multirow{2}{*}{\multicolumn{2}{|c|}{ Rugosidade $(\mu \mathrm{m})$}} \\
\hline & \begin{tabular}{|l|} 
nível (1) \\
\end{tabular} & 1,2 & 0,9 & 120 & 300 & & \\
\hline & nível (-1) & 0,6 & 0,5 & 80 & 180 & & \\
\hline & \multirow{2}{*}{$\begin{array}{l}\text { Ordem } \\
\text { aleatória }\end{array}$} & \multicolumn{4}{|c|}{ Modelo Base 2 (a quarta) } & \multirow{2}{*}{\multicolumn{2}{|c|}{ Réplicas }} \\
\hline & & $\mathbf{A}$ & B & \begin{tabular}{|l|}
$\mathbf{C}$ \\
\end{tabular} & $\mathbf{D}$ & & \\
\hline \multirow{2}{*}{1} & \multirow{2}{*}{2 e 24} & -1 & -1 & -1 & -1 & Y1 (1) & Y17 (2) \\
\hline & & 0,6 & 0,5 & 80 & 180 & 1,95 & 2,04 \\
\hline \multirow{2}{*}{2} & \multirow{2}{*}{13 e 31} & +1 & -1 & -1 & -1 & Y2 (1) & Y18 (2) \\
\hline & & 1,2 & 0,5 & 80 & 180 & 2,41 & 2,47 \\
\hline \multirow{2}{*}{3} & \multirow{2}{*}{16 e 30} & -1 & +1 & -1 & -1 & Y3 (1) & Y19 (2) \\
\hline & & 0,6 & 0,9 & 80 & 180 & 1,93 & 2,39 \\
\hline \multirow{2}{*}{4} & \multirow{2}{*}{20 e 27} & +1 & +1 & -1 & -1 & Y4 (1) & Y20 (2) \\
\hline & & 1,2 & 0,9 & 80 & 180 & 2,27 & 2,23 \\
\hline \multirow{2}{*}{5} & \multirow{2}{*}{9 e 23} & -1 & -1 & +1 & -1 & Y5 (1) & Y21 (2) \\
\hline & & 0,6 & 0,5 & 120 & 180 & 1,24 & 1,29 \\
\hline \multirow{2}{*}{6} & \multirow{2}{*}{5 e 14} & +1 & -1 & +1 & -1 & Y6 (1) & Y22 (2) \\
\hline & & 1,2 & 0,5 & 120 & 180 & 2,42 & 2,49 \\
\hline \multirow{2}{*}{7} & \multirow{2}{*}{7 e 10} & -1 & +1 & +1 & -1 & Y7 (1) & Y23 (2) \\
\hline & & 0,6 & 0,9 & 120 & 180 & 2,10 & 1,98 \\
\hline 8 & 18 e 28 & +1 & +1 & +1 & -1 & Y8 (1) & Y24 (2) \\
\hline 8 & $18 \mathrm{e} 28$ & 1,2 & 0,9 & 120 & 180 & 2,51 & 2,54 \\
\hline 9 & 11 e 22 & -1 & -1 & -1 & +1 & Y9 (1) & Y25 (2) \\
\hline 9 & $11 \mathrm{e} 22$ & 0,6 & 0,5 & 80 & 300 & 1,52 & 1,99 \\
\hline 10 & $6 \mathrm{e} 26$ & +1 & -1 & -1 & +1 & Y10(1) & Y26 (2) \\
\hline 10 & $0 \mathrm{e} 20$ & 1,2 & 0,5 & 80 & 300 & 5,08 & 5,93 \\
\hline & 12 e 21 & -1 & +1 & -1 & +1 & Y11(1) & Y27 (2) \\
\hline 11 & $12 \mathrm{e} 21$ & 0,6 & 0,9 & 80 & 300 & 1,56 & 1,62 \\
\hline & $3=25$ & +1 & +1 & -1 & +1 & $\mathrm{Y} 12(1)$ & Y28 (2) \\
\hline 12 & $3 \mathrm{e} 25$ & 1,2 & 0,9 & 80 & 300 & 3,15 & 3,40 \\
\hline & & -1 & -1 & +1 & +1 & Y13 (1) & Y29 (2) \\
\hline 13 & $4 \mathrm{e} 15$ & 0,6 & 0,5 & 120 & 300 & 1,93 & 2,00 \\
\hline & & +1 & -1 & +1 & +1 & Y14 (1) & Y30 (2) \\
\hline 14 & $8 \mathrm{e} 17$ & 1,2 & 0,5 & 120 & 300 & 6,08 & 6,38 \\
\hline & & -1 & +1 & +1 & +1 & Y15(1) & Y31 (2) \\
\hline 15 & 1 e 29 & 0,6 & 0,9 & 120 & 300 & 1,48 & 1,37 \\
\hline & & +1 & +1 & +1 & +1 & Y16 (1) & Y32 (2) \\
\hline 16 & 19 e 32 & 1,2 & 0,9 & 120 & 300 & \begin{tabular}{|l|}
3,67 \\
\end{tabular} & 4,03 \\
\hline
\end{tabular}


Tabela 41 - Modelo experimental ensaio DOE para 4 fatores a 2 níveis (LASAG- rugosidade).

\begin{tabular}{|c|c|c|c|c|c|c|c|}
\hline & & ensaio & lado MA & IOR Rus & yosidade & & \\
\hline & & $\begin{array}{c}\text { Ens } \\
\text { DOE }\end{array}$ & $\begin{array}{l}\text { saio fatc } \\
\text { realizac }\end{array}$ & $\begin{array}{l}\text { rial } 2 \\
\text { do na } L\end{array}$ & $\begin{array}{l}(4)=16 \\
A S A G\end{array}$ & & \\
\hline & & Fator & es de Co & ontrole & & & \\
\hline $\mathrm{N}^{\circ}$ & 2 niveis & $\begin{array}{c}\text { Energia } \\
\text { do } \\
\text { Pulso }\end{array}$ & $\begin{array}{l}\text { Largura } \\
\text { Temporal } \\
\text { do Pulso }\end{array}$ & $\begin{array}{c}\text { Pressão } \\
\text { Gás }\end{array}$ & $\begin{array}{l}\text { Vel. de } \\
\text { Corte }\end{array}$ & Resp & osta \\
\hline do & & {$[\mathrm{J}]$} & {$[\mathrm{ms}]$} & [psi] & {$[\mathrm{mm} / \mathrm{min}]$} & & \\
\hline & nivel (1) & 1,05 & 0,5 & 120 & 500 & & \\
\hline & nivel (-1) & 0,65 & 0,4 & 80 & 300 & Rugosi & idade \\
\hline & Ordem & & lodelo Base & 2 (a quar & a) & & \\
\hline & aleatória & $\mathbf{A}$ & B & C & D & Répli & icas \\
\hline 1 & 19 e 24 & -1 & -1 & -1 & -1 & Y1 & Y17 \\
\hline & & 0,65 & 0,4 & 80 & 300 & 2,36 & 5,59 \\
\hline & & & & & & & \\
\hline 2 & $10 e 27$ & +1 & -1 & -1 & -1 & $\begin{array}{l}\text { Y2 } \\
\text { (1) }\end{array}$ & $\begin{array}{l}\text { Y18 } \\
(2)\end{array}$ \\
\hline & & 1,05 & 0,4 & 80 & 300 & 3,50 & 6,20 \\
\hline & & & & & & & \\
\hline 3 & 12 e 32 & -1 & +1 & -1 & -1 & $\begin{array}{l}\text { Y3 } \\
\text { (1) }\end{array}$ & $\begin{array}{l}\text { Y19 } \\
(2)\end{array}$ \\
\hline & & 0,65 & 0,5 & 80 & 300 & 5,30 & 4,60 \\
\hline & & & & & & & \\
\hline 4 & $20 e 26$ & +1 & +1 & -1 & -1 & $\begin{array}{l}\text { Y4 } \\
(1)\end{array}$ & $\begin{array}{l}\text { Y20 } \\
(2)\end{array}$ \\
\hline & & 1,05 & 0,5 & 80 & 300 & 3,98 & 4,65 \\
\hline & & & & & & & \\
\hline 5 & 4 e 30 & -1 & -1 & +1 & -1 & $\begin{array}{l}\text { Y5 } \\
\text { (1) }\end{array}$ & $\begin{array}{l}\text { Y21 } \\
(2)\end{array}$ \\
\hline & & 0,65 & 0,4 & 120 & 300 & 2,50 & 2,20 \\
\hline & & & & & & & \\
\hline 6 & 6 e 18 & +1 & -1 & +1 & -1 & $\begin{array}{l}\text { Y6 } \\
\text { (1) }\end{array}$ & $\begin{array}{l}\text { Y22 } \\
(2)\end{array}$ \\
\hline & & 1,05 & 0,4 & 120 & 300 & 2,46 & 2,00 \\
\hline 7 & $15 e 23$ & -1 & +1 & +1 & -1 & $\begin{array}{l}Y 7 \\
\text { (1) }\end{array}$ & $\begin{array}{l}\mathrm{Y} 23 \\
\text { (2) }\end{array}$ \\
\hline & & 0,65 & 0,5 & 120 & 300 & 4,20 & 4,17 \\
\hline & & & & & & & \\
\hline 8 & 13 e 14 & +1 & +1 & +1 & -1 & $\begin{array}{l}Y 8 \\
(1)\end{array}$ & $\begin{array}{l}\text { Y24 } \\
(2)\end{array}$ \\
\hline & & 1,05 & 0,5 & 120 & 300 & 3,86 & 3,79 \\
\hline & & & & & & & \\
\hline 9 & $5 e 9$ & -1 & -1 & -1 & +1 & $\begin{array}{l}\text { Y9 } \\
(1)\end{array}$ & $\begin{array}{l}\text { Y25 } \\
(2)\end{array}$ \\
\hline & & 0,65 & 0,4 & 80 & 500 & 5,30 & 7,20 \\
\hline & & & & & & & \\
\hline 10 & 17 e 25 & +1 & -1 & -1 & +1 & $\begin{array}{l}\text { Y10 } \\
(1)\end{array}$ & $\begin{array}{l}\text { Y26 } \\
(2)\end{array}$ \\
\hline & & 1,05 & 0,4 & 80 & 500 & 3,90 & 5,00 \\
\hline & & & & & & & \\
\hline 11 & 8 e 29 & -1 & +1 & -1 & +1 & $\begin{array}{l}\text { Y11 } \\
(1)\end{array}$ & $\begin{array}{l}Y 27 \\
(2)\end{array}$ \\
\hline & & 0,65 & 0,5 & 80 & 500 & 5,10 & 4,79 \\
\hline & & & & & & & \\
\hline 12 & 11 e 28 & +1 & +1 & -1 & +1 & $\begin{array}{c}\mathrm{Y} 12 \\
(1)\end{array}$ & $\begin{array}{l}\text { Y28 } \\
(2)\end{array}$ \\
\hline & & 1,05 & 0,5 & 80 & 500 & 10,20 & 6,80 \\
\hline 13 & 3 e 21 & -1 & -1 & +1 & +1 & $\begin{array}{l}\text { Y13 } \\
(1)\end{array}$ & $\begin{array}{l}\text { Y29 } \\
(2)\end{array}$ \\
\hline & & 0,65 & 0,4 & 120 & 500 & 3,50 & 4,52 \\
\hline & & & & & & & \\
\hline 14 & $1 e 16$ & +1 & -1 & +1 & +1 & $\begin{array}{l}\text { Y14 } \\
(1)\end{array}$ & $\begin{array}{l}\text { Y30 } \\
\text { (2) }\end{array}$ \\
\hline & & 1,05 & 0,4 & 120 & 500 & 3,33 & 6,00 \\
\hline & & & & & & & \\
\hline 15 & $2 e 22$ & -1 & +1 & +1 & +1 & $\begin{array}{l}\text { Y15 } \\
(1)\end{array}$ & $\begin{array}{l}\text { Y31 } \\
(2)\end{array}$ \\
\hline & & 0,65 & 0,5 & 120 & 500 & 3,70 & 5,00 \\
\hline & & & & & & & \\
\hline 16 & 7 e 31 & +1 & +1 & +1 & +1 & $\begin{array}{c}\mathrm{Y} 16 \\
(1)\end{array}$ & $\begin{array}{l}Y 32 \\
(2)\end{array}$ \\
\hline & & 1,05 & 0,5 & 120 & 500 & 10,20 & 7,11 \\
\hline
\end{tabular}

\begin{tabular}{|c|c|c|c|c|c|c|c|}
\hline & & ensaic & lado me & nor Rus & gosidade & & \\
\hline & & $\begin{array}{r}E n \\
D O E\end{array}$ & $\begin{array}{l}\text { saio fat } \\
\text { realiza }\end{array}$ & $\begin{array}{l}\text { Prial } 2 \\
\text { do na } L\end{array}$ & $\begin{array}{l}(4)=16 \\
A S A G\end{array}$ & & \\
\hline & & Fato & es de Co & ntrole & & & \\
\hline $\mathrm{N}^{\circ}$ & 2 niveis & $\begin{array}{c}\text { Energia } \\
\text { do } \\
\text { Pulso }\end{array}$ & $\begin{array}{l}\text { Largura } \\
\text { Temporal } \\
\text { do Pulso }\end{array}$ & $\begin{array}{c}\text { Pressão } \\
\text { Gás }\end{array}$ & $\begin{array}{l}\text { Vel. de } \\
\text { Corte }\end{array}$ & Resp & osta \\
\hline $\begin{array}{l}\text { do } \\
\text { teste }\end{array}$ & & {$[\mathrm{J}]$} & {$[\mathrm{ms}]$} & [psi] & {$[\mathrm{mm} / \mathrm{min}]$} & & \\
\hline & nivel (1) & 1,05 & 0,5 & 120 & 500 & & \\
\hline & nivel (-1) & 0,65 & 0,4 & 80 & 300 & Kugos & m) \\
\hline & Ordem & & lodelo Bas & 2 (a quar & ta) & & \\
\hline & aleatória & $\mathbf{A}$ & B & \begin{tabular}{|c|} 
\\
\end{tabular} & D & Répli & icas \\
\hline 1 & $16 \mathrm{e} 17$ & -1 & -1 & -1 & -1 & Y1 & Y17 \\
\hline & & 0,65 & 0,4 & 80 & 300 & 4,14 & 3,50 \\
\hline & & & & & & & \\
\hline 2 & $10 e 22$ & +1 & -1 & -1 & -1 & $\begin{array}{l}Y 2 \\
\text { (1) }\end{array}$ & $\begin{array}{l}\text { Y18 } \\
(2)\end{array}$ \\
\hline & & 1,05 & 0,4 & 80 & 300 & 10,60 & 5,50 \\
\hline & & & & & & & \\
\hline 3 & 18 e 32 & -1 & +1 & -1 & -1 & $\begin{array}{l}\text { Y3 } \\
\text { (1) }\end{array}$ & $\begin{array}{l}\text { Y19 } \\
(2)\end{array}$ \\
\hline & & 0,65 & 0,5 & 80 & 300 & 6,55 & 4,80 \\
\hline & & & & & & & \\
\hline 4 & 11 e 24 & +1 & +1 & -1 & -1 & $\begin{array}{l}Y 4 \\
(1)\end{array}$ & $\begin{array}{l}\text { Y20 } \\
(2)\end{array}$ \\
\hline & & 1,05 & 0,5 & 80 & 300 & 4,46 & 4,20 \\
\hline & & & & & & & \\
\hline 5 & 7 e 30 & -1 & -1 & +1 & -1 & $\begin{array}{l}\text { Y5 } \\
\text { (1) }\end{array}$ & $\begin{array}{l}\text { Y21 } \\
(2)\end{array}$ \\
\hline & & 0,65 & 0,4 & 120 & 300 & 2,43 & 3,83 \\
\hline & & & & & & & \\
\hline 6 & $15 e 27$ & +1 & -1 & +1 & -1 & $\begin{array}{l}\text { Y6 } \\
\text { (1) }\end{array}$ & $\begin{array}{l}\text { Y22 } \\
(2)\end{array}$ \\
\hline & & 1,05 & 0,4 & 120 & 300 & 2,47 & 2,61 \\
\hline & & & & & & & \\
\hline 7 & $2 e 3$ & -1 & +1 & +1 & -1 & $\begin{array}{l}\text { Y7 } \\
\text { (1) }\end{array}$ & $\begin{array}{l}\text { Y23 } \\
(2)\end{array}$ \\
\hline & & 0,65 & 0,5 & 120 & 300 & 2,26 & 4,01 \\
\hline & & & & & & & \\
\hline 8 & 25 e 31 & +1 & +1 & +1 & -1 & $\begin{array}{l}Y 8 \\
\text { (1) }\end{array}$ & $\begin{array}{l}\text { Y24 } \\
\text { (2) }\end{array}$ \\
\hline & & 1,05 & 0,5 & 120 & 300 & 3,25 & 2,50 \\
\hline & & & & & & & \\
\hline 9 & 8 e 26 & -1 & -1 & -1 & +1 & $\begin{array}{l}\text { Y9 } \\
\text { (1) }\end{array}$ & $\begin{array}{l}\text { Y25 } \\
(2)\end{array}$ \\
\hline & & 0,65 & 0,4 & 80 & 500 & 2,60 & 5,40 \\
\hline & & & & & & & \\
\hline 10 & 6 e 23 & +1 & -1 & -1 & +1 & $\begin{array}{l}\text { Y10 } \\
(1)\end{array}$ & $\begin{array}{l}\text { Y26 } \\
(2)\end{array}$ \\
\hline & & 1,05 & 0,4 & 80 & 500 & 4,70 & 7,00 \\
\hline & & & & & & & \\
\hline 11 & 4 e 14 & -1 & +1 & -1 & +1 & $\begin{array}{l}\text { Y11 } \\
\text { (1) }\end{array}$ & $\begin{array}{l}\text { Y27 } \\
\text { (2) }\end{array}$ \\
\hline & & 0,65 & 0,5 & 80 & 500 & 5,14 & 5,64 \\
\hline & & & & & & & \\
\hline 12 & 1 e 9 & +1 & +1 & -1 & +1 & $\begin{array}{l}\text { Y12 } \\
\text { (1) }\end{array}$ & $\begin{array}{l}\text { Y28 } \\
\text { (2) }\end{array}$ \\
\hline & & 1,05 & 0,5 & 80 & 500 & 6,53 & 10,90 \\
\hline & & & & & & & \\
\hline 13 & 19 e 29 & -1 & -1 & +1 & +1 & $\begin{array}{l}\text { Y13 } \\
\text { (1) }\end{array}$ & $\begin{array}{l}\text { Y29 } \\
\text { (2) }\end{array}$ \\
\hline & & 0,65 & 0,4 & 120 & 500 & 4,54 & 4,10 \\
\hline & & & & & & & \\
\hline 14 & $12 e 28$ & +1 & -1 & +1 & +1 & $\begin{array}{l}\text { Y14 } \\
(1)\end{array}$ & $\begin{array}{l}\text { Y30 } \\
(2)\end{array}$ \\
\hline & & 1,05 & 0,4 & 120 & 500 & 4,14 & 5,50 \\
\hline & & & & & & & \\
\hline 15 & 13 e 21 & -1 & +1 & +1 & +1 & $\begin{array}{l}\text { Y15 } \\
\text { (1) }\end{array}$ & $\begin{array}{l}\text { Y31 } \\
(2)\end{array}$ \\
\hline & & 0,65 & 0,5 & 120 & 500 & 4,50 & 4,60 \\
\hline & & & & & & & \\
\hline 16 & 5 e 20 & +1 & +1 & +1 & +1 & $\begin{array}{l}\text { Y16 } \\
\text { (1) }\end{array}$ & $\begin{array}{l}\text { Y32 } \\
\text { (2) }\end{array}$ \\
\hline & & 1,05 & 0,5 & 120 & 500 & 5,80 & 7,80 \\
\hline
\end{tabular}


O acréscimo da rugosidade média $\left(R_{a}\right)$ é observado nos maiores avanços, na alta energia, posição focal dentro da superfície e com uso da lente de $50 \mathrm{~mm}$. Esse aspecto de orientação se assemelha à investigação inicial realizada com energia versus taxa de sobreposição (repetição de pulsos). Como visto anteriormente, a menor velocidade de processo, i.e. maior sobreposição, acarreta na diminuição da rugosidade, reiterando a indicação de que o aplainamento da superfície está associado à maior transferência térmica juntamente com expulsão do material fundido. Em contrapartida, altas velocidades causariam maiores ondulações na superfície em razão do menor aporte de calor.

$\mathrm{Na}$ avaliação da circunstância advinda pela influência da energia, nota-se uma mesma propensão de detrimento da qualidade superficial, conforme o aumento dos seus valores. Esse fato é mais notório no gráfico de influência realizado com quatro fatores, apresentado na Figura 77 B.

Ao efetuar uma análise comparativa dos gráficos de influência entre os resultados obtidos, referentes à formação de rebarba e à rugosidade superficial, verificam-se duas semelhanças e várias divergências entre os parâmetros. A velocidade de corte (D), a energia de pulso (A) e largura temporal (B) exibem uma tendência contrária entre cada abordagem (rebarba $\mathrm{x}$ rugosidade). Entretanto, a rugosidade é reduzida pela variação do comprimento focal da lente $(E)$, da mesma forma que ocorre em relação à quantidade de rebarbas. Em ambos os casos, a utilização da lente de $100 \mathrm{~mm}$ propicia uma melhor condição de acabamento superficial.

Em contraposição ao efeito verificado na formação de rebarba, o parâmetro da pressão do gás (C) apresentou pouco efeito para o acréscimo da rugosidade superficial. Provavelmente, as tensões de cisalhamento provocadas pela ação do 
gás são imprescindíveis para remoção do material líquido fundido, mas pouco significativa para o aplainamento da superfície.

$\mathrm{Na}$ análise com quatro fatores fica evidente o grau de influência dos fatores energia de pulso (A), velocidade de corte e largura temporal (B), inclusive observase no diagrama de Pareto as quatro barras que indicam um maior peso são relativas aos três parâmetros e suas interações. Esse resultado reforça a hipótese já mencionada, sobre o vínculo entre energia e duração do pulso.

A verificação dos gráficos resultantes do projeto fatorial aplicado no equipamento laser Lasag permite observar que a velocidade de corte (D) é o fator de maior efeito, semelhante ao perfil alcançado no laboratório.

Os fatores energia (A) e largura temporal (B) estão posicionados em alternância nos diagramas de Pareto referente a menor e maior rebarba. A variação de disposição pode estar associada com alguma discrepância em conseqüência dos ajustes realizados nos valores da rugosidade média.

Outra divergência notada está relacionada à pressão do gás $(\mathrm{C})$, pois neste caso apresentou maior influência. Como já citado na revisão da literatura, a geometria do bocal interfere no processamento de materiais a laser. Na usinagem efetuada pelo equipamento Lasag utilizou-se do bocal padrão, fornecido pela empresa, com diâmetro diferente do aplicado no laboratório. Isso pode ter ocasionado a desigualdade, verificada entre os resultados, apresentados na Figura 78.

Destaca-se na Figura 79 a variação de rugosidade superficial ente as amostras $\mathrm{Y}(5)$ e $\mathrm{Y}(14)$ obtidas pela aplicação do projeto fatorial para 4 fatores, executado na CPML. A condição Y(5) proporcionou o menor valor de rugosidade na superfície de corte das amostras processadas com gás argônio. 
Gráfico de influência para cada parâmetroemrespostaa Rugosidade Diagrama de Pareto para as influências

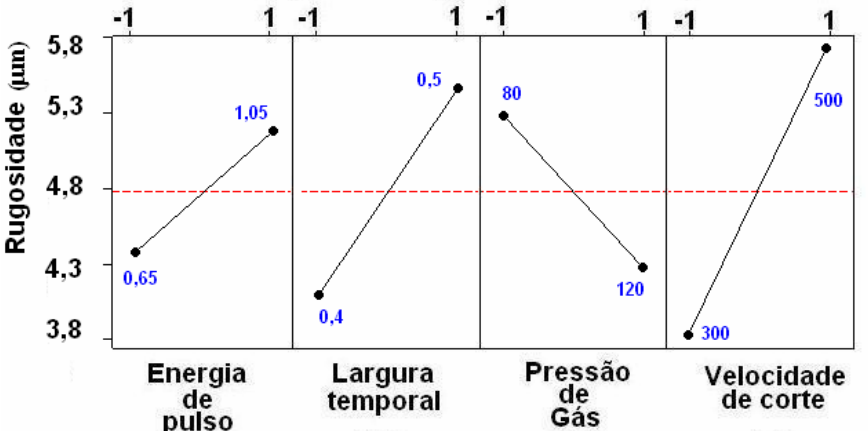

(A)

(B)

(C)

(D)

Lado de menor

(A)

Gráfico de influência para cada parâmetro em resposta aRugosidade Diagrama de Pareto para as influências

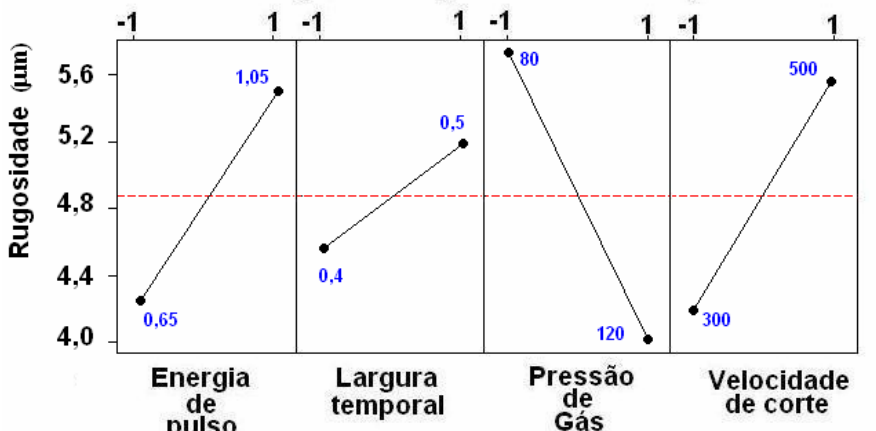

(A)

(B)

(C)

(D)

(B)

Lado de maior

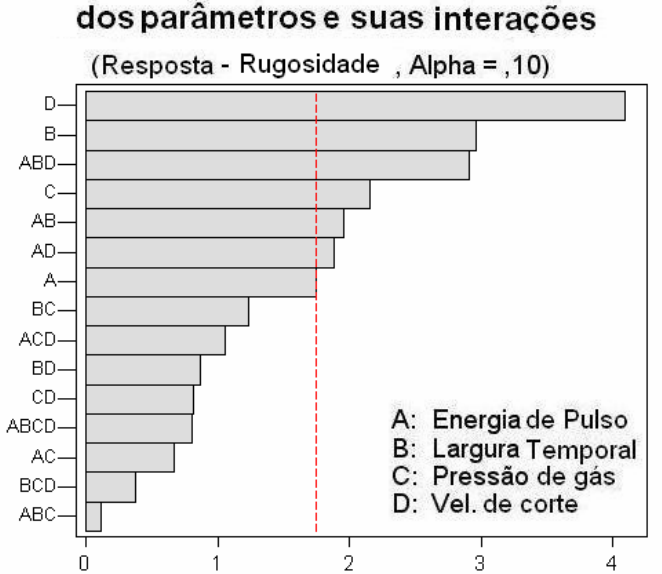
dos parâmetros e suas interações

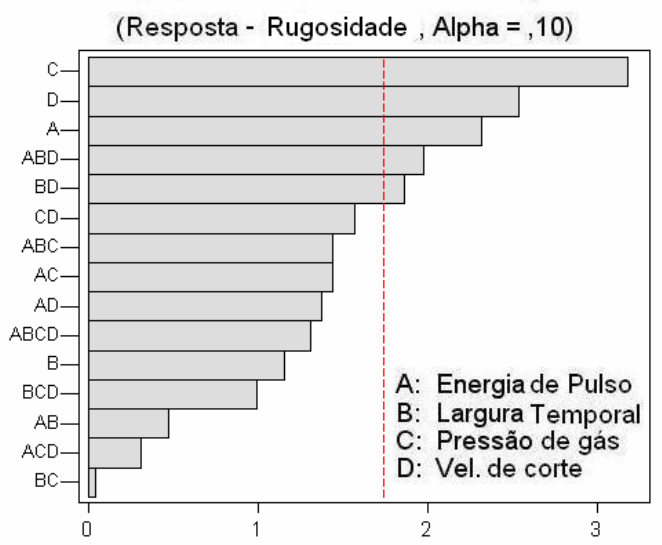

Figura 78 - Diagramas de influência para DOE 4 fatores na LASAG:

(A) lado de menor rugosidade $(B)$ lado de maior rugosidade.

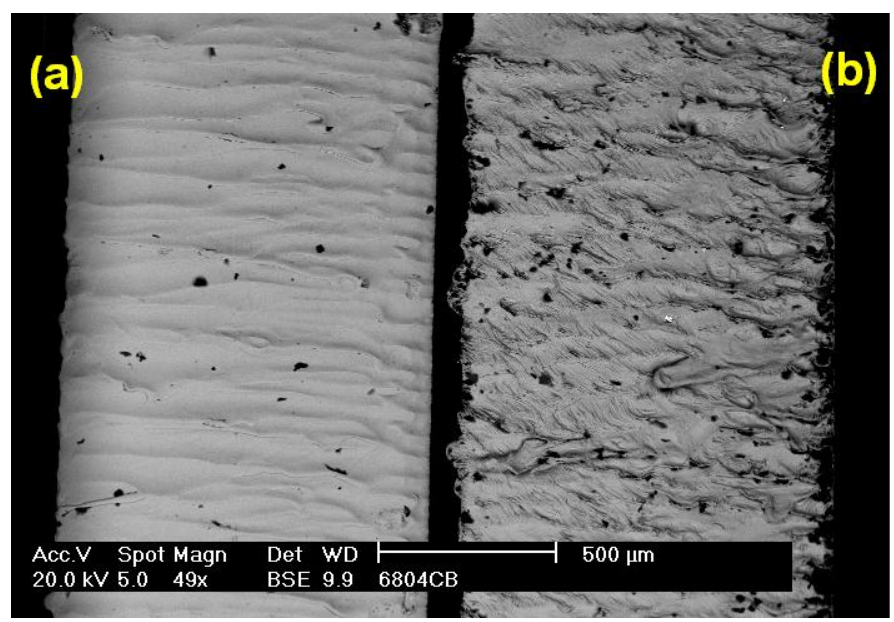

Figura 79 - Superfície de corte - diferença de rugosidade

a)condição $Y(5)$ menor rugosidade, b) condição $Y(14)$ maior rugosidade. 


\section{CONCLUSÕES}

Do ponto de vista de obtenção de menor quantidade de rebarbas, a análise preliminar do processo de corte mostrou que é preferível a utilização de pulsos de alta energia e baixa taxa de repetição do que pulsos com baixa energia e alta taxa de repetição. Pulsos mais energéticos retiram maior quantidade de material fundido e/ou produzem menor quantidade deste material.

Nesta aproximação, maior energia e menor taxa de sobreposição dos pulsos leva a uma quantidade menor de rebarbas e a uma rugosidade maior. Ao contrário, uma menor energia com maior taxa de sobreposição resulta em menor rugosidade, porém com maior acúmulo de rebarbas.

O uso de nitrogênio como gás de assistência, nestas condições, leva à formação de TiN, com aumento acentuado da dureza na superfície usinada, como foi comprovado pelos resultados de difração de raios-X e dos ensaios de microdureza. Isto se torna um problema importante nos casos em que é necessário um processo mecânico sobre esta superfície, como o caso de roscas ou escareamento, por exemplo.

O uso do gás Hélio, Argônio ou misturas destes elimina a formação de nitretos de titânio e a superfície de corte não apresenta aumento de dureza significativo.

Neste estudo, quando se procurou a minimização da quantidade de rebarbas, o projeto de experimentos demonstrou ser uma ferramenta adequada à otimização do processo de corte com laser pulsado. Conforme foi verificado nas chapas da liga Ti$6 \mathrm{Al}-4 \mathrm{~V}$ com espessura de $1 \mathrm{~mm}$, em que se obteve um valor de $0,1 \mathrm{~mm}^{2}$, relativo a formação de rebarbas, em um corte com comprimento de $15 \mathrm{~mm}$.

As análises, obtidas pela realização do projeto de experimentos DOE, indicaram que o comprimento focal da lente de focalização e a pressão do gás 
exercem uma grande influência no processo. A opção pela lente com comprimento focal de $100 \mathrm{~mm}$, ao invés da lente de $50 \mathrm{~mm}$, aponta ser uma vantagem. Neste aspecto, o posicionamento do foco sobre a superfície da peça também é preferível ao posicionamento abaixo desta. A pressão do gás sempre exibiu melhores resultados para os valores mais altos, até o limite operacional do equipamento de 120 psi $\left(828 \times 10^{3} \mathrm{~Pa}\right)$.

Os resultados da análise do projeto fatorial, também demonstraram que maiores velocidades são as mais adequadas no processo de corte e contribuem para a menor formação de rebarbas. Isto vai ao encontro dos resultados iniciais em que uma menor taxa de sobreposição se mostrou mais eficiente na redução de rebarbas.

Dentro do limite operacional dos equipamentos, a largura temporal do pulso laser não apresentou influência no parâmetro rebarba. Obviamente que sua influência está relacionada à intensidade, a qual sofre uma variação muito maior quando se altera o diâmetro do ponto focal, pela mudança da lente de focalização ou pela alteração da posição do seu foco.

No projeto experimental inicial composto pelos seis fatores, o parâmetro energia (A), como efeito principal, apresentou pouca relevância e somente foi significativo nas interações com os outros fatores. Ao se aproximar da região de otimização do processo, referente à redução de rebarbas, a energia $(A)$ tornou-se importante exercendo maior influência individualmente.

Em uma das configurações executadas que resultou na menor aderência de rebarbas, também se observou à eliminação da camada de $\mathrm{TiN}$, mesmo com o uso do nitrogênio como gás de assistência. Isto pode indicar que não houve a formação deste nitreto de titânio ou que este foi retirado juntamente com o material fundido, 
expelido da região de corte pela ação do gás. De qualquer maneira, este resultado é muito significativo para o processo de corte de chapas de titânio, pois ao mesmo tempo em que quase elimina a formação de rebarbas, ainda permite a utilização de um gás mais barato, sem os inconvenientes de um endurecimento demasiado da superfície de corte.

As mudanças de fase encontradas no material ressolidificado e/ou na zona afetada pelo calor não acarretam aumento expressivo na dureza superficial do titânio. Verifica-se a transformação martensitíca na zona de fusão e uma microestrutura apresentando as fases $\alpha$ equiaxial $+\beta$ intragranular, o que uma característica de uma liga Ti-6Al-4V.

Quanto aos resultados relacionados à variável de saída rugosidade, é preciso ressaltar que o processo de refinamento não procurou minimizar este fator, e sim a formação de rebarbas. A análise para o conjunto de quatro fatores foi realizada nesta variável apenas com o intuito de verificar as influências dos diversos fatores sobre ela. Assim, o menor resultado apresentou uma rugosidade de 1,2 $\mu \mathrm{m}$. No entanto é claro que existe a possibilidade de obter melhores resultados em relação à superfície.

Para esta variável, pode-se dizer que o efeito da pressão do gás é menor do que o observado na formação de rebarbas.

Além disso, nesta investigação constatou-se que as maiores velocidades contribuíram para o aumento da rugosidade, o que corrobora com os resultados preliminares obtidos neste trabalho, em que as pequenas taxas de sobreposição levaram também a rugosidades altas. 
A utilização da lente de $f=100 \mathrm{~mm}$ resultou em superfícies com menor rugosidade, assim como o posicionamento do seu foco na superfície da peça. A configuração destes fatores nestas condições também é favorável para o caso de formação de rebarbas.

A largura temporal do pulso laser mostrou uma influência bem maior no caso da rugosidade do que no caso da rebarba. Aqui, uma largura temporal maior levou a rugosidades menores.

A energia também aparece de maneira importante nas interações com outros fatores, sendo mais influente como fator independente na região de refinamento dos parâmetros. Neste caso, menores energias resultam em uma superfície com menor rugosidade.

Um quadro geral demonstrando a influência destes fatores no processo de corte pode ser resumido como:

Lente de comprimento focal $\mathrm{f}=100 \mathrm{~mm}$ produz menor quantidade de rebarbas e também uma menor rugosidade;

$>$ Velocidade mais alta reduz a formação de rebarbas ao mesmo tempo em que aumenta a rugosidade;

Pressão alta reduz a quantidade de rebarbas, mas tem pouca influência na rugosidade;

A largura temporal tem pouca influência na formação de rebarbas, mas o seu aumento reduz a rugosidade;

> A energia se mostrou importante nas interações com outros parâmetros e apresentou maior influência após o refinamento destes. Neste caso, menor energia causa menor rebarba e também menor rugosidade. 


\section{REFERÊNCIAS}

\footnotetext{
${ }^{1}$ KATULIN, V.A. Laser Technology in Industry. H. Interactions, v.37, p.423 - 432, 1987.

${ }^{2}$ WETTER, N.U.; ROSSI, W. ICS Lectures on Industrial Applications of Lasers. Vienna, Unido Publication. S. P. Morato, Editor, v 1, 2000.

${ }^{3}$ GRASSI, F. Industrial Applications of Power Lasers on Metal Fabrications. Training course on laser sources and industrial applications ICS-UNIDO, Argentina, July 1998.
}

${ }^{4}$ CHEN, K.; YAO, Y.L. Process optimization in pulsed laser micromachining with applications in medical device manufacturing. The international Journal of Advanced Manufacturing Technology, v.16, p. 243-249, 2000.

${ }^{5}$ RAO, B.T.; KAUL, R.; TIWARI, P.; NATH, A.K. Inert gas cutting of titanium sheet with pulsed mode $\mathrm{CO}_{2}$ laser, Optics and Lasers in Engineering, v.43, p. 1330-1348, 2005.

${ }^{6}$ MIYAMOTO, B.L.M. Laser Materials Processing. Proceedings of ICALEO, Ed. P. Denney, v.2306, 1993.

${ }^{7}$ ROHDE, H. Sharp cutting and drilling with pulsed solid state lasers. VDI-Tantung'96, Sttutgart, Deutchland, p.1-10, 1996.

${ }^{8}$ MAWAKDIYE, A. A resposta dos metais. Revista metalurgia \& materiais, Edição 546.

${ }^{9}$ BOYER, R.R. An overview on the use of titanium in the aerospace industry. Mater Sci Eng A, v. 213, p. 103-104, 1996.

${ }^{10}$ WELLER, M.; CHATTERJEE, A.; HANECZOK, G., et al. Mechanical properties of intermetallic y-TiAl based alloys at elevated temperatures. Defect Diffus Forum, v. 194-1, p. 589-594, 2001.

${ }^{11}$ ES-SOUNI, M.; BRANDIES, H.F. On the transformation behaviour, mechanical properties and biocompatibility of two NiTi-based shape memory alloys: NiTi42 and NiTi42Cu7, Biomaterials, v.22: (15), p. 2153-2161, 2001.

12 SHANJIN; LV.; WANG YANG. An investigation of pulsed laser cutting of titanium alloy sheet. Optics and Lasers in Engineering, v.44 (10), p. 1067-1077, 2006.

${ }^{13}$ MODEST, M.F. Laser Machining of Ablating/Decomposing Materials - Through Cutting and Drilling Models. ICALEO, 96. Proceedings sec. Laser Cutting'96 (711P), 1996.

${ }^{14}$ HAN, A.; GUBENCU, D.; PILLON, G. A Generalized structure based on systemic principles of the characteristic variables of material laser processing. Optics \& Laser Technology, v.37, p.577-581, 2005.

${ }^{15}$ BANDYOPADHYAY; S.; GOKHALE, H.; SARIN SUNDAR, A.J.K.; SUNDARARAJAN, G.; JOSHI, S.V. A statistical approach to determine process parameter impact in Nd:YAG laser drilling of IN718 and Ti-6Al-4V sheets. Optics and Lasers in Engineering, v.43, p. 163-182, 2005.

${ }^{16}$ BREYFOGLE III, F.W.; CUPELLO, J.M.; e MEADOWS, B. A Practical Guide to Understanding, Assessing, and Implementing the Strategy That Yields Bottom-Line Success, $1^{\text {st }}$ ed. John Wiley \& Sons, INC., New York, 2001. 
${ }^{17}$ MONTGOMERY, D.C. Design and Analysis of Experiments. $4^{\text {th }}$ ed. New York: John Wiley \& Sons, 1997.

${ }^{18}$ BETNER, D.R, et al. Introduction to Titanium and Its Alloys. $9^{\text {th }}$ ed. Ohio: Metals Handbook, American Society for Metals, v.3, p. 353 - 360, 1985.

${ }^{19}$ COLLINGS, E.W. The Physical Metallurgy of Titanium Alloys. Ohio: American Society for Metals, Metals Park, p. 261, 1984.

${ }^{20}$ BARSKDALE, J. Titanium- its occurrence, chemistry and technology, $2^{\text {nd }}$ ed. Metals Park, p.139-163, 1997.

${ }^{21}$ EVERHART, J.L. Titanium and Titanium Alloys Materials \& Methods Reinhold Publishing Corporation, New York, N.Y, 1954.

22 SCIENTIFIC ANNOUCEMENT. Produced by Dr. GUSEIN BAKHLUDOVICH SADYKHOV Moscou. Disponível em: < www.informnauka.ru/eng/2006/2006-04-14-06_31_e.htm> Acesso em: 27 março 2007.

${ }^{23}$ SCIENCE. Disponível em: < www.csiro.au/science/ps19i.html> Acesso em: 10 fev. 2007.

${ }^{24}$ CHEN G.Z.; FRAY D.J. E; FARTHING, T.W. Cathodic deoxygenation of alpha-case on titanium and alloys in molten calcium chloride. Metall.Mater.Trans. B, v.32B, p.1041-1052, 2001.

${ }^{25}$ GERDEMANN, S.J. Titanium: Process Technologies. Advanced Materials \& Processes, v.1, 2001.

${ }^{26}$ LONG, M.; RACK, H.J. Titanium and alloys in total join replacement: a materials science perspective. Biomaterials, v.19 (18), p.1621-1639, 1998.

${ }^{27}$ BROOKS, C.R. Heat Treatment, Structure and Properties of Nonferrous Alloys; American Society for Metals (ASM), Metals Park, Ohio, USA, chapter 9, p.329-387, 1982.

${ }^{28}$ DONACHIE JR., M.J. Titanium: A Technical Guide; ASM International, Metals Park, Ohio, USA, 1988.

${ }^{29}$ TAL-GUTELMACHER, E.; ELIEZER. D. The Hydrogen embrittlement of titanium-based alloys . JOM, p.46, 2005.

${ }^{30}$ BHADESHIA, H.K.D.H. Metallurgy of Titanium and its Alloys. Disponível em: <http://www.msm.cam.ac.uk/phasetrans/2004/titanium/WebDesign_TempPage35645.htm> Acesso em: 15 março 2007.

${ }^{31}$ AZEVEDO, C.R.F. Microestrutura do Titânio e suas Ligas para Implantes Cirúrgicos. M\&M - Metalurgia e Materiais, São Paulo, v. Julho, n. 2003, p. 445-447, 2003.

${ }^{32}$ CALLISTER, W.D. Materials science and engineering: an introduction. New York: Wiley, 1985.

${ }^{33}$ FLOWER, H.M. Micro structural Development in Relation to Hot Working of Titanium Alloys. Materials Science and Technology, v.6, p.1082-1092, 1990. 
${ }^{34}$ SCHACKELLFORD, F. Introduction to materials science for engineering. $3^{\text {rd }}$ ed., Macmillan Publishing Company. 1990.

${ }^{35}$ PRIMA, F.; VERMAUT, P.; THIBON, I., et al. A low cost metastable beta titanium alloy: microstructures and mechanical properties. J PHYS IV, v.11: (PR4), p. 241-248, 2001.

${ }^{36}$ SERGUEEVA, A.V.; STOLYAROV, V.V.; VALIEV, R.Z., et al. Advanced mechanical properties of pure titanium with ultrafine grained structure. Scripta Mater, v.45 (7), p. 747752, 2001.

${ }^{37}$ SHAWN M. KELLY. Characterization and thermal modeling of Laser formed Ti-6AI-4V thesis submitted to the Faculty of the Virginia Polytechnic Institute and State University, Blacksburg, Virginia, 2002.

${ }^{38}$ ROCHA MELO, G. M. Transformações de fases e características microestruturais de ligas Ti-Al e Ti-Nb. Dissertação de Mestrado - Universidade Estadual de Campinas, Campinas, 2000.

${ }^{39}$ BLOOR, D.; BROOK R.; FLEMINGS, M.; MAHAJAN, S. The Encyclopedia of Advanced Materials, v. 1, 4, Elsevier Science Inc., New York, p.66 e 2868,1994.

${ }^{40}$ MARINO, C.E.B.; ROCHA-FILHO, R.C.; BIAGGIO, S.R . Investigação da Estabilidade de Materiais Biocompatíveis por Análise Microestrutural. In: $23^{a}$ Reunião Anual da Sociedade Brasileira de Química (SBQ), Poços de Caldas (MG), 2000.

${ }^{41}$ REED HILL, R.E.; ABBASCHIAN, R. Physical Metallurgy Principles. $3^{\text {rd }}$ ed. PWS-Kent Co., 1992.

${ }^{42}$ DIETER, G. Mechanical Metallurgy, McGraw-Hill, $3^{\text {rd }}$ ed., 1986.

${ }^{43}$ FROES, F.H.; EYLON, D.; BOMBERGER, H.B. Titanium Technology: Present Status and Future Trends, The Titanium Development Association, 1985.

${ }^{44}$ BANIA, P.J. Beta Titanium Alloys and their role in the Titanium Industry, Journal of Metals, v.46(7), p. 16-19, 1994.

${ }^{45}$ SCHENEIDER, S.G. Obtenção e caracterização da liga Ti-13Nb-13Zr para aplicação como biomaterial. São Paulo, 2001. Tese de Doutorado em Tecnologia Nuclear. Instituto de Pesquisas Energéticas Nucleares (IPEN), 2001.

${ }^{46}$ NIINOMI, M. Mechanical properties of biomedical titanium alloys. Materials Science and Engineering A, v.243, p. 231-236, 1998.

${ }^{47}$ MOLCAHNOVA, E.K. Phase Diagrams of Titanium Alloys [Translation of Atlas Diagram Sostoyaniya Titanovyk Splavov], Israel Program for Scientific Translations, Jerusalem, 1965.

${ }^{48}$ FROES F.H. Getting better: big boost for titanium MIM prospects. Metal Powder Report, v.61 (11), p. 20-23, 2006.

${ }^{49}$ FROES F.H. Titanium Alloys: Handbook of Advanced Materials, James K. Wessel, Wiley Interscience Ed., p. 271, 2004. 
${ }^{50}$ ASSOCIATION TITANE pesquisa de mercado mundial realizado pela Secretaria de finanças e da Indústria da França. Disponível em: < http://www.titane.asso.fr> Acesso em: 25 novembro 2006.

51 SALAMA, M.M.; MURALI, J.; JOOSTEN, M.W. Titanium drilling risers - application and qualification. Journal of Offshore Mechanics and Arctic Engineering, v.122 (1), p.47-51, 2000.

${ }^{52}$ LUCKEY, H.A. Titanium Alloys in Surgical Implants, 3M Orthopedic Products, RMI Company, Arizona, 1981.

${ }^{53}$ WILLIAMS, D.F. Titanium as a metal for implantation -part1: physical properties, Journal of Medical Engineering and technology, v.1, p. 195-198, 1977.

${ }^{54}$ LEVENTHALL, G.S. Titanium, a metal for Surgery, Journal of Bone and Joint Surgery, v.33(A), p. 473, 1951.

${ }^{55}$ BRÄNEMARK, R.; RYDEVIK, B.; MYERS, R. R. Osseointegration in skeletal reconstruction and rehabilitation: A review. Journal of Rehabilitation Research and Development, v.38 (2), p. 175-181, 2001.

${ }^{56}$ DAVIDSON, J. A.; MISHRA, A.K; KOVASC, P.; POGGIE, R. A. New surface-hardened, low-modulus, corrosion-resistant Ti-13Nb-13Zr alloy for total hip arthroplasty. Bio-Medical Materials and Engineering, v.4, p.231-243, 1994.

${ }^{57}$ GEETHA, M.; SINGH, A. K.; GOGIA, A. K.; ASOKAMANI, R. Effect of thermomechanical processing on evolution of various phases in Ti-Nb-Zr alloys Journal of Alloys and Compounds, v. 384, p. 131-144, 2004.

${ }^{58}$ COM CIÊNCIA - Revista Eletrônica de Jornalismo científico SBPC Artigo: Implantes de aço inoxidável cada vez mais resistente à corrosão. Disponível em:

< http://www.comciencia.br/200407/noticias/2/quimica.htm> Acesso em: 10 janeiro 2007.

59 JAIMES, R.F.V.V.; AFONSO, M.L.C.A.; AGOSTINHO, S.M.L; BARBOSA, C.A. Evolução temporal da interfase aço inoxidável P558/solução de cloreto de sódio por espectroscopia de impedância eletroquímica, REM: Revista Escola de Minas, Ouro Preto, v.60(1), p. 63-68, 2007.

${ }^{60}$ ANVISA - Agência Nacional de Vigilância Sanitária, Boas Práticas de Fabricação de Produtos Médicos (BPFPM's). Disponível em: <http://www.anvisa.gov.br/produtosaude/ boas.htm> Acesso em: 24 outubro 2006.

${ }^{61}$ AZEVEDO, C.R.F.; HIPPERT JR., E. Análise de falhas de implantes cirúrgicos no Brasil: a necessidade de uma regulamentação adequada, Cad. Saúde Pública, Rio de Janeiro, v.18 (5), p.1347-1358, 2002.

${ }^{62}$ CURTISS- WRIGHT CORPORATION, Increased Production: reduced costs through a better understanding of the machining process and control of materials, tools, machines, U.S. Air Force Machinability Report, v.2, Wood-Ridge, New Jersey, 1951.

${ }^{63}$ DINIZ, A. E.; MARCONDES, F.C.; COPPINI, N.L. Tecnologia da usinagem dos materiais, $2^{\mathrm{a}}$ Ed., Artliber Editora Ltda, São Paulo, 2000. 
${ }^{64}$ KAHLES, J.F.; FILED, M.; EYLON, D.; FROES, F.H. Machining of Titanium, Journal of Metals, v.4, p. 27-35, 1985.

${ }^{65}$ MACHADO, A.R.; WALLBANK, J. Machining of Titanium and Its Alloys - a review Proceedings of the Institution of Mechanical Engineers $B$, Journal of Engineering Manufacture, v.204(B1), p. 53-60, 1990.

${ }^{66}$ TRUCKS, H.E. Machine and Tool Blue Book, p. 39-41, 1987.

${ }^{67}$ BHATTACHARYYA, S.K.; PASHBY, I.R.; EZUGWU, E.O.; MACHADO, Á.R. The Milling of Titanium with Coated Carbide Tools, Anais do $8^{\circ}$ CEBECIMAT, p. 271-275, 1988.

${ }^{68}$ BRIAN, J.H.; OLEXA, R. First Look at Tomorrow's Technology - Manufacturing research papers presented at NAMRC, Manufacturing Engineering, v.127 (1), chapter 11, 2001.

${ }^{69}$ KOECHNER, W. Solid State Laser Engineering, Series: Springer- Verlag 5 edition, 1999.

${ }^{70}$ VASCONCELLOS, E. O laser e a pesquisa básica. Série reportagens.

Disponível em: < http://www.comciencia.br/reportagens/fisica/fisica13.htm>. Acesso em 13 março 2007.

${ }^{71}$ BAGNATO, V.S. Os fundamentos da Luz Laser. Física na escola, v.2 (2), 2001.

${ }^{72}$ SCHAWLOW, A.L.; TOWNES, C.H. Infrared and Optical Masers, Physical Review, v. 112, p.6, 1958.

${ }^{73}$ BERTOLOTTI, M. Masers and Lasers; An historical approach, Bristol, Adam Hilger, Ltda, 1983.

${ }^{74}$ MAIMAN, T.H. Simulated optical radiation in ruby, Nature, v.187, p.493-494, 1960.

${ }^{75}$ BLAIR, B. Scientists who made a difference Ali Javan. Azerbaijan International, v. 4(2), 1996.

${ }^{76}$ BROMBERG, J.L. The laser in America: 1950 - 1970, MIT Press, 1950.

77 TRÄGER, F. Springer Handbook of Lasers and Optics, Springer Science + Business Media, LLC New York, 2007, chap. 11, p. 583, 2007.

${ }^{78}$ ENCYCLOPEDIA BRITANNICA ONLINE

Disponível em: <http://www.britannica.com/ebc/art-90017/Stimulated-emission-in-a-lasercavity> Acesso em: 16 março 2007.

${ }^{79}$ KINCADE, K.; ANDERSON, S. Laser Marketplace 2007: laser industry navigates its way back profitability. Disponível em: < http://www.laserfocusworld.com/articles/282527> Acesso em: abril 2007.

${ }^{80}$ BELFORTE, D. A. Fiber lasers tip the scale. Disponível em: <http://www.industriallasers.com/display_article/246483/39/ARTCL/none/none/Fiber-lasers-tip-the-scale/> Acesso em: 10 março 2007.

${ }^{81}$ M\&A ANALYSIS AND RESEARCH ON LASER INDUSTRY OF CHINA, 2007. Disponível em: <http://www.acunion.nett/en/ma/Laser.htm> Acesso em: 10 abril 2007. 
${ }^{82}$ MUKHERJEE; MAZUNDER, J. Lasers in Metallurgy; Proc. of the Metallurgical Society of AIME, Illinois, K. (Ed.), p. 263 - 278, 1981.

${ }^{83}$ FEINBERG, R.; HOLMES, L. Scientific and Engineering Applications of Commercial Laser Devices; Morris Levitt (Ed.) Proc. SPIE, v. 610, 1986.

${ }^{84}$ UHLENBUSH, J.; BIELESCH, U.; KLEIN, S.; NAPP, M.; SCHAFER, J. H. Recent developments in metal processing with pulsed technology; Applied Surface Science, v. 106, p. $228-234,1996$.

${ }^{85}$ STEEN, W. M. Laser Material Processing, Springer, $3^{\text {rd }}$ ed., 2003.

${ }^{86}$ ROSSI, W.; LIMA, M. S. F.; GUZZO, P.L.; AMORIM, F.L.; RASLAN, A.A. Processos Especiais de Usinagem, capítulo 7, Tecnologias Avançadas de Manufatura, Coleção Fábrica do Milênio, Ed. Novos Talentos, v.1, p. 125-145, 2005.

${ }^{87}$ WIKIPEDIA Disponível em: <http://www.en.wikipedia.org.wiki//mage:Laser_spectral_ lines.svg > Acesso em: 17 fevereiro 2007.

${ }^{88}$ CHRYSSOLOURIS, G. Laser machining, theory and practice. New York, Springer, 1991.

${ }^{89}$ VON ALLMEN, M. Laser beam interactions with materials. Berlin, Springer, 1987.

${ }^{90}$ MATT, H.; HARRISON, P.M.; HENDERSON, I.; BROWNELL, M. Laser milling - A practical industrial solution for machining a wide variety of materials, Fifth International Symposium on Laser Precision Microfabrication, Proc. of SPIE, v.5662, p.627-632, 2004.

91 PUBLICATION LAL Disponível em: <http://www.publication.lal.in2p3.fr/2001/web/node 139.html> Acesso em: 20 março 2007

${ }^{92}$ COHERENT Disponível em: < http://www.coherent.com/lasers.htm acesso jan 2007-1022> Acesso em: 20 março 2007.

${ }^{93}$ LEIDDINGER, D.; PENZ, A.; SCHUÖCKER, D. Improved manufacturing processes with high power lasers, Infrared Physics Technology, v.36(1), p. 251-266, 1995.

${ }^{94}$ SONA, A. Lasers in industry: metalworking processes and systems. Physica Scripta, v.T23, p. 288-292, 1998.

${ }^{95}$ POWELL, J.; IVARSON, A.; KAMALU, J.; BRODEN, G.; MAGNUSSON, C. Role of oxygen purity in laser cutting of mild steel, ICALEO 1992, p. 433-442, 1992.

${ }^{96}$ MAN, H.C.; DUAN, J.; YUE, T.M. Design and characteristics analysis of supersonic nozzles for high pressure gas laser cutting, Optics \& Laser Technology, v.30, p. 497-509, 1998.

97 JACKSON, M.J.; ROBINSON,G.M.; GILL,M.D.H.; O’NEILL, W. The effect of nozzle design on laser micro-machining of M2 tool steels, J Mater Process Tech v.160, p. 198-212, 2005.

${ }^{98}$ FIERET, J., et all, Overview of flow dynamics in gas-assisted laser cutting, SPIE, High Power Lasers, v.801, p.243-250, 1987. 
${ }^{99}$ MAN, H.C.; DUAN, J.; YUE, T.M. Dynamic characteristics of gas jets from subsonic and supersonic nozzles for high pressure gas laser cutting, J Mater Process Tech v.63, p. 217222, 1997.

${ }^{100}$ QUINTERO, F.; POU, J.; FERNÁNDEZ, J.L.; DOVAL, A.F., et al. Optimization of an offaxis nozzle for assist gas injection in laser fusion cutting, Optics \& Laser Technology, v.44, p. 1158-1171, 2006.

${ }^{101}$ RIVEIRO, A.; GÓMEZ, B.; QUINTERO, F.; LUSQUIÑOS, F.; COMESAÑA, R.; POU, J. Cutting of aeronautic aluminium alloys by novel supersonic laser cutting head, Proceedings of Fourth International WLT- Conference on Lasers in Manufacturing 2007, Munich, 2007.

102 STEINBERG, D.M.; HUNTER, W.G. Experimental design: review and comment. Technometrics. v.26 (2), p. 71-97, 1984.

${ }^{103}$ BAILEY JR., W. A.; CLARK, T. D. JR. Taxi management and route control: A systems study and simulation experiment. In Proceedings of the 1992 Winter Simulation Conference, J. J. Swain, D. Goldsman, R. C. Crain, and J. R. Wilson (Ed.), Arlington, VA, p. 1217-1222. 1992.

${ }^{104}$ GORDON, S. C.; AUSINK, J. J.; BERDINE, R. J. Using experimental design techniques for spacecraft control simulation. Simulation, v.62, p. 303-309, 1994.

${ }^{105}$ KUEI, C. H.; MADU, C. N. Polynomial metamodelling and Taguchi designs in simulation with application to the maintenance float policy. European Journal of Operational Research, v.72, p. 364- 375, 1994.

${ }^{106}$ SILVEIRA, Z. C. Análise Estatística e Otimização de Parâmetros de Projeto em Componentes de Sistemas Mecânicos - Tese de Doutorado - Faculdade de Engenharia Mecânica da Universidade Estadual de Campinas, Campinas, 2003.

${ }^{107}$ MONTGOMERY, D. C.; PECK, E. A. Introduction to linear regression analysis. (2nd ed.). New York: Wiley, 1992.

${ }^{108}$ FU, L. Neural network in computer intelligence. India: Tata Mc Graw Hill Edition, 2003.

${ }^{109}$ ZADEH, L. A. Fuzzy sets and application: Selected papers. R. R. Yager, S. Ovchinnikov, M. Tong, \& H. T. Nguyen Eds., 1973.

${ }^{110}$ ROSS, P. J. Taguchi techniques for quality engineering. New York: McGraw-Hill, 1989.

${ }^{111}$ HILLIER, F. S.; LIEBERMANN, G. J. Operations research (2nd ed.). Delhi: CBS Publishers and Distributors, 1999.

112 HASSAN, G.A.; SULIMAN, S.M.A. Experimental modeling and optimization of turning carbon steel. International Journal of Production Research, v. 28 (6), p. 1057-1965, 1990.

${ }^{113}$ MUKHERJEE, I.; RAY, P.K. A review of optimization techniques in metal cutting processes, Computers \& Industrial Engineering, v. 50, p. 15-34, 2006.

114 BRUNS R.E.; SCARMINIO I.S.; BARROS NETO, B. Como fazer experimentos:

Pesquisa e desenvolvimento na ciência e na indústria. Campinas: Editora da Unicamp, p. 401, 2001. 
${ }^{115}$ REALUM - Indústria e comércio de metais puros e ligas Itda.

Disponível em: < http://www.realum.com.br/titanio3.htm> Acesso em: 10 fevereiro 2007.

${ }^{116}$ BOYER, R.R.; RWELSCH, G.; COLLINGS, E.W. Materials properties handbook titanium alloys, ASM International, Materials Park, Ohio, 1994.

${ }^{117}$ ROSS, R.B. Metals Handbook Specification Handbook, $4^{\text {th }}$ ed., Chapman \&Hall, London, 1992.

${ }^{118}$ WHITE MARTINS PRAXAIR TECNOLOGY, INC. Divisão São Paulo - informações sobre os gases. Disponível em: < http://www.praxair.com> Acesso em: 20 novembro 2006.

${ }^{119}$ ASCONGRAPH LTDA empresa representante no Brasil do Software Mastercam Software aplicado mastercam versão 8. Disponível em: < http:// www.ascongraph.com.br/ > Acesso em: 20 setembro 2006.

120 INDUSTRIA EMANOEL ROCCO S.A. - fresadora Rocco modelo F700 GL nº 094 série: CNC com comando numérico Heidenhan Diadur 630.

${ }^{121}$ SELAMAT, M.S.; BAKER, T.N.; WATSON, L.M. Study of the surface layer formed by the laser processing of Ti-6Al-4V alloy in a dilute nitrogen environment, $\mathbf{J}$ Mater Process Tech v.113 (1-3), p. 509-515, 2001.

122 LASERTOOLS TECNOLOGIA LTDA. Disponível em: < http://www.lasertools.com.br> Acesso em: 10 janeiro 2007.

${ }^{123}$ OSADCHUK,R.; KOSTER, W.P.; KAHLES, J.F. Recommended Techniques for Polishing Ti for Metallographic Examination , Metal Progress, v.64 (4), 1953.

${ }^{124}$ OSADCHUK, R.; KOSTER, W.P.; KAHLES, J.F. Metallography structures in commercial titanium, Metal Progress, v.64 (2), 1953.

${ }^{125}$ SEAGLE, S; BARTLO, L.J. Physical Metallurgy and Metallography of Ti Alloys, ASM Met. Eng. Quart.8, p.1-10, 1968.

126 JESUÍNO, G.A.; RIBEIRO, L.M.F.; NAKAZATO, F.; NAKAZATO, .Z.; CODARO, E.N.; HEIN, L.R. DE O. Propriedades mecânicas e resistência à corrosão da liga Ti-4AI-4V obtida da reciclagem da liga Ti-6AI-4V. Trabalho apresentado no $14^{\circ} \mathrm{CBECIMAT,} \mathrm{Águas}$ de São Pedro, SP, 2000.

${ }^{127}$ ZHANG, L.; GOBBI, S. L.; NORRIS, I.; ZOLOTOVSKY, S.; RICHTER, K. H. Laser welding techniques for titanium alloy sheet, Journal of Materials Processing Technology, v. 65, p. 203-208, 1997.

${ }^{128}$ CAIAZZO, F.; CURCIO, F.; DAURELIO, G.; MINUTOLO, F. M. C. Ti6AI4V sheets lap and butt joints carried out by $\mathrm{CO} 2$ laser: mechanical and morphological characterization, Journal of Materials Processing Technology, v. 149, p.546-55, 2003.

${ }^{129}$ BERAHA, E.; SPHIGLER, B. Color Metallography, American Society for Metals (ASM), Metals Park, Ohio 440073, USA, p.111, 1977. 
${ }^{130}$ OLIVER, W.C.; PHARR, G.M. An improved technique for determining hardness and elastic modulus using load and displacement sensing indentation experiments, J.Mater.Res., v.7, p.1564-83, 1992.

${ }^{131}$ ALMEIDA, I. A.; ROSSI, W.; LIMA, M. S. F.; BERRETTA, J. R.; MORATO, S. P. Corte de Titânio por Laser Pulsado de Neodímio:YAG In: Anais do XXIX CONSOLDA - Congresso Nacional de Soldagem, São Paulo, p.CT11, 2003.

${ }^{132}$ ETAQQI, S.; HAYS, V.; HANTZPERGUE, J.J.; SAINDRENAN, G.; REMY, J.C. Surface and Coating Technology, v.100-101 p.428-432, 1998.

${ }^{133}$ KLOOSTERMAN, A.B.; DE HOSSON, J.TH.M. Microstructural characterization of laser nitrided titanium. Scripta Metallurgica et Materialia, v.33 (4), p. 567-574, 1995.

${ }^{134}$ ROSSI, W.; VIEIRA JÚNIOR, N. D.; BERRETTA, J. R.; ALMEIDA, I. A.; MORATO, S. P. Quando o Laser de Nd:YAG pulsado pode ser mais interessante. Revista Máquinas e Metais, São Paulo, V..XL, n.456, p.112 - 125, 2004.

${ }^{135}$ AKGUN, O. V.; INAL, O. T. Laser-Surface Modification of Ti-6al-4v Alloy. Journal of Materials Science, v. 29(5), 1159-1168, 1994.

${ }^{136}$ XUE et al. Laser gas nitriding of Ti-6Al-4v part2: characteristics of nitrided layers, Advanced Performance Materials, v.4, p.389-408, 1997.

${ }^{137}$ LIMA, M.S.F. Laser Beam Welding of Titanium Nitride coated Titanium using pulseshaping. Materials Research, v.8 (3), p. 323-328, 2005.

${ }^{138}$ LIMA, M.S.F.; FOLIO, F.; MISCHLER, S. Microstructure and surface properties of laser remelted titanium nitride coatings on titanium. Surface \& Coatings Technology, v. 199, p. 83-91, 2005.

139 RICKERBY, D.S.; BURNETT, P.J. The wear and erosion resistance of hard PVD coatings, Surface \& Coatings Technology, v.33, p. 191-211. 1997.

${ }^{140}$ POWELL, J. CO2 laser cutting. New York: Springer; 1993.

${ }^{141}$ KEY TO METALS KNOWLODGE Base general characteristics of other nonferrous metals Disponível em: < http://www. Key-tometals.com> Acesso em: 20 junho 2004.

${ }^{142}$ ALMEIDA, I.A.; ROSSI, Laser Cutting optimization of titanium alloy, Proceedings of Fourth International WLT- Conference on Lasers in Manufacturing 2007, Munich, 2007.

${ }^{143}$ ALMEIDA, I.A.; ROSSI, W. DE; LIMA, M.S.F.; BERRETTA, J.R.; NOGUEIRA, G.E.C.; WETTER, N.U.; VIEIRA JR, N.D.: Optimization Of Titanium Cutting By Factorial Analysis Of The Pulsed Nd:Yag Laser Parameters. Journal of Materials Processing Technology, v.179 (1-3), p.105-110, 2006.

${ }^{144}$ ABDEL GHANY, K.; NEWISHY, M. Cutting of $1.2 \mathrm{~mm}$ thick austenitic stainless steel sheet using pulsed and CW Nd:YAG laser. Journal of Materials Processing Technology, v.168, p. 438-447, 2005.

145 SANTOS, R. de BRITO - Microfuração por Laser Pulsado - Dissertação (mestrado)Instituto de Pesquisas Energéticas Nucleares- IPEN, São Paulo,2001. 